\title{
Planning en controle bij uitkapbeheer met casestudies in Kolkbos, Oude Trekerbos en Boombos
}

J.J. Jansen ${ }^{1}$, P.A. Zuidema ${ }^{1}$, J.P.G. de Klein ${ }^{2}$, J. den Ouden ${ }^{1}$ en G.M.J. Mohren ${ }^{1}$,

FEM Groei en Productie Rapport 2019 - 1

WAGENINGEN

UNIVERSITY \& RESEARCH

1 Forest Ecology and Forest Management group, Wageningen University, Department of Environmental Sciences

2 Silve, Wageningen 
Jansen, J.J., P.A. Zuidema, J.P.G. de Klein, J. den Ouden en G.M.J. Mohren. 2019. Planning en controle bij uitkapbeheer, met casestudies in Kolkbos, Oude Trekerbos en Boombos. FEM Groei en Productie Rapport 2019 - 1, 98 blz.

Synopsis: Van 1984 tot 2012 zijn er drie studies verricht in ongelijkjarig gemengd bos, in twee daarvan is uitkapbeheer toegepast. De bosontwikkeling werd gemonitord in termen van groei, sterfte, ingroei en kap. De diametergroei werd verklaard op basis van boomsoort, grondvlak per ha van licht, middelzwaar en zwaar hout en de periode van groei. Met een aangepast IPM werden de springkansen berekend. Met transitionmatrices met spring-, sterfte, kap- en ingroeikansen en eigenvectoren werd de evenwichtstoestand bepaald. Hierbij werd met name de uitkap opnieuw gedefinieerd. Verjonging van lichtboomsoorten blijkt problematisch. Uitkapbeheer blijkt in het Kolkbos en Oude Trekerbos mogelijk, maar ook in het thans zonder kap beheerde Boombos is terugkeer naar het uitkapbeheer een optie. Het gevoerde uitkapbeheer voldeed deels aan de verantwoorde kap volgens Heyer.

Abstract: From 1984 to 2012, three studies were carried out in an uneven-aged mixed species forest, two of which were managed as selection forests. Forest development was monitored in terms of tree growth, mortality, ingrowth and harvest. The diameter increment was described as a function of tree type, basal area per hectare of small, medium and large sized trees, and the period of growth. Using a modified IPM the probabilities of moving into a higher diameter class were calculated. With transition matrices with probabilities for moving up, mortality, harvest, and in-growth, were estimated and using eigenvectors the stable state was determined. Notably, the selection cut was redefined. Regeneration of light demanding tree species proved to be problematic. Selection forest management appeared possible in the Kolkbos and Oude Trekerbos; in the Boombos, currently managed without harvest, a return to selective cutting management appears to be an option. The current selective harvesting partly meets the conditions of Heyer's allowable cut.

Keywords: Selection cutting, uneven-aged mixed species forest, The Netherlands, transition matrix, modified IPM, eigenvector, stable state, allowable cut.

Dit rapport is gratis te downloaden op: https://doi.org/10.18174/508355

Dit rapport is gebaseerd op de databases:

De Klein, J.P.G. , J.J. Jansen, G.M.J. Mohren \& J. den Ouden, 2016. FEM growth and yield data Selection forest - Kolkbos. DANS: https://doi.org/10.17026/dans-zt3-7qfc.

Den Ouden, J., J.J. Jansen, L.G. Goudzwaard, J.F. Oldenburger \& G.M.J. Mohren. 2016. FEM growth and yield data - Uneven-aged - Beech-Oak. Dans: http://dx.doi.org/10.17026/danszdq-b8vz.

Jansen, J.J., J.P.G. de Klein, G.M.J. Mohren \& J. den Ouden, 2016. FEM growth and yield data Selection forest - Het Oude Trekerbos. DANS: http://dx.doi.org/10.17026/dans-29d-qffx 


\section{VOORWOORD}

Jop de Klein heeft begin tachtiger jaren nieuw leven ingeblazen in een oud project van Becking uit 1953 om bos te beheren volgens het principe van het uitkapbos in het Oude Trekerbos op het landgoed De Treek/Henschoten. Daarnaast startte hij een vergelijkbare studie in het Kolkbos op het Landgoed Schovenhorst. Hij wist met financiering van de Directie Wetenschapsbeleid van het Ministerie van Landbouw en Visserij een AIO-project te starten, waarvoor Maurice Heusèrr als kandidaat werd geworven. Helaas heeft Maurice dit project nooit afgerond. Ik had ten behoeve van Maurice een theoretische verhandeling geschreven over het "Schatten van stochastische transitionmatrices van boomklasse-indelingen. Toegelicht met het Kolkbos 1984-1990". Deze verhandeling is nooit gepubliceerd, maar wel ingediend met wat andere stukken als eindverantwoording naar de Directie Wetenschapsbeleid. Hoofdstuk 1 tot en met 3 zijn grotendeels op deze verhandeling gebaseerd. Maar sindsdien is er elders een nieuwe methode (IPM) ontwikkeld om springkansen te schatten en deze is ook in Hoofdstuk 3 geïntegreerd.

Naast de casestudie in het Kolkbos, komen ook de casestudies in het Oude Trekerbos en die in Boombos aan de orde.

Hans Jansen, 2019 


\section{INHOUD}

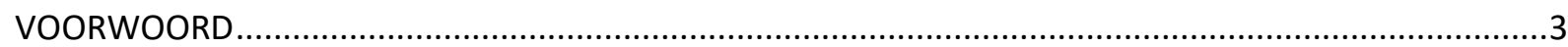

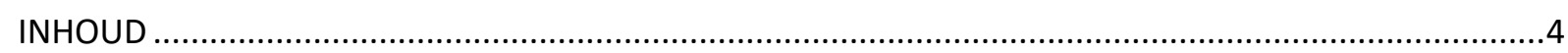

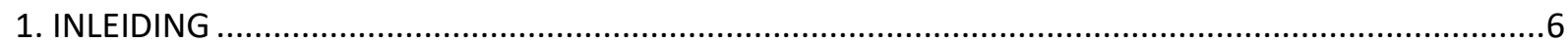

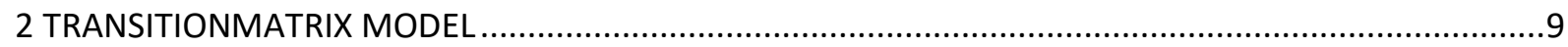

3. SCHATTINGSMETHODEN VOOR KANSEN IN TRANSITIONMATRIX............................................12

3.1 Directe schatting springkansen met ratioschatter ..............................................................12

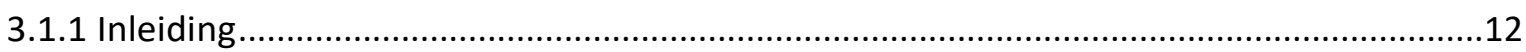

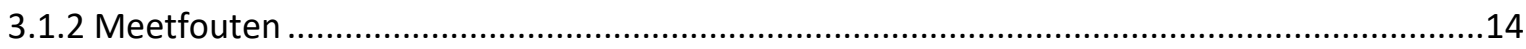

3.1.3 Tijdreeksen ...............................................................................................................

3.1.4 Springkansen indien alleen sprongen van één klasse voorkomen ……..............................15

3.1.5 Springkansen indien sprongen over twee of meer klassen voorkomen .................................17

3.2 Indirecte schatting springkansen met diameterbijgroei.................................................18

2.2.1 Relatie springkans en diameterbijgroei ........................................................................18

3.2.2 Het schatten van de diameterbijgroei .......................................................................20

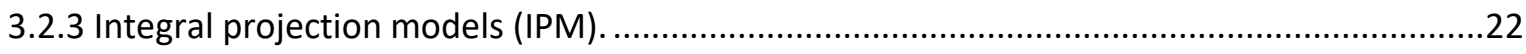

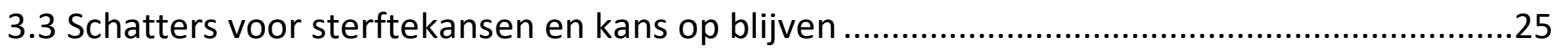

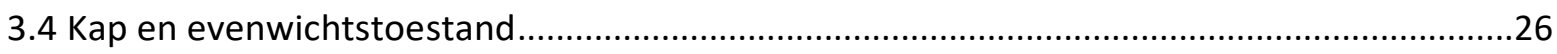

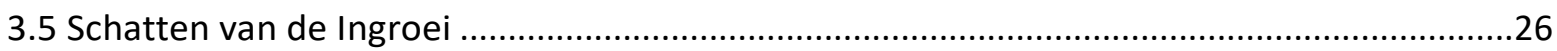

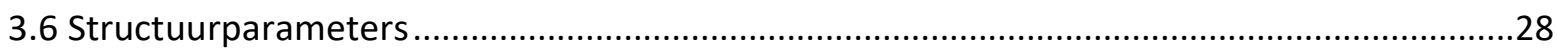

3.7. Gebruik van grondvlak en volume bij uitwerking ……………….........................................29

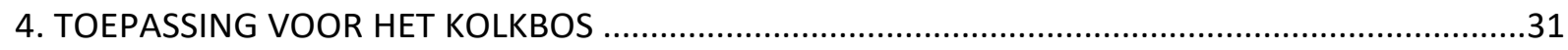

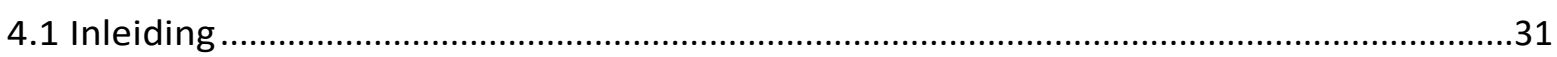

4.1.1 Vereiste gegevens bij uitkapbeheer ..................................................................................

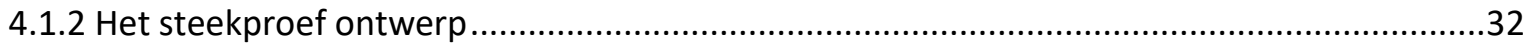

4.2 Springkansen bepaald met de ratiomethode.....................................................................32

4.3 Springkansen indirect bepaald via de diameterbijgroei (IPM) ...........................................33

4.4 Bepaling sterftekansen .......................................................................................................

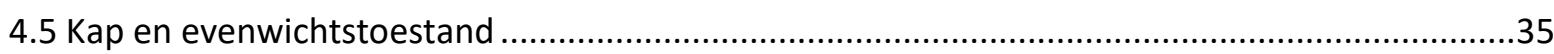

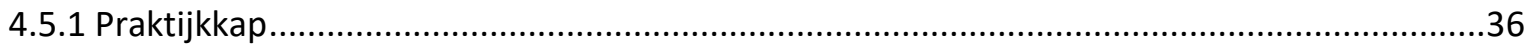

4.5.2 Kap met het doel een vaste $q$-waarde te realiseren in evenwicht ........................................37

4.5.3 Vergelijking van de kapstrategieën ...............................................................................

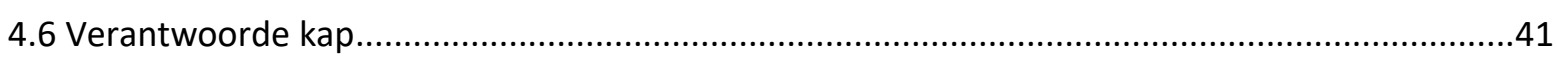

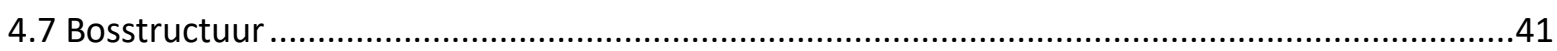

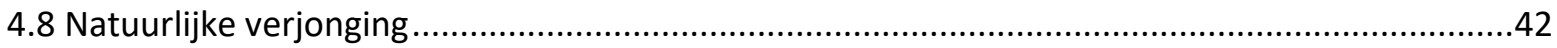

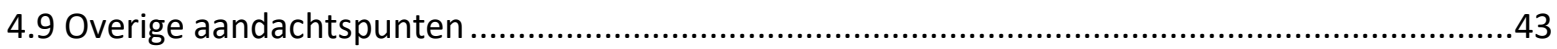

5. TOEPASSING IN HET OUDE TREKERBOS …………………….............................................

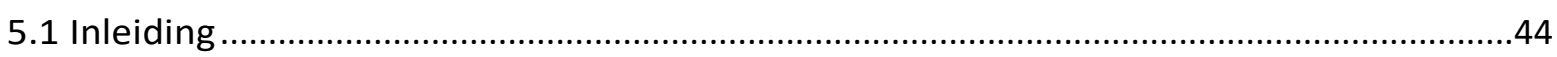




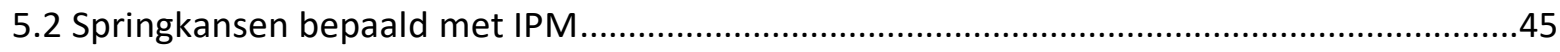

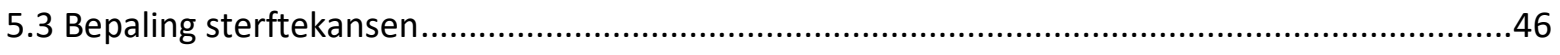

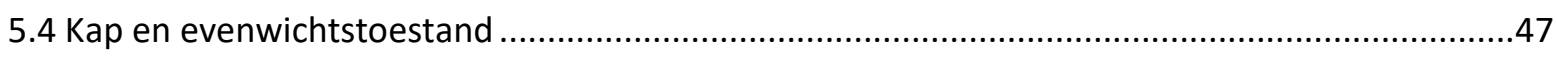

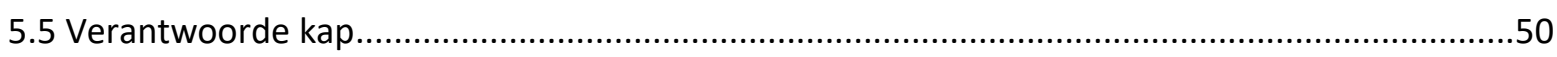

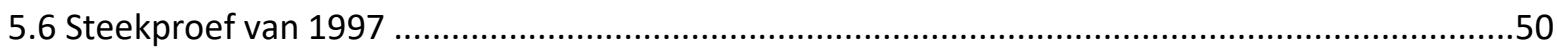

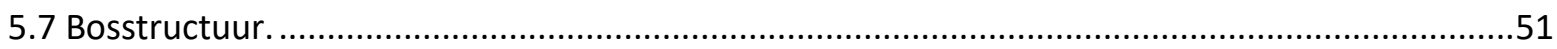

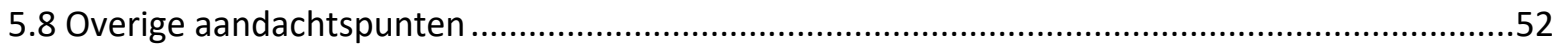

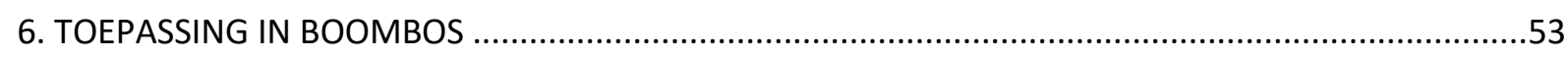

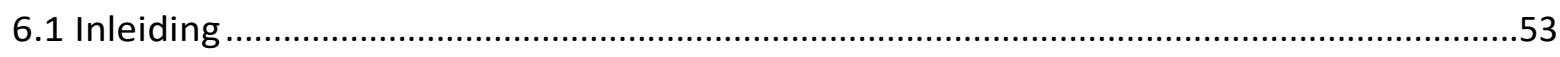

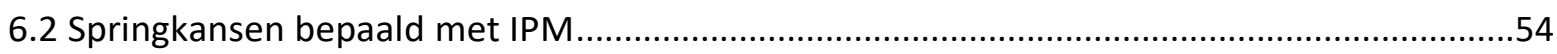

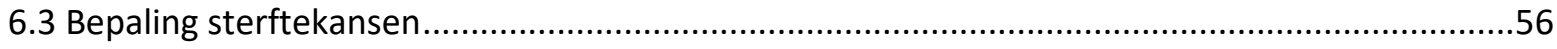

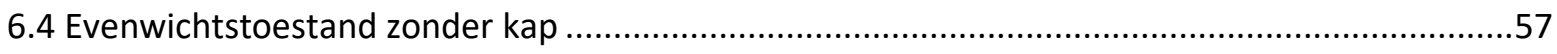

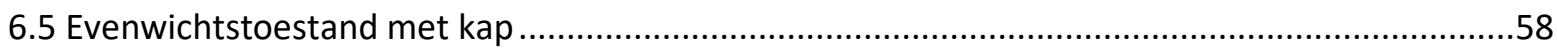

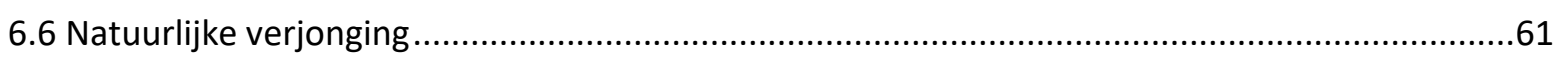

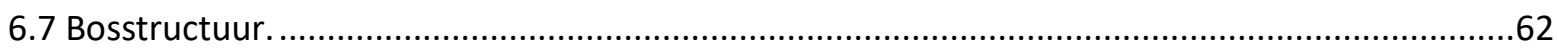

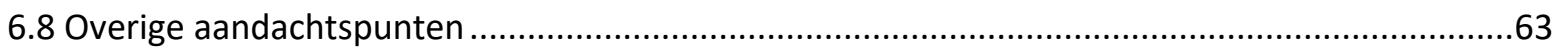

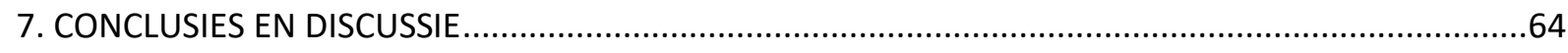

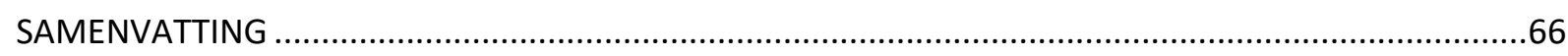

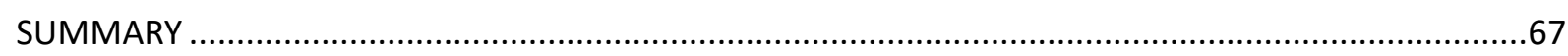

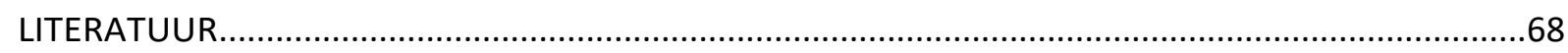

BIJLAGE 1. LIJST MET SYMBOLEN/LIST WITH SYMBOLS..............................................................

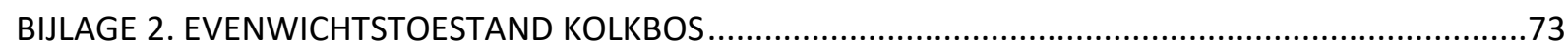

BIJLAGE 3. EVENWICHTSTOESTAND OUDE TREKERBOS ................................................................ 79

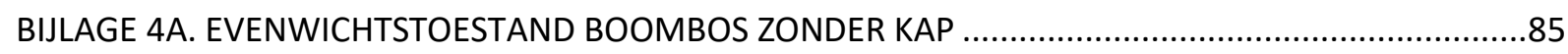

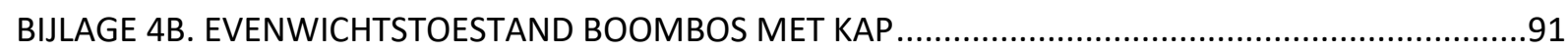

BIJLAGE 5. ANALYSE JAARRINGEN VAN STAMSCHIJVEN IN BOOMBOS ............................................97 


\section{INLEIDING}

Bij planning van bosbeheer is het gebruikelijk de verantwoorde kap te berekenen. Daar bestaan legio methoden voor deze verantwoorde kap in ha, volume of stamtal duiden, vaak is leeftijd en of omloop een van de variabelen in de formule, deze komen niet in aanmerking bij uitkapbeheer. De door Heyer (1841) ontworpen formule is ontworpen voor leegkapbeheer, maar is volgens de Klein et al. (1997) ook geschikt voor uitkapbeheer:

$$
\begin{aligned}
& A C=I_{c}+\frac{V-V_{n}}{t_{a d j}} \\
& \text { where } A C=\text { allowable cut in } \mathrm{m}^{3} \mathrm{ha}^{-1} \mathrm{yr}^{-1} \\
& I_{c}=\text { current volume increment } \mathrm{n} \mathrm{m}^{3} \mathrm{ha}^{-1} \mathrm{yr}^{-1} \\
& V=\text { total Volume on time of planning in } \mathrm{m}^{3} \mathrm{ha}^{-1} \\
& V_{n}=\text { normal Volume in far future in } \mathrm{m}^{3} \mathrm{ha}^{-1} \\
& t_{a d j}=\text { adjusting time in year }
\end{aligned}
$$

Heyer hanteert een vereffeningsperiode van een halve omloop, dat is bij uitkap bos niet aan de orde en gaan we uit van een periode van 30 jaar.

Er bestaan formules die de verantwoorde kap in stamtal weergeven, alle gebaseerd op het werk van Brandis (1897), zoals bijvoorbeeld het Indonesisch T.P.I. (Mendoza \& Setyarso, 1986). Ook deze methoden zijn voor ons uitkapbeheer niet bruikbaar, omdat alleen bomen die een zekere doeldiameter bereiken gekapt worden, en daarvoor alleen sterfte een rol speelt.

De enige onbekende in Formule (1) is $V_{n}$ het normale volume.

Bij uitkapbos en natuurbos wordt de samenstelling van de boomcomponent in de bosstructuur vaak statisch beschreven als aantallen bomen met dezelfde combinatie boomsoort/afmeting. Deze is schematisch weer te geven met een diameterstamtal-curve. De Liocourt (1898) formuleerde de normale diameterstamtal-curve, die de evenwichtstoestand voor uitkapbos voorstelt, als een rekenkundige reeks. Meyer (1933) herformuleerde die reeks tot een exponentiele functie en Leak (1965) introduceerde hiervoor dezelfde functie als kansdichtheid. Vaak worden niet alle afzonderlijke boomsoorten onderscheiden, maar wordt er met boomsoortgroepen gewerkt. Bij deze normale diameterstamtal-curve horen uiteraard andere eigenschappen van de bomen, zoals bijvoorbeeld grondvlak of volume en hiermee is dan het normale volume uit Formule (1) te berekenen.

Uit de dynamiek van deze diameterstamtal-verdeling in de tijd ontwikkelde Prodan (1949) een methode om de evenwichtstoestand en de volumebijgroei af te leiden en de oogst te prognosticeren. Usher (1966) introduceerde het begrip 'transitionmatrix' ter beschrijving van de dynamiek in diameterstamtal-verdeling. Buongiorno \& Michie (1980) pasten het model verder aan voor uitkapbos.

Haight, Brodie en Adams (1985) en Michie (1988) gebruikten de matrices om oogststrategieën te evalueren, ten aanzien van de financiële opbrengst. Pukkala \& Kolström (1988) gebruikten de methode om het beheer van bossen met een verre van ongelijkjarige en gemengde structuur te sturen richting uitkapbeheer.

De dynamiek in het bomenbestand, dus de veranderingen (groei, ingroei of verjonging, sterfte en kap) die in de loop van de tijd plaats vinden, kan met een (of meerdere) transitionmatrices worden beschreven, met het doel:

- Evenwichtssituaties te bepalen;

- Omvormingstrategieën te evalueren;

- Groeiprognoses te geven; 
- Oogststrategieën te evalueren.

Michie \& Buongiorno (1984) geven schattingsmethoden voor de elementen uit de matrices. Bonnor \& Magnusson (1987) gebruiken lineaire regressietechniek om de matrixelementen per soortgroep te bepalen, daarmee schoksgewijze overgangen tussen de opeenvolgende klassen voorkomend. Shifley et al. (1993) besteden aandacht aan de ingroeicomponenten van dynamische model

Dit rapport handelt over het schatten van de elementen in die transitionmatrices, die betrekking hebben op groei, ingroei, sterfte en kap. Zo'n transitionmatrix bevat in wezen de kansen dat een boom behorend tot een zekere afmetingsklasse na een zekere tijd:

- Nog steeds tot die klasse behoord (kans op blijven);

- Naar een hogere klasse is doorgegroeid (kans op springen);

- Uit het systeem verdwenen is door sterfte (sterftekans);

- Uit het systeem verdwenen is door kap (kapkans);

- In het systeem uit het niets verschijnt door ingroei (kans op ingroei) of in het systeem uit het niets verschijnt door verjonging (kans op verjonging).

Zo'n transitionmatrix wordt gebruikt in de volgende vergelijking:

$\mathbf{T} \cdot \vec{y}_{t}=\vec{y}_{t+d t}$

where $\mathbf{T}$ the transition matrix, a $n \times n$ matrix with the probabilities

of changes during interval time $d t$

$\vec{y}_{t}$ a vector with $n$ elements $y_{t j}$ for $j=1, \cdots n$ at time $t$

$y_{t j}$ number of trees $N_{j}$ in size class $j$ at time $t$

Deze ingewikkelde wiskundige benadering van de veranderingen in uitkapbos wordt gekozen omdat zo' $n n \times n$ matrix T als wiskundige eigenschap heeft dat er $n$ eigenvectoren $\vec{e}$ bestaan met ieder een eigenwaarde $\lambda$, zodanig dat er geldt

$\mathbf{T} \cdot \vec{e}=\lambda \cdot \vec{e}$

Van die eigenvectoren en eigenwaarden is er bij onze transitionmatrices slechts één interessant, namelijk, die waarbij geldt $\lambda=1$. Als er zo'n eigenvector bestaat dan beschrijft die de theoretische evenwichtstoestand van het uitkapbos.

De onderzoekvragen die daarbij centraal staan:

1. Hoe schatten we de kansen op natuurlijke veranderingen in de transitionmatrix zo nauwkeurig mogelijk;

2. Wat is de invloed daarbij als er sprake is van langere meetseries met variabele $d t$;

3. Hoe definiëren de kapstrategie en de daarbij behorende kapkansen;

4. Hoe interpreteren we de eigenvector als evenwichtstoestand en voldoet deze aan De Liocourt-curve;

5. Hoe zetten we deze stamtal-benadering om naar een volume-benadering;

6. Voldoet de toegepaste uitkap in de studiecases aan de eisen van verantwoorde volumeoogst;

Daarnaast als aanvullende vraag

7. Is met structuurparameters te schatten of de huidige toestand van het bos voldoet aan criteria voor diversiteit en een random stamvoetpatroon. 
Een gangbare werkwijze om direct springkansen en andere matrixelementen te schatten is de ratio-methode (Usher, 1966; Buongiorno \& Michie, 1980) deze wordt besproken en verbeterd in Paragraaf 3.1. In Paragraaf 3.2 wordt IPM (Integral Projection Model) gebruikt en verbeterd om indirect via de diameterbijgroei springkansen te berekenen. Easterling et al. (2000) ontwikkelden IPM, een methode om elementen van transitionmatrices van zowel het type Leslie (1945) als Lefkovitch (1965) als Usher (1966) te schatten, zie ook Zuidema et al. (2010) en Metcalf et al. (2013). De diameterbijgroei hierin wordt via een niet-lineair regressiemodel geschat. Op bijpassende wijze worden de matrixelementen voor sterfte geschat in Paragraaf 3.3. In Paragraaf 3.4 wordt de kap geïntegreerd in de modellen. De ingroei wordt in Paragraaf 3.5 behandeld en in Paragraaf 3.6 worden structuurparameters behandeld. Tot slot wordt In paragraaf 3.7 wordt de transformatie naar volume en grondvalk besproken.

Aan de hand van drie casestudies worden de methoden toegelicht (Hoofdstuk 4, 5 en 6). Het daarbij gebruikte rekenwerk is deels uitgevoerd met IBM SPSS, deels met MS Excel en deels geprogrammeerd in Fortran.

Alvorens deze methoden te bespreken wordt eerst In Hoofdstuk 2 het transitionmatrix model toegelicht 


\section{TRANSITIONMATRIX MODEL}

In De verandering van de boomklassevector $\underline{\vec{y}}_{j}$ uit Formule (2) voor bomen tussen de tijdstippen $t_{j}$ en $t_{j+\Delta t}$ kunnen we wiskundig met een stochastische transition matrix $\underline{\mathbf{T}}$ duiden.

In Figuur 1 is een voorbeeld van zo'n transitionmatrix en een boomklassevector gegeven.

$\underline{\mathbf{T}}=\left[\begin{array}{lllllll}\underline{t}_{11} & \underline{t}_{12} & \underline{t}_{13} & \underline{t}_{14} & \underline{t}_{15} & \underline{t}_{16} & \underline{t}_{17} \\ \underline{t}_{21} & \underline{t}_{22} & \underline{t}_{23} & \underline{t}_{24} & t_{25} & \underline{t}_{26} & \underline{t}_{27} \\ \underline{t}_{31} & \underline{t}_{32} & \underline{t}_{33} & \underline{t}_{34} & \underline{t}_{35} & \underline{t}_{36} & \underline{t}_{37} \\ \underline{t}_{41} & \underline{t}_{42} & \underline{t}_{43} & \underline{t}_{44} & \underline{t}_{45} & \underline{t}_{46} & \underline{t}_{47} \\ \underline{t}_{51} & \underline{t}_{52} & \underline{t}_{53} & \underline{t}_{54} & \underline{t}_{55} & \underline{t}_{56} & \underline{t}_{57} \\ \underline{t}_{61} & \underline{t}_{62} & \underline{t}_{63} & \underline{t}_{64} & \underline{t}_{65} & \underline{t}_{66} & \underline{t}_{67} \\ \underline{t}_{71} & \underline{t}_{72} & \underline{t}_{73} & \underline{t}_{74} & \underline{t}_{75} & \underline{t}_{76} & \underline{t}_{77}\end{array}\right] \quad \vec{y}_{j}=\left[\begin{array}{l}y_{j 1} \\ y_{j 2} \\ y_{j 3} \\ y_{j 4} \\ y_{j 5} \\ y_{j 6} \\ y_{j 7}\end{array}\right]$

Figuur 1. Voorbeeld van de structuur van een stochastische transition matrix $\underline{\mathrm{I}}$ en een boomklasse vector $\vec{y}_{j}$ voor een boomsoortgroep, zeven diameterklassen in $\Delta t$ jaar

Figure 1. Example of the structure of a stochastically transition matrix $\mathbf{I}$ and a tree class vector $\vec{y}_{j}$ for one tree species class, seven diameter classes in $\Delta t$ years.

De elementen op de diagonaal van de matrix stellen de blijvers voor, dus

$\underline{t}_{k, k}=\underline{t}_{G 0, k}-\underline{t}_{M, k}-\underline{t}_{H, k}$

where $\underline{t}_{G 0, k}$ represents the mutation that a tree in diameter class $k$ after growth in one year is still in diameter class $k$

$\underline{t}_{M, k} \quad$ represents the mutation that a tree in diameter class $k$ is dead after $\Delta t$ year

$\underline{t}_{H, k} \quad$ represents the mutation that a tree in diameter class $k$ is harvested after $\Delta t$ year

De elementen net onder de diagonaal van de matrix stellen de springers voor, dus

$\underline{t}_{k+1, k}=\underline{t}_{G 1, k}$

where $\underline{t}_{G 1, k}$ represents the mutation that a tree in diameter class $k$

after growth in $\Delta t$ year has moved up to diameter class $k+1$

De elementen in de bovenste rij van de matrix en niet op de diagonaal stellen de ingroei of verjonging weer. Wij zullen werken met een model de een diameterdrempel $D_{0}$, dus gaat het om de ingroei.

$\underline{t}_{1, k}=\underline{t}_{R, k}$

where $\underline{t}_{R, k}$ represents the recruitment mutation that a tree with a $d b h<d_{0}$ at time $j$

after growth in $\Delta t$ year has moved up to the first diameter class $(k=1)$

this element is linked to number of trees in $y_{k}$ as a replacement for trees

disappearing by mortality and harvest

Overige elementen slaan op gebeurtenissen die niet mogen voorkomen of die we kunnen uitsluiten door een juiste keuze van de periodelengte $\Delta t$ en de klassebreedte $w$.

Voor bijvoorbeeld $\underline{t}_{31}$ geldt: 
$\underline{t}_{31}=\underline{t}_{G 2,1}$

where $\underline{t}_{G 2,1}$ represents the mutation that a tree in diameter class 1

after growth in $\Delta t$ years has moved up with two classes to diameter class 3

En voor $\underline{t}_{23}$ geldt:

$\underline{t}_{23}=\underline{t}_{G-1,3}$

where $\underline{t}_{G-1,3}$ represents the mutation that a tree in diameter class 3

after growth in $\Delta t$ years has moved down with one class to diameter class 2

Voor de elementen van Formule (5) geldt:

$\underline{t}_{G 1, k}= \begin{cases}1 & \text { if } k_{i j}=k \text { and } k_{i, j+\Delta t}=k+1 \\ 0 & \text { else }\end{cases}$

en:

$\mathrm{P}\left\{\underline{t}_{G 1, k}=1\right\} \square p_{G 1, k}$

$\mathrm{P}\left\{\underline{t}_{G 1, k}=0\right\}=1-p_{G 1, k}$

Voor de verwachting van de elementen $\underline{t}_{G 1, k}$ :

$\mathcal{E}\left\{\underline{t}_{G 1, k}\right\}=0 \cdot P\left\{\underline{t}_{G 1, k}=0\right\}+1 \cdot P\left\{\underline{t}_{G 1, k}=1\right\}=p_{G 1, k}$

Voor alle overige elementen uit $\underline{\mathbf{I}}$ zijn met Formule (11) vergelijkbare kansen te definiëren. Als we vervolgens de matrix ontwikkelen voor een periode van één jaar en een zodanige klassebreedte $w$ dat allen sprongen van 1 klasse kunnen voorkomen ontstaat voor de verwachting van T de matrix $\mathbf{P}$ (zie Figuur 2)

$\mathbf{P}=\left[\begin{array}{lllllll}p_{11} & p_{12} & p_{13} & p_{14} & p_{15} & p_{16} & p_{17} \\ p_{21} & p_{22} & 0 & 0 & 0 & 0 & 0 \\ 0 & p_{32} & p_{33} & 0 & 0 & 0 & 0 \\ 0 & 0 & p_{43} & p_{44} & 0 & 0 & 0 \\ 0 & 0 & 0 & p_{54} & p_{55} & 0 & 0 \\ 0 & 0 & 0 & 0 & p_{65} & p_{66} & 0 \\ 0 & 0 & 0 & 0 & 0 & p_{76} & p_{77}\end{array}\right]$

Figuur 2. Voorbeeld van de structuur van de verwachting van een stochastische transition matrix I voor een boomsoortgroep, zeven diameterklassen in één jaar

Figure 2 Example of the structure of the expectation of the stochastically transition matrix $\mathbf{T}$ for one tree species class, seven diameter classes in one year.

De matrix van Figuur 1 is in principe een Usher transitionmatrix, omdat ze de veranderingen in een diameterklasse-vector weergegeven. Maar zowel Usher (1966) , Buongiorno \& Michie (1980) als bijvoorbeeld Pukkala \& Kolström (1988) gaan op andere wijze met de kap en ingroei om, hier wordt verder niet op ingegaan.

Er zijn nog drie andachtspunten, bij het zojuist ontwikkelde model. 
1. Krimp van bomen waardoor ze in een lagere diameter terechtkomen komt anders dan in Figuur 2 is weergegeven in de praktijk wel degelijk, door meetfouten of door een voorstadium van sterfte. In Hoofdstuk 3 wordt hier nader op ingegaan.

2. De hier ontwikkelde theorie levert geen eenduidig transitionmatrices op. Ze zijn immers afhankelijk van de intervallengte tussen de tijdstippen $t_{j}$ en $t_{j+\Delta \tau}$. We hebben $\underline{\mathbf{I}}$ ontwikkeld voor een periode van 1 jaar, en stel we willen een prognose geven voor de toestand na $m$ jaar, dan geldt:

$\varepsilon \underline{\vec{y}}_{j+m}=\varepsilon\left\{\underline{\mathbf{T}}_{m} \cdot\left(\underline{\mathbf{T}}_{m-1} \cdot\left(\cdots \cdots \underline{\mathbf{T}}_{1} \cdot \vec{y}_{j}\right)\right)\right\} \square \varepsilon\left\{\underline{\mathbf{T}}^{(m)} \cdot \vec{y}_{j}\right\} \neq\{\boldsymbol{\varepsilon} \underline{\mathbf{T}}\}^{m} \cdot \vec{y}=\mathbf{P}^{m} \cdot \vec{y}$

De in vergelijking (12) voorkomende ongelijkheid is van dezelfde orde als de bekende waarschijnlijkheidstransformatie $\varepsilon\{\underline{x} \cdot \underline{x}\}=\varepsilon \underline{x}^{2} \neq(\varepsilon \underline{x})^{2}$

Veel auteurs negeren de ongelijkheid van Formule(12) en verliezen daarmee uit het oog dat de verandering van boomklasse het gevolg van een proces is, waarop de ontwikkeling van het bos en de individuele bomen in voorafgaande perioden een belangrijke rol spelen. Zo gebruiken bijvoorbeeld Haight et al. (1985) bij een optimalisatievraagstuk P in plaats van. De kansen op klassenverandering van de bomen zijn in hun voorbeeld onafhankelijk van hun voorgeschiedenis en die van de opstand met als mogelijk gevolg onzuivere schatters en mogelijk suboptimale oplossingen. Harrison \& Michie (1985) gebruiken $\mathbf{P}$ van een 13-jarige periode in plaats van $\mathbf{I}$ om $\mathbf{P}$ te schatten voor een 1-jarige periode. Zij constateren terecht nogal wat problemen om een goede schatter te vinden, maar negeren de werkelijke oorzaak van het probleem. Net als Haight et al. gaan ook zij volledig voorbij aan het stochastische karakter van $\underline{\mathbf{T}}$. Door alleen naar de verwachting aan het eind van de periode te kijken, blijkt het onmogelijk een zuivere schatter te vinden voor $\mathbf{P}$ voor 1 jaar uit $\mathbf{P}$ voor 13 jaar.

3. Tot nu toe is met één boomsoortgroep gewerkt, in de praktijk zullen er meer voorkomen. Aangezien mutaties tussen de groepen, anders dan bij de verjonging onmogelijk zijn en omdat we met een meetdrempel werken kunnen zijn de boomsoortgroepen verder onderling onafhankelijk en heeft dat geen invloed op het model. Wel moeten de groepen worden gedefinieerd. Vanclay (1991) constateerde dat soorten, die qua bijgroei in eenzelfde groep thuishoorden, niet per se dezelfde sterftepatronen vertonen. Boomsoortgroepen dienen dus in principe voor ingroei, groei en sterfte afzonderlijk te worden samengesteld. 


\section{SCHATTINGSMETHODEN VOOR KANSEN IN TRANSITIONMATRIX}

In dit hoofdstuk worden methoden beschreven om de kansen op verandering van klasse door groei, sterfte ingroei en kap, te schatten als elementen van het transitionmodel. Paragraaf 3.1 vormt de inleiding en geeft de gebruikelijke methode met ratioschatters. Hierbij wordt aangeduid welke complicaties hierbij op kunnen treden, waarop dan verder wordt ingegaan. In Paragraaf 3.2 wordt een methode geïntroduceerd waarbij de springkansen indirect geschat worden met behulp van de diameterbijgroei en IPM, hierbij wordt een gemodificeerde IPM ontwikkeld. Voor beide methoden geldt dat het bepalen van de springkansen gebeurt over alle bomen, die niet gestorven of gekapt zijn in de periode tussen twee opnames. Een bepaling van de sterftekansen na correctie voor kap vindt plaats in Paragraaf 3.3. In Paragraaf 3.4 wordt de kap toegevoegd aan het model en komt de evenwichtstoestand aan de orde en in Paragraaf 3.5 de ingroei. In Paragraaf 3.6 wordt enigszins buiten het kader van dit hoofdstuk aandacht besteed aan andere structuurparameters dan de diameter-stamtal-curves. Tot slot wordt aandacht besteed aan de bepaling van het grondvlak en het volume in Paragraaf 3.7.

\subsection{Directe schatting springkansen met ratioschatter}

\subsubsection{Inleiding}

Prodan (1949) introduceerde de begrippen springerfractie voor $p_{G, \Delta k=1 \mid k, \Delta t}$ en blijverfractie voor

$p_{G, \Delta k=0 \mid k, \Delta t}$. We zullen de kansen om zichtbaar $w \cdot \Delta k \mathrm{~mm}$ te groeien in $\Delta t$ jaar, naar analogie van Prodan springkansen noemen (men zou kunnen spreken van groeistuipen). Uit opvolgende opnames in de tijd kunnen de springkansen $p_{G, \Delta k \mid k, \Delta t}$ en sterftekansen $p_{M, k \mid \Delta t}$ per soort en per diameterklasse worden geschat.

Traditioneel worden spring- en sterftekansen direct geschat, als de fractie bomen met eenzelfde nieuwe situatie op $t_{2}$ ten opzichte van alle bomen met dezelfde uitgangsituatie op $t_{1}$ (Bioley, 1920; Meijer, 1933; Prodan, 1949). De werkwijze hierbij laat zich het best demonstreren met behulp van een kruistabel.

Tabel 1. Voorbeeld veranderingen in boomklasse-indeling tussen $t_{j}$ en $t_{j+1}$ voor één boomsoortgroep.

Table 1. Example changes in tree classes between $t_{j}$ and $t_{j+1}$ for one tree species group.

\begin{tabular}{|c|c|c|c|c|c|c|c|c|c|}
\hline & \multirow[b]{2}{*}{ recruitment } & \multicolumn{6}{|c|}{ diameter class at $t_{j}$} & \multirow[b]{2}{*}{ total } \\
\hline & & & 1 & 2 & 3 & 4 & 5 & ..... & \\
\hline \multicolumn{2}{|c|}{ total befor cut } & & 148 & 156 & 93 & 101 & 108 & $\ldots .$. & 958 \\
\hline \multicolumn{2}{|c|}{ cut at $t_{j}$} & & 5 & 14 & 12 & 16 & 9 & $\ldots .$. & 71 \\
\hline \multicolumn{2}{|c|}{ total after cut } & & 143 & 142 & 81 & 85 & 99 & $\ldots .$. & 887 \\
\hline \multirow{8}{*}{ 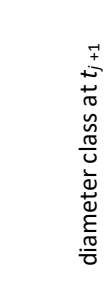 } & 1 & 112 & $=73$ & & & & & & 185 \\
\hline & 2 & 17 & 60 & -82 & 1 & & & & 160 \\
\hline & 3 & 1 & 4 & 55 & -55 & & & & 115 \\
\hline & 4 & & & 4 & 23 & -47 & -3 & & 77 \\
\hline & 5 & & & 1 & 2 & 36 & -61 & & 100 \\
\hline & 6 & & & & & 1 & 33 & & 86 \\
\hline & 7 & & & & & & 1 & & 89 \\
\hline & $\vdots$ & & & & & & & & \\
\hline \multicolumn{2}{|c|}{ mortality between $t_{j}$ and $t_{j+1}$} & & 6 & 1 & & 1 & 1 & $\ldots .$. & 12 \\
\hline \multicolumn{2}{|c|}{ total at $t_{j+1}$} & 130 & & & & & & & 1017 \\
\hline
\end{tabular}

In Tabel 1 is een voorbeeld van een kruistabel gegeven en daarin zien we:

- In de tweede regel boven het centrale deel van de tabel: bomen, die gekapt zijn aan het begin van de periode tussen twee opnames.

- Op de diagonaal van het centrale deel: bomen die nog steeds in dezelfde boomklasse zitten als in de uitgangsituatie, de zogenaamde blijvers; 
- In de onder-driehoek: bomen die een of meer boomklassen hoger beland zijn, de springers;

- In de boven-driehoek: enkele bomen die in een lagere boomklasse zitten dan voorheen;

- Onder het centrale deel van de tabel: bomen die afgestorven zijn, de wijkers.

De springkansen worden volgens de ratiomethode geschat door het aantal bomen dat in de $(j+1)^{\mathrm{e}}$ opname in klasse $k+\Delta k$ aanwezig is, onder voorwaarde dat het bij de $j^{\mathrm{e}}$ opname in klasse $k$ was, te delen door het voor kap gereduceerde totaal aantal bomen in klasse $k$ bij de $j^{\mathrm{e}}$ opname:

$\hat{p}_{G \Delta k, k}=\frac{y_{G \Delta k, k}}{y_{\text {remaining }}}=\frac{y_{j+1, k+\Delta k, k}}{y_{j, k}-y_{M, j, k}-y_{H, j, k}}$

De sterftekansen worden overeenkomstig geschat door het aantal bomen dat in de $(j+1)^{\mathrm{e}}$ opname gestorven is en in de $j^{\mathrm{e}}$ opname in klasse $k$ aanwezig is te delen door het voor kap gereduceerde totaal aantal bomen bij de $j^{\mathrm{e}}$ opname in klasse $k$ :

$\hat{p}_{M, k}=\frac{y_{M, j, k}}{y_{j, k}-y_{H, j, k}}$

Met het voorbeeld uit Tabel 1 voor de tweede diameterklasse en een periode-lengte van $\Delta t_{j}$ jaar vinden we:

$$
\begin{array}{ll}
\hat{p}_{G 0,2}=\frac{82}{156-14-1}=0.582 & \hat{p}_{G 1,2}=\frac{55}{156-14-1}=0.390 \\
\hat{p}_{G 2,2}=\frac{4}{156-14-1}=0.028 & \hat{p}_{G 3,2}=\frac{1}{156-14-1}=0.007 \\
\hat{p}_{M, 2}=\frac{1}{156-14}=0.007 &
\end{array}
$$

Voor de derde en vijfde diameterklasse in het Tabel 1 is er het probleem van "krimpende" bomen, bomen die in een lagere diameterklasse belanden bij een volgende opname. De reden voor dit "krimpen" is terug te voeren tot:

- Onderdrukte bomen die bezig zijn te sterven hebben een geringere zuigspanning waardoor de gemeten diameter kan afnemen, in principe moet de diameter hier gecorrigeerd worden naar de oude diameter, het gaat hier om slechts een of enkele $\mathrm{mm}$ krimp. Alleen indien de vorige diameter net boven een klassegrens ligt kan er sprake zijn waargenomen krimp in de klasse. Deze categorie krimp is nagenoeg verwaarloosbaar;

- Het meetproces en de daarbij gemaakte meetfouten. Als we fouten "naar beneden" hebben, zullen we ook wel fouten "naar boven" hebben. De nauwkeurigheid van de springkansen over meer dan een klasse is daarom eveneens problematisch bij de andere diameterklassen.

Een ander probleem ontstaat als we lange meetseries krijgen, waarin de periodes tussen twee opnames van ongelijke lengte zijn. Aan deze meetfouten, verschillende lengte van de periode tussen opnamen en het bepalen van springkansen voor twee of meer klassen wordt in de volgende sub-paragrafen allereerst aandacht besteed, vooraleer op de andere methoden wordt ingegaan.

De inventarisaties op tj kunnen zowel volledige opnamen als steekproeven betreffen. In de hier te ontwikkelen theorie wordt uitgegaan van een steekproef met $n$ aselecte permanente proefcirkels van gelijke grootte, die op onregelmatige tijdstippen zijn opgenomen (dus met verschillend periode-interval). Eventuele randplots worden volgens de juiste procedure gespiegeld (Schmidt - Haas, 1969). Er is dus sprake van "Continuous Forest Inventory". Om logistieke redenen wordt in de praktijk meestal een systematisch steekproefnet aangelegd. Meestal wordt 
deze verwerkt als ware het een aselecte steekproef, in de wetenschap dat de varianties iets overschat worden (De Vries, 1986).

\subsubsection{Meetfouten}

Bij het meten hebben we te maken met werkelijke waarden en gemeten waarden:

$\left.\begin{array}{l}\mathrm{d}_{j+1}=D_{j+1}+\underline{e}_{j+1} \\ \mathrm{~d}_{j}=D_{j}+c_{j}\end{array}\right\} \rightarrow i_{d}=\frac{D_{j+1}-D_{j}+\underline{e}_{j+1}-\underline{e}_{j}}{\Delta t}=I_{D}+\underline{e}_{i_{d} \mid \Delta t}$

where $d$ and $i_{d}$ respectively the measured diameter and diameter increment;

$D$ and $I_{D}$ respectively the true diameter and diameter increment;

$\underline{e}_{j}$ the measuring error

De variantie van de meetfout is bij gebruik van dezelfde opnamemethode onafhankelijk van het opnametijdstip. Er wordt een zuivere opnametechniek verondersteld. Er geldt dus:

$$
\begin{aligned}
& \varepsilon_{\underline{e}_{j}}=\varepsilon_{\underline{e}_{j+1}}=0 \\
& \varepsilon_{\underline{e}_{j}} \cdot \underline{e}_{j+1}=0 \\
& \operatorname{var} \underline{\underline{e}}_{j}=\operatorname{var} \underline{e}_{j+1}=\sigma_{m f}^{2} \\
& \operatorname{var}_{\underline{e}_{i d} \mid \Delta t}=\frac{2 \cdot \sigma_{m f}^{2}}{(\Delta t)^{2}}
\end{aligned}
$$

where $m f$ the measuring error

Hieruit volgt dat hoe langer het interval tussen twee opnamen is, des te kleiner de meetfout van de diametergroei is.

\subsubsection{Tijdreeksen}

Hebben we de beschikking over meerdere opnames, dan kan zich een ander probleem voordoen, namelijk dat niet alle periodes tussen de opnames, zogenaamde tijdreeksen, even lang zijn. Om uit meerdere opnamen met variabele duur tussen de opnames een schatter te maken voor de springkansen, zullen deze tijdreeksen eerst moeten worden geschaald naar hetzelfde tijdsinterval. De beste keus hiervoor is een lengte van een jaar, omdat:

- Alle willekeurig tijdsintervallen daardoor onderling kunnen worden vergeleken;

- De kans op het springen over twee of meer klassen hiermee op nul te stellen is.

Indien dit laatste dan nog niet het geval is, dient de klassebreedte vergroot te worden om dit fenomeen uit te sluiten. In Paragraaf 3.1.5 zal worden aangetoond dat een goede schatter voor springkansen over twee of meer klassen nauwelijks te ontwikkelen is.

Zoals reeds in Hoofdstuk 2 aangegeven bespreken Harrison en Michie (1985) een aantal methoden om een $\mathbf{P}_{G}$ matrix voor een lange periode om te zetten in matrix voor een periode van een jaar. We hebben geconstateerd, dat ze hierbij het stochastische karakter van $\underline{\mathbf{I}}_{G}$ niet betrekken. Bij het bepalen van de springkansen wordt het groeiritme, dat wil zeggen de springkansen in het verleden, van de bomen niet meegenomen. Door enkel naar de verwachting aan het einde van een periode te kijken, lukt het niet een zuivere schatter te vinden voor $\mathbf{P}_{\mathrm{G}}$ voor 1 jaar uit $\mathbf{P}_{\mathrm{G}}$ voor $\mathrm{x}$ jaar. Veel eenvoudiger is het de $\mathbf{P}_{G}$ matrix voor welk interval dan ook direct uit het basismateriaal te schatten. Voor een periode van een jaar, moeten we eerst de denkbeeldige diameter op tijdstip $t_{j+1}$ bepalen met:

$$
\hat{d}_{i, j+1}=d_{i j}+\frac{d_{i, j+1}-d_{i j}}{t_{j+1}+t_{j}}
$$


Daarna wordt de boomklassen-indeling opnieuw gemaakt, en weer in een kruistabel gezet. Indien de klassebreedte zodanig is gekozen dat de maximaal mogelijke diameterbijgroei kleiner is dan de klassebreedte, dan zijn als springers van 2 klassen of meer theoretisch uitgesloten. Indien deze of negatieve springers wel voorkomen berust dit op meetfouten. Op deze wijze zijn er betreffende de springkansen slechts waarden groter dan nul voor $\mathbf{P}_{G, 0}$ en $\mathbf{P}_{G, 1}$. De verwachting van de meetfout $e_{j}$ uit vergelijking (16) bedraagt nul, bij een transformatie naar klassen bedraagt deze nog steeds nul.

Bij het bepalen van de springkansen uit een serie van meer dan twee opnames treedt nog een ander probleem op. De herhaalde metingen zijn onderling gecorreleerd en statistisch gezien dus niet onafhankelijk. Dit hoeft niet al te problematisch zijn, indien het aantal metingen klein is in vergelijking met het aantal steekproefeenheden (Vanclay 1995). In dit rapport wordt van deze laatste veronderstelling uitgegaan.

\subsubsection{Springkansen indien alleen sprongen van één klasse voorkomen}

Voor de verwachting van $\Delta k$ bij een periode lengte van een jaar geldt:

$$
\varepsilon \Delta k \mid\{k, \Delta t=1\}=\sum_{\Delta k=-\infty}^{\infty} \Delta k \cdot p_{G, \Delta k \mid k, \Delta t=1}
$$

Indien er sprake is van het schatten van transitionmatrices met een transition-periode van een jaar zal de toevoeging " $\Delta t=1$ " weggelaten worden. Vergelijking (18a) luidt dan:

$$
\varepsilon \Delta k \mid k=\sum_{\Delta k=-\infty}^{\infty} \Delta k \cdot p_{G, \Delta k \mid k}
$$

Aangezien onder de gestelde condities in paragraaf 3.1.3 geldt:

$$
p_{G, \Delta k \mid k}=0 \text {, voor } \Delta k \notin\{0,1\}
$$

volgt uit vergelijkingen (18) en (19) de kans op het springen van één klasse:

$$
\varepsilon \Delta k \mid k=0 \cdot p_{G, 0 \mid k}+1 \cdot p_{G, 1 \mid k}=p_{G, 1 \mid k}
$$

We kunnen nu $P_{G, 1 k}$ eenvoudig met de inverse functie schatten:

$p_{G, 1 \mid k}=\overline{\Delta k} \mid k=\frac{\sum_{\Delta k=-\infty}^{\infty} \Delta k \cdot \hat{y}_{\left(t_{j}+1, k+\Delta k \mid j, k\right)}}{y_{j, k}-y_{M, j, k}-y_{H, j, k}}$

De schatter voor de kans op blijven in de klasse volgt uit (19) en (21):

$$
p_{G, 0 \mid k}=1-p_{G, 1 \mid k}
$$

We kunnen nu met vergelijking (21) en (22) de springkansen per opname berekenen en een gewogen gemiddelde berekenen over alle perioden als volgt:

$p_{G, 1 \mid k}=\frac{\sum_{j=1}^{j_{\max }-1} w g t_{j} \cdot\left\{\sum_{\Delta k=-\infty}^{\infty} \Delta k \cdot \hat{y}_{\left(t_{j}+1, k+\Delta k \mid j, k\right)}\right\}}{\sum_{j=1}^{j_{\max }-1} w g t_{j} \cdot\left(y_{j, k}-y_{M, j, k}-y_{H, j, k}\right)}$ with $w g t_{j}=\frac{\Delta t_{j}}{\sum_{j=1}^{j_{\max }-1} \Delta t_{j}}$

where $w g t_{j}$ weight for the $j^{e}$ period and $j_{\max }$ number latest recording

De keuze voor het periodegewicht $w t_{j}$ volgt uit vergelijking (16), de eis voor gelijke varianties bij de bewerking van waarnemingen en de eis voor een zuivere schatter. Om de notatie in de 
variantieformules beheersbaar te houden, wordt nu met weglating van de boomklasse aanduiding de volgende notatie gebruikt:

$$
\begin{aligned}
& p \doteq P_{G, 1 \mid k} \\
& N_{G} \doteq \sum_{j=1}^{j_{\max }-1} w g t_{j} \cdot\left\{\sum_{\Delta k=-\infty}^{\infty} \Delta k \cdot \hat{y}_{\left\{t_{j}+1, k+\Delta k \mid j, k\right\}}\right\} \\
& \mathrm{N} \doteq \sum_{j=1}^{j_{\max }-1} w g t_{j} \cdot y_{j k}^{*}
\end{aligned}
$$

Vergelijking (23) luidt nu kortheidshalve:

$p=\frac{N_{G}}{N}$

We kunnen $p$ beschouwen als de ratio van een ratioschatter met de erbij behorende variantieschatter (zie De Vries, 1986, p 57 e.v.). In principe zouden we de waarden per plot moeten berekenen, maar aangezien er $7 \times 15$ combinaties $\{\mathrm{sg}, \mathrm{k}\}$ zijn, maar met gemiddeld 5.7 boom per plot en $95 \%$ in het interval $\{1,12\}$ is het onmogelijk voor een redelijk aantal klassen schattingen te krijgen. Daarom zijn de afzonderlijke bomen als de totale steekproef beschouwd, ondanks dat dit geen aselect trekking is uit van $\mathrm{n}$ bomen uit het onbekende totaalaantal bomen in het bos. Een ander probleem, heeft te maken met de gewichten. Er zijn gemiddeld ongeveer 750 bomen in het Kolkbos, maar het gewogen aantal gewogen waarnemingen bedraagt 3460 . Het model dient daarom herschreven te worden tot een lineair regressie model door de oorsprong:

$\underline{y}_{j}=p \cdot x_{j}+\sigma \cdot \underline{e}_{j}$

$$
\begin{aligned}
\text { where } y_{j}=\Delta k_{j} & =\sum_{j=1}^{j_{\max }-1} w g t_{j} \cdot \Delta k_{i j} \cdot x_{i j} \\
x_{j} & =\sum_{j=1}^{j_{\max }-1} w g t_{j} \cdot x_{i j} \\
x_{i j} & =x_{i j}= \begin{cases}1 & \text { if } k_{i j}=k \text { and tree not cut or dead } \\
0 & \text { if } k_{i j} \neq k\end{cases}
\end{aligned}
$$

Per boomklasse worden de springerkansen nu geschat met:

$$
\begin{aligned}
& \hat{p}=\frac{\sum_{j=1}^{n} x_{j} \cdot y_{j}}{\sum_{j=1}^{n} x_{j} \cdot x_{j}} \\
& \text { where } i=\text { folowing number of alle weighted observations in time (total } n \text { pieces) } \\
& \quad \text { and } x_{i} \text { and } y_{i} \text { as in Formula (25) }
\end{aligned}
$$

Voor de variantie geldt:

vâr $\hat{p}=\frac{1}{\sum x_{j}^{2}} \cdot \hat{\sigma}^{2}=\frac{1}{\sum x_{j}^{2}} \cdot f p c \cdot \frac{\sum_{j=1}^{n}\left(y_{j}-\hat{p} \cdot x_{j}\right)^{2}}{n-1}$

$$
\text { where } f p c \text { (finite population correction) }=\frac{N-n}{N} \approx 1
$$


Gaat het om niet gewogen waarnemingen tussen twee opnamen dan levert Formule (21) van de ratioschatter hetzelfde resultaat op als Formule (26)

\subsubsection{Springkansen indien sprongen over twee of meer klassen voorkomen}

Indien de combinatie van gekozen klassebreedte $w$ en tijdsinterval $\Delta t$ (hier dus $1 \mathrm{jr}$, maar eventueel langer) van de operand $\mathbf{T}_{G}$ ook waarden anders dan 'nul' bij $P_{G, \Delta k k}$ voor $\Delta k \geq 2$ toelaat, dan moet Vergelijking (18b) anders dan in Formule (20) opnieuw herschrijven tot:

$$
\begin{aligned}
\varepsilon \Delta k & =\left\{\sum_{\Delta k=-\infty}^{-1} \Delta k \cdot p_{G, \Delta k \mid k}\right\}+\sum_{\Delta k=0}^{\Delta k_{\max }} \Delta k \cdot p_{G, \Delta k \mid k}+\left\{\sum_{\Delta t=\Delta k_{\max }+1}^{\infty} \Delta k \cdot p_{G, \Delta k \mid k}\right\} \\
& =0+\sum_{\Delta k=0}^{\Delta k_{\max }} \Delta k \cdot p_{G, \Delta k \mid k}+0=\sum_{\Delta k=0}^{\Delta k_{\max }} \Delta k \cdot p_{G, \Delta k \mid k}
\end{aligned}
$$

We kunnen nu $P_{G, \Delta k k}$ naar analogie van Formule (23) voorlopig schatten met:

$$
p_{G, 1 \mid k}=\frac{\sum_{j=1}^{j_{\max }-1} w g t_{j} \cdot\left\{\sum_{\Delta k=-\infty}^{\infty} \Delta k \cdot \hat{y}_{\left(t_{j}+1, k+\Delta k \mid j, k\right)}\right\}}{\sum_{j=1}^{j_{\max }-1} w g t_{j} \cdot\left(y_{j, k}-y_{M, j, k}-y_{H, j, k}\right)} \quad \text { with wgt } t_{j}=\frac{\Delta t_{j}}{\sum_{j=1}^{j_{\max }-1} \Delta t_{j}}
$$

where $w g t_{j}$ weight for the $j^{e}$ period and $j_{\max }$ number latest recording

Alle springkansen voor $\Delta k \leq-1$ zijn per definitie gelijk aan nul. De springkansen voor $\Delta k \leq 1$ moeten geadjusteerd worden met een correctiefactor $c f$ in verband met eventuele waargenomen "negatieve groei":

$$
c f=\frac{\sum_{d k=0}^{d k_{\max }} d k \cdot \tilde{p}_{G, \Delta k \mid k}}{\sum_{d k=d k_{\min }}^{d \max } d k \cdot \tilde{p}_{G, \Delta k \mid k}} \text { where } d k \text { the observed } \Delta k
$$

Voor de geadjusteerde schatter geldt nu:

$$
\hat{p}_{G, \Delta k \mid k}=\left\{\begin{array}{llr}
0 & \text { for } & \Delta k<0 \\
c f . \tilde{p}_{G, \Delta k \mid k} & \text { for } 1 \leq & \Delta k \leq d k_{\max } \\
1-\sum_{d k=1}^{d k_{\max }} c f . \tilde{p}_{G, \Delta k \mid k} & \text { for } & \Delta k=0
\end{array}\right.
$$

De procedure levert wel een zuivere schatter voor de som van de springkansen, maar vermoedelijk niet voor alle springkansen afzonderlijk. De negatieve sprongen worden min of meer naar rato gereduceerd in alle klassen, hetgeen redelijk lijkt maar niet goed hoeft te zijn. Werkelijke negatieve waarde door krimp als voorloper van sterfte dient b.v. gecorrigeerd te worden naar de klasse "blijvers". Een zuivere ratioschatter voor sprongen van twee of meer klassen bestaat derhalve slechts als er geen meetfouten worden gemaakt. Dit is echter geen reële optie. Daarentegen is het altijd mogelijk een zodanige boomklasse-indeling te maken dat de kans op een sprong van 2 of meer klassen gelijk aan nul is en dit probleem vermeden wordt. Een formule voor de variantie van de schatters is nauwelijks af te leiden wegens het groot aantal afhankelijkheden in de 
schatter-formules, een Jack-knife-procedure kan hier uitkomst bieden. Overigens zal ook Formule (27) een redelijke benadering geven, indien hier met de ongecorrigeerde waarden voor $p$ wordt gewerkt. In het theoretische geval dat er geen meetfouten voorkomen, is de correctiefactor $c f$ van Vergelijking (30) gelijk aan 1 en Vergelijking (31) geldt nog steeds. Er dan sprake van een voor verschil in periodelengte aangepaste variant van Vergelijking (13), maar zonder bias-correctie in verband met meetfouten.

\subsection{Indirecte schatting springkansen met diameterbijgroei.}

Bonnor \& Magnussen (1987) schatten de springkans direct uit de diameterklasse $\mathrm{cl}$.

$p_{G, c l}=c_{0}+c_{1} \cdot c l_{i j}+c_{2} \cdot c l_{i j}^{2}$ with different parmeters for each species group

Deze methode verbeterd de ratioschatter van Paragraaf 3.1 aanzienlijk, maar de nauwkeurigheid wordt in grote mate bepaald door de meetnauwkeurigheid van de diameter, in eenheden van $w \mathrm{~mm}$ d.w.z. de klassebreedte. Aangezien we de diameter veel nauwkeuriger kennen, ligt het voor de hand om een relatie te zoeken tussen de diameterbijgroei (de bron van het springen) en de springkans.

Daarop zal in deze paragraaf worden ingegaan.

We gaan er weer vanuit dat de klassebreedte zo groot is dat springkansen voor sprongen van meer dan een klasse nul zijn (of bij benadering nul). Volgens Prodan (1949) geldt voor de jaarlijkse gemiddelde diameterbijgroei van de $k^{\mathrm{e}}$ klasse:

$\overline{I D} \mid k=\frac{w}{\Delta t} \cdot p_{G, 1 \mid k, \Delta k}$

Uit formule (33) volgt de inverse functie voor een periode van een jaar:

$p_{G, 1 \mid k}=p_{G, 1 \mid k, \Delta k}=\frac{\overline{I D} \mid k}{w}=\frac{i_{d \mid k}}{w}$

Met behulp van de relatie (33) kan PG indirect geschat worden door eerst via lineaire regressie een relatie te fitten tussen diameter en diameterbijgroei.

We moeten hiertoe drie problemen oplossen:

- Levert vergelijking (34) een zuivere schatter voor $P_{G}$ en zo niet hoe schatten we $P_{G}$ dan met behulp van $i_{d}$ ?

- Hoe verwerken we op de beste wijze de tijdreeksen van diameterbijgroei van de bomen?

- Hoe voorspellen we de diameterbijgroei zo nauwkeurig mogelijk?

\subsubsection{Relatie springkans en diameterbijgroei}

Een boom springt een klasse indien zijn bijgroei ervoor zorgt dat die boom het jaar erop over de klassegrens is gegroeid. Voor de springkans geldt derhalve:

$$
\begin{aligned}
& p_{G, 1 \mid k} \square \mathrm{P}\{\underline{D}+\underline{I D} \in k+1 \mid \underline{D} \in k\} \\
& \quad \text { where } D \in k \text { means: }\left\{D_{0}+w \cdot k-w \leq D \leq D_{0}+w \cdot k\right\}
\end{aligned}
$$

We zullen derhalve de kansdichtheden van $D$ en $I D$ moeten beschouwen, teneinde de gevraagde conditionele waarschijnlijkheid van (34) af te leiden.

Laten we daartoe continue kansdichtheden definiëren voor de hulpvariabelen $z_{1}, z_{2}$ en $z_{3}$ :

- Met $\mathrm{z}_{1}$ een continue variabele: het verschil van $D$ en $D$ min, dus de afstand (meestal) in $\mathrm{mm}$ van $D$ tot de ondergrens van de klasse $D_{0}+w \cdot k-w$;

- Met $z_{2}$ een continue variabele: de diameterbijgroei $I D$ voor de boom in de klasse $k$ in $\mathrm{mm}$;

- Met $z_{3}$ een continue variabele: het verschil van $(D+I D)$ en $D_{\min }$. 
Uit de definities en (35) volgen (voor iedere diameterklasse $k$ ) de hulpvariabelen:

$\left.\underline{z}_{1}\left[=\underline{z}_{1}(k)\right)\right]=\underline{D}-D_{0}-w \cdot k+w$

$\left.\underline{z}_{2}\left[=\underline{z}_{2}(k)\right)\right]=\underline{I D} \mid \underline{D} \in k$ for $\left\{0 \leq \underline{z}_{2} \leq w\right\}$

$\left.\underline{z}_{3}\left[=\underline{z}_{3}(k)\right)\right]=\underline{z}_{1}+\underline{z}_{2}$

De springkans van vergelijking (35) is nu te herschrijven tot:

$p_{G, 1 \mid k}=\mathrm{P}\left\{w \leq \underline{z}_{3} \leq 2 w\right\}$ for $\left\{0 \leq \underline{z}_{3} \leq 2 w\right\}$

Voor de kansdichtheid van $\underline{z}_{3}$ hierin geldt:

$\mathrm{P}\left(\underline{z}_{3}=z_{3}\right)=\sum_{z_{2}=0}^{w} \mathrm{P}\left(\underline{z}_{1}=z_{3}-z_{2}\right) \cdot \mathrm{P}\left(\underline{z}_{2}=z_{2}\right)$

Uit vergelijking (39) en (40) volgt:

$$
\begin{aligned}
p_{G, 1 \mid k} & =P\left\{w \leq \underline{z}_{3} \leq 2 w\right\} \\
& =\int_{z_{3}=w}^{2 w} P\left(\underline{z}_{3}=z_{3}\right)=\int_{z_{3}=w}^{2 w} \int_{z_{2}=0}^{w} P\left(\underline{z}_{1}=z_{3}-z_{2}\right) \cdot P\left(\underline{z}_{2}=z_{2}\right) \\
& =\int_{z_{3}=w}^{2 w}\left[\left\{\int_{z_{2}=0}^{w} P\left(\underline{z}_{1}=z_{3}-z_{2}\right)\right\} \cdot P\left(\underline{z}_{2}=z_{2}\right)\right]=\int_{z_{3}=w}^{2 w}\left[\left\{\int_{z_{1}=\max \left(0, w-z_{2}\right)}^{\min \left(w, 2 w-z_{2}\right)} P\left(\underline{z}_{1}=z_{1}\right)\right\} \cdot P\left(\underline{z}_{2}=z_{2}\right)\right] \\
& =\int_{z_{3}=w}^{2 w}\left[\left\{\int_{z_{1}=w-z_{2}}^{w} P\left(\underline{z}_{1}=z_{1}\right)\right\} \cdot P\left(\underline{z}_{2}=z_{2}\right)\right]=\int_{z_{3}=w}^{2 w}\left[h_{z_{2}} \cdot P\left(\underline{z}_{2}=z_{2}\right)\right] \\
& =\varepsilon_{z_{2}}\left(h_{z_{2}}\right) \text { where } h_{z_{2}}=\int_{z_{1}=w-z_{1}}^{w} P\left(\underline{z}_{1}=z_{1}\right)
\end{aligned}
$$

Met (veronderstelde) kennis over de kansdichtheid van $\underline{z}_{1}$ is vergelijking (41) oplosbaar en we vinden dan een model-based schatter voor $p_{G, 1 \mid k}$.

Het gangbare concept in de bosbouw voor de beschrijving van de frequenties van de stamtallen per diameter in de evenwichtssituatie betreft een (negatief) exponentiele kansdichtheid met verschoven x-as (naar Murphy en Farrar, 1981):

$f_{D}=\lambda \cdot e^{-\lambda\left(D-D_{0}\right)} \quad$ for $D \geq D_{0}$

In de bosbouw staat de discrete variant van deze continue kansdichtheid bekend onder de naam "De Liocourt"-curve; een meetkundige reeks met reden $q^{-1}$ :

$N_{k}=q \cdot N_{k+1}$ for $D \geq D_{0}$

where $k$ is tree class with class width $w$

$N_{k}$ the number if trees in diameter class $k$

Voor de relatie tussen (42) en (43) geldt:

$q=e^{\lambda w}$

$\lambda=\ln (q) / w$ 
Een tweede kansdichtheid van belang voor de te ontwikkelen theorie is de uniforme kansdichtheid:

$f_{z_{1}}=\frac{1}{w}$, for $0 \leq \underline{z}_{1} \leq w$

Indien $z_{1}$ uniform verdeeld is op het interval $\{0, w\}$, dan volgt voor

$$
\begin{aligned}
& \text { voor } h_{z_{1}} \text { geldt } h_{z_{1}}=\int_{z_{1}=w-z_{1}}^{w} g_{z_{1}}\left(z_{1}\right) d z_{1}=\int_{z_{1}=w-z_{2}}^{w} \frac{1}{w} d z_{1}=\frac{z_{2}}{w} \\
& \rightarrow p_{G, 1 \mid k}=\varepsilon_{z_{2}}\left(h_{z_{2}}\right)=\frac{\varepsilon \underline{z}_{2}}{w}=\frac{\overline{z_{2}}}{w}\left\{=\frac{\overline{I D} \mid k}{w}\right\}
\end{aligned}
$$

Uit vergelijking (47) volgt dat de relatie (34) alleen geldt, indien er sprake is van een uniforme diameterverdeling binnen een diameterklasse. Een omstandigheid die zich in uitkapbos waarschijnlijk niet zal voordoen. Er is dus een relatie tussen de springkans en de diameterbijgroei, deze is mede afhankelijk van de kansdichtheid van $\underline{z}_{1}$. In de volgende paragraaf zal daarom eerst een model voor de diameterbijgroei worden ontwikkeld.

\subsubsection{Het schatten van de diameterbijgroei}

Vooruitlopend op de behandeling van de casestudie Kolkbos in Hoofdstuk 4 laat Figuur 3 zien dat voor de douglas weinig verband is tussen de diameter en de diameterbijgroei. Voor andere soorten zijn vergelijkbare resultaten gevonden

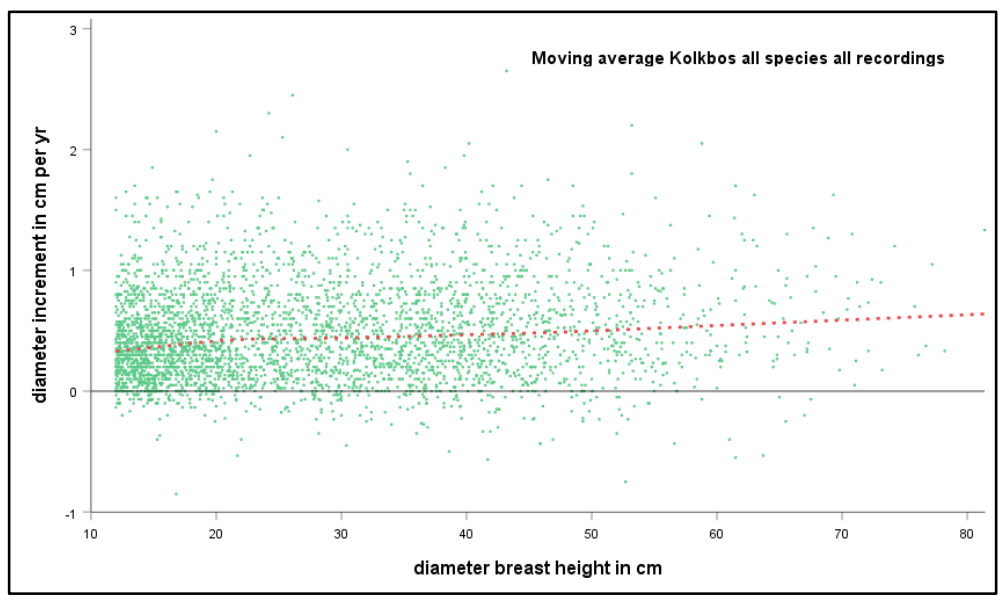

Figuur 3. Verband diameter en diameterbijgroei douglas in casestudie Kolkbos met rode lijn is het voortschrijdend gemiddelde.

Figure 3. Relation diameter and diameter increment Douglas in case study Kolkbos where the red line represents the moving average.

We kunnen nu een regressiefunctie voor id bedenken, waarbij bijvoorbeeld per soort een tweedegraadspolynoom in $d$ wordt gebruikt, aangevuld met steekproefpuntvariabelen die met de dichtheid ter plaatse te maken hebben. Hiervoor komt het grondvlak $G$ in aanmerking. Naast het totale grondvlak kan dan de werking van het aandeel loof- en naaldhout of aandelen van boomsoorten respectievelijk boomsoortgroepen in dit grondvlak worden onderzocht. Ook een splitsing in zwaarteklassen van het hout behoort tot de mogelijkheden. Stel er zijn $g r_{\max }$ groepen $g r$ om $G$ te splitsen mogelijk, de regressiefunctie zou dan kunnen luiden: 


$$
\begin{aligned}
& \text { id } \begin{aligned}
& c_{0}\left(s g_{i}\right)+c_{1}\left(s g_{i}\right) \cdot d_{i j}+c_{2}\left(s g_{i}\right) \cdot d_{i j}^{2}+\sum_{g r=1}^{g r_{\text {max }}} b_{g r} \cdot G_{g r, j, i p}=f(d, s g, G, g r) \\
\text { where } \quad c_{0}\left(s g_{i}\right) & =c_{01}+\sum_{l=2}^{n_{s g}} c_{0 l} \cdot \mu_{l, i j} \\
c_{1}\left(s g_{i}\right) & =c_{11}+\sum_{l=2}^{n_{s g}} c_{1 l} \cdot \mu_{l, i j} \cdot d_{i j} \\
c_{2}\left(s g_{i}\right) & =c_{21}+\sum_{l=2}^{n_{s g}} c_{2 l} \cdot \mu_{l, i j} \cdot d_{i j}^{2} \\
\mu_{l, i j} & =\left\{\begin{array}{l}
1 \text { if } s g=l \\
0 \text { if } s g \neq l
\end{array} \text { with / on interval }\left\{2, n_{s g}\right\}\right. \\
G_{g r, j, i p} & =\text { basal area per ha of subgroup gr at } t_{j} \text { of the } i p^{\text {th }} \text { plot }
\end{aligned}
\end{aligned}
$$

In onze data gaat het om meerdere perioden met verschillende lengten $\Delta t$. We veronderstellen daarbij een mogelijk verschillend niveau, aangeduid met een periode-index $P I$.

$$
\underline{i d}_{i j}=f(d, s g, G, g r) \cdot P l_{j}\left(\Delta t_{j}\right)+\sigma \underline{e} \text { with } \sum_{j=1}^{j_{\max }-1} P l_{j}=j_{\max }-1
$$

where $f(d, s g, G, g r)$ same as in Formula (48) and $\mathrm{Pl}_{j}$ a period index for the $j^{\text {th }}$ period

We lossen vergelijking (48) op door de vergelijkingen (48) en (49) te combineren tot

$$
\begin{aligned}
\ddot{i d}_{i j}= & \left\{c_{0}\left(s g_{i}\right)+c_{1}\left(s g_{i}\right) \cdot d_{i j}+c_{2}\left(s g_{i}\right) \cdot d_{i j}^{2}+\sum_{g r=1}^{g r_{\max }} b_{g r} \cdot G_{g r, j, i p}\right\} \cdot P I_{j}\left(\Delta t_{j}\right)+\sigma \underline{e} \text { with } \sum_{j=1}^{j_{\max }} P I_{j}=1 \\
& \text { where } c_{0}\left(s g_{i}\right), c_{1}\left(s g_{i}\right), c_{2}\left(s g_{i}\right) \text { and } G_{g r, j, i p} \text { the same as in the Formula (48) } \\
& \text { and } P l_{j} \text { the same as in the Formula (49) }
\end{aligned}
$$

Hierin schatten de regressieconstanten $P I_{j}$ voor $j=\left\{l, j_{\max }-1\right\}$ de periodeniveaus. Met een backward of "forward elimination procedure" in lineaire regressie kunnen de significante boomsoortgroepen en grondvlakgroepen geïdentificeerd worden. Daamen en Schoonderwoerd (1990 en Schoonderwoerd, 1993) voorspellen de diameterbijgroei uit de bijgroei van het boomgrondvlak, waarbij de Kraftse boomklasse (Kraft, 1884) een belangrijke rol speelt. Deze informatie is in onze data echter niet beschikbaar. Voor uitkapbos ligt overigens als vergelijkbare informatie Dawkins belichting index (1956) meer voor de hand, maar ook deze informatie is niet beschikbaar.

Bij toepassing van Formule (50) geldt de gemiddelde $P l_{j}$ waarde dus 1 , de resterende variabelenkunnen als arrays van de matrix $\mathbf{Z}$ worden opgevat en de coëfficiënten als de vector $c$. Het model is dan ook te schrijven als:

$\underline{\overrightarrow{i d}}=\mathbf{Z}^{\prime} \cdot \vec{c}+\sigma \cdot \underline{\vec{e}}$

Voor de schatter van $c$ geldt:

$$
\underline{\vec{c}}=\left(Z^{\prime} Z\right)^{-1} \cdot\left(\mathbf{Z}^{\prime} \underline{\overrightarrow{i d}}\right)
$$

Invulling van vergelijking (51) voor een willekeurige combinatie boomsoortgroep/diameter en grondvlakgroep levert een lineaire combinatie van $\vec{c}$ :

$\underline{i d}=\vec{r}^{\prime} \cdot \vec{c}$ 
Voor de variantie geldt:

$$
\begin{aligned}
& \operatorname{vâr}(\underline{i d})=\vec{r}^{\prime} \cdot\left(\mathbf{Z}^{\prime} \mathbf{z}\right)^{-1} \cdot \underline{\vec{r}} \cdot \sigma^{2} \cdot f p c \\
& \rightarrow \hat{\sigma}=\sqrt{\operatorname{vâr}(\underline{\text { id }})}
\end{aligned}
$$

\subsubsection{Integral projection models (IPM).}

Easterling et al. (2000) definieerden een kernel $k$ op een continue variabele met dezelfde werking als een transitionmatrix op een discrete variabele als volgt:

$$
\begin{aligned}
& n(y, t+1)=\int_{\Omega} k(y, x) \cdot n(y, t)=\int_{\Omega}[p(x, y)+f(x, y)] \cdot n(y, t) \\
& \text { where } p(x, y) \text { is a growth/survivor function } \\
& \quad f(x, y) \text { the fecundity or recruitement function } \\
& y \text { the entities of existing individual and } x \text { for new individuals } \\
& \Omega \text { all possible combinations }
\end{aligned}
$$

In ons geval betreft zowel de $x$ als $y$ de $d b h$. Voor het onderdeel springkansen $p(x, y)$ kunnen we Model (50) gebruiken en de integraal in Functie (55) is dan numeriek oplosbaar door in zeer kleine stappen $d_{j, t+1}=d_{j, t}+\hat{i}_{d_{j}}$ te berekenen voor een periode van één jaar en daarbij de afmetingklassen van $d_{j, t+1}$ en $d_{j, t}$ te turven. Voor een zekere diameterklasse $k$ en soortgroep sg met $w=4$ en stappen van $0.01 \mathrm{~cm}$ volgt:

$$
\begin{aligned}
& N_{k . s g, t}=1 \text { for } d_{j, t} \in(k, s g) \text { and } d_{j}=d_{0}+\frac{\text { step }}{400} \text { while step }=0.5,1.5,2.5 \cdots 399.5 \\
& N_{k, s g, t+1}=\left\{\begin{array}{l}
0 \text { for } d_{j, t+1} \in(k, s g) \\
1 \text { for } d_{j, t+1} \in(k+1, s g)
\end{array}\right. \\
& \text { where } d_{j, t+1}=d_{j, t}+i d_{j} \\
& d_{0} \text { the smallest value of } d \in(k, s g)
\end{aligned}
$$

Hieruit wordt de springkans als volgt berekend:

$$
p_{G, 1 \mid k, s g}=\frac{\sum_{j=0}^{399} N_{k, s g, t+1} / 400}{\sum_{j=0}^{399} N_{k, s g, t} / 400}
$$

Hiermee wordt echter de kansdichtheid van diameter impliciet uniform verondersteld. In ons geval zullen we daarom wel rekening moeten houden met een negatief exponentiele kansdichtheid, zie Figuur 4. 


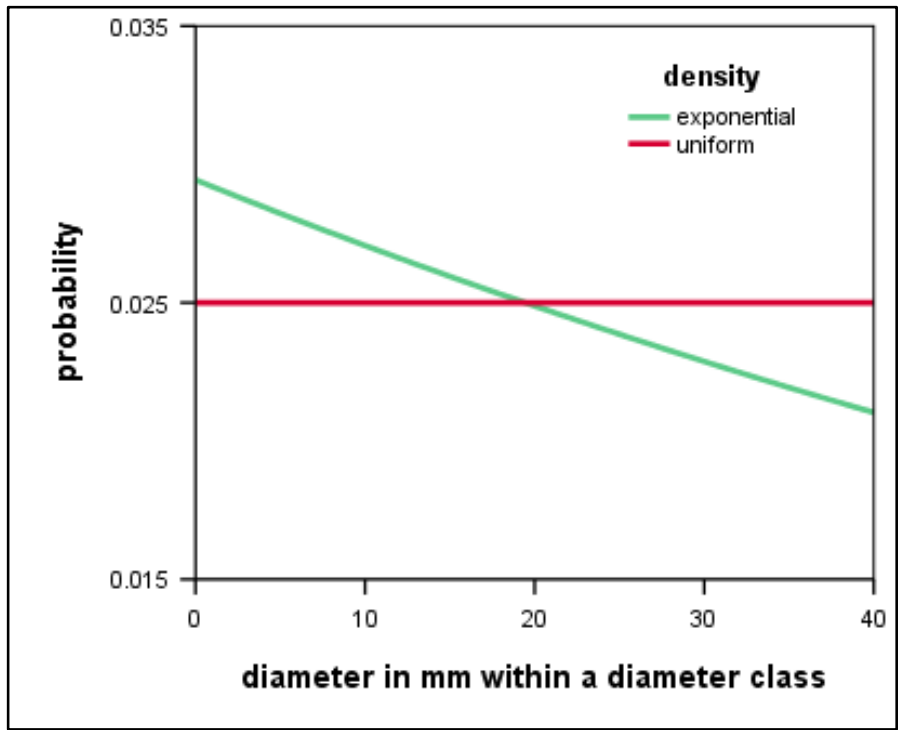

Figuur 4. Exponentiele en uniforme kansdichtheid van de diameter binnen een klasse.

Figure 4. Exponential and uniform density of the diameter within a class.

Voor een zekere diameterklasse $k$ en soortgroep $s g$ met $w=4$ en stappen van $0.01 \mathrm{~mm}$ moet Formule (56) herschreven worden tot:

$N_{k . s g, t}=p_{d_{j}}$ for $d_{j, t} \in(k, s g)$

$N_{k, s g, t+1}=\left\{\begin{array}{l}0 \text { for } d_{j, t+1} \in(k, s g) \\ p_{d j} \text { for } d_{j, t+1} \in(k+1, s g)\end{array}\right.$

where $d_{j, t+1}=d_{j, t}+i d_{j}$

$$
\begin{aligned}
& d_{j}=d_{0}+\frac{\text { step }}{400} \text { while step }=0.5,1.5,2.5 \cdots 399.5 \\
& d_{0} \text { the smallest value of } d \in(k, s g) \\
& p_{d_{j}}=\frac{e^{-\lambda \cdot\left(d_{j}-0.05\right)}-e^{-\lambda \cdot\left(d_{j}+0.05\right)}}{e^{-\lambda \cdot\left(d_{0}\right)}-e^{-\lambda \cdot\left(d_{0}+4\right)}}
\end{aligned}
$$

Voor de springkans volgt nu naar analogie van Formule (57).

$$
p_{G, 1 k, s g}=\frac{\sum_{j=0}^{399} N_{k, s g, t+1} / \sum_{j=0}^{399} p_{d_{j}}}{\sum_{j=0}^{399} N_{k, s g, t} / \sum_{j=0}^{399} p_{d_{j}}}
$$

De gemiddelde waarde van $p_{d}$ binnen een diameterklasse in de Formules (58) en (59) bedraagt 1. Uit Formule (45) volgt $\lambda=\ln (q) / w$, hierbij kan $q$ simpel per diameterklasse worden geschat met

$q \mid k=\sqrt{\sum_{j=1}^{j_{\max }} y_{j, k-1} / \sum_{j=1}^{j_{\max }} y_{j, k+1}}$ 
Voor de laagste en hoogste diameterklasse is uiteraard een aangepaste schatter nodig. Maar in plaats van deze waarde per soortgroep en diameterklasse te schatten kan dat ook met één waarde voor de hele soortgroep worden geschat:

$N_{k}=q^{-k+1} \cdot N_{k_{0}}$

where $k$ is tree class with class width $w$

$N_{k_{0}}$ number of trees in lowest diameter classce above the thresshold $D=D_{0}$

$N_{k}$ number of trees in diameter class $k$

Hierin zijn $q$ en $N_{k}$ te schatten parameters, $k$ de x-variabele en $N_{k}$ de y-variabele.

Aangezien de aldus gevonden schatters voor $p_{G, 11 k}$ alle gebaseerd zijn op de diametergroei aan levende bomen hoeft niet gecorrigeerd te worden voor sterfte en kap.

De parameter $q$ is in principe een geschatte stochastische variabele die een extra variantiecomponent aan Formule (59) toevoegt. Bij de toepassingen in de cases zal gewerkt worden met één ingestelde waarde van $q$ voor alle soortgroepen en diameterklassen. Hierdoor wordt ook $p_{d_{j}}$ in de Formules (58) en (59) een scalaire variabele. Formule (59) is daarom herschreven tot een functie van de stochastische variabele $\underline{i d}$ :

$p_{G, 1 k, s g}=\sum_{j=0}^{399} f\left(d_{j}+i d_{j}\right)$

Voor de variantie is geen directe formule te ontwikkelen. Er zijn in principe drie benaderingsmethoden om de variantie te schatten:

1. Jack-knife-methode;

2. Bootstrap-methode;

3. Monte Carlo-methode.

Bij de eerste twee methoden wordt naast de springkans $p_{G, 1 \mid k, s g}$ berekening met de Formules (50), (58) en (59) met de volledige dataset, deze berekening $k h$ ook herhaalt door bij de berekening steeds andere delen van de dataset respectievelijk systematisch of at random uit te sluiten. Daarna moeten de $k h$ springkansen uit de gereduceerde datasets via een ingewikkelde formule gelinkt worden aan de met de volledige dataset berekende springkans. $\mathrm{Er}$ volgen daaruit $k h$ geadjusteerde springkansen. En hieruit is de variantie van de springkans te berekenen. Afhankelijk hoe die uit te sluiten delen worden gedefinieerd zijn beide schatters van de varianatie zuiver of asymptotische raak, de nauwkeurigheid is afhankelijk van $k h$.

Wij zullen de Monte Carlo methode kiezen. Hierbij wordt uitgegaan dat id berekend wordt met Formule (53).

$d_{j, s p, t+1}=d_{j, s p, t}+\hat{i}_{d_{j, s p}}+\hat{\sigma} \cdot \underline{e}$

where $\hat{i}_{d_{j, s p}}$ is calculated with Formula (53), $\hat{\sigma}$ is calculated with Formula (54)

and several values for $\boldsymbol{e}$ are found with a pseudo random value from a normal distribution

Door de berekening met Formule (63) bijvoorbeeld 10.000 maal te herhalen, volgt met formule (59) ook 10.000 schatters voor de springkans, en hieruit volgt de variantie, standaard error en afwijkingspercentage:

$E \%=\frac{2 \cdot \hat{\sigma}_{\hat{p}}}{\hat{p}} \cdot 100 \quad$ (per cent $)$ 


\subsection{Schatters voor sterftekansen en kans op blijven}

In de inleiding van Hoofdstuk 4 is voor een voorbeeld (Tabel 1) tussen twee opnamen al de ratioschatter voor de mortaliteit in een diameterklasse gegeven in de vergelijking (14):

$\hat{p}_{M, k \mid \Delta t}=\frac{y_{M, j, k \mid j+1=0}}{y_{j, k}-y_{H, j, k}}$

Sterfte wordt pas geconstateerd vanaf de $2^{\mathrm{e}}$ opname. Voor alle perioden tezamen geldt dan:

$\hat{p}_{M, k \mid \Delta t}=\frac{\sum_{j=2}^{j_{\max }} w g t_{j} \cdot y_{M, j, k \mid j+1=0}}{\sum_{j=2}^{j_{\max }} w g t_{j} \cdot\left(y_{j, k}-y_{H, j, k}\right)} \quad$ with $w g t_{j}=\frac{\Delta t_{j}}{\sum_{j=2}^{j_{\max }} \Delta t_{j}}$

where $w g t_{j}$ Sis the weight for the $j^{\text {th }}$ period and $j_{\max }$ number latest recording

Omdat er bomen doodgingen in een klasse waar weinig bomen aanwezig waren, is met een voortschrijdend gemiddelde gewerkte over steeds 5 diameterklassen. De aldus gevonden waarden zijn met de hyperbool van Formule Error! Reference source not found. gefit, hierbij is het "aantal bomen in de klasse" $n$ als regressiegewicht gebruikt aldus:

$\underline{p}_{M}=\max \left\{0, b_{0}+\frac{b_{1}}{d b h}\right\}+\sigma \frac{1}{\sqrt{n}} \cdot \underline{e} \rightarrow \underline{y}=\max \left\{0, b_{0} \cdot x_{1}+b_{1} \cdot x_{2}\right\}+\sigma \cdot \underline{e}$

where $y=p_{m} \cdot \sqrt{n}, x_{1}=\sqrt{n}$ and $x_{2}=\frac{\sqrt{n}}{d b h}$ and $n=\sum_{i=k-2}^{k+2}\left\{\sum_{j=2}^{j_{\max }} w g t_{j} \cdot y_{i j}^{*}\right\}$ with $w g t_{j}=\frac{\Delta t_{j}}{\sum_{j=2}^{j_{\max }} \Delta t_{j}}$

$w g t_{j}$ weight for the $j^{\text {th }}$ period and $j_{\max }$ number latest recording

and $y_{i j}^{*}$ number of not harvested trees in $i^{\text {th }}$ diameter class in the $j^{\text {th }}$ period

Vooruitlopend op de toepassingen in de Hoofdstukken 4, 5 en 6 zijn in Figuur 5 zijn de met Formule (66) berekende sterftekansen voor de beide soortgroepen in het Boombos als functie van de diameter weergegeven.

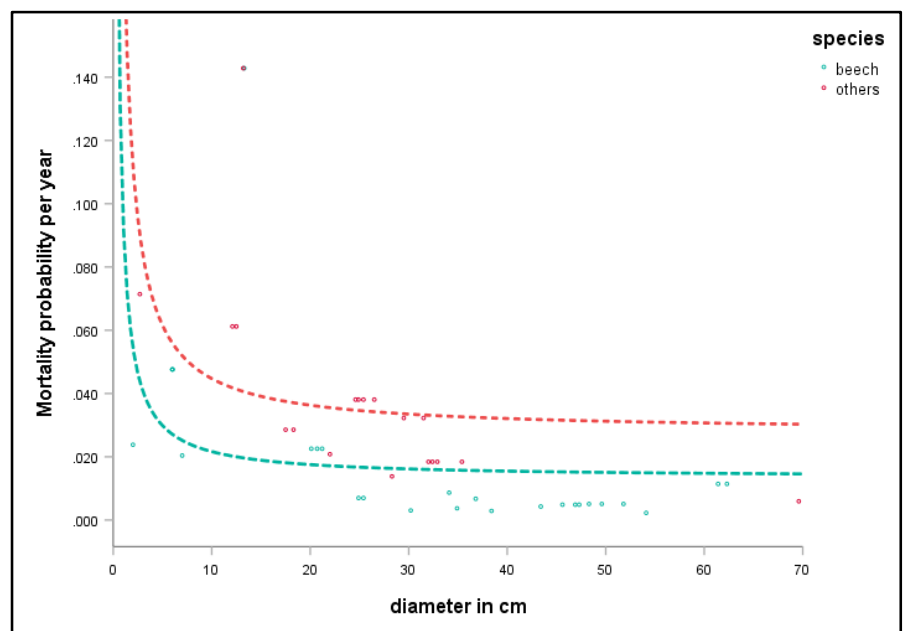

Figuur 5. Sterftekans als functie van de diameter per soort, de stippellijnen door de puntenwolk betreffen de gefitte hyperbolen per soortgroep.

Figure 5. Mortality probability as a function of the diameter per species, the dotted lines through the point cloud represent the fitted hyperbolas by species group.

De varianties worden met de standaardprocedure berekend. 
Aangezien de som van de kansen op blijven, springen en sterven per definitie 1 is volgt voor de kans op blijven $P$ :

$\hat{p}_{G, 0 \mid k}=1-\hat{p}_{G, 1 \mid k}-\hat{p}_{M, k}$

En aangezien de kans op sterven onafhankelijk van de kans op springen is, volgt voor de variantie van de kans op blijven:

$$
\operatorname{vâr}\left(\hat{p}_{G, 0 \mid k}\right)=\operatorname{vâr}\left(\hat{p}_{G, 1 \mid k}\right)+\operatorname{vâr}\left(\hat{p}_{M, k}\right)
$$

\subsection{Kap en evenwichtstoestand}

Usher (1966) beschrijft kap en evenwichtstoestand met de volgende vergelijking:

$$
\mathrm{T}^{*} \cdot \vec{e}=\lambda \cdot \vec{e}
$$

$$
\begin{aligned}
& \text { where } \mathbf{T}^{*} \cdot \vec{e}=\mathbf{T} \cdot \vec{e}+(1-\vec{h}) \cdot \vec{e} \text { and } \mathbf{T} \text { the combination of } \mathbf{T}_{G} \text { and } \mathbf{T}_{R} \\
& \qquad \vec{e} \text { a eigenvector before harvest with eigenvalue } \lambda>1 \text {, for } \vec{h}_{i}=(\lambda-1) \cdot \vec{s}
\end{aligned}
$$

Usher heeft geen diameterdrempel en relateert de ingroei aan de kap in de hoogste diameterklassen, ook komt sterfte bij hem niet voor. Het model is ongeschikt voor onze toepassing.

Buongiorno en Michie (1980) beschrijven kap en evenwichtstoestand met de volgende vergelijking:

$\mathbf{T}^{*} \cdot \vec{e}=\lambda \cdot \vec{e}$

$$
\begin{gathered}
\text { where } \mathbf{T}^{*} \cdot \vec{e}=\mathbf{T} \cdot \vec{e}+(1-\vec{h}) \cdot \vec{e} \text { and } \mathbf{T} \text { the combination of } \mathbf{T}_{G}, \mathbf{T}_{M} \text { en } \mathbf{T}_{R} \\
\vec{e} \text { a eigenvector before harvest with eigenvalue } \lambda-1
\end{gathered}
$$

Hun planningsperiode is 5 jaar, maar ze laten het bos 35 jaar doorgroeien en kappen pas daarna:

$$
\begin{aligned}
& \left(\mathbf{T}^{*}\right)^{7} \cdot \vec{y}_{1}=\vec{y}_{7}-\vec{h}=\vec{e}_{35} \\
& \text { where } \mathbf{T}^{*} \text { is the combination of } \mathbf{T}_{G}, \mathbf{T}_{M} \text { and } \mathbf{T}_{R} \\
& \vec{e}_{35} \text { a steady state after harvest after } 35 \text { year }
\end{aligned}
$$

Dit model is in strijd met in Formule (12) gesignaleerde ongelijkheid en is daarom ongeschikt voor onze toepassing.

Wij integreren de kap in $\mathbf{T}^{*}$ :

$$
\mathrm{T}^{*} \cdot \vec{e}=\lambda \cdot \vec{e}
$$

$$
\begin{aligned}
& \text { where } \mathbf{T}^{*} \cdot \vec{e}=\mathbf{T} \cdot \vec{e}+(1-\vec{h}) \cdot \vec{e} \text { and } \mathbf{T} \text { is combination of } \mathbf{T}_{G}, \mathbf{T}_{H}, \mathbf{T}_{M} \text { and } \mathbf{T}_{R} \\
& \vec{e} \text { an eigenvector after harvest with eigenvalue } \lambda=1
\end{aligned}
$$

\subsection{Schatten van de Ingroei}

In populatie-ecologische modellen is er meestal een duidelijke relatie tussen kenmerken van de populatie en de verjonging ervan, die via het "Fecundity" deel van de transitionmatrix kan worden beschreven. In ons beschreven deel van de populatie ontbreekt die relatie geheel, omdat informatie over alle stadia van verjonging tot de bosontwikkeling tot de meetdrempel onbekend is. Dus veel meer dan het aantal ingroeiers op $t_{2}$ te relateren aan het totaalaantal blijvende (niet gestorven en ook niet gekapte) bomen op $t_{1}$ is niet mogelijk:

$$
\hat{p}_{R \mid \Delta t_{j}}=\frac{y_{R, j-1, k=1 j j=\varnothing}}{y_{j, k}-y_{M, j, k}-y_{H, j, k}}
$$


Voor een periode van een jaar geldt dan:

$\hat{p}_{R \mid \Delta t_{j}}=\frac{y_{R, j-1, k=1 j j=\varnothing}}{\Delta t_{j} \cdot\left(y_{j, k}-y_{M, j, k}-y_{H, j, k}\right)}$

Over alle opnamen moeten we weer met een gewicht in de ratio werken:

$\hat{p}_{R \mid \Delta t=1}=\frac{\sum_{j=1}^{j_{\max }-1} w g t_{j} \cdot y_{R, j-1, k=1 \mid j=\varnothing}}{\sum_{j=1}^{j_{\max }-1} w g t_{j} \cdot\left(y_{j, k}-y_{M, j, k}-y_{H, j, k}\right)} \quad$ with $w g t_{j}=\frac{\Delta t_{j}}{\sum_{j=1}^{j_{\max }-1} \Delta t_{j}}$

where $w g t_{j}$ is the weight for de $j^{\text {th }}$ period and $j_{\max }$ number latest recording

Problemen bij deze methode zijn:

- Geringe nauwkeurigheid van de schatters;

- De relatie (75) is alleen rekenkundig en heeft geen inhoudelijke betekenis;

- Bij bossen in de overgangsfase tussen monocultuur en ongelijkjarig, gemengd bos, bestaande uit veel mini-opstanden is de kans groot, dat er veel bomen uit zo'n miniopstand tegelijker- tijd over de meetdrempel groeien, waardoor een overschatting ten opzichte van het na te streven ideale bos plaats;

- De kans dat het stelsel transitionmatrices geen eigenvector heeft met een eigenwaarde 1 is aanwezig.

Daarom zijn er twee alternatieven ontwikkeld in de Formules (76) en (77)

$$
\left\{\begin{array}{l}
t_{1,1}=1-\hat{p}_{G, 1 \mid k=1}-\hat{p}_{M \mid k=1}-\hat{p}_{H \mid k=1} \\
t_{2,1}=\left(1-t_{1,1}\right) \cdot \frac{e_{1}}{e_{2}}
\end{array}\right.
$$

where $e_{1}$ and $e_{2}$ respectively the $1^{\text {st }}$ and $2^{\text {nd }}$ element of the eigenvector with eigenvalue $\lambda=1$

$$
\left\{\begin{array}{l}
t_{1,1}=1-\hat{p}_{G, 1 \mid k=1}-\hat{p}_{M \mid k=1}-\hat{p}_{H_{1}}+c \cdot \hat{p}_{H_{1}} \\
t_{j, 1}=c \cdot \hat{p}_{H_{j}} \text { for } j \geq 2
\end{array}\right.
$$

where $c$ is a to estimated parameter

In Figuur 6 is een voorbeeld gegeven van zo'n samengestelde transitionmatrix. Deze matrix bevat elementen op de diagonaal en net daaronder en voor de rest nullen, behalve op de eerste rij waar bij Formule (76) één element boven de diagonaal ongelijk 0 is en bij Formule (77) alle elementen boven de diagonaal ongelijk 0 zijn.

Voor het berekenen van de eigenvector geven beide Formules (76) en (77) hetzelfde resultaat alleen de weg van het huidige bos naar de evenwichtstoestand verschilt, wij zullen Formule (76) gebruiken. 


$\mathbf{T}_{76}=\left[\begin{array}{lllllll}t_{1,1} & t_{2,1} & 0 & 0 & \cdots & 0 & 0 \\ t_{1,2} & t_{2,2} & 0 & 0 & \cdots & 0 & 0 \\ 0 & t_{3,2} & t_{3,3} & 0 & \cdots & 0 & 0 \\ 0 & 0 & t_{4,3} & t_{4,4} & \cdots & 0 & 0 \\ \cdots & \cdots & \cdots & \cdots & \cdots & 0 & 0 \\ 0 & 0 & 0 & 0 & \cdots & t_{n-1, n-1} & 0 \\ 0 & 0 & 0 & 0 & \cdots & t_{n-1, n} & t_{n, n}\end{array}\right]$ and $\mathbf{T}_{77}=\left[\begin{array}{lllllll}t_{1,1} & t_{2,1} & t_{3,1} & t_{4,1} & \cdots & t_{n-1,1} & t_{n, 1} \\ t_{1,2} & t_{2,2} & 0 & 0 & \cdots & 0 & 0 \\ 0 & t_{3,2} & t_{3,3} & 0 & \cdots & 0 & 0 \\ 0 & 0 & t_{4,3} & t_{4,4} & \cdots & 0 & 0 \\ \cdots & \cdots & \cdots & \cdots & \cdots & 0 & 0 \\ 0 & 0 & 0 & 0 & \cdots & t_{n-1, n-1} & 0 \\ 0 & 0 & 0 & 0 & \cdots & t_{n-1, n} & t_{n, n}\end{array}\right]$

Figuur 6. Voorbeeld samengestelde transitionmatrix (76) en (77).

Figure 6. Example composite transitionmatrix (76) and (77).

Voor beide formules is geen theoretische onderbouwing en dient om de vergelijking $\mathbf{T} \cdot \vec{e}=\lambda \cdot \vec{e}$ kloppend te maken. Met dien verstande dat Formule (77) veel weg heeft van de vergelijking van Usher (1966), waarbij het lijkt of de echte ingroei wordt berekend, dat is echter niet het geval. Het een theoretisch evenwicht, maar dan moet er ook gelden:

$N_{R}=N_{H}+N_{M}$

Om dit te bereiken zal de kap hieraan moeten voldoen.

\subsection{Structuurparameters}

De bomen in het bos staan in een bepaald patroon, dat kan regelmatig (door plantverband) of random (in natuurbossen) zijn. Doch afhankelijk van de verjongingsstrategie van een boomsoort komen per soort ook clusterpatronen voor. Zo'n patroon van stamvoeten, maar ook van bijvoorbeeld boomkronen of open plek- ken kan in kaart gebracht worden. Er zijn ook parameters in omloop die een waarde aan die structuur toekennen, b.v. de Cox index of dispersion (Cox \& Lewis, 1966):

$Q=\frac{\operatorname{var} Y}{\bar{Y}}$

where $Y$ number of tree on small area unit

Volgens o.a. Morisito (1954) en Essed (1955) Zou het aantal bomen op een kleine oppervlakte in natuurlijk (random bos) een Poissonverdeling vertonen. Voor "random bos" is de Q-waarde daarom gelijk aan 1 , voor geclusterde patronen $>1$ en voor regelmatige patronen $<1$.

In principe heeft een diameter-soort-frequentieverdeling $x_{i j}$ van Formule (8) heeft betrekking op de structuur, zo is het ongelijkjarige bos structuurrijker dan het ongelijkjarige bos. Zouden we een diameter-soort-frequentieverdeling maken van een boswachterij met allemaal gelijkjarige monoculturen van een uiteenlopend aantal leeftijden dan zal deze verdeling overeenkomen met die van een ongelijkjarig bos. De schaal waarop er structuurverschillen bestaan speelt hierbij dus een rol. Er zijn een aantal diversiteitparameters ontwikkeld om de variatie in soort en afmeting weer te geven, b.v. de Shannon-index $H$ (Shannon,1948):

$H=-\sum\left(p_{i} \cdot \ln p_{i}\right) \quad$ where $p_{i}$ fraction trees in tree class $i$

En de Simpson-index C (Simpson, 1949):

$C=1-\sum p_{i}^{2} \quad$ where $p_{i}$ fraction trees in tree class $i$ 
Deze indices kunnen gebruikt worden als prestatie-indicator bij omvormingsbeheer van gelijkjarig naar ongelijkjarig bos. Een nadeel van de drie genoemde indices is de gevoeligheid ervan voor de oppervlakte van het plot.

\subsection{Gebruik van grondvlak en volume bij uitwerking}

De evenwichtstoestand is gebaseerd op stamtallen per ha. Bij het beheer wordt veelal in termen van grondvlak en volume gedacht.

In huidige toestand gaat dat om de som van individuele boomgrondvlakken en boomvolumes.

Bij de eigenvector gaat het om de grondvlakken per diameterklasse, hiervoor geldt de zogenaamde correctie van Sheppard:

$g_{k}=\left(d_{k}^{2}+\frac{w^{2}}{12}\right) \cdot \frac{\pi}{4}$

Deze correctie van Sheppard is gebaseerd op de aanname dat de individuele bomen binnen de klassebreedte $w$ een uniforme kansverdeling hebben. In ons geval moeten we echter uitgaan van de negatief exponentiele kansverdeling van Formule (42). Voor het grondvlak van de diameterklasse volgt:

$g_{k}=\frac{\pi}{4} \cdot \int_{x=d_{k}-1 / 2 w}^{d_{k}+1 / 2 w} x^{2} \cdot \lambda \cdot e^{-\lambda \cdot x} d x$

Voor de berekening van het volume is in de databases het volumetarief van Berkhout (1922) gebruikt $v_{i}=c_{1} \cdot d_{i}^{c_{2}}$ Bij het gebruik bij diameterklassen volgt dan:

$v_{k}=c_{1} \cdot \int_{x=d_{k}-1 / 2 w}^{d_{k}+1 / w w} x^{c_{2}} \cdot \lambda \cdot e^{-\lambda \cdot x} d x$

De integraal van Formule (83) is oplosbaar, indien $c_{2}$ geen natuurlijk getal is, is de oplossing van integraal (84) alleen te benaderen. In beide gevallen is gekozen om dezelfde numerieke procedure via de 400 stappen van $0.01 \mathrm{~cm}$ bij IPM te volgen. Voor $g_{k}$ luidt dat:

$$
\begin{aligned}
& g_{k}=\sum_{i=0}^{399} p_{d_{j}} \cdot g_{j} / \sum_{i=0}^{399} p_{d_{j}} \\
& \text { where } g_{j}=\frac{\pi}{4} \cdot d_{j}^{2}, d_{j}=d_{0}+1 / 100 \text { and } d_{0} \text { the smallest value of } d \in(k, s g) \\
& \qquad p_{d_{j}}=e^{-\lambda \cdot\left(d_{j}+0.05 \cdot\right)}-e^{-\lambda \cdot\left(d_{j}-0.05 \cdot\right)}
\end{aligned}
$$

En voor $v_{k}$ volgt:

$$
\begin{aligned}
& v_{k}=\sum_{i=0}^{399} p_{d_{j}} \cdot v_{j} / \sum_{i=0}^{399} p_{d_{j}} \\
& \text { where } v_{j}=c_{1} \cdot d_{j}^{c_{2}}, d_{j}=d_{0}+1 / 100 \text { and } d_{0} \text { the smallest value of } d \in(k, s g) \\
& p_{d_{j}}=e^{-\lambda \cdot\left(d_{j}+0.05 \cdot\right)}-e^{-\lambda \cdot\left(d_{j}-0.05 \cdot\right)}
\end{aligned}
$$

Voor de lopende volumebijgroei $i c v_{k}$ volgt: 


$$
i c v_{k}=\sum_{i=0}^{399} p_{d_{j}} \cdot i c v_{j} / \sum_{i=0}^{399} p_{d_{j}}=\sum_{i=0}^{399} p_{d_{j}} \cdot\left(v_{2 j}-v_{1 j}\right) / \sum_{i=0}^{399} p_{d_{j}}
$$

where $v_{1 j}=c_{1} \cdot d_{j}^{c_{2}}, v_{2 j}=c_{1} \cdot\left(d_{j}+i_{d j}\right)^{c_{2}}, d_{j}=d_{0}+i / 100$

$$
p_{d_{j}}=e^{-\lambda \cdot\left(d_{j}+0.05\right)}-e^{-\lambda \cdot\left(d_{j}-0.05 \cdot\right)} \text { and } d_{0} \text { the smallest value of } d \in(k, s g)
$$




\section{TOEPASSING VOOR HET KOLKBOS}

Na de inleiding worden in een aantal paragrafen elementen van de transitionmatrix geschat, normaliter worden deze voor een planningsperiode van 4 jaar berekend. Maar omdat er bij de dikkere reuzenzilversparren per 4 jaar veel sprongen voorkwamen van meer dan $4 \mathrm{~cm}$ is gekozen om de springkansen en overige kansen in de transitionmatrix per jaar te definiëren.

\subsection{Inleiding}

Het 'Kolkbos' is een bosgebied van 20.4 ha op het landgoed Schovenhorst in Nederland op de Veluwe in de buurt van Putten (Kaartblad 32F, $x=171.34, y=473.51$ ). Het is gelegen op een late negentiende-eeuwse heidebebossing op lemig zand. Het landgoed is eigendom van een stichting, die innovatief onderzoek ter ondersteuning van de praktijk van het bos bevordert. Sinds 1960 is deels groepenkap, deels schermkap en deels uitkap toegepast. Naast natuurlijke verjonging, is ook met kunstmatige verjonging door onderplanting gebruikt op zeer kleine schaal variërend van $10 \mathrm{~m}^{2}$ tot $0.25 \mathrm{ha}$. Dit beheer resulteerde anno 1990 in een bosstructuur met ongeveer 10\% van de oppervlakte uitkapbos (Plenterwald, Gebied 1), zowel boomsgewijs als groepsgewijs. De rest van het gebied heeft kent een groepenkap, (Femelschlagwald, Gebied 2) maar in sommige delen ogen de groepen nog steeds als gelijkjarige monoculturen.

Sinds 1984 wordt overal uitkapbeheer toegepast. Beide gebieden zijn in de overgang naar een optimale uitkapbosstructuur. In Figuur 7 zijn enkele kenmerken van de bosstructuur getoond.

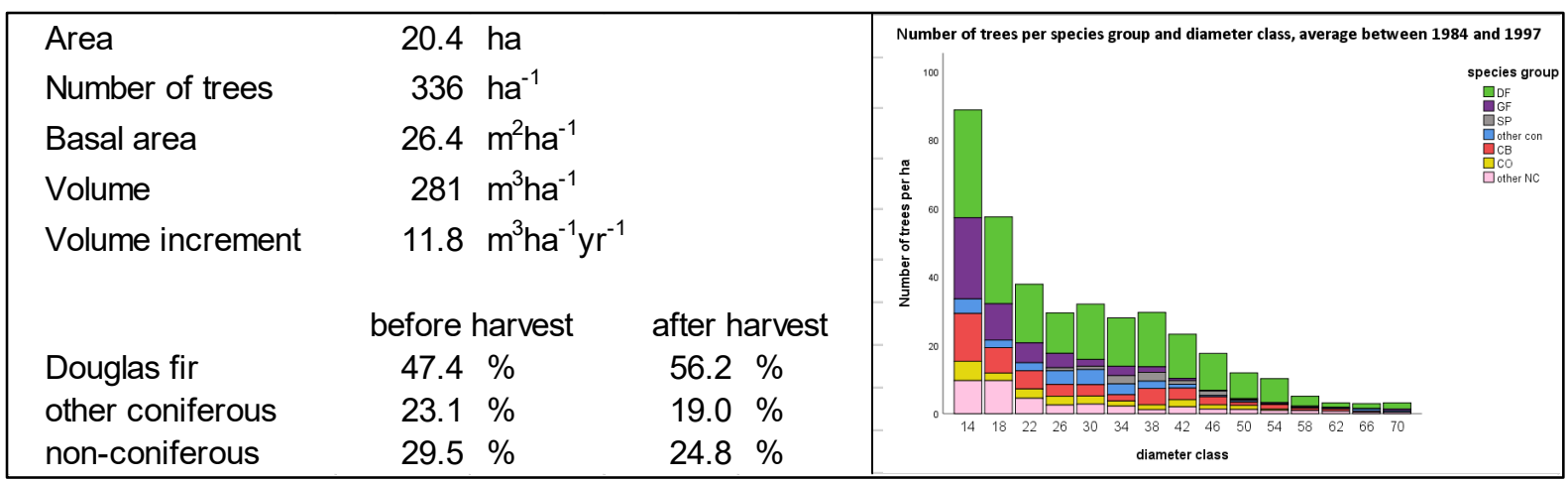

Figuur 7. Opstandkenmerken van het Kolkbos in 1984 (Links). Stamtal per ha per diameterklasse en soortgroep in Kolkbos gemiddeld tussen 1984 en 1997 (Rechts).

Figure 7. Stand characteristics Kolkbos in 1984 (Left) and Number of trees per ha per diameter class and species group in Kolkbos average between 1984 and 1997 (Right).

In deze case is gewerkt met 7 boomsoortgroepen, te weten: douglas (DF), Abies species (GF), grove den (SP), overige naaldboomsoorten (con), beuk (CB), eik (CB) en overige loofboomsoorten (NC). Hiervan waren douglas, beuk en eik geselecteerd op grond van hun belang voor het beheer en de overige omdat ze significante regressies vertoonden in enige modellen.

Vanwege de mogelijkheid tot onderlinge vergelijking van de methoden zijn ze voor alle methoden gebruikt. De gevolgde strategie bij het indelen in soortgroepen komt niet overeen met de gangbare werkwijzen, waarbij de soorten worden ingedeeld op basis van hun karakteristieken betreffende ingroei, groei en sterfte. (Vanclay, 1995).

Hoewel opeenvolgende metingen onderling gecorreleerd zijn en niet statistisch onafhankelijk zijn (Vanclay, 1995), is er toch met de gegevens van vier opnamen gewerkt. Het aantal opnamen is namelijk veel kleiner dan het aantal steekproefpunten en het aantal bomen in de opname en dit leidt niet tot problemen (Vanclay, 1995). 


\subsubsection{Vereiste gegevens bij uitkapbeheer}

Bij uitkapbeheer is het noodzakelijk om over informatie te beschikken over het aantal bomen, grondvlak en volume per hectare en de verdeling daarvan over de diameterklassen en boomsoorten of soortgroepen. Bovendien is behoefte aan informatie over verjonging en ingroei (over de meetdrempel) en over sterfte (meer informatie is te vinden bij De Klein en Jansen 1992).

\subsubsection{Het steekproef ontwerp}

Uit logistieke overwegingen is gekozen voor een systematisch steekproefontwerp met een raster $40 \mathrm{x}$ 40 meter wordt gebruikt. De uitkomsten zijn beschouwd alsof ze uit een aselecte steekproef afkomstig zijn, hiermee wordt de variantie mogelijk iets overschat (De Vries, 1986). In 1984 zijn er 138 plots uitgezet en de middelpunten zijn gemarkeerd. Binnen een straal van $7.98 \mathrm{~m}$ (dus in een oppervlakte van $200 \mathrm{~m}^{2}$ ) zijn alle bomen boven de meetdrempel van $12 \mathrm{~cm}$ bemonsterd. De diameter is gemeten, de soort is bepaald en de positie is in poolcoördinaten vastgelegd. In ieder plot is van twee bomen ook de hoogte gemeten, met het doel met behulp van out-place elementen (volumetabellen) tot een volumetarief te komen.

Door de aanleg van een fietspad zijn twee plots verloren. De overige 136 plots zijn in 1988, 1990, 1994 en 1997 opnieuw ingemeten en daarbij werd het type verandering genoteerd, onderscheiden werden de categorieën: geen verandering anders dan groei, verdwenen of dood, gekapt, ingroei over de meetdrempel. Er zijn in de loop van de tijd wat wijzigingen in de opnamemethodiek aangebracht door de meetdrempel naar $8 \mathrm{~cm}$ te verlagen en te werken met concentric sample points (CSP), maar in deze studie zijn alleen waarnemingen geselecteerd die in het eerst gedefinieerde SSP (simple sampling point) van $200 \mathrm{~m}^{2}$ vielen. De data zijn beschikbaar op de DANS-site (De Klein et al., 2016). De opnameformulieren zijn gearchiveerd bij de Stichting Schovenhorst. Niet bij alle opnamen zijn er op alle plots bomen aanwezig boven de meetdrempel.

\subsection{Springkansen bepaald met de ratiomethode}

De ratiomethode geeft schattingen van springkansen voor alleen die boomklassen, die ook werkelijk voorkomen (zie Tabel 3). Indien de klasse slechts uit een boom bestaat, dan is de variantie niet schatbaar. Indien er zich meerdere bomen in de klasse bevinden maar ze allemaal springen of blijven, dan is in principe de variantie wel schatbaar, doch het resultaat is nul. Dat is weinig realistisch en derhalve als "niet schatbaar beschouwd". In plaats van de variantie of de standaarddeviatie is als relatieve maat voor de nauwkeurigheid hier gewerkt met het afwijkingspercentage (E\%) van Formule (64).

Tabel 2 geeft de springkansen als resultaat van de vergelijkingen (26) voor alle boomklassen. Het afwijkingspercentage van de ratiomethode bij gebruik van het regressiemodel met gelijke varianties zie model (27) is gegeven in het rechterdeel van Tabel 2. De berekende kans voor grove den in de diameterklasse 48-52 cm bleek negatief, omdat hier maar één boom aanwezig was die iets "kromp", waardoor de diameter een klassegrens passeerde. Deze waarde is vervangen door 0 . In principe is de uitkomst van Tabel 2 niet meer een zuivere schatting. 
Tabel 2. Geschatte springkansen en de bijbehorende afwijkingspercentages per jaar, berekend via ratioschatter.

Table 2. Estimated moving up probabilities and corresponding deviation percentages per years, calculated using ratio estimate.

\begin{tabular}{|c|c|c|c|c|c|c|c|c|c|c|c|c|c|c|c|c|}
\hline \multirow{2}{*}{$\begin{array}{l}\text { diameter } \\
\text { in } \mathrm{cm}\end{array}$} & \multicolumn{8}{|c|}{ moving up probabilities Methode 1} & \multicolumn{8}{|c|}{ deviation percentages } \\
\hline & DF & GF & SP & con & CB & CO & NC & total & DF & GF & SP & con & CB & CO & NC & total \\
\hline $12-16$ & 0.088 & 0.068 & • & 0.029 & 0.065 & 0.004 & 0.070 & 0.069 & 19 & 22 & • & 91 & 31 & 246 & 36 & 12 \\
\hline $16-20$ & 0.095 & 0.118 & • & 0.069 & 0.066 & 0.076 & 0.043 & 0.085 & 18 & 27 & • & 90 & 41 & 74 & 47 & 13 \\
\hline $20-24$ & 0.115 & 0.103 & • & 0.091 & 0.068 & 0.056 & 0.043 & 0.091 & 20 & 37 & - & 56 & 50 & 73 & 69 & 15 \\
\hline $24-28$ & 0.142 & 0.090 & 0.000 & 0.095 & 0.089 & 0.046 & 0.052 & 0.102 & 18 & 47 & • & 41 & 53 & 97 & 69 & 15 \\
\hline $28-32$ & 0.112 & 0.145 & 0.000 & 0.050 & 0.053 & 0.033 & 0.102 & 0.090 & 20 & 53 & • & 69 & 94 & 106 & 48 & 17 \\
\hline $32-36$ & 0.123 & 0.067 & 0.040 & 0.086 & 0.148 & 0.031 & 0.063 & 0.098 & 22 & 72 & 104 & 43 & 38 & 134 & 96 & 17 \\
\hline $36-40$ & 0.112 & 0.063 & 0.038 & 0.071 & 0.072 & 0.141 & 0.114 & 0.096 & 18 & 159 & 97 & 71 & 47 & 65 & 99 & 17 \\
\hline $40-44$ & 0.113 & 0.125 & 0.056 & 0.056 & 0.066 & 0.048 & 0.080 & 0.093 & 19 & 92 & 163 & 131 & 50 & 82 & 63 & 17 \\
\hline $44-48$ & 0.102 & 0.125 & 0.018 & 0.063 & 0.071 & 0.089 & 0.083 & 0.089 & 27 & 123 & 185 & 185 & 99 & 68 & 85 & 23 \\
\hline $48-52$ & 0.123 & 0.188 & 0.000 & 0.050 & 0.100 & 0.050 & 0.107 & 0.111 & 26 & 78 & • & 246 & 79 & 145 & 69 & 22 \\
\hline $52-56$ & 0.092 & 0.125 & • & - & 0.071 & 0.063 & 0.100 & 0.088 & 38 & 246 & • & - & 98 & 246 & 79 & 32 \\
\hline $56-60$ & 0.091 & 0.125 & • & 0.083 & 0.125 & • & 0.094 & 0.100 & 72 & 142 & • & 123 & 88 & • & 106 & 44 \\
\hline $60-64$ & 0.179 & 0.250 & - & 0.083 & 0.083 & - & 0.083 & 0.129 & 54 & 0 & • & 246 & 126 & - & 123 & 44 \\
\hline $64-68$ & 0.125 & 0.250 & - & 0.063 & - & - & 0.125 & 0.103 & 61 & 0 & - & 161 & • & - & 142 & 51 \\
\hline$\geq 68$ & 0.117 & 0.250 & - & 0.083 & 0.000 & • & 0.083 & 0.135 & 64 & 25 & • & 246 & • & • & 185 & 41 \\
\hline Total & 0.108 & 0.092 & 0.030 & 0.069 & 0.073 & 0.048 & 0.067 & 0.088 & 6 & 13 & 62 & 21 & 15 & 30 & 18 & 5 \\
\hline
\end{tabular}

-) Not to be estimated

\subsection{Springkansen indirect bepaald via de diameterbijgroei (IPM)}

Allereerst is met Model (50) in vier stappen de diameterbijgroei geschat. Met alleen een tweedegraadspolynoom zonder soortgroepen werd een $R^{2}$ adj van slechts 0.015 gevonden. Door de soortgroepen toe te voegen steeg $R^{2}$ adj naar 0.096. In de volgende stap werd een grondvlakcomponent toegevoegd in Model (50) $c_{0}\left(s g_{i}\right)=c_{01}+b_{1} \cdot G_{L, j, i p}+b_{2} \cdot G_{M, j, i p}+b_{3} \cdot G_{z, j, i p}+\sum_{l=2}^{n_{s g}} c_{01} \cdot \mu_{l, i j}$. Hierin staat $G_{L, j, i p}$ voor het grondvlak per ha van het lichte hout $(d b h \leq 30 \mathrm{~cm})$ in de $j^{\mathrm{e}}$ opname in het ip plot, $M$ voor middelzwaar $(30 \mathrm{~cm}<d b h \leq 50) \mathrm{cm}$ en $Z$ voor zwaar hout $(d b h>50 \mathrm{~cm})$. Door toevoeging van deze grondvlakcomponent steeg $R^{2}$ adj naar 0.147. Na de toevoeging van de periode-index zoals in Formule (50), weglating van de niet significante parameters werd een $R^{2}$ adj naar 0.246 bereikt. Met het gemiddelde $G_{L}=1.80 \mathrm{~m}^{2} \mathrm{ha}^{-1}$ voor alle opnamen en plots, evenzo $G_{M}=4.40 \mathrm{~m}^{2} \mathrm{ha}^{-1}$ en $G_{Z}=20.75$ $\mathrm{m}^{2} \mathrm{ha}^{-1}$ werden de volgende parameters per soortgroep gevonden (Tabel 3).

Tabel 3. Parameters voor de tweedegraadspolynoom in id $=c_{0}+c_{1} \cdot d b h+c_{2} \cdot d b h^{2}$

Table 3. Parameters for the second-degree polynomial id $=c_{0}+c_{1} \cdot d b h+c_{2} \cdot d b h^{2}$

\begin{tabular}{|l|rrrrrrr|r|}
\hline & \multicolumn{1}{|c}{ DF } & \multicolumn{1}{c}{ GF } & \multicolumn{1}{c}{ SP } & \multicolumn{1}{c}{ con } & \multicolumn{1}{c}{ CB } & \multicolumn{1}{c}{ CO } & n.c. & tot \\
\hline$c_{0}$ & 0.1771 & 0.4352 & -0.1311 & 0.0071 & 0.3892 & -0.1311 & 0.1771 & 0.2021 \\
$c_{1}$ & 0.019595 & 0.001874 & 0.019595 & 0.019595 & -0.002076 & 0.019595 & 0.010875 & 0.012937 \\
$c_{2}$ & -0.0001905 & 0.0000801 & -0.0001905 & -0.0001905 & 0.0000979 & -0.0001905 & -0.0000845 & -0.0000936 \\
\hline
\end{tabular}

Vervolgens zijn met de aangepaste IPM-procedure van Formule (59) de springkansen geschat. Hiervoor zijn de $q$-waarden nodig, deze zijn geschat met Formule (60), zie Tabel 4.

Tabel 4. Geschatte $q$-waarden

Table 4. Estimated Liocourt's $q$ values

\begin{tabular}{|l|rrr|l|rrr|}
\hline species group & $\boldsymbol{q}$ & $\boldsymbol{R}^{\mathbf{2}}$ adj & $\mathbf{n}$ & species group & $\mathbf{q}$ & $\boldsymbol{R}^{\mathbf{~}^{\mathbf{a d j}}}$ & $\mathbf{n}$ \\
\hline Douglus fir & 1.179 & 0.892 & 2415 & common beech & 1.345 & 0.847 & 1031 \\
grand fir & 1.919 & 0.984 & 258 & common oak & 1.212 & 0.748 & 1370 \\
Sots pine & 1.096 & -0.009 & 399 & other non con. & 1.362 & 0.920 & 551 \\
\cline { 5 - 8 } other con. & 1.164 & 0.632 & 355 & total & 1.255 & 0.939 & 6379 \\
\hline
\end{tabular}

Op grond van de grote variatie in q-waarden per soortgroep en de nauwkeurigheid is besloten met de $q$-waarde van 1.250 van alle soorten tezamen te werken. 
Formule (59) is voor de diameterbijgroei numeriek opgelost. Met stapjes van $0.1 \mathrm{~mm}$ is voor diameters tussen 12 en $70 \mathrm{~cm}$ de diameterbijgroei bepaald en gekeken is of $d b h_{t+1}=d b h_{t}+\hat{i}_{d}$ (de voorspelde diameter na 1 jaar met de tweedegraadspolynoom in $d b h$ en de parameters van Tabel 3 ) in dezelfde diameterklasse als $d b h$ blijft of juist één of meerdere klassen opschuift. Sprongen van meer dan één klasse kwamen niet voor (noch in het model, noch in de data). Tabel 5 geeft in het linkerdeel het resultaat met Formule (59) en rechts de met de procedure beschreven op Pagina 24 bij Formule (63). Indien Formule (57) wordt gebruikt, dus met een uniforme kansdichtheid binnen een diameterklasse dan blijken de springkansen ongeveer $10 \%$ hoger uit te vallen. We hebben hier te maken met een redelijk nauwkeurige "model based" schatting voor de springkansen. Onder de aanname dat het model de werkelijk natuur van de diameter-stamtal-curve beschrijft is de schatter ook zuiver. Voor douglas tussen 16 en $60 \mathrm{~cm}$ ook zeer nauwkeurig.

Tabel 5. Springkansen berekend met aangepaste IPM. Links de springkansen, rechts de Monte Carlo simulatie van de afwijkingspercentages.

Table 5. Moving up probabilities calculated with adjusted IPM. Left the probabilities, right the Monte Carlo simulations of the deviation percentages.

\begin{tabular}{|c|c|c|c|c|c|c|c|c|c|c|c|c|c|c|}
\hline \multirow{2}{*}{$\begin{array}{l}\text { diameter } \\
\text { in } \mathrm{cm}\end{array}$} & \multicolumn{7}{|c|}{ Moving up probabilities with adjusted IPM } & \multicolumn{7}{|c|}{ deviation percentages } \\
\hline & DF & GF & SP & con & CB & $\mathrm{CO}$ & Ncon & DF & GF & SP & con & CB & CO & Ncon \\
\hline $8-12$ & 0.085 & 0.106 & 0.017 & 0.048 & 0.085 & 0.017 & 0.066 & 10 & 13 & 64 & 25 & 17 & 65 & 14 \\
\hline $12-16$ & 0.098 & 0.109 & 0.030 & 0.060 & 0.086 & 0.030 & 0.074 & 7 & 9 & 32 & 18 & 12 & 33 & 11 \\
\hline $16-20$ & 0.110 & 0.114 & 0.041 & 0.072 & 0.087 & 0.041 & 0.081 & 5 & 8 & 22 & 14 & 10 & 21 & 11 \\
\hline $20-24$ & 0.120 & 0.118 & 0.051 & 0.082 & 0.089 & 0.051 & 0.087 & 4 & 9 & 17 & 12 & 10 & 17 & 10 \\
\hline $24-28$ & 0.130 & 0.124 & 0.060 & 0.091 & 0.092 & 0.060 & 0.093 & 4 & 9 & 15 & 11 & 11 & 14 & 9 \\
\hline $28-32$ & 0.137 & 0.130 & 0.067 & 0.099 & 0.095 & 0.067 & 0.099 & 4 & 11 & 13 & 11 & 11 & 13 & 10 \\
\hline $32-36$ & 0.144 & 0.137 & 0.073 & 0.105 & 0.099 & 0.073 & 0.103 & 4 & 11 & 12 & 10 & 11 & 12 & 10 \\
\hline $36-40$ & 0.148 & 0.144 & 0.078 & 0.110 & 0.104 & 0.078 & 0.107 & 4 & 11 & 12 & 10 & 11 & 12 & 10 \\
\hline $40-44$ & 0.152 & 0.152 & 0.081 & 0.113 & 0.109 & 0.081 & 0.111 & 4 & 12 & 11 & 10 & 11 & 12 & 9 \\
\hline $44-48$ & 0.154 & 0.160 & 0.083 & 0.115 & 0.116 & 0.083 & 0.114 & 4 & 13 & 12 & 10 & 9 & 12 & 11 \\
\hline $48-52$ & 0.155 & 0.169 & 0.084 & 0.116 & 0.123 & 0.084 & 0.116 & 5 & 15 & 13 & 10 & 13 & 13 & 13 \\
\hline $52-56$ & 0.154 & 0.179 & 0.083 & 0.115 & 0.130 & 0.083 & 0.118 & 6 & 18 & 15 & 11 & 16 & 14 & 15 \\
\hline $56-60$ & 0.152 & 0.188 & 0.081 & 0.113 & 0.139 & 0.081 & 0.119 & 7 & 22 & 17 & 13 & 21 & 17 & 19 \\
\hline $60-64$ & 0.149 & 0.199 & 0.078 & 0.109 & 0.148 & 0.078 & 0.119 & 9 & 26 & 19 & 15 & 25 & 21 & 23 \\
\hline $64-68$ & 0.144 & 0.211 & 0.073 & 0.104 & 0.157 & 0.073 & 0.119 & 12 & 29 & 27 & 19 & 30 & 27 & 27 \\
\hline$\geq 68$ & 0.137 & 0.222 & 0.066 & 0.098 & 0.168 & 0.066 & 0.118 & 16 & 35 & 31 & 24 & 35 & 36 & 32 \\
\hline
\end{tabular}

De ratiomethode van Paragraaf 4.2 is ongeschikt vanwege de geringe nauwkeurigheid en het onvermogen voor iedere klasse een schatting te vinden. Opvallend is dat voor douglas tussen de 12 en 44 $\mathrm{cm}$ waar de nauwkeurigheid van de zuivere ratioschatter het grootst is de springkansen van de ratioschatter ongeveer $16 \%$ hoger uitvallen dan die met IPM. Dit blijkt bijna volledig verklaart door de periode-index in Formule (50), indien we deze ook zouden toepassen is het verschil nog maar $5 \%$.

We zullen de aangepaste IPM-schatting van Tabel 5 gebruiken.

\subsection{Bepaling sterftekansen}

Met vergelijking (65) zijn de ratioschattingen voor de sterftekansen bepaald. De afwijkingspercentages zijn bepaald op vergelijkbare wijze als in Paragraaf 4.2 met plot- of boomgegevens. De gemiddelde sterftekans per jaar voor alle bomen bedroeg 0.0137 met een $95 \%$ betrouwbaarheidsinterval $\{0.0062 ; 0.0211\}$. Omdat er bomen doodgingen in een klasse waar weinig bomen aanwezig waren, is met een voortschrijdend gemiddelde gewerkt over steeds 5 diameterklassen. De aldus gevonden waarden zijn met model (66) gefit, hierbij is het "aantal bomen in de klasse" $n$ als regressiegewicht gebruikt aldus:

Met $R^{2}$ adj $=0.698$ werden de parameters van Tabel 6 gevonden. De resultaten van deze berekeningen zijn in Tabel 7 weergegeven. 
Tabel 6. Geschatte parameters van Formule (66).

Table 6. Estimated parameters of Formula (66).

\begin{tabular}{|c|rrrrrrr|}
\hline par & DF & GF & SP & con & CB & CO & n.c. \\
\hline$b_{0}$ & \multicolumn{7}{c|}{ 0 (not significant) } \\
$b_{1}$ & 0.14322 & 0.33738 & 0.25828 & 0.14322 & 0.07161 & 0.23343 & 0.25968 \\
\hline
\end{tabular}

Tabel 7. Geschatte sterftekansen per jaar.

Table 7. Estimated mortality rates per year.

\begin{tabular}{|c|rrrrrrr|}
\hline diameter & \multicolumn{7}{|c|}{ mortality rates } \\
\cline { 2 - 7 } cm & DF & GF & SP & con & CB & CO & n.c. \\
\hline $12-16$ & 0.010 & 0.024 & 0.018 & 0.010 & 0.005 & 0.017 & 0.019 \\
$16-20$ & 0.008 & 0.019 & 0.014 & 0.008 & 0.004 & 0.013 & 0.014 \\
$20-24$ & 0.007 & 0.015 & 0.012 & 0.007 & 0.003 & 0.011 & 0.012 \\
$24-28$ & 0.006 & 0.013 & 0.010 & 0.006 & 0.003 & 0.009 & 0.010 \\
$28-32$ & 0.005 & 0.011 & 0.009 & 0.005 & 0.002 & 0.008 & 0.009 \\
$32-36$ & 0.004 & 0.010 & 0.008 & 0.004 & 0.002 & 0.007 & 0.008 \\
$36-40$ & 0.004 & 0.009 & 0.007 & 0.004 & 0.002 & 0.006 & 0.007 \\
$40-44$ & 0.003 & 0.008 & 0.006 & 0.003 & 0.002 & 0.006 & 0.006 \\
$44-48$ & 0.003 & 0.007 & 0.006 & 0.003 & 0.002 & 0.005 & 0.006 \\
$48-52$ & 0.003 & 0.007 & 0.005 & 0.003 & 0.001 & 0.005 & 0.005 \\
$52-56$ & 0.003 & 0.006 & 0.005 & 0.003 & 0.001 & 0.004 & 0.005 \\
$56-60$ & 0.002 & 0.006 & 0.004 & 0.002 & 0.001 & 0.004 & 0.004 \\
$60-64$ & 0.002 & 0.005 & 0.004 & 0.002 & 0.001 & 0.004 & 0.004 \\
$64-68$ & 0.002 & 0.005 & 0.004 & 0.002 & 0.001 & 0.004 & 0.004 \\
$\geq 68$ & 0.002 & 0.005 & 0.004 & 0.002 & 0.001 & 0.003 & 0.004 \\
\hline
\end{tabular}

\subsection{Kap en evenwichtstoestand}

Wat betreft de boomsgewijze uitkap is er geen bestaand model dit te berekenen, wel heeft de kap een grote invloed op de evenwichtstoestand voor kap, die te berekenen is met de eigenvector.

$\mathbf{T}^{*} \cdot \vec{e}=\lambda \cdot \vec{e}$

met $\mathbf{T}^{*}$ is de resultante van $\mathbf{T}_{G}, \mathbf{T}_{M}, \mathbf{T}_{H}$ en $\mathbf{T}_{R}$

$\vec{e}$ een eigenvector met eigenwaarde $\lambda$

Zie Figuur 8 voor een voorbeeld van de transitionmatrix $\mathbf{T}^{*}$, met bijvoorbeeld $\varepsilon_{\underline{t}_{2,3}}=p_{G, \Delta k=1 k=2}$ en

$\varepsilon \underline{t}_{2,2}=1-p_{G, \Delta k=1 \mid k=2}-p_{M, k=2}$. Indien er een eigenvector bestaat met als hoogste eigenwaarde $\lambda=1$ geeft deze eigenvector de evenwichtstoestand aan. Het berekenen van elementen van $\vec{e}$ per soortgroep is het oplossen van een stelsel van 15 vergelijkingen met 15 onbekenden. Door voor het laatste element $\vec{e}_{k=15}$ de waarde 1 toe te kennen en omdat op iedere rij van $\mathrm{T}^{*}$ slechts 2 waarden $\neq 0$ voorkomen is de oplossing vrij eenvoudig in een spreadsheet te berekenen. Er bestaan ook computerprogramma's die alle 15 eigen- vectoren met bijbehorende 15 eigenwaarden berekenen. Je moet dan kijken of er één niet-complexe oplossing bij is met eigenwaarde 1. Let wel: de te vinden oplossing betreft dan de richting van die evenwichtstoestand per soort in een 15-dimensionale ruimte en nog niet de grootte van die evenwichtstoestand. 


$$
\underline{\mathbf{T}}^{*}=\left[\begin{array}{llllll|}
\underline{t}_{1,1}-\underline{t}_{H, 1} & \underline{t}_{1,2} & 0 & 0 & \cdots & 0 \\
\underline{t}_{2,1} & \underline{t}_{2,2}-\underline{t}_{H, 2} & 0 & 0 & \cdots & 0 \\
0 & \underline{t}_{3,2} & \underline{t}_{3,3}-\underline{t}_{H, 3} & 0 & \cdots & 0 \\
0 & 0 & \underline{t}_{4.3} & \underline{t}_{4,4}-\underline{t}_{H, 4} & \cdots & 0 \\
\cdots & \cdots & \cdots & \cdots & \cdots & \cdots \\
0 & 0 & 0 & 0 & \cdots & \underline{t}_{k, k}-\underline{t}_{H, k}
\end{array}\right]
$$

Figuur 8. Voorbeeld samengestelde matrix $\underline{I}^{*}$ en stochastische kapvariabele.

Figure 8. Example composite Matrix $\underline{~}^{*}$ and stochastic harvest variable.

Er zijn 2 kapstrategieën geanalyseerd:

1. Praktijkkap;

2. Kap met het doel een vaste $q$-waarde te realiseren

\subsubsection{Praktijkkap}

De kap is in het Kolkbos destijds geblest door Smit van het Schoutenhuis, in de traditie van Leibundgut en Schädelin (1984). We waren daarover zeer tevreden. Per diameterklasse en soortgroep daarmee de kapkans $p_{H}$ te berekenen, na vereffening over beide indelingen volgen de kapkansen van Tabel 8 . In de praktijk wordt meestal om de 4 jaar een uitkap gerealiseerd, daarom zijn de percentages in Tabel 8 per 4 jaar gegeven. In het matrixmodel zullen deze per jaar worden ingevoerd.

Tabel 8. Kapkansen per soortgroep en diameterklasse bij praktijkkap

Table 8. Cutting probabilities per species group and diameter class in practice harvest

\begin{tabular}{|c|rrrrrrr|r|}
\hline diameter & \multicolumn{7}{|c|}{ cutting probabilities per 4 year } \\
\cline { 2 - 8 } in cm & DF & GF & SP & con & CB & CO & n.c. & total \\
\hline $12-16$ & 0.141 & 0.064 & 0.000 & 0.127 & 0.033 & 0.051 & 0.075 & 0.100 \\
$16-20$ & 0.224 & 0.101 & 0.000 & 0.202 & 0.053 & 0.081 & 0.120 & 0.160 \\
$20-24$ & 0.294 & 0.133 & 0.147 & 0.265 & 0.069 & 0.106 & 0.158 & 0.214 \\
$24-28$ & 0.287 & 0.130 & 0.143 & 0.259 & 0.068 & 0.104 & 0.154 & 0.209 \\
$28-32$ & 0.253 & 0.115 & 0.126 & 0.228 & 0.060 & 0.091 & 0.136 & 0.184 \\
$32-36$ & 0.282 & 0.128 & 0.140 & 0.254 & 0.066 & 0.102 & 0.151 & 0.205 \\
$36-40$ & 0.207 & 0.094 & 0.103 & 0.187 & 0.049 & 0.075 & 0.111 & 0.151 \\
$40-44$ & 0.176 & 0.080 & 0.088 & 0.159 & 0.042 & 0.064 & 0.095 & 0.129 \\
$44-48$ & 0.148 & 0.067 & 0.074 & 0.134 & 0.035 & 0.054 & 0.080 & 0.108 \\
$48-52$ & 0.084 & 0.038 & 0.042 & 0.076 & 0.020 & 0.030 & 0.045 & 0.061 \\
$52-56$ & 0.103 & 0.047 & 0.052 & 0.093 & 0.024 & 0.037 & 0.055 & 0.075 \\
$56-60$ & 0.103 & 0.047 & 0.000 & 0.093 & 0.024 & 0.037 & 0.055 & 0.074 \\
$60-64$ & 0.054 & 0.024 & 0.000 & 0.049 & 0.013 & 0.019 & 0.029 & 0.038 \\
$64-68$ & 0.056 & 0.025 & 0.000 & 0.051 & 0.013 & 0.020 & 0.030 & 0.040 \\
$\geq 68$ & 0.207 & 0.094 & 0.000 & 0.187 & 0.049 & 0.075 & 0.111 & 0.148 \\
\hline total & 0.207 & 0.094 & 0.070 & 0.187 & 0.049 & 0.075 & 0.111 & 0.150 \\
\hline
\end{tabular}

De gewenste grootte van de eigenvector is bepaald door het grondvlak ervan gelijk te maken met $120 \%$ van het gemiddelde grondvlak voor oogst in de vijf opnamen. Bij het bepalen van het gemiddelde grondvlak gedurende de vijf opnamen gaat het om sommeren van individuele boomgrondvlak ken. Bij de eigenvector gaat het om de grondvlakken per diameterklasse, hiervoor geldt Formule (85) . Hierbij is de eerder gevonden $q$-waarde van $1.25(\lambda=\ln (q) / w=0.055786)$ gebruikt.

Voor de berekening van het volume is per diameterklasse is Formule (86) gebruikt en voor de volumebijgroei Formule (87). Hiermee kan dan ook het volume van de kap $V_{H}$ en de sterfte $V_{M}$ berekend 
worden. Met $k=0$ volgt in deze formule het volume van de ingroei, hiervoor moet de diameterbijgroei in Paragraaf 4.3 met Formule (50) ook voor de diameterklasse $8-12 \mathrm{~cm}$ worden bepaald. Hierbij wordt impliciet verondersteld de ingroei over de meetdrempel gelijk is aan de totale volumebijgroei van diameterklasse onder meetdrempel.

\subsubsection{Kap met het doel een vaste $q$-waarde te realiseren in evenwicht}

De waarde 1.25 is gekozen omdat deze gemiddeld is gevonden tussen 1984 en 1997. Daarnaast achten De Klein en Jansen (1992 een hogere waarde dan 1.3 onmogelijk in verband met verjongingsmogelijkheden.

Uit vergelijking (88) is af te leiden:

$$
\begin{aligned}
& q_{j}=\frac{e_{j}}{e_{j+1}} \\
& \rightarrow q_{i} \cdot p_{G_{j}}=p_{G_{j+1}}+p_{M_{j+1}}+p_{H_{j+1}} \\
& \rightarrow p_{H_{j}}=q \cdot p_{G_{j-1}}-p_{G_{j}}-p_{M j} \\
& \quad \text { where } e_{j} \text { the } j^{\text {the }} \text { element of } \vec{e}
\end{aligned}
$$

In Formule (89) komt een onbekende voor bij het berekenen $p_{H_{1}}$, namelijk $p_{G_{0}}$, deze is berekend door bij Paragraaf 4.3 de diameterklasse $8-12 \mathrm{~cm}$ mee te nemen. De berekening leidt bij enkele boomsoorten voor de laagste diameterklassen tot een negatieve kapkans, hier is de kapkans op 0 gesteld. Door die aanpassing bij de toepassing van Formule (89) blijkt in het eindresultaat niet voor alle diameterklassen de $q$-waarde constant (zie Tabel 9).

Daarnaast is deze procedure herhaald voor een $q$-waarde van 1.4, die vaak gevonden is in de plenterbossen in de Jura en de Vogezen.

\subsubsection{Vergelijking van de kapstrategieën}

In Tabel 9 zijn de drie kapstrategieën vergeleken op grond van de berekende eigenvector. Opvallend is dat de praktijkkap, die wij geschikt vonden voor het bos in de toestand tussen 1984 en 1997 tot een onmogelijke bostructuur in het oneindige leidt. Met $q$-waarden bij jong bos die de Klein \& Jansen (1992) voor onmogelijk hielden. Bioley (1928) wil slechts sturen bij de kap om een verhouding tussen de diameterklassen voor licht, middelzwaar en zwaar hout van 20,30 en $50 \%$ te behalen. Dat is nergens haalbaar maar de $q=1.25$ kap benaderd dat het best. Ook de volumebijgroei lijkt met 10 $\mathrm{m}^{3} \mathrm{ha}^{-1} \mathrm{jr}^{-1}$ het meest aan te sluiten bij de realisatie in het meettijdvak.

Gekozen is daarom voor de kap bij een $q$-waarde van 1.25.

In Figuur 9 is dit "ideale bos" vergeleken met de toestand tussen 1984 en 1997. Er is te zien dat de stamtallen in het ideale bos tot diameterklasse 34 flink toenemen, maar dat deze voor het wat zwaardere hout van 38 tot $54 \mathrm{~cm}$ flink afnemen en vanaf $68 \mathrm{~cm}$ weer iets toenemen.

In Tabel 9 is ook te zien dat het evenwicht in stamtallen tussen enerzijds ingroei $N_{R}=9.4$ en anderzijds het verdwijnen door sterfte $\left(N_{M}=3.5\right)$ en $\operatorname{kap}\left(N_{H}=5.8\right)$ met een verschil van $1 \%$ ontbreekt. Om hier wel evenwicht te krijgen moet een $q$-waarde van 1.2698 worden gekozen. Dit verschil is overigens niet zo belangrijk dat hiervoor gekozen is. Eigenlijk moet voor iedere soortgroep een eigen $q$ worden gebruikt. Er overigens ook geen evenwicht tussen de volumebijgroei en het volume van de kap en sterfte, dit verschil is veel groter en bedraagt $26 \%$. In Figuur 10 is het oogstvolume en in Figuur 11 de volumebijgroei per diameterklasse en soortgroep weergegeven, hier blijkt een duidelijke reden, de optimale bijgroei wordt bij veel lagere diameters bereikt dan de kap. 


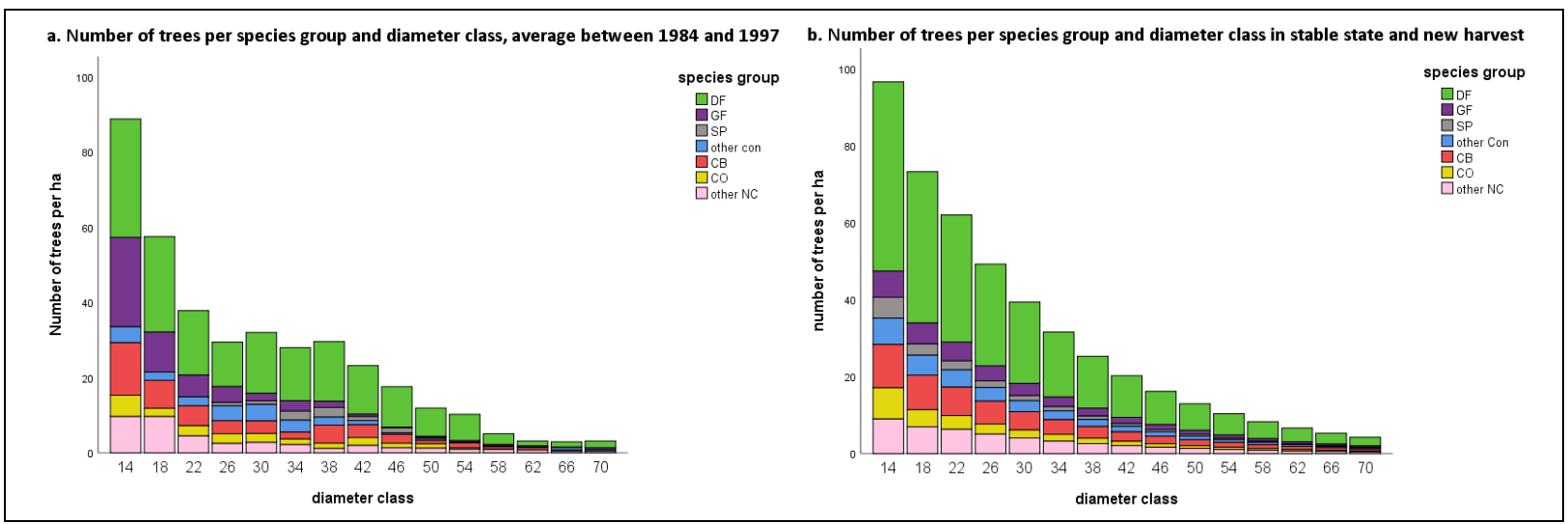

Figuur 9. Stamtal per ha per diameterklasse en soortgroep in Kolkbos gemiddeld tussen 1984 en 1997 (a) en in evenwichtstoestand met nieuwe kap bij $q=1.25$ (b).

Figure 9. Number of trees per ha per diameter class and species group in Kolkbos average between 1984 and 1997 (a) and in stable state with new cutting at $q=1.25$ (b).

Tabel 9. Vergelijking van de kapstrategieën

Table 9. Comparison of the harvest strategies

\begin{tabular}{|c|c|c|c|c|c|}
\hline \multirow[b]{2}{*}{ characteristic } & \multirow[b]{2}{*}{ unit } & \multirow{2}{*}{$\begin{array}{c}\text { Kolkbos } \\
1984 \text { - } 1997\end{array}$} & \multicolumn{3}{|c|}{ stable state } \\
\hline & & & $\begin{array}{c}\text { harvest } \\
\text { from practice }\end{array}$ & $\begin{array}{c}\text { harvest } \\
\text { with } q=1.25\end{array}$ & $\begin{array}{c}\text { harvest } \\
\text { with } q=1.4\end{array}$ \\
\hline number of trees $N$ & $\mathrm{ha}^{-1}$ & 380 & 716 & 461 & 649 \\
\hline basal area $G$ & $m^{2} h a^{-1}$ & 29.2 & 35.0 & 35.0 & 35.0 \\
\hline volume $V$ & $m^{3} h a^{-1}$ & 315 & 347 & 363 & 344 \\
\hline$\%$ light timber $V_{\text {, }}$ & $\%$ & $23 \%$ & $39 \%$ & $26 \%$ & $42 \%$ \\
\hline$\%$ medium timber $V_{m}$ & $\%$ & $50 \%$ & $29 \%$ & $40 \%$ & $39 \%$ \\
\hline$\%$ heavy timber $V_{z}$ & $\%$ & $27 \%$ & $32 \%$ & $34 \%$ & $19 \%$ \\
\hline "mean" diameter $d_{g}$ & $\mathrm{~cm}$ & 31.3 & 25.0 & 31.1 & 26.2 \\
\hline current volume increment $\mathrm{IcV}$ & $\mathrm{m}^{3} \mathrm{ha}^{-1} \mathrm{yr}^{-1}$ & 10.5 & 14.4 & 12.7 & 14.0 \\
\hline harvested volume $V_{H}$ & $\mathrm{~m}^{3} \mathrm{ha}^{-1} \mathrm{yr}^{-1}$ & 9.8 & 11.2 & 8.4 & 12.3 \\
\hline volume of mortality $V_{M}$ & $\mathrm{~m}^{3} \mathrm{ha}^{-1} \mathrm{yr}^{-1}$ & 0.6 & 1.9 & 1.7 & 1.9 \\
\hline Ingrowth $N_{R}$ & $\mathrm{ha} \mathrm{y}^{-1} \mathrm{yr}^{-1}$ & 13.7 & 34.9 & 9.4 & 19.8 \\
\hline harvest $N_{H}$ & $\mathrm{ha}^{-1} \mathrm{yr}^{-1}$ & 1.3 & 27.8 & 5.8 & 14.9 \\
\hline mortality $N_{M}$ & $\mathrm{ha}^{-1} \mathrm{yr}^{-1}$ & 8.7 & 6.6 & 3.5 & 5.4 \\
\hline mean Lioucourt ratio $q$ & & 1.25 & 1.35 & 1.25 & 1.39 \\
\hline
\end{tabular}

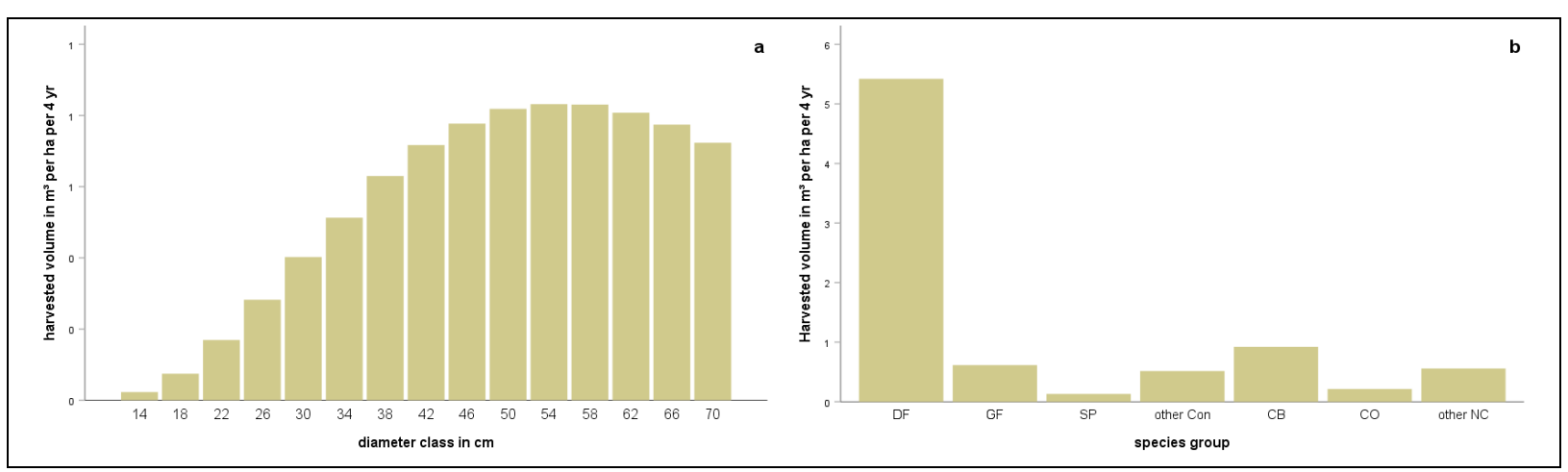

Figuur 10. Kolkbos evenwichtstoestand, gekapt volume in $m^{3}$ per ha per 4 jaar per diameterklasse (a) en soortgroep (b)

Figure 10. Kolkbos stable state, harvested volume in $m^{3}$ per hectare per 4 years per diameter class (a) and species group (b) 


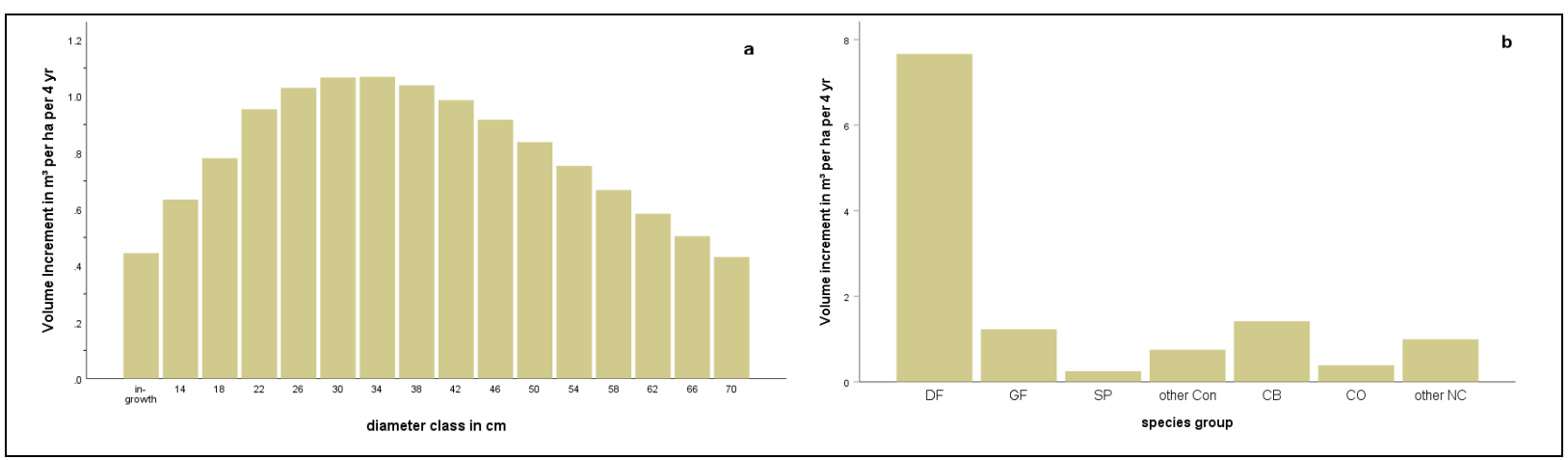

Figuur 11. Kolkbos evenwichtstoestand, volumebijgroei in $m^{3}$ per ha per 4 jaar per diameterklasse (a) en soortgroep (b)

Figure 11. Kolkbos stable state, volume increment in $m^{3}$ per hectare per 4 years per diameter class (a) and species group (b)

De eigenvector is slechts een wiskundige eigenschap van een matrix met groei-, sterfte-, ingroei- en kapkansen. Door er een schaalfactor (met het doel $120 \%$ van het gemeten grondvlak te realiseren) aan toe te voegen ontstaat een hypothetische evenwichtstoestand. De vraag is of dat een realistische weergave van het te ontwikkelen bos in het Kolkbos is. Daartoe is naar het stamtal en grondvlak gekeken van de 136 steekproefpunten tussen 1984 en 1997.

In Figuur 12 zijn de frequentiehistogrammen van het stamtal per ha in 1984 en in 1997 weergegeven.

Het $95 \%$ betrouwbaarheidsinterval ligt in 1984 voor het stamtal $\{50 ; 750\}$, in 1997 is dat $\{150 ; 1080\}$ De 461 stuks in de evenwichtstoestand past dus bij verandering tussen 1984 en 1997.

Ook voor het grondvlak per ha blijkt zowel het gemiddelde als de spreiding tussen 1984 en 1997 toe te nemen. In Figuur 13 zijn de frequentiehistogrammen van het grondvlak per ha in 1984 en in 1997 weergegeven. Het $95 \%$ betrouwbaarheidsinterval ligt in 1984 voor het grondvlak per ha $\{4.2 ; 60.1\}$, in 1997 is dat $\{6.6 ; 62.9\}$ en het gemiddelde steeg van 28.5 naar $32.3 \mathrm{~m}^{2} \mathrm{ha}^{-1}$. Door de gekozen schaalfactor voor het grondvlak van de eigenvector gelijk te stellen aan $120 \%$ van het gemiddeld grondvlak in de vijf opnamen Is het grondvlak van de evenwichtstoestand nu $35.0 \mathrm{~m}^{2} \mathrm{ha}^{-1}$, deze waarde behoort zeker bij het bestaande bosbeeld en haar variatie.

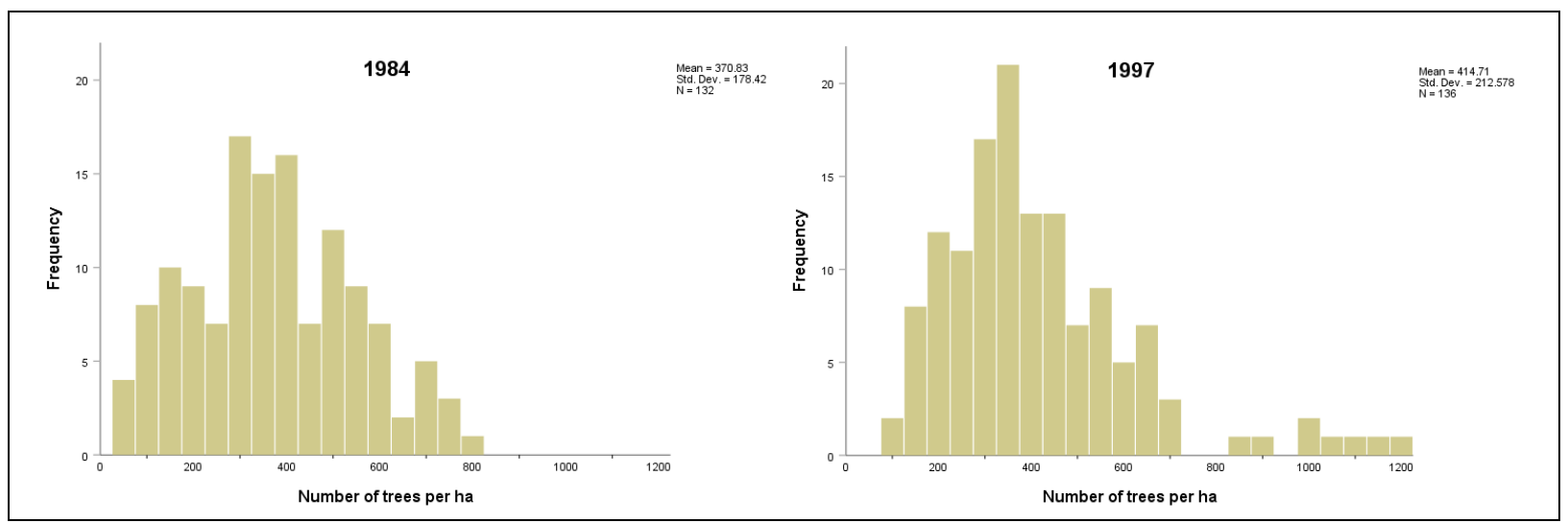

Figuur 12. Stamtal per ha per steekproefplot Kolkbos in 1984 (L) en in 1997 (R).

Figure 12. Number of trees per hectare per sample plot Kolkbos in 1984 (L) and in 1997 (R). 


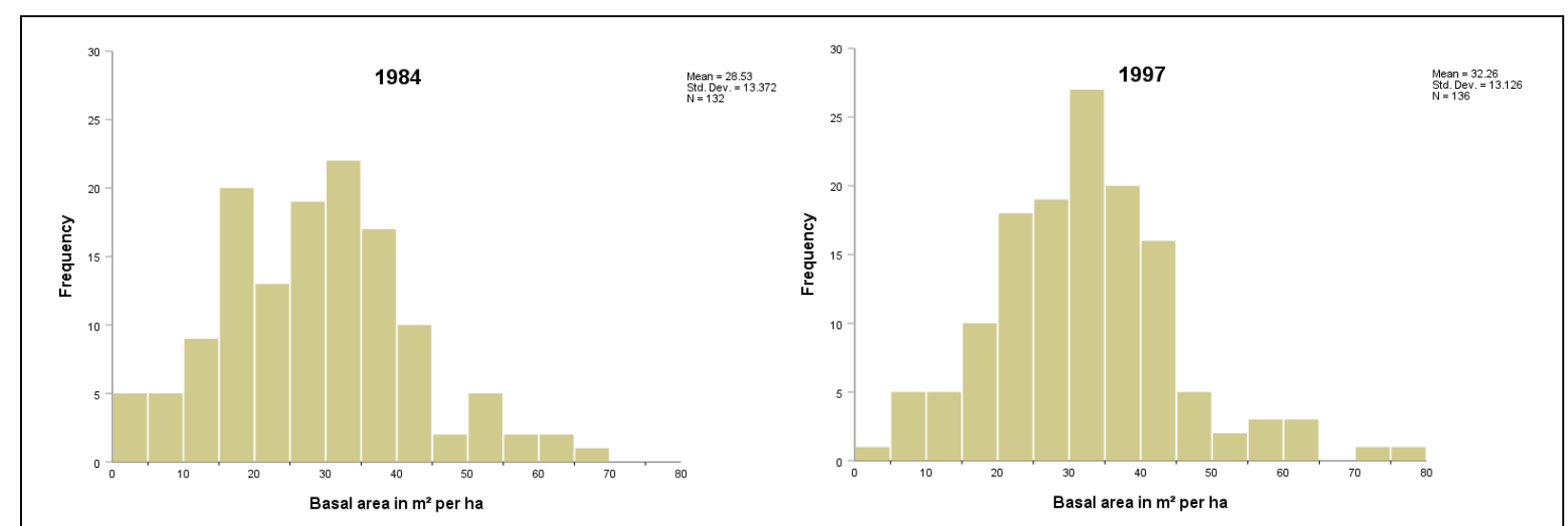

Figuur 13. Grondvlak in $m^{2}$ per ha per steekproefplot Kolkbos in 1984 (L) en in 1997 (R).

Figure 13. Basal area in $m 2$ per hectare per sample plot Kolkbos in 1984 (L) and in 1997 (R).

In Tabel 10a en10b staan de berekende kapkansen bij een kap gericht op een q-waarde van 1.25.

Voor praktisch gebruik in het beheer zijn in Tabel 10b ook de gemiddelde kapkansen per zwaarteklasse berekend en in Tabel 10a de kapkansen voor alle diameterklassen

Tabel 10a. Kapkansen per soortgroep en diameterklasse van kapstrategie met $\boldsymbol{q}$-waarde $\mathbf{= 1 . 2 5}$.

Table 10a. Cutting probabilities by species group and diameter class of harvest strategy with $q$-value $=1.25$.

\begin{tabular}{|c|rrrrrrr|r|}
\hline diameter & \multicolumn{7}{|c|}{ cutting probabilities per 4 year } \\
\cline { 2 - 8 } in cm & DF & GF & SP & con & CB & CO & n.c. & total \\
\hline $12-16$ & 0.000 & 0.000 & 0.000 & 0.000 & 0.062 & 0.000 & 0.000 & 0.007 \\
$16-20$ & 0.020 & 0.017 & 0.000 & 0.000 & 0.065 & 0.000 & 0.000 & 0.020 \\
$20-24$ & 0.043 & 0.033 & 0.000 & 0.005 & 0.066 & 0.000 & 0.008 & 0.035 \\
$24-28$ & 0.062 & 0.045 & 0.000 & 0.024 & 0.067 & 0.000 & 0.023 & 0.049 \\
$28-32$ & 0.080 & 0.055 & 0.000 & 0.042 & 0.069 & 0.000 & 0.037 & 0.062 \\
$32-36$ & 0.095 & 0.063 & 0.000 & 0.057 & 0.070 & 0.000 & 0.049 & 0.074 \\
$36-40$ & 0.109 & 0.073 & 0.027 & 0.070 & 0.073 & 0.030 & 0.060 & 0.086 \\
$40-44$ & 0.121 & 0.080 & 0.040 & 0.082 & 0.075 & 0.042 & 0.068 & 0.097 \\
$44-48$ & 0.131 & 0.088 & 0.051 & 0.092 & 0.078 & 0.053 & 0.077 & 0.106 \\
$48-52$ & 0.140 & 0.098 & 0.061 & 0.101 & 0.082 & 0.062 & 0.084 & 0.114 \\
$52-56$ & 0.147 & 0.106 & 0.067 & 0.108 & 0.086 & 0.069 & 0.090 & 0.120 \\
$56-60$ & 0.153 & 0.115 & 0.074 & 0.114 & 0.092 & 0.076 & 0.096 & 0.127 \\
$60-64$ & 0.157 & 0.123 & 0.079 & 0.118 & 0.099 & 0.080 & 0.099 & 0.132 \\
$64-68$ & 0.160 & 0.133 & 0.082 & 0.120 & 0.104 & 0.084 & 0.105 & 0.136 \\
$\geq 68$ & 0.161 & 0.146 & 0.083 & 0.120 & 0.109 & 0.084 & 0.107 & 0.138 \\
\hline total & 0.061 & 0.045 & 0.011 & 0.033 & 0.070 & 0.012 & 0.030 & 0.050 \\
\hline
\end{tabular}

Tabel 10b. Kapkansen per soortgroep per zwaarteklasse

Table 10b. Cutting probabilities by species group and timber class

\begin{tabular}{|c|c|rrrrrrr|r|}
\hline timber & diameter & \multicolumn{7}{c|}{ cutting probabilities per 4 year } \\
\cline { 3 - 9 } & in cm & DF & GF & SP & con & CB & CO & n.c. & total \\
\hline Light & $\leq 30$ & 0.033 & 0.025 & 0.000 & 0.010 & 0.065 & 0.000 & 0.010 & 0.029 \\
Medium & $30-50$ & 0.114 & 0.077 & 0.029 & 0.076 & 0.074 & 0.031 & 0.064 & 0.091 \\
Heavy & $>50$ & 0.154 & 0.120 & 0.075 & 0.115 & 0.095 & 0.077 & 0.098 & 0.129 \\
\hline \multicolumn{2}{|c|}{ total } & 0.061 & 0.045 & 0.011 & 0.033 & 0.070 & 0.012 & 0.030 & 0.050 \\
\hline
\end{tabular}

In Bijlage 2 zijn nog wat aanvullende kenmerken van de evenwichtstoestand vermeld. 


\subsection{Verantwoorde kap}

In de Hoofdstuk 1 is de Formule van Heyer (1) gegeven om de verantwoorden kap e berekenen. Toegepast op het Kolkbos halverwege 1984 en 1997 volgt:

$A C=I_{c}+\frac{V-V_{n}}{t_{a d j}}=10.5+\frac{315-366}{30}=8.8 \mathrm{~m}^{3} \mathrm{ha}^{-1} \mathrm{yr}^{-1}$, De Klein et al. (1997) geven een marge van 80 tot $120 \%$ van de berekende waarde waarbinnen de werkelijke kap mag vallen. De werkelijke kap in die periode bedroeg $9.8 \mathrm{~m}^{3} \mathrm{ha}^{-1} \mathrm{jr}^{-1}$, en voldoet dus uitstekend aan eisen van een duurzame houtoogst. De Formule van Heyer houdt overigens geen rekening met sterfte, deze bedroeg in deze periode $0.6 \mathrm{~m}^{3} \mathrm{ha}^{-1} \mathrm{jr}^{-1}$.

\subsection{Bosstructuur}

Bij de opname in 1988 is aangegeven of het plot ligt in een gebied met 1 een ongelijkjarig gemengde bosstructuur of 2 een overgangsstructuur met groepenkap, er zijn hiervoor geen meetbare criteria gebruikt.

Per gebied en opname is de Cox index of dispersion met behulp van Formule (79) berekend op basis van het aantal bomen per steekproefcirkel-kwadrant van $50 \mathrm{~m}^{2}$. In Tabel 11 staan de resultaten.

Tabel 11. Cox index of dispersion $Q$ per deelgebied en opname.

Table 11. Cox index of dispersion $Q$ per subarea and recording

\begin{tabular}{|c|cc|}
\hline & \multicolumn{2}{|c|}{ Cox-index } \\
recording & subarea 1 & subarea 2 \\
\hline 1984 & 0.69 & 0.70 \\
1988 & 0.71 & 0.73 \\
1990 & 1.13 & 0.68 \\
1994 & 0.98 & 0.79 \\
1997 & 1.03 & 0.88 \\
\hline mean & 0.91 & 0.76 \\
\hline
\end{tabular}

Er zijn 13 plots in gebied 1 en 123 plots in gebied 2 De zware schommelingen in de $Q$-waarde per opname zijn vooral een gevolg van kap en ingroei. Er blijkt sprake van patronen tussen regelmatig en random bos (Poissonbos) er is geen sprake van een tendens naar dit Poissonbos. Gebied 1 voldoet iets beter aan de criteria voor een Poissonbos en bevestigt daarmee de waarnemingen van opnemers.

Op dezelfde gebied en opnamen zijn de Shannon-index $H$, van Formule (80) en de Simpson-index $C$ van Formule (81) berekend, zie Tabel 12. Hierbij is indeling in diameterklassen vereenvoudigd naar de drie klassen die bij het uitkapbeheer in de Jura en Vogezen gebruikelijk zijn, te weten licht hout met $\mathrm{dbh}<30 \mathrm{~cm}$, middelzwaar hout met $30 \leq \mathrm{dbh}<50 \mathrm{~cm}$ en zwaar hout met $\mathrm{dbh} \geq 50 \mathrm{~cm}$. Ook de indeling in soortgroep is vereenvoudigd tot een indeling in vier klassen:

1. Lichtbehoeftig naaldhout

2. Schaduwverdragend naaldhout

3. Lichtbehoeftig loofhout

4. Schaduwverdragend loofhout

Het aantal boomklassen komt hiermee op 12 in plaats van de 105 bij de eerder gebruikte indeling, dat voorkomt het groot aantal nullen in de berekening. 
Tabel 12. Variatie in Shannon en Simpson index per opname en gebied.

Table 12. Variation in Shannon and Simpson index per recording and subarea.

\begin{tabular}{|c|c|c|c|c|c|c|c|c|c|}
\hline \multirow[b]{2}{*}{ recording } & \multicolumn{2}{|c|}{ Shannon index } & \multicolumn{2}{|c|}{ Simpson index } & \multirow{2}{*}{$\begin{array}{l}\text { weighted mean } \\
\text { recording }\end{array}$} & \multicolumn{2}{|c|}{ Shannonindex } & \multicolumn{2}{|c|}{ Simpson index } \\
\hline & subarea 1 & subarea 2 & subarea 1 & subarea 2 & & subarea 1 & subarea 2 & subarea 1 & subarea 2 \\
\hline 1984 & 0.92 & 0.92 & 0.48 & 0.53 & $\mathrm{n}$ & 13 & 123 & 13 & 123 \\
\hline 1988 & 1.06 & 1.01 & 0.58 & 0.57 & mean & 0.99 & 0.95 & 0.54 & 0.54 \\
\hline 1990 & 0.99 & 0.92 & 0.55 & 0.52 & $s d v$ & 0.47 & 0.40 & 0.23 & 0.19 \\
\hline 1994 & 1.04 & 0.96 & 0.57 & 0.53 & minimum & 0.10 & 0.00 & 0.06 & 0.00 \\
\hline 1997 & 1.09 & 0.99 & 0.59 & 0.55 & maximum & 1.64 & 1.87 & 0.81 & 0.83 \\
\hline weighted mean & 0.99 & 0.95 & 0.54 & 0.54 & \multirow{3}{*}{$\begin{array}{l}\text { theoretisal minimum } \\
\text { theoretical maximum } \\
\text { stable state }\end{array}$} & \multicolumn{2}{|c|}{0.00} & \multicolumn{2}{|c|}{0.00} \\
\hline & & & & & & \multirow{2}{*}{\multicolumn{2}{|c|}{$\begin{array}{l}2.48 \\
1.82\end{array}$}} & \multirow{2}{*}{\multicolumn{2}{|c|}{$\begin{array}{l}0.92 \\
0.75\end{array}$}} \\
\hline & & & & & & & & & \\
\hline & & & & & relative score & $55 \%$ & $53 \%$ & $72 \%$ & $71 \%$ \\
\hline
\end{tabular}

Uit het linkerdeel van Tabel 12 blijkt dat de verschillen per opname verwaarloosbaar zijn, ze blijken ook significant niet te verschillen. In het rechterdeel van Tabel 12 is te zien dat de verschillen voor beide indices tussen de gebieden niet significant zijn in de hier getoonde gemiddelde opname. Als er maar één boomklasse aanwezig is in een plot zijn beide indices gelijk aan nul, dit komt alleen voor in gebied 2 . Als alle klassen even vaak voorkomen, dus $p_{i}=1 / 12$ wordt een theoretisch maximum bereikt voor de indices, dat maximum wordt nergens behaald. Met de gekozen evenwichtstoestand van Paragraaf 4.5 zijn ook de Shannon- en Simpson-index berekend en de gemiddelde index is gerelateerd aan deze maximale waarde. De visuele observaties waarop de gebiedsindeling is gebaseerd wordt dus niet gestaafd door verschillen in de gekozen indicatoren.

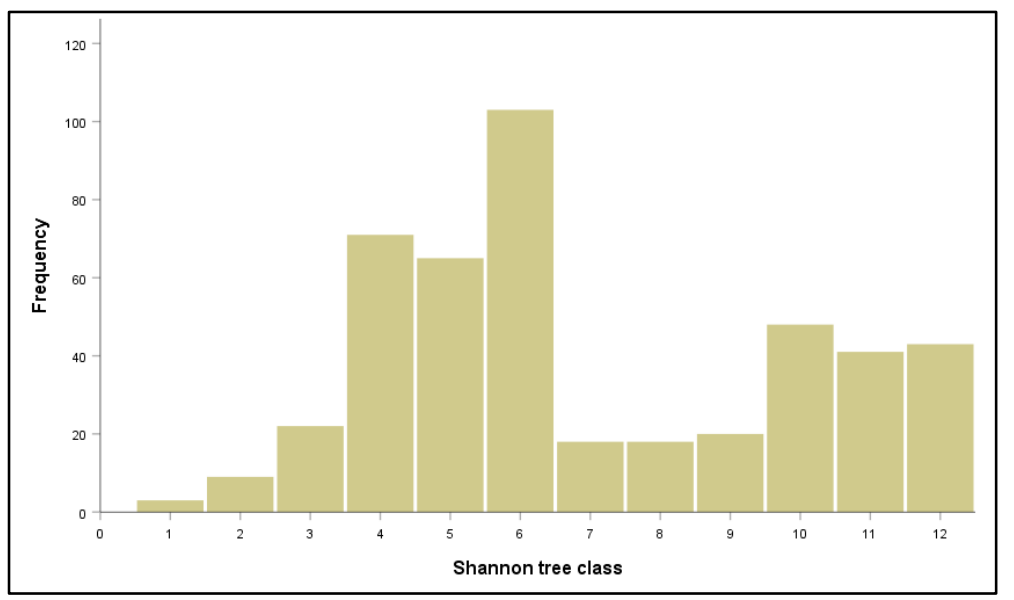

Figuur 14. Histogram van Shannon boomklasse verdeling in 1997.

Figure 14. Histogram of Shannon tree class distribution in 1997.

In Figuur 14 is te zien dat de bomklassen 1 en 2 (lichtbehoeftig naaldhout tot $30 \mathrm{~cm} \mathrm{dbh}$ ) nagenoeg ontbreken. De vraag is of er in de toekomst nog wel plaats $i_{d}$ voor lichtbehoeftig naaldhout. Daarom is in Paragraaf 4.8 bekeken hoe het met de verjonging in het algemeen is gesteld en voor lichtbehoeftig naaldhout in het bijzonder.

\subsection{Natuurlijke verjonging}

Bij de eerste opname in 1984 is op de steekproefplots waargenomen of er sprake is van verjonging. In 59 plots was er geen verjonging, In de rest van de plots was er sprake van natuurlijke verjonging van schaduwverdragend naald- en loofhout in bedekkingen variërend van 10 tot $100 \%$ (gemiddeld $33 \%)$, zie Figuur 15. 


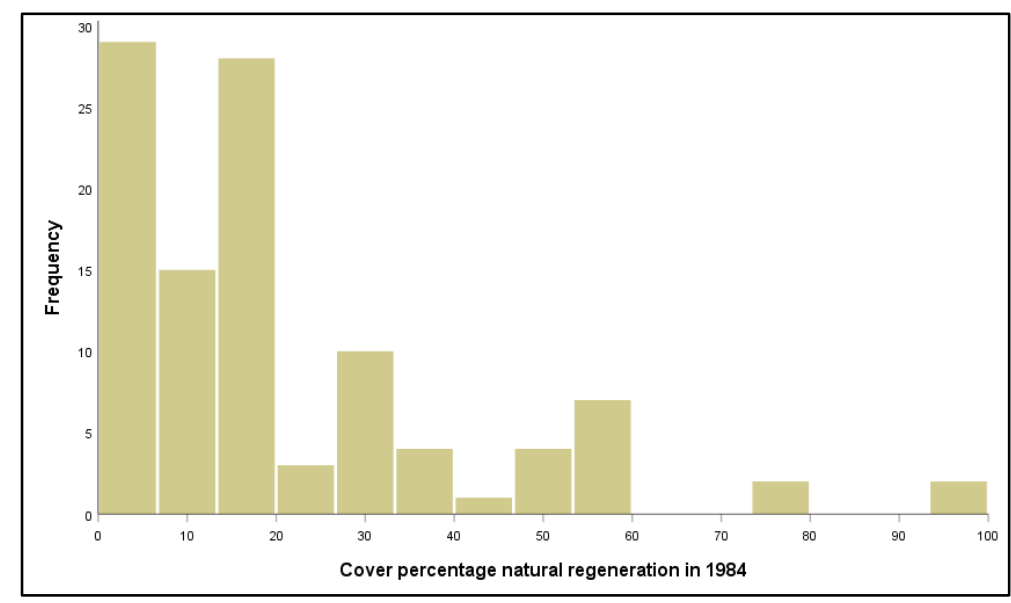

Figuur 15. Histogram van bedekking natuurlijke verjonging in 1984.

Figure 15. Histogram of cover percentage natural regeneration in 1984.

Er bleek in zeer gering mate wat verjonging van lichtbehoeftige boomsoorten plaats te vinden; een plot met $70 \%$ bedekking van Oostenrijkse den en Weymouthden en in acht plots werd bedekkingsgraden van 2 tot $20 \%$ van eik en berk aangetroffen, met daarnaast tot $100 \%$ schaduwverdragende boomsoorten. Ook werden er enkele solitaire jonge eiken, berken en lijsterbessen aangetroffen. De opname werd in 1988 herhaald, er werden geen belangrijke veranderingen aangetroffen. Buiten de plots werden nog wel wat grove den waargenomen met hoogtes onder de $1 \mathrm{~m}$, maar alle in schotgevoelige locaties.

\subsection{Overige aandachtspunten}

Het gevolgde systeem bij het vaststellen van de grootte van de eigenvector leidt ertoe dat de gemiddelde verhouding in grondvlakaandelen van de zes soortgroepen gefixeerd zijn bij de bepaling van de evenwichtstoestand. Het echte bos is natuurlijk veel flexibeler en verschuivingen ten gunste van schaduwverdragende boomsoorten zal zeker plaatsvinden. Door ingrepen in de vorm van enige groepenkap en kunstmatige verjonging is hierin te sturen, maar wachten op wat storm- of brandschade blijft een optie. Zonder deze kunstmatige of natuurlijke openingen in het kronendak zal de grove den uit het bos verdwijnen en zal er ook voor de zomereik nauwelijks plaats zijn.

Uitkap met een rotatie een jaar is modelmatig aangehouden, de kappercentages zijn gepresenteerd voor een periode van 4 jaar, maar een langere rotatie zal geen invloed hebben op de modelresultaten. 


\section{TOEPASSING IN HET OUDE TREKERBOS}

\subsection{Inleiding}

Het 'Oude Trekerbos' is een bosgebied van 8.65 ha op het familielandgoed Den Treek/Henschoten in Nederland ten Noorden van de Utrechtse Heuvelrug in de buurt van Leusden (Kaartblad 32D, $x=$ 155.09, $y=457.69$ ).

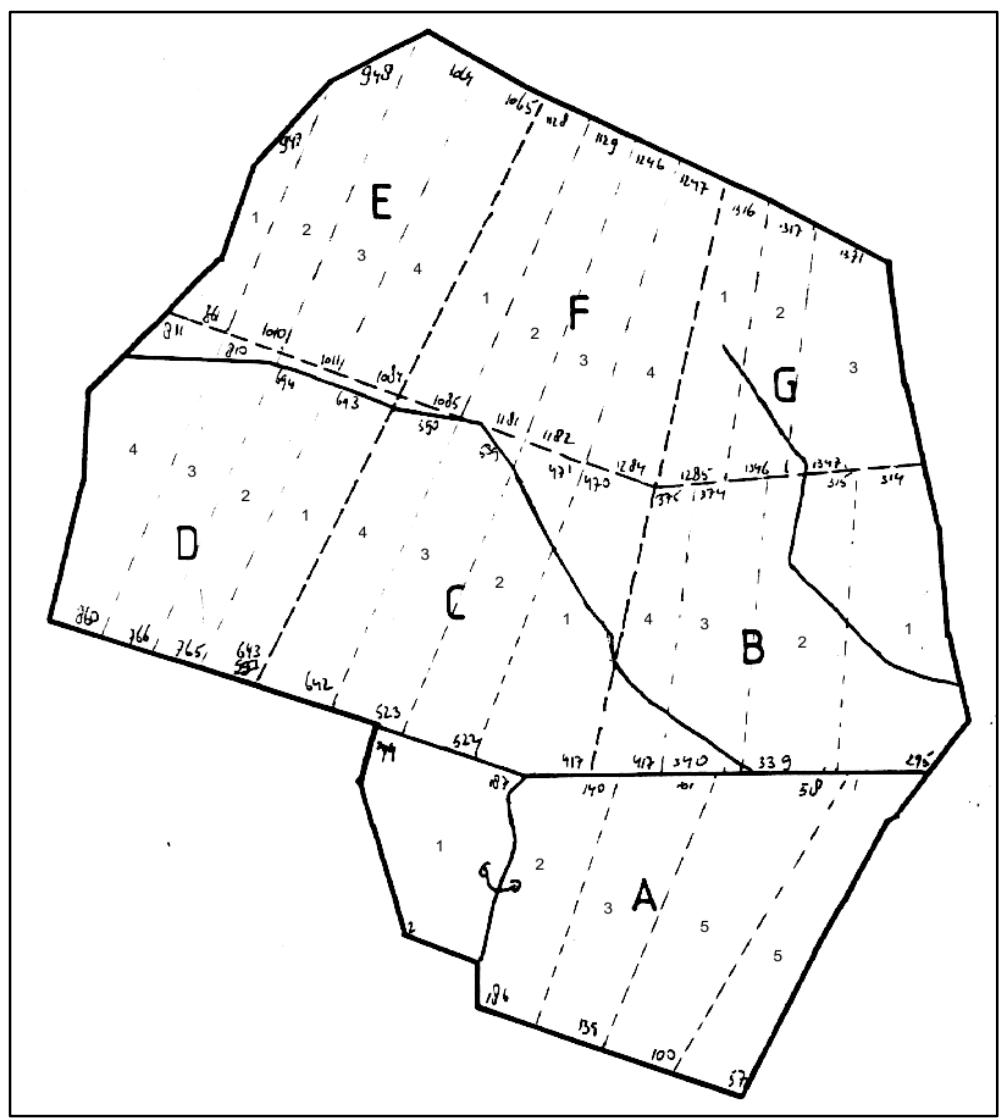

Figuur 16. Kaart van het Oude Trekerbos met indeling in plots en subplots.

Figure 16. Map of the Old Trekerbos with classification in plots and subplots.

Oorspronkelijk heeft Becking hier in 1953 een proef met uitkapbeheer aangelegd. In 1984, is de proef hervat, maar een link naar de oude gegevens bleek niet mogelijk, daarna zijn de opname herhaald in 1990, 1995 en 1997. In die periode is uitkapbeheer toegepast. In Tabel 13 staan wat terreinkarakteristiek vermeld.

Tabel 13. Opstandkenmerken van het Oude Trekerbos, (gemiddeld tussen 1984 en 1997). Table 13. Stand characteristics of the Oude Trekerbos, (on average between 1984 and 1997).

\begin{tabular}{|lr|}
\hline Area & $8.65 \mathrm{ha}$ \\
Number of trees & $234 \mathrm{ha}^{-1}$ \\
$\quad$ coniferous & $75 \%$ \\
non-coniferous & $25 \%$ \\
Basal area & $22.6 \mathrm{~m}^{2} \mathrm{ha}^{-1}$ \\
Volume & $226 \mathrm{~m}^{3} \mathrm{ha}^{-1}$ \\
$\quad 59 \%$ \\
$\quad$ coniferous & $51 \%$ \\
non-coniferous & $7.0 \mathrm{~m}^{3} \mathrm{ha}^{-1} \mathrm{yr}^{-1}$ \\
Volume increment & $2.2 \mathrm{~m}^{3} \mathrm{ha}^{-1} \mathrm{yr}^{-1}$ \\
Volume harvest &
\end{tabular}


In deze case is gewerkt met 7 boomsoortgroepen, te weten: DF (douglas + zilverspar+ tsuga), NS (fijnspar en andere sparren), SP (grove den en andere dennen), JL (Japanse lariks), CB (beuk) en CO (zomereik en overige loofboomsoorten).

In dit Hoofdstuk wordt de studie in het Kolkbos (Hoofdstuk 4) herhaald, waarbij alleen de aangepaste IPM wordt toegepast met kapbeheer met het doel een vaste $q$-waarde realiseren.

In 1984, 1990 en 1993 is er met een volledige opname gewerkt, daarna in 1997 is er met steekproefpunten gewerkt. Hierbij zij 77 steekproefcirkels uitgelegd van $200 \mathrm{~m}^{2}$, hierin zijn alle bomen met dbh $\geq 8 \mathrm{~cm}$ gemeten. Daarnaast zijn de bomen vanaf $45 \mathrm{~cm}$ ook binnen een cirkel van $400 \mathrm{~m}^{2}$ opgenomen. Bij de volledige opname bedroeg de meetdrempel $16 \mathrm{~cm}$. De datafile is geïntegreerd met alle bomen met een $\mathrm{dbh} \geq 12 \mathrm{~cm}$, die ook op de locatie van de 2 are steekproefcirkels aanwezig waren. Met leemtevulling zijn de gegevens geschat van bomen die bij de opname van 1984 en 1990 dunner waren dan $16 \mathrm{~cm}$ maar wel dikker dan $12 \mathrm{~cm}$. Voor de complete dataset en toelichting zie Jansen et al. (2016).

Tussen 1984 en 1990 is van 291 bomen ook de hoogte gemeten met het doel een volumetarief te maken. Deze bomen zijn volgens het principe van de verspreide hoogtemeting gekozen en de gegevens waren achteraf niet meer te linken aan de opname van 1984.

\subsection{Springkansen bepaald met IPM}

Met Model (55) is de diameterbijgroei geschat. Met een $R^{2}$ adj van 0.549 werd het model $c_{0}\left(s g_{i}\right)=\left(c_{01}+b_{1} \cdot G_{L, j, i p}+b_{2} \cdot G_{M, j, i p}+b_{3} \cdot G_{Z, j, i p}+\sum_{l=2}^{n_{s g}} c_{0 l} \cdot \mu_{l, i j}\right) \cdot P l$ opgelost Hierin staat $G_{L, j, i p}$ voor het grondvlak per ha van het lichte hout $(d b h \leq 30 \mathrm{~cm})$ in de $j^{\mathrm{e}}$ opname in het $i p^{\mathrm{e}}$ plot, $M$ voor middelzwaar $(30 \mathrm{~cm}<d b h \leq 50) \mathrm{cm}$ en $Z$ voor zwaar hout $(d b h>50 \mathrm{~cm})$. Met het gemiddelde $G_{L}=7.85$ $\mathrm{m}^{2}$ ha ${ }^{-1}$ voor alle opnamen en plots, evenzo $G_{M}=7.77 \mathrm{~m}^{2} \mathrm{ha}^{-1}$ en $G_{Z}=8.71 \mathrm{~m}^{2} \mathrm{ha}^{-1}$ en een periode index $(P I)$ van 1 werden de volgende parameters per soortgroep gevonden (Tabel 14).

Tabel 14. Parameters voor de tweedegraadspolynoom id $=c_{0}+c_{1} \cdot d b h+c_{2} \cdot d b h^{2}$ Table 14. Parameters for the second-degree polynomial $i d=c_{0}+c_{1} \cdot d b h+c_{2} \cdot d b h^{2}$

\begin{tabular}{|l|rrrrrr|r|}
\hline & DF & NS & SP & JL & CB & CO & total \\
\hline$c_{0}$ & 0.4171 & 0.3202 & 0.4171 & 0.4921 & 0.6014 & 0.4171 & 0.2021 \\
$c_{1}$ & 0.022487 & 0.008001 & -0.002576 & 0.012320 & -0.001068 & -0.003848 & 0.012937 \\
$c_{2}$ & -0.0002131 & -0.0000968 & -0.0000280 & -0.0002131 & -0.0000189 & 0.0000473 & -0.0000936 \\
\hline
\end{tabular}

Formule (59) is voor de diameterbijgroei numeriek opgelost. De gemiddelde $q$-waarde bleek 1.30, dat komt overeen met $\lambda=0.06559$, deze waarde is in Formules (59) gebuikt om de springkans te schatten. Met stapjes van $0.1 \mathrm{~mm}$ is voor diameters tussen $12 \mathrm{en} 84 \mathrm{~cm}$ de diameterbijgroei bepaald en gekeken is of $d b h_{t+1}=d b h_{t}+\hat{i}_{d}$ (de voorspelde diameter na 1 jaar) in dezelfde diameterklasse als $d b h$ blijft of juist één of meerdere klassen opschuift. Tabel 15 geeft in het linkerdeel het resultaat en rechts de met de procedure beschreven op Pagina 24 bij Formule (63) berekende afwijkingspercentage. Er is daarbij geschat tot de diameterklasse $82 \mathrm{~cm}$. Omdat er bijgroeiwaarden van meer dan 1 $\mathrm{cm}$ per jaar werden gevonden is voor het model een periode lengte van 1 jaar aangehouden. 
Tabel 15. Springkansen berekend met aangepaste IPM. Links de springkansen, rechts de Monte Carlo simulatie van de afwijkingspercentages.

Table 15. Moving up probabilities calculated with modified IPM. Left the probabilities, right the Monte Carlo simulations of the deviation percentages.

\begin{tabular}{|c|c|c|c|c|c|c|c|c|c|c|c|c|}
\hline \multirow{2}{*}{$\begin{array}{c}\text { diameter } \\
\text { in } \mathbf{~ c m}\end{array}$} & \multicolumn{6}{|c|}{ Moving up probabilities per year with modified IPM } & \multicolumn{6}{|c|}{ deviation percentages } \\
\hline & DF & NS & SP & JL & CB & CO & DF & NS & SP & JL & CB & CO \\
\hline $12-16$ & 0.159 & 0.093 & 0.082 & 0.141 & 0.113 & 0.081 & 2 & 5 & 8 & 5 & 7 & 6 \\
\hline $16-20$ & 0.173 & 0.098 & 0.079 & 0.145 & 0.111 & 0.080 & 2 & 4 & 8 & 4 & 6 & 6 \\
\hline $20-24$ & 0.185 & 0.101 & 0.075 & 0.148 & 0.110 & 0.078 & 2 & 4 & 8 & 3 & 5 & 7 \\
\hline $24-28$ & 0.196 & 0.104 & 0.072 & 0.150 & 0.108 & 0.077 & 2 & 4 & 9 & 3 & 4 & 7 \\
\hline $28-32$ & 0.205 & 0.106 & 0.068 & 0.149 & 0.106 & 0.076 & 2 & 5 & 9 & 4 & 4 & 7 \\
\hline $32-36$ & 0.213 & 0.107 & 0.064 & 0.148 & 0.104 & 0.075 & 2 & 5 & 8 & 6 & 5 & 8 \\
\hline $36-40$ & 0.219 & 0.108 & 0.060 & 0.144 & 0.102 & 0.075 & 2 & 5 & 10 & 7 & 5 & 8 \\
\hline $40-44$ & 0.224 & 0.108 & 0.055 & 0.140 & 0.099 & 0.075 & 2 & 6 & 10 & 9 & 5 & 9 \\
\hline $44-48$ & 0.227 & 0.107 & 0.051 & 0.133 & 0.097 & 0.075 & 3 & 6 & 11 & 11 & 6 & 9 \\
\hline $48-52$ & 0.228 & 0.106 & 0.046 & 0.125 & 0.094 & 0.076 & 3 & 7 & 12 & 14 & 6 & 11 \\
\hline $52-56$ & 0.228 & 0.103 & 0.041 & 0.115 & 0.091 & 0.077 & 4 & 10 & 15 & 17 & 6 & 13 \\
\hline $56-60$ & 0.227 & 0.101 & 0.036 & 0.104 & 0.088 & 0.079 & 6 & 12 & 20 & 23 & 6 & 15 \\
\hline $60-64$ & 0.223 & 0.097 & 0.030 & 0.092 & 0.085 & 0.081 & 7 & 16 & 28 & 31 & 7 & 18 \\
\hline $64-68$ & 0.218 & 0.093 & 0.025 & 0.077 & 0.082 & 0.082 & 9 & 21 & 43 & 42 & 7 & 20 \\
\hline $68-72$ & 0.212 & 0.088 & 0.019 & 0.062 & 0.079 & 0.085 & 11 & 27 & 70 & 60 & 8 & 25 \\
\hline $72-76$ & 0.204 & 0.082 & 0.013 & 0.045 & 0.075 & 0.088 & 12 & 34 & 115 & 93 & 10 & 28 \\
\hline $76-80$ & 0.194 & 0.076 & 0.008 & 0.027 & 0.072 & 0.091 & 16 & 44 & 187 & 153 & 13 & 32 \\
\hline$\geq 82$ & 0.183 & 0.069 & 0.005 & 0.013 & 0.068 & 0.094 & 18 & 57 & 253 & 259 & 17 & 36 \\
\hline
\end{tabular}

Indien Formule (57) wordt gebruikt, dus zonder aanpassing voor een negatief exponentiële kansdichtheid binnen een diameterklasse blijken de springkansen ongeveer $10 \%$ groter.

\subsection{Bepaling sterftekansen}

Met vergelijking (65) zijn de ratioschattingen voor de sterftekansen bepaald. De gemiddelde sterftekans per jaar voor alle bomen bedroeg 0.0023 met een $95 \%$ betrouwbaarheidsinterval $\{-0.092$; $0.097\}$. Omdat er bomen doodgingen in een klasse waar weinig bomen aanwezig waren, is met een voortschrijdend gemiddelde gewerkte over steeds 5 diameterklassen. De aldus gevonden waarden zijn met model (66) gefit, hierbij is het "aantal bomen in de klasse" $n$ als regressiegewicht.

Met $R^{2}$ adj $=0.792$ werden de parameters van Tabel 16 gevonden. De resultaten van deze berekeningen zijn in Tabel 17 weergegeven.

Tabel 16. Geschatte parameters van Formule (66).

Table 16. Estimated parameters of Formula (66).

\begin{tabular}{|c|c|c|c|c|c|c|}
\hline par & DF & NS & SP & JL & CB & $\mathrm{CO}$ \\
\hline$b_{0}$ & 0.00000 & 0.00062 & -0.00499 & 0.00000 & 0.00000 & -0.00357 \\
\hline$b_{1}$ & 0.05717 & 0.05717 & 0.19558 & 0.02865 & 0.02726 & 0.18865 \\
\hline
\end{tabular}


Tabel 17. Geschatte sterftekansen per jaar.

Table 17. Estimated mortality rates per year.

\begin{tabular}{|c|cccccc|}
\hline diameter & \multicolumn{7}{|c|}{ mortality rates } \\
\cline { 2 - 7 } in cm & DF & NS & SP & JL & CB & CO \\
\hline $12-16$ & 0.0041 & 0.0047 & 0.0090 & 0.0020 & 0.0019 & 0.0099 \\
$16-20$ & 0.0032 & 0.0038 & 0.0059 & 0.0016 & 0.0015 & 0.0069 \\
$20-24$ & 0.0026 & 0.0032 & 0.0039 & 0.0013 & 0.0012 & 0.0050 \\
$24-28$ & 0.0022 & 0.0028 & 0.0025 & 0.0011 & 0.0010 & 0.0037 \\
$28-32$ & 0.0019 & 0.0025 & 0.0015 & 0.0010 & 0.0009 & 0.0027 \\
$32-36$ & 0.0017 & 0.0023 & 0.0008 & 0.0008 & 0.0008 & 0.0020 \\
$36-40$ & 0.0015 & 0.0021 & 0.0002 & 0.0008 & 0.0007 & 0.0014 \\
$40-44$ & 0.0014 & 0.0020 & 0.0000 & 0.0007 & 0.0006 & 0.0009 \\
$44-48$ & 0.0012 & 0.0019 & 0.0000 & 0.0006 & 0.0006 & 0.0005 \\
$48-52$ & 0.0011 & 0.0018 & 0.0000 & 0.0006 & 0.0005 & 0.0002 \\
$52-56$ & 0.0011 & 0.0017 & 0.0000 & 0.0005 & 0.0005 & 0.0000 \\
$56-60$ & 0.0010 & 0.0016 & 0.0000 & 0.0005 & 0.0005 & 0.0000 \\
$60-64$ & 0.0009 & 0.0015 & 0.0000 & 0.0005 & 0.0004 & 0.0000 \\
$64-68$ & 0.0009 & 0.0015 & 0.0000 & 0.0004 & 0.0004 & 0.0000 \\
$68-72$ & 0.0008 & 0.0014 & 0.0000 & 0.0004 & 0.0004 & 0.0000 \\
$72-76$ & 0.0008 & 0.0014 & 0.0000 & 0.0004 & 0.0004 & 0.0000 \\
$76-80$ & 0.0007 & 0.0014 & 0.0000 & 0.0004 & 0.0003 & 0.0000 \\
$\geq 82$ & 0.0007 & 0.0013 & 0.0000 & 0.0003 & 0.0003 & 0.0000 \\
\hline
\end{tabular}

\subsection{Kap en evenwichtstoestand}

Wat betreft de boomsgewijze uitkap is er geen model dit te berekenen, wel heeft de kap een grote invloed op de evenwichtstoestand voor kap, die te berekenen is met de eigenvector van Formule (88) . Op dezelfde wijze als in Paragraaf 4.5.2 voor het Kolkbos is vervolgens de evenwichtstoestand bepaald met een kap met het doel een vaste $q$-waarde van 1.30 te realiseren. Deze waarde is gekozen omdat deze overeenkomt met de situatie tussen 1984 en 1997. De kappercentages zijn berekend met Formule (89).

De gewenste grootte van de eigenvector is bepaald door het grondvlak ervan gelijk te maken met $120 \%$ van het gemiddelde grondvlak voor oogst in de vier opnamen.

Zoals eerder vermeld is evenwichtstoestand bepaald bij een periodelengte van 1 jaar. In de praktijk zullen ingrepen om de 4 jaar plaatsvinden, daarom zijn de kappercentages in Tabel 18a en 18b per 4 jaar vermeld.

Tabel 18a. Kapkansen per soortgroep en zwaarteklasse

Table 18a. Cutting probabilities by species group and timber class

\begin{tabular}{|c|c|c|c|c|c|c|c|c|}
\hline \multirow{2}{*}{$\begin{array}{l}\text { timber } \\
\text { class }\end{array}$} & \multirow{2}{*}{$\begin{array}{c}\begin{array}{c}\text { diameter } \\
\text { in } \mathrm{cm}\end{array} \\
\end{array}$} & \multicolumn{7}{|c|}{ cutting probabilities per 4 year } \\
\hline & & DF & NS & SP & $\mathrm{JL}$ & CB & CO & total \\
\hline Light & $\leq 30$ & 0.134 & 0.084 & 0.089 & 0.149 & 0.135 & 0.081 & 0.114 \\
\hline Medium & $30-50$ & 0.230 & 0.119 & 0.093 & 0.187 & 0.130 & 0.090 & 0.144 \\
\hline Heavy & $>50$ & 0.278 & 0.127 & 0.062 & 0.167 & 0.115 & 0.088 & 0.145 \\
\hline \multicolumn{2}{|c|}{ total } & 0.162 & 0.094 & 0.088 & 0.158 & 0.133 & 0.083 & 0.122 \\
\hline
\end{tabular}


Tabel 18b. Kapkansen per soortgroep en diameterklasse van kapstrategie met $q$-waarde $=\mathbf{1 . 3 0}$

Table 18b. Cutting probabilities by species group and diameter class of harvest strategy with $q$-value $=1.30$

\begin{tabular}{|c|rrrrrr|r|}
\hline diameter & \multicolumn{7}{|c|}{ cutting probabilities per 4 year } \\
\cline { 2 - 7 } in cm & DF & NS & SP & JL & CB & CO & total \\
\hline $12-16$ & 0.096 & 0.068 & 0.078 & 0.130 & 0.135 & 0.070 & 0.100 \\
$16-20$ & 0.124 & 0.080 & 0.088 & 0.145 & 0.136 & 0.078 & 0.111 \\
$20-24$ & 0.148 & 0.090 & 0.092 & 0.158 & 0.136 & 0.086 & 0.120 \\
$24-28$ & 0.170 & 0.099 & 0.098 & 0.168 & 0.135 & 0.091 & 0.128 \\
$28-32$ & 0.190 & 0.106 & 0.102 & 0.176 & 0.134 & 0.095 & 0.135 \\
$32-36$ & 0.208 & 0.112 & 0.105 & 0.183 & 0.132 & 0.098 & 0.141 \\
$36-40$ & 0.225 & 0.117 & 0.093 & 0.187 & 0.131 & 0.086 & 0.142 \\
$40-44$ & 0.239 & 0.122 & 0.089 & 0.190 & 0.129 & 0.086 & 0.145 \\
$44-48$ & 0.251 & 0.125 & 0.085 & 0.191 & 0.127 & 0.086 & 0.147 \\
$48-52$ & 0.262 & 0.127 & 0.080 & 0.190 & 0.124 & 0.087 & 0.148 \\
$52-56$ & 0.270 & 0.129 & 0.075 & 0.186 & 0.122 & 0.087 & 0.149 \\
$56-60$ & 0.277 & 0.129 & 0.070 & 0.181 & 0.119 & 0.087 & 0.148 \\
$60-64$ & 0.281 & 0.129 & 0.064 & 0.174 & 0.116 & 0.087 & 0.147 \\
$64-68$ & 0.284 & 0.128 & 0.059 & 0.165 & 0.113 & 0.088 & 0.145 \\
$68-72$ & 0.285 & 0.125 & 0.053 & 0.155 & 0.110 & 0.089 & 0.143 \\
$72-76$ & 0.284 & 0.122 & 0.046 & 0.141 & 0.107 & 0.091 & 0.140 \\
$76-80$ & 0.280 & 0.119 & 0.036 & 0.121 & 0.103 & 0.093 & 0.135 \\
$\geq 82$ & 0.275 & 0.114 & 0.024 & 0.087 & 0.100 & 0.095 & 0.129 \\
\hline total & 0.162 & 0.094 & 0.088 & 0.158 & 0.133 & 0.083 & 0.122 \\
\hline
\end{tabular}

Het grondvlak, volume en volumebijgroei per diameterklasse zijn berekend met de formules van Paragraaf 3.7. In Tabel 19 is de kapstrategie vergeleken met de toestand tussen 1984 en 1997.

Tabel 19. Vergelijking van de kapstrategie en de toestand tussen 1984 en 1997

Tabel 19. Comparison of the harvest strategy and the condition between 1984 and 1997

\begin{tabular}{|l|l|c|c|}
\hline characteristic & unit & $\begin{array}{c}\text { Het Oude Trekerbos } \\
\mathbf{1 9 8 4} \mathbf{- 1 9 9 7}\end{array}$ & $\begin{array}{c}\text { Stable state } \\
\text { with harvest at } \mathbf{q}=\mathbf{1 . 3 0}\end{array}$ \\
\hline number of trees $N$ & $\mathrm{ha}^{-1}$ & 234 & 357 \\
basal area $G$ & $\mathrm{~m}^{2} \mathrm{ha}^{-1}$ & 20.8 & 25.0 \\
volume $V$ & $\mathrm{~m}^{3} \mathrm{ha}^{-1}$ & 226 & 262 \\
$\%$ light timber $V_{I}$ & $\%$ & $19 \%$ & $28 \%$ \\
$\%$ medium timber $V_{m}$ & $\%$ & $37 \%$ & $37 \%$ \\
$\%$ heavy timber $V_{z}$ & $\%$ & $44 \%$ & $35 \%$ \\
"mean" diameter $d_{g}$ & $\mathrm{~cm}^{3}$ & 33.7 & 29.9 \\
current volume increment $/ c$ & $\mathrm{~m}^{3} \mathrm{ha}^{-1} \mathrm{yr}^{-1}$ & 7.0 & 10.1 \\
harvested volume $V_{H}$ & $\mathrm{~m}^{3} \mathrm{ha}^{-1} \mathrm{yr}^{-1}$ & 2.2 & 9.2 \\
volume of mortality $V_{M}$ & $\mathrm{~m}^{3} \mathrm{ha}^{-1} \mathrm{yr}^{-1}$ & 0.2 & 0.4 \\
Ingrowth $N_{R}$ & $\mathrm{ha}^{-1} \mathrm{yr}^{-1}$ & 6.7 & 10.9 \\
harvest $N_{H}$ & $\mathrm{ha}^{-1} \mathrm{yr}^{-1}$ & 5.5 & 10.9 \\
mortality $N_{M}$ & $\mathrm{ha}^{-1} \mathrm{yr}^{-1}$ & 0.3 & 1.0 \\
mean Lioucourt ratio $\mathrm{q}$ & & 1.23 & 1.30 \\
\hline
\end{tabular}


In Figuur 17 is dit "ideale bos" vergeleken met de toestand tussen 1984 en 1997. Er is te zien dat de stamtallen van vooral het loofhout flink toenemen in de lichtere zwaarteklassen. Het huidige bos kent namelijk veel oude beuk en eik en veel minder oud naaldhout.

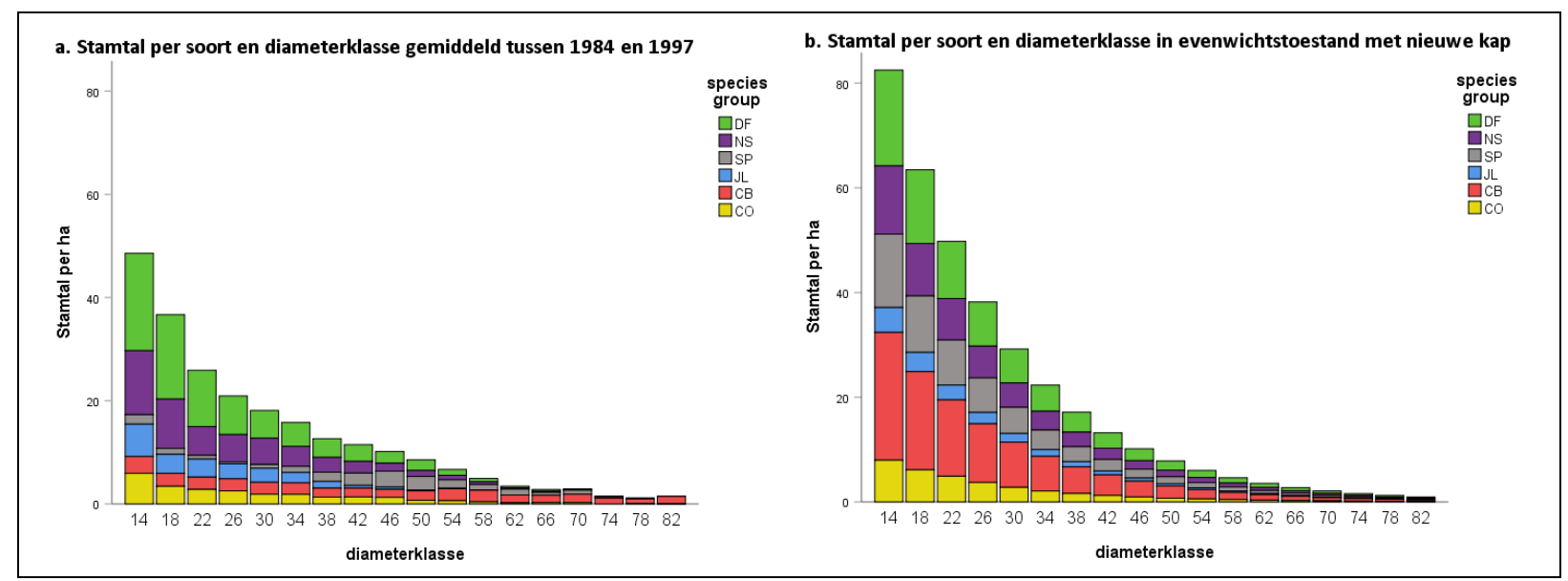

Figuur 17. Stamtal per ha per diameterklasse en soortgroep in het Oude Trekerbos gemiddeld tussen 1984 en 1997 (a) en in evenwichtstoestand met nieuwe kap bij $q=1.30$ (b).

Figure 17. Number of trees per ha per diameter class and species group in the Oude Trekerbos average between 1984 and 1997 (a) and in stable state with new harvest at $q=1.30$ (b).

In Figuur 18 is het oogstvolume en in Figuur 19 de volumebijgroei per diameterklasse en soortgroep weergegeven.

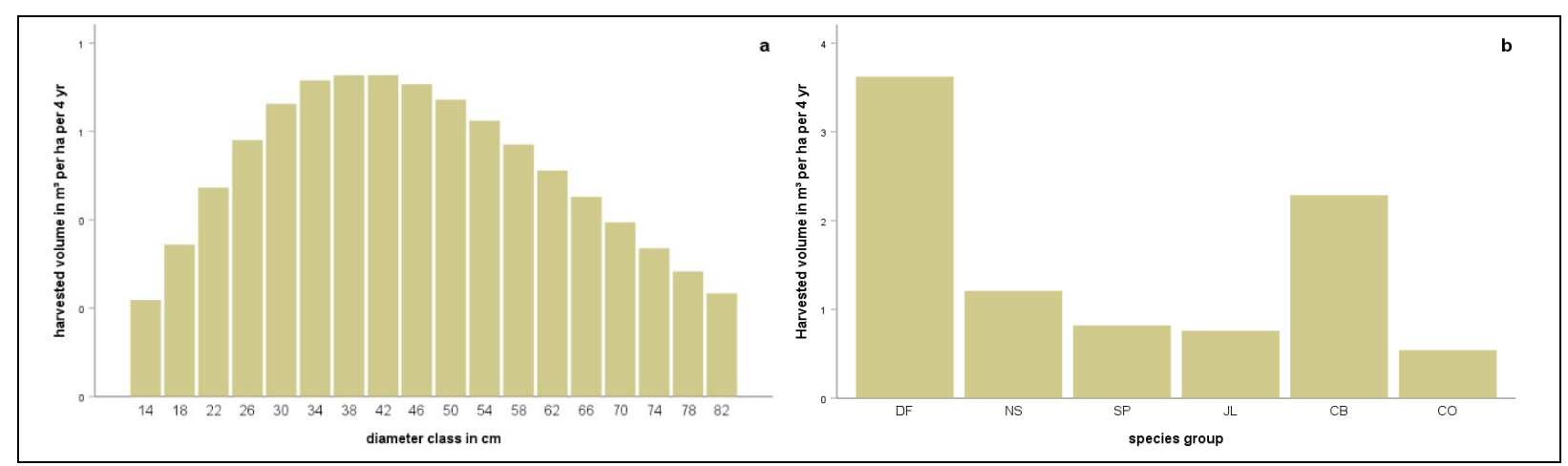

Figuur 18. Oude Trekerbos evenwichtstoestand, gekapt volume in $\mathbf{m}^{3}$ per ha per 4 jaar per diameterklasse (a) en soortgroep (b)

Figure 18. Oude Trekerbos stable state, cut down volume in $m^{3}$ per hectare per 4 years per diameter class (a) and species group (b)

De eigenvector is slechts een wiskundige eigenschap van een matrix met groei-, sterfte-, ingroei- en kapkansen. Door er een schaalfactor (met het doel 120\% van het gemeten grondvlak te realiseren) aan toe te voegen ontstaat een hypothetische evenwichtstoestand. De vraag is of dat een realistische weergave van het te ontwikkelen bos in het Oude Trekerbos is. Gezien de opnametechniek is de steekproef niet geschikt voor controle, er is daarom gewerkt met de subplots. Op de 28 subplot stonden in 1984232 bomen per ha in de range $\{69 ; 563\}$ met een grondvlak per ha van $18.4 \mathrm{~m}^{2} \mathrm{ha}^{-1}$ in de range $\{6.7 ; 48.5\}$ in 1997 was dat 240 bomen per ha in de range $\{60 ; 664\}$ met een grondvlak per ha van $23.9 \mathrm{~m}^{2} \mathrm{ha}^{-1}$ in de range $\{9.2 ; 61.9\}$. De waarden uit de evenwichtstoestand $\mathrm{N}=357 \mathrm{ha}^{-1} \mathrm{en} \mathrm{G}$ $=25.0 \mathrm{~m}^{2} \mathrm{ha}^{-1}$ passen hier dus goed, en we zijn mogelijk iets te voorzichtig. 


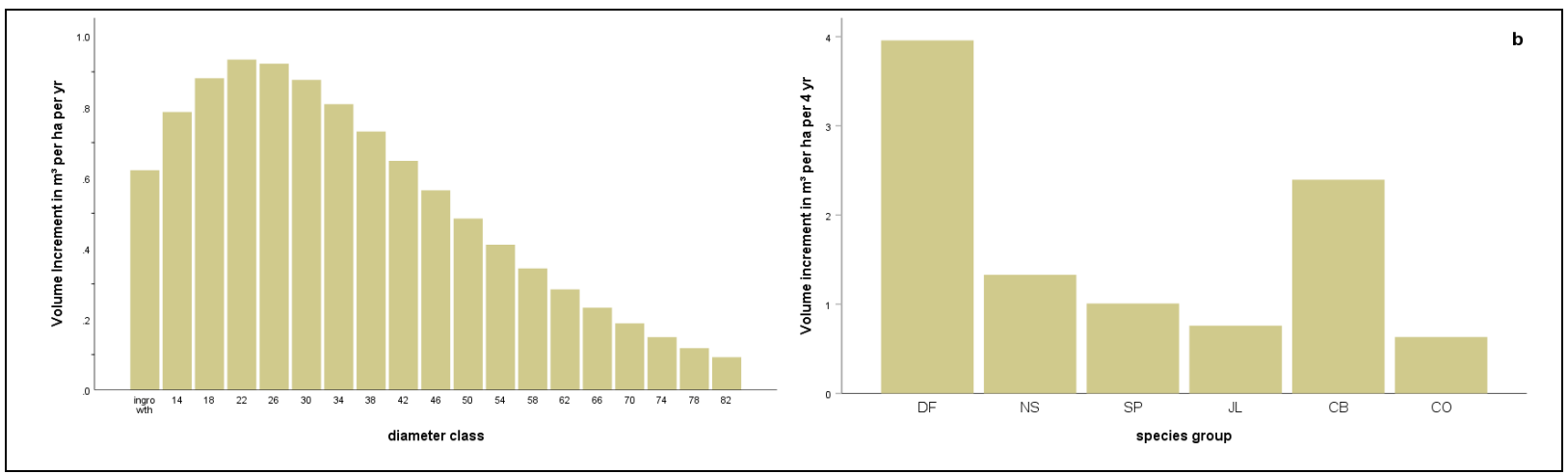

Figuur 19. Oude Trekerbos evenwichtstoestand, volumebijgroei in $\mathrm{m}^{3}$ per ha per 4 jaar per diameterklasse (a) en soortgroep (b).

Figure 19. Oude Trekerbos stable state, volume increment in $\mathrm{m}^{3}$ per hectare per 4 years per diameter class (a) and species group (b).

In Bijlage 3 zijn nog wat aanvullende kenmerken van de evenwichtstoestand vermeld.

\subsection{Verantwoorde kap}

In de Hoofdstuk 1 is de Formule van Heyer (1) gegeven om de verantwoorden kap te berekenen. Toegepast op het Oude Trekerbos halverwege 1984 en 1997 volgt:

$A C=I_{c}+\frac{V-V_{n}}{t_{a d j}}=7.0+\frac{226-262}{30}=5.9 \mathrm{~m}^{3} \mathrm{ha}^{-1} \mathrm{yr}^{-1}$, De Klein et al. (1997) geven een marge van 80 tot

$120 \%$ van de berekende waarde waarbinnen de werkelijke kap mag vallen. In deze periode is slechts eenmaal een volledige uitkap over het gehele complex uitgevoerd. Gemiddeld over 13 jaar bedraagt de werkelijke kap in die periode bedroeg $2.2 \mathrm{~m}^{3} \mathrm{ha}^{-1} \mathrm{jr}^{-1}$, en voldoet dus niet aan de eisen van een duurzame houtoogst. De Formule van Heyer houdt overigens geen rekening met sterfte, deze bedroeg in deze periode $0.2 \mathrm{~m}^{3} \mathrm{ha}^{-1} \mathrm{jr}^{-1}$.

\subsection{Steekproef van 1997}

In paragraaf 5.1 Is al aangegeven dat in 1997 met 77 steekproefpunten is gewerkt met 2 en 4 are cirkels. Op de 2 are cirkels zouden alle bomen dikker dan $8 \mathrm{~cm}$ worden geklemd. Daarnaast zijn er op een cirkel met een straal van $1 \mathrm{~m}$ alle zaailingen en boompjes tot $50 \mathrm{~cm}$ geteld en benoemd, dat waren 51 stuks (omgerekend 2108 per ha). Op een cirkel met een straal van $2 \mathrm{~m}$ zijn alle bomen geteld met een hoogte van 0.50 tot $1.30 \mathrm{~m}$ en alle bomen met een diameter tot $8 \mathrm{~cm}$. Tot een hoogte van $1.30 \mathrm{~m}$ waren er 63 bomen (omgerekend 651 per ha). Met een diameter tot $8 \mathrm{~cm}$ ging het om 49 stuks (omgerekend 506 per ha). Tot nu toe is met een soortgroep CO gewerkt voor zomereik en overig loofhout, maar zomereik komt op deze kleine cirkel in het geheel niet voor, daarom is deze soortgroep gesplitst in CO (zomereik) en "other" (overig loofhout). In Tabel 20 is het gevonden stamtal per ha per soortgroep en afmetingsklasse gegeven. 
Tabel 20. Stamtallen per ha per afmetingsklasse en soortgroep.

Table 20. Number of trees per ha per size class and species group.

\begin{tabular}{|c|c|c|c|c|c|c|c|c|c|}
\hline \multicolumn{2}{|c|}{ size class } & \multicolumn{7}{|c|}{ species group } & \multirow[b]{2}{*}{ total } \\
\hline$d b h$ & $\boldsymbol{h}$ & DF & NS & SP & $\mathrm{JL}$ & CB & $\mathrm{CO}$ & other & \\
\hline & $<0.5$ & 992 & 124 & 165 & 331 & 124 & & 372 & 2108 \\
\hline & $0.5-1.3$ & 186 & 31 & & & 52 & & 382 & 651 \\
\hline$<8$ & & 196 & 21 & 10 & 31 & 62 & & 186 & 506 \\
\hline $8-12$ & & 28 & 18 & & 10 & 3 & 4 & 10 & 73 \\
\hline $12-16$ & & 27 & 17 & 1 & 10 & 6 & 4 & 3 & 68 \\
\hline $16-20$ & & 16 & 6 & 3 & 3 & 3 & 2 & 2 & 34 \\
\hline $20-24$ & & 13 & 4 & 1 & 3 & 4 & 1 & 3 & 29 \\
\hline $24-28$ & & 11 & 4 & & 5 & 3 & 1 & 1 & 25 \\
\hline $28-32$ & & 6 & 5 & & 6 & 2 & 3 & 1 & 23 \\
\hline $32-36$ & & 5 & 5 & 1 & 3 & 3 & 1 & 1 & 19 \\
\hline $36-40$ & & 7 & 3 & 4 & 1 & 2 & 1 & & 18 \\
\hline $40-44$ & & 5 & 6 & 2 & 3 & 3 & 1 & 1 & 20 \\
\hline $44-48$ & & 4 & 2 & 3 & 1 & 1 & 1 & & 12 \\
\hline $48-52$ & & 5 & 1 & 3 & 1 & 1 & 2 & & 12 \\
\hline $52-56$ & & 1 & & & 1 & 3 & & & 4 \\
\hline $56-60$ & & 1 & 1 & 2 & & 2 & & & 6 \\
\hline $60-64$ & & 1 & & 1 & & 1 & & & 3 \\
\hline $64-68$ & & 1 & 1 & & & 1 & & & 2 \\
\hline $68-72$ & & 1 & & 2 & & 2 & 1 & & 6 \\
\hline $72-76$ & & & & 1 & & 1 & & & 2 \\
\hline $76-80$ & & & & 1 & & 1 & & & 2 \\
\hline$\geq 82$ & & & 1 & & & 1 & & & 2 \\
\hline & & 1505 & 248 & 201 & 407 & 279 & 24 & 961 & 3625 \\
\hline
\end{tabular}

De verjonging tot een hoogte van $0.5 \mathrm{~m}$ was volledig natuurlijk, bij de boompjes tussen 0.50 en 1.30 $\mathrm{m}$ bleek $8 \%$ aangeplant, en voor de rest was het natuurlijke verjonging. Van de bomen tot $8 \mathrm{~cm}$ dikte bleek $24 \%$ aangeplant. Er is ook gekeken naar de vraatschade deze bleek verwaarloosbaar. Er is geen andere oorzaak gevonden die de snelle verminderen van het stamtal in de onderste afmetingsklasse verklaart. De zomereik blijkt niet te verjongen en zal zonder aangepaste beheermaatregelen uit het systeem verdwijnen. Dat geldt vermoedelijk ook voor de grove den, deze verjongd wel maar groeit niet door naar hogere klassen, mogelijk ten gevolge van schot, maar dat is niet geconstateerd.

\subsection{Bosstructuur.}

De subplots zijn te groot, maar met behulp van de 2 are steekproefcirkels uit 1997 is het mogelijk om iets zinnigs te zeggen over de structuurparameters van Paragraaf 3.6. Hiertoe is een groepsindeling gemaakt met de drie zwaarteklassen en naald- versus loofhout. Met deze 6 groepen zijn de Shannon en Simpson indices berekend. In Tabel 21 zijn de resultaten vermeld. De huidige variatie in groepsstructuur is dus ongeveer halverwege die van het ideale uitkapbos.

De Cox-index is berekend in de steekproefcirkel met een straal van $2 \mathrm{~m}$. Voor de Cox-index werd een waarde van 9.2 gevonden, dus in het Oude Trekerbos is geen sprake van een Poissonbos. 
Tabel 21. Structuurparameters.

Table 21. Structure parameters.

\begin{tabular}{|l|c|c|}
\hline weighted mean recording & Shannonindex & Simpson index \\
\hline $\mathrm{n}$ & 77 & 77 \\
mean & 0.75 & 0.45 \\
$\mathrm{sdv}$ & 0.43 & 0.24 \\
minimum & 0.00 & 0.00 \\
maximum & 1.43 & 0.75 \\
\hline theoretisal minimum & 0.00 & 0.00 \\
theoretical maximum & 1.79 & 0.83 \\
stable state & 1.60 & 0.68 \\
\hline relative score & $55 \%$ & $66 \%$ \\
\hline
\end{tabular}

\subsection{Overige aandachtspunten}

Het gevolgde systeem bij het vaststellen van de grootte van de eigenvector leidt ertoe dat de gemiddelde verhouding in grondvlakaandelen van de zes soortgroepen gefixeerd zijn bij de bepaling van de evenwichtstoestand. Het echte bos is natuurlijk veel flexibeler en verschuivingen ten gunste van schaduwverdragende boomsoorten zal zeker plaatsvinden. Door ingrepen in de vorm van enige groepenkap en kunstmatige verjonging is hierin te sturen, maar wachten op wat storm- of brandschade blijft een optie. Zonder deze kunstmatige of natuurlijke openingen in het kronendak zal de zomereik uit het bos verdwijnen en zal er ook voor de grove den nauwelijks plaats zijn. 


\section{TOEPASSING IN BOOMBOS}

\subsection{Inleiding}

In het voormalige gemeenschappelijk bos (malebos) van Speuld zijn nog steeds restanten te vinden van het oorspronkelijke ongelijkjarige, gemengde loofhoutbos, tegenwoordige bekend onder de naam boombos (Kaartblad 32F x=174.00 y=475.00). Ook elders in Nederland, maar voornamelijk op de Veluwe komt dit bostype voor. In totaal gaat het volgens de $4^{\mathrm{e}}$ Bosstatistiek (CBS, 1985) om 608 ha, waarvan ongeveer de helft in het Speulder en Sprielderbos ligt. Hoewel er formeel slechts in enkele delen een status van bosreservaat geldt, vindt in de praktijk vanaf 1960 nauwelijks meer kap plaats en sinds 1980 wordt ook nog nauwelijks dood hout afgevoerd. Buis (1985) vindt zeer veel juridisch en technische documentatie over het beheer van de malenschappen, maar geen enkele bosbeheerkundige aanwijzing over de te kappen bomen. Gegeven de huidige verschijningsvorm behoren uitkap, groepenkap tot de meest waarschijnlijke opties, maar volgens een stamschijfanalyse (zie Bijlage 5) is plaatselijk ook hakhout of middenbos niet uitgesloten. Dit bostype wordt vegetatiekundig het wintereiken-beuken-bos genoemd. Naast wintereik en beuk komen er in het kronendak ook zomereik, grove den en ruwe berk voor. Er bestaan nog steeds stukken boombos met minder dan $50 \%$ beuk, maar in het overgrote deel van het boombos ligt het aandeel van de beuk ver boven de $80 \%$. We zullen de huidige dynamiek analyseren met de techniek besproken in de Hoofdstuk 3. Hiervoor worden de data van Den Ouden et al. (2016) gebruikt, dit betreffen 6 proefperken in het Speulderbos en 3 steekproefpunten uit de $\mathrm{HOSP}^{3}$ in het Elspeterbos, maximaal 4 maal opgemeten tussen 1985 en 2002. In Tabel 22 staan wat terreinkarakteristiek vermeld.

Tabel 22. Kenmerken van het Boombos, (gemiddeld tussen 1985 en 2002).

Table 22. Characteristics of the Boombos, (on average between 1985 and 2002).

\begin{tabular}{|l|l|cc|}
\hline characteristic & uniit & Speulderbos & Elspeterbos \\
\hline Area & ha & 5.92 & 1.59 \\
Number of trees & $\mathrm{ha}^{-1}$ & 191 & 158 \\
$\quad$ of which beech & $\%$ & 81 & 98 \\
Basal area & $\mathrm{m}^{2} \mathrm{ha}^{-1}$ & 27.4 & 27.5 \\
Volume & $\mathrm{m}^{3} \mathrm{ha}^{-1}$ & 281 & 285 \\
$\quad$ of which beech & $\%$ & 85 & 99 \\
Volume increment & $\mathrm{m}^{3} \mathrm{ha}^{-1} \mathrm{yr}^{-1}$ & 4.0 & 2.0 \\
Volume mortality & $\mathrm{m}^{3} \mathrm{ha}^{-1} \mathrm{yr}^{-1}$ & 9.3 & 19.6 \\
\hline
\end{tabular}

In deze casestudie is echter alleen gewerkt met de gegevens uit het Speulderbos. Er zijn 2 boomsoortgroepen, te weten: 1 beuk en 2 overig. De groep ov bestaat naast de vier eerdergenoemde soorten van het kronendak te weten zomereik, wintereik, ruwe berk en grove den ook uit soorten uit de ondergroei te weten hulst en lijsterbes. Maar in verjongingsgaten zijn nu ook exoten te vinden zoals douglas.

In dit Hoofdstuk wordt de studie in het Kolkbos (Hoofdstuk 4) herhaald, waarbij alleen de aangepaste IPM wordt toegepast zonder kap en ook met kapbeheer met het doel een vaste $q$-waarde realiseren.

In 1985, 1992, 1995 en 2002 is in de 6 proefperken van $50 \times 50$ m van alle bomen de diameter gemeten. In 1985 is per proefperk een verspreide hoogtemeting uitgevoerd. In 2002 is ook de verjonging geïnventariseerd. Binnen het Speulderbos zijn er meerdere locaties met boombos. De proefperken

3 HOSP is een acroniem voor "Houtoogst-Statistiek en Prognose oogstbaar hout" 
SP11, SP12 ${ }^{4}$, SP13 ${ }^{4}$ en SP14 liggen in de Drieërsingels en de perken SP15 en SP16 ${ }^{5}$ in de Woeste Wouden, deze laatste hebben een status van bosreservaat. Zie Figuur 20 voor indruk van het bostype.

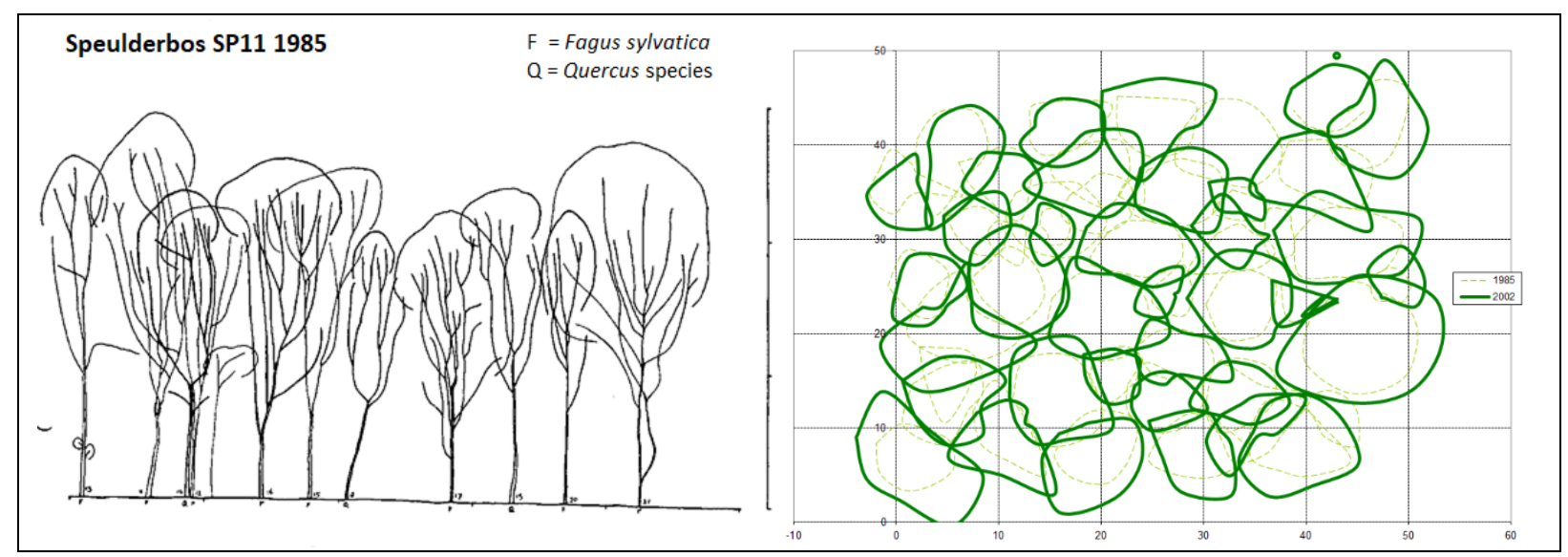

Figuur 20. SP11 Transect 1985 (L) en kroonprojectiekaart 1985-2002 (R).

Figure 20. SP11 Transect 1985 (L) and crown area map 1985-2002 (R).

\subsection{Springkansen bepaald met IPM}

In Figuur 21 is te zien dat de diameterbijgroei voor zowel beuk als de overige soorten tot een diameter van $42 \mathrm{~cm}$ nagenoeg dezelfde lijn volgt, daarna divergeren beide lijnen.

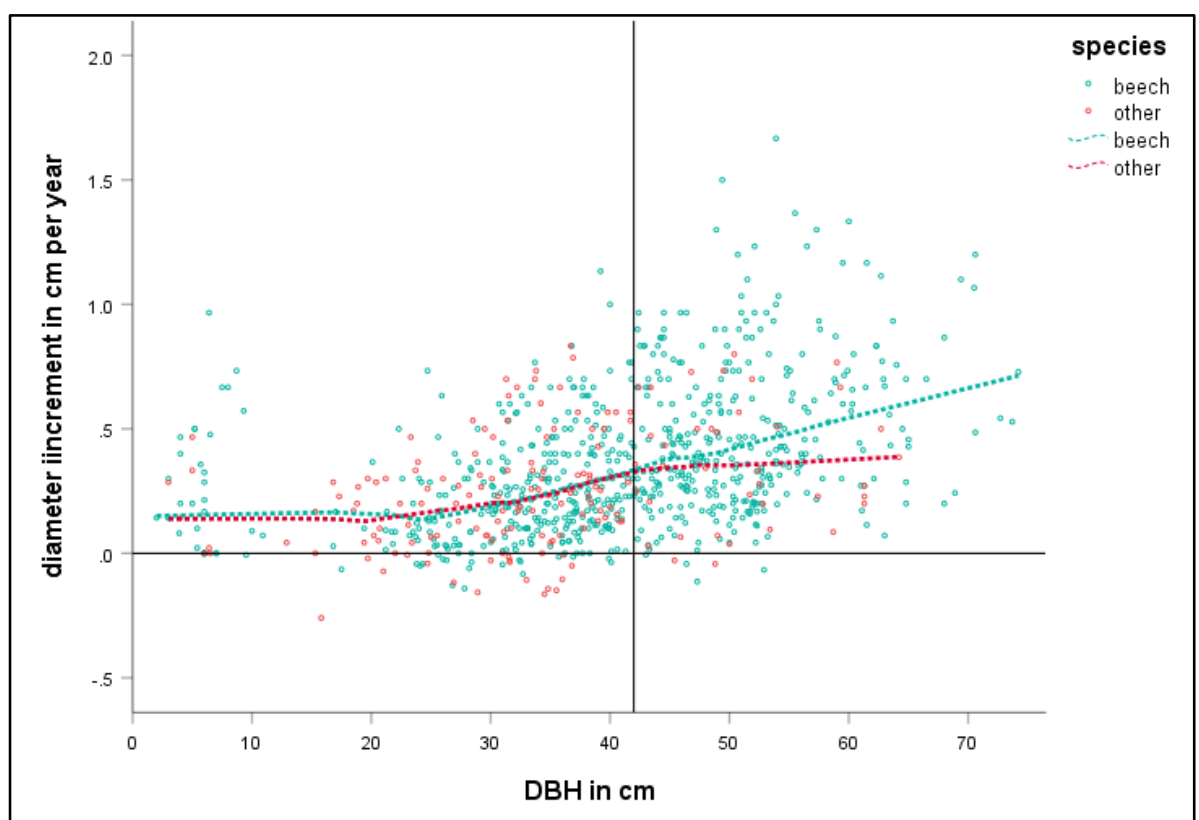

Figuur 21. Diameterbijgroei in cm per jaar als functie van de diameter per soort, de stippellijnen door de puntenwolk betreffen de voortschrijdende gemiddelde waarden.

Figure 21. Diameter increment in cm per year as a function of the diameter per species, the dotted lines through the point cloud represent the moving average values.

Model (50) is daarom als volgt aangepast

4 SP12 en SP13 zijn volgens het afdelingsregister geen boombos, maar geplante beuk uit 1780

5 Proefperk SP16 is iets kleiner (0.23 ha) omdat een deel in een ander bostype ligt 


$$
\begin{aligned}
& i d_{i j}=(f(d, s g, G)) \cdot P I \\
& f(d, s g, G)= \begin{cases}G_{\text {term }}+c_{0}+c_{2} \cdot d_{i j}^{2} & \text { for } s g=1 \\
G_{\text {term }}+c_{0}+c_{2} \cdot d_{i j}^{2} & \text { for } s g=2 \text { and } d b h<42 \mathrm{~cm} \\
G_{\text {term }}+c_{0}+c_{1} \cdot d_{i j} & \text { for } s g=2 \mathrm{nd} d b h \geq 42 \mathrm{~cm}\end{cases} \\
& G_{\text {term }}=b_{1} \cdot G_{L, j, i p}+b_{2} \cdot G_{M, j, i p}+b_{3} \cdot G_{Z, j, i p}
\end{aligned}
$$

Met een $R^{2}$ adj van 0.517 werd het model opgelost Hierin staat $G_{L, j, i p}$ voor het grondvlak per ha van het lichte hout $(d b h \leq 30 \mathrm{~cm})$ in de $j^{\mathrm{e}}$ opname in het $i p^{\mathrm{e}}$ plot, $M$ voor middelzwaar $(30 \mathrm{~cm}<d b h \leq 50)$ $\mathrm{cm}$ en $Z$ voor zwaar hout $(d b h>50 \mathrm{~cm})$. Met het gemiddelde $G_{L}=1.81 \mathrm{~m}^{2} \mathrm{ha}^{-1}$ voor alle opnamen en plots, evenzo $G_{M}=15.78 \mathrm{~m}^{2}$ ha ${ }^{-1}$ en $G_{Z}=9.66 \mathrm{~m}^{2} \mathrm{ha}^{-1}$ en een periode index $(P I)$ van 1 werden de volgende parameters per soortgroep gevonden (Tabel 23), deze parameters betreffen de bijgroei in $\mathrm{cm}$ per jaar.

Tabel 23. Parameters voor de tweedegraadspolynoom in id $=c_{0}+c_{1} \cdot d b h+c_{2} \cdot d b h^{2}$ Table 23. Parameters for the second-degree polynomial id $=c_{0}+c_{1} \cdot d b h+c_{2} \cdot d b h^{2}$

\begin{tabular}{|l|r|rr|r|}
\hline & beech & $\mathbf{d b h}<\mathbf{4 2}$ & $\mathbf{d b h} \geq \mathbf{4 2}$ & total \\
\hline$c_{0}$ & 0.1292 & 0.1292 & 0.1292 & 0.1332 \\
$c_{1}$ & 0.000000 & 0.000000 & 0.004460 & 0.000000 \\
$c_{2}$ & 0.0001267 & 0.0001267 & 0.0000000 & 0.0001217 \\
\hline
\end{tabular}

Formule (59) is voor de diameterbijgroei numeriek opgelost. De gemiddelde $q$-waarde bleek 1.30, dat komt overeen met $\lambda=0.06559$, deze waarde is in Formules (59) gebuikt om de springkans te schatten. Met stapjes van $0.1 \mathrm{~mm}$ is voor diameters tussen 0 en $78 \mathrm{~cm}$ de diameterbijgroei bepaald en gekeken is of $d b h_{t+1}=d b h_{t}+\hat{i}_{d}$ (de voorspelde diameter na 1 jaar met de tweedegraadspolynoom in $d b h$ en de parameters van Tabel 23 ) in dezelfde diameterklasse als $d b h$ blijft of juist één of meerdere klassen opschuift. Tabel 24 geeft in het linkerdeel het resultaat en rechts de met de procedure beschreven op Pagina 24 bij Formule (63) berekende afwijkingspercentage. Er is daarbij geschat tot de diameterklasse $82 \mathrm{~cm}$. Omdat er bijgroeiwaarden van meer dan $1 \mathrm{~cm}$ per jaar werden gevonden is voor het model een periode lengte van 1 jaar aangehouden. 
Tabel 24. Springkansen per jaar per soort en diameterklasse berekend met aangepaste IPM.

Table 24. Moving up probabilities estimated with modified IPM.

\begin{tabular}{|c|cc|cc|}
\hline diameter & \multicolumn{2}{|c|}{ Moving up probabilities per year } & \multicolumn{2}{|c|}{ deviation percentages } \\
\cline { 2 - 4 } in cm & beech & other & 22 & other \\
\hline $0-4$ & 0.029 & 0.029 & 19 & 19 \\
$4-8$ & 0.031 & 0.031 & 18 & 18 \\
$8-12$ & 0.033 & 0.033 & 16 & 16 \\
$12-16$ & 0.035 & 0.035 & 13 & 13 \\
$16-20$ & 0.040 & 0.040 & 11 & 9 \\
$20-24$ & 0.044 & 0.044 & 9 & 7 \\
$24-28$ & 0.051 & 0.051 & 7 & 5 \\
$28-32$ & 0.057 & 0.057 & 5 & 4 \\
$32-36$ & 0.064 & 0.064 & 5 & 16 \\
$36-40$ & 0.073 & 0.073 & 4 & 17 \\
$40-44$ & 0.082 & 0.071 & 4 & 17 \\
$44-48$ & 0.093 & 0.075 & 4 & 18 \\
$48-52$ & 0.104 & 0.080 & 5 & 18 \\
$52-56$ & 0.116 & 0.084 & 5 & 19 \\
$56-60$ & 0.129 & 0.089 & 5 & 19 \\
$60-64$ & 0.143 & 0.091 & 6 & 19 \\
$64-68$ & 0.157 & 0.095 & 6 & 20 \\
$68-72$ & 0.173 & 0.100 & 7 & 20 \\
$72-76$ & 0.191 & 0.104 & 7 & 7 \\
$\geq 76$ & 0.207 & 0.107 & & \\
\hline
\end{tabular}

\subsection{Bepaling sterftekansen}

In 1991 is er wat stormschade geweest en 7 half omgevallen bomen zijn toen uit veiligheidsoverweging gekapt en geoogst, deze zijn niet tot de uitkap maar tot de sterfte gerekend. Daarnaast zijn er gedurende het hele meettijdvak nog 6 andere bomen gekapt, zonder informatie waarom, deze zijn niet tot de sterfte gerekend.

Met de Formules (65) en (66) zijn de ratioschattingen voor de sterftekansen bepaald per diameterklasse en soortgroep, zie ook Figuur 5.

Met $R^{2}$ adj $=0.460$ werd Model (66) opgelost en werden de parameters van Tabel 25 gevonden .

Tabel 25. Parameters bij Formule (66).

Table 25. Parameters at Formula (66).

\begin{tabular}{|c|cc|}
\hline & beech & others \\
\hline$b_{0}$ & 0.0090 & 0.0274 \\
$b_{1}$ & 0.0794 & 0.1547 \\
\hline
\end{tabular}

Daarmee zijn de sterftekansen berekend, zie Tabel 26. 
Tabel 26. Sterftekansen per jaar per soort en diameterklasse.

Table 26. Mortality rates per year per species and diameter class.

\begin{tabular}{|c|cc|cc|c|}
\hline \multirow{2}{*}{$\begin{array}{c}\text { diameter } \\
\text { in } \mathbf{c m}\end{array}$} & \multicolumn{2}{|c|}{ Mortality rates per year per species and diameter class } & diameter \\
\cline { 2 - 4 } & beech & other & beech & other & in cm \\
\hline $0-4$ & 0.049 & 0.105 & 0.011 & 0.031 & $40-44$ \\
$4-8$ & 0.022 & 0.053 & 0.011 & 0.031 & $44-48$ \\
$8-12$ & 0.017 & 0.043 & 0.011 & 0.030 & $48-52$ \\
$12-16$ & 0.015 & 0.038 & 0.010 & 0.030 & $52-56$ \\
$16-20$ & 0.013 & 0.036 & 0.010 & 0.030 & $56-60$ \\
$20-24$ & 0.013 & 0.034 & 0.010 & 0.030 & $60-64$ \\
$24-28$ & 0.012 & 0.033 & 0.010 & 0.030 & $64-68$ \\
$28-32$ & 0.012 & 0.033 & 0.010 & 0.030 & $68-72$ \\
$32-36$ & 0.011 & 0.032 & 0.010 & 0.029 & $72-76$ \\
$36-40$ & 0.011 & 0.031 & 0.010 & 0.029 & $\geq 76$ \\
\hline
\end{tabular}

\subsection{Evenwichtstoestand zonder kap}

De transition matrix wordt nu alleen bepaald door de sterfte- en springkansen

De gewenste grootte van de eigenvector is bepaald door het grondvlak ervan gelijk te maken met $100 \%$ van het gemiddelde grondvlak voor oogst in de vier opnamen. Zoals eerder vermeld is de evenwichtstoestand bepaald bij een periodelengte van 1 jaar. De eigenvector is slechts een wiskundige eigenschap van een matrix met groei-, sterfte- en ingroeikansen. Door er een schaalfactor (met het doel $100 \%$ van het gemeten grondvlak te realiseren) aan toe te voegen ontstaat een hypothetische evenwichtstoestand. In Figuur 22 is het "ideale bos zonder kap" vergeleken met de gemiddelde toestand tussen 1985 en 2002. Er is te zien dat stamtallen tot diameterklasse 30 nagenoeg ontbreken in het werkelijke bos, maar door de keuze van de schaalfactor is ook het totale stamtal vanaf diameterklasse 30 in de evenwichtstoestand lager dan in het werkelijke bos, omdat dit totale grondvlak per ha nu uitgesmeerd wordt over alle diameterklassen. Dit is dus mogelijk een te voorzichtige benadering. Ondanks het nagenoeg ontbreken van "jong" bos in de huidige situatie is er wel degelijk sprake van verjonging, maar dat was tijdens de opnamen merendeels lager dan $1.30 \mathrm{~m}$. In Paragraaf 6.6 wordt nader ingegaan op de stamtallen van verjonging lager dan $1.30 \mathrm{~m}$.
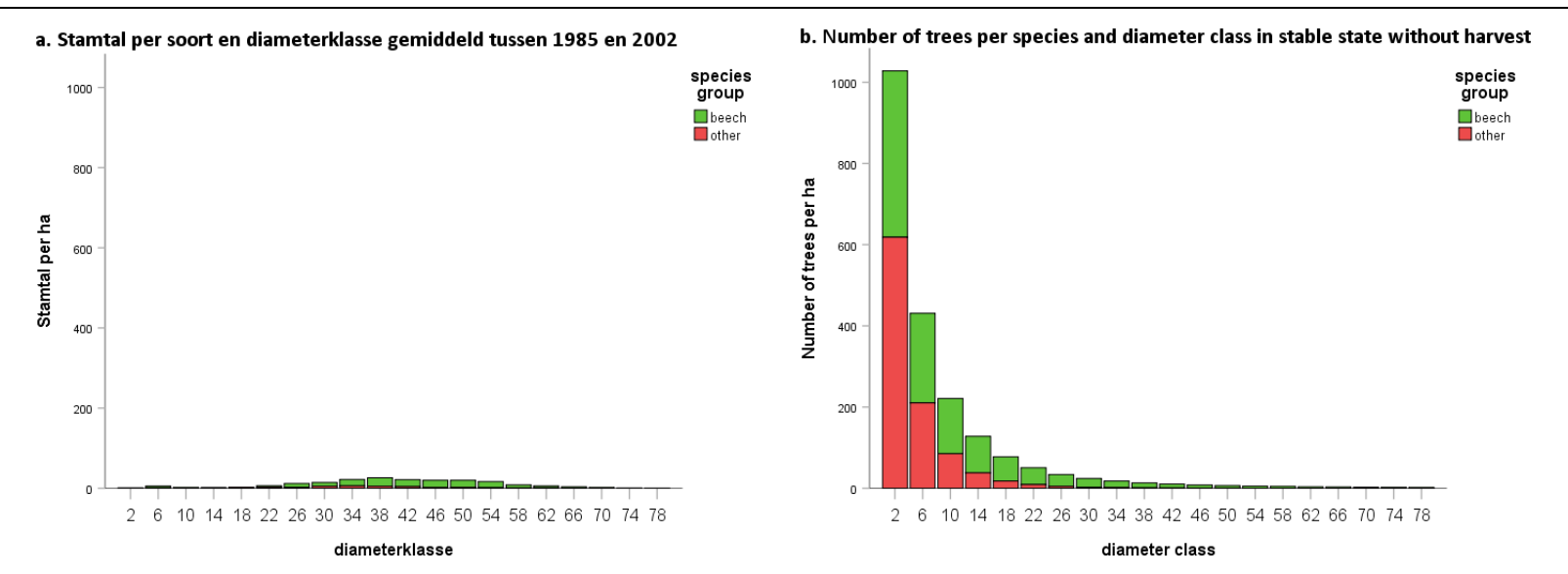

Figuur 22. Stamtal per ha per diameterklasse en soortgroep in het Boombos gemiddeld tussen 1985 en 2002 (a) en in evenwichtstoestand zonder kap (b).

Figure 22. Number of trees per ha per diameter class and species group in the Boombos in average between 1985 and 2002 (a) and in stable state without harvest (b). 
In Tabel 29 is zowel de evenwichtstoestand zonder kap als die met kap (Paragraaf 6.5) vergeleken met de gemiddelde toestand tussen 1985 en 2002. Bij de verwerking van grondvlak, volume en volumebijgroei is de procedure van Paragraaf 3.7 gevolg. Dit geldt ook bij de berekening met kap.

In Bijlage 4A zijn nog wat aanvullende kenmerken van de evenwichtstoestand zonder kap vermeld.

\subsection{Evenwichtstoestand met kap}

Hoewel uitkapbeheer vermoedelijk geen optie is voor het boombos in het Speulder- en Spielderbos is een uitkapbeheer gemodelleerd.

Op dezelfde wijze als in Paragraaf 4.5.2 voor het Kolkbos is de evenwichtstoestand bepaald met een kap met het doel een vaste $q$-waarde van 1.30 te realiseren. Deze waarde is gekozen omdat deze overeenkomt met de gemiddelde situatie tussen 1985 en 2002. De kappercentages zijn berekend met Formule (89). Bij de berekening moet het sterftepercentage bekend zijn. Verwacht wordt dat de sterfte enorm zal reduceren en we hebben aangenomen dat de sterfte $20 \%$ van de normale sterfte zonder kap bedraagt. Daar waren wat iteraties voor nodig voor stabiele waarden voor $p_{H}$ en $p_{M}$ werden gevonden. Voor de dbh tot $12 \mathrm{~cm}$ wordt niet gekapt en wordt met de volledige sterfte zonder kap gewerkt.

De gewenste grootte van de eigenvector is bepaald door het grondvlak ervan gelijk te maken met $100 \%$ van het gemiddelde grondvlak van de blijvende opstand in de vier opnamen, waarvan $80 \%$ is toebedeeld aan de beuk en de rest voor de overige boomsoorten.

In Figuur 23 is het "ideale bos met kap" vergeleken met de gemiddelde toestand tussen 1985 en 2002. Er is te zien stamtallen tot diameterklasse 30 nagenoeg ontbreken in het werkelijke bos, maar door de keuze van de schaalfactor $100 \%$ is ook het totale stamtal vanaf diameterklasse 30 in de evenwichtstoestand nog steeds lager dan in het werkelijke bos, omdat dit totale grondvlak per ha nu uitgesmeerd wordt over alle diameterklassen. Dit is dus mogelijk een te voorzichtige benadering. Ondanks het nagenoeg ontbreken van "jong" bos in de huidige situatie is er wel degelijk sprake van verjonging, maar dat was tijdens de opnemen merendeels lager dan $1.30 \mathrm{~m}$. In Paragraaf 6.6 wordt nader ingegaan op de stamtallen van verjonging lager dan $1.30 \mathrm{~m}$.

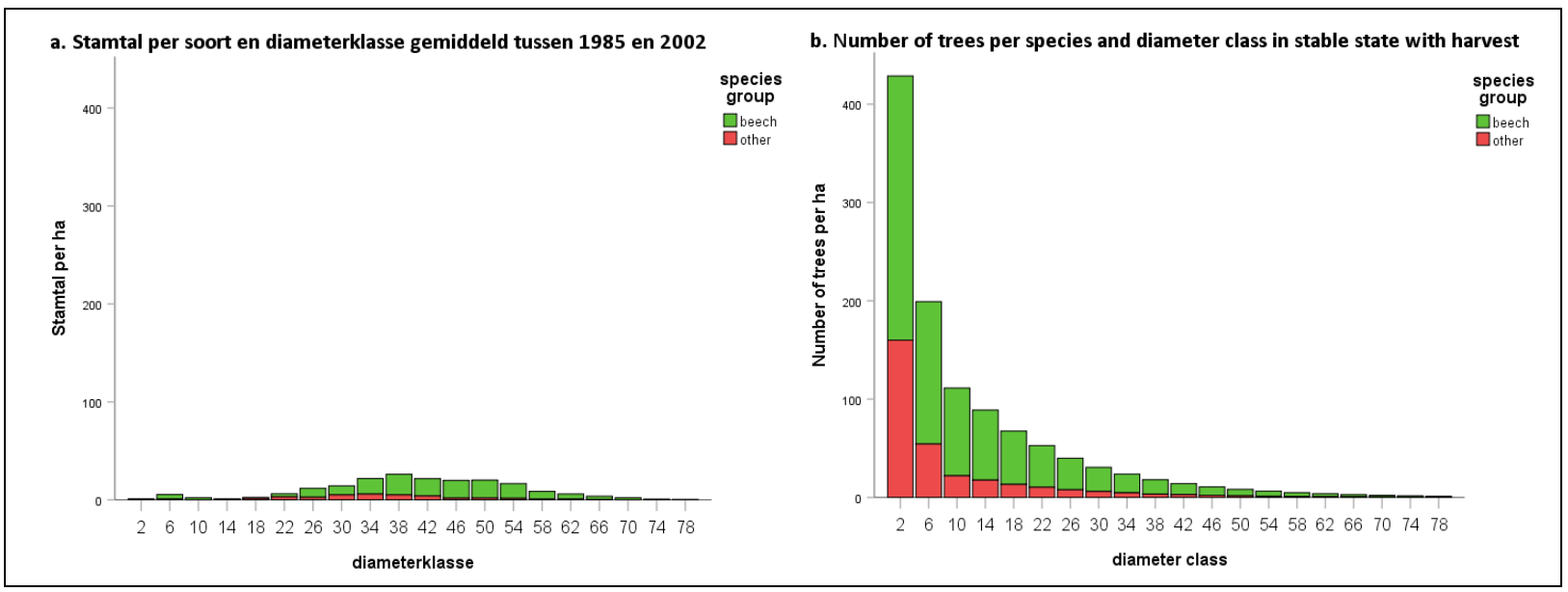

Figuur 23. Stamtal per ha per diameterklasse en soortgroep in het Boombos gemiddeld tussen 1985 en 2002 (a) en in evenwichtstoestand met kap (b).

Figure 23. Number of trees per ha per diameter class and species group in the Boombos in average between 1985 and 2002 (a) and in stable state with harvest (b).

Zoals eerder vermeld is evenwichtstoestand bepaald bij een periodelengte van 1 jaar. In de praktijk zullen ingrepen om de 4 jaar plaatsvinden, daarom zijn de kappercentages per 4 jaar vermeld. 
Tabel 27a. Kapkansen per soortgroep en diameterklasse.

Table 27a. Cutting probabilities per species group and diameter class.

\begin{tabular}{|c|cc|cc|c|}
\hline $\begin{array}{c}\text { diameter } \\
\text { in cm }\end{array}$ & \multicolumn{3}{|c|}{ cutting probabilities per 4 year } & diameter \\
\cline { 2 - 5 } in cm \\
\hline $0-4$ & beech & other & beech & other & $40-44$ \\
$4-8$ & 0.000 & 0.000 & 0.044 & 0.056 & $44-48$ \\
$8-12$ & 0.000 & 0.000 & 0.053 & 0.066 & $48-52$ \\
$12-16$ & 0.000 & 0.000 & 0.062 & 0.060 & $52-56$ \\
$16-20$ & 0.013 & 0.008 & 0.073 & 0.066 & $56-60$ \\
$20-24$ & 0.021 & 0.014 & 0.084 & 0.074 & $60-64$ \\
$24-28$ & 0.022 & 0.013 & 0.096 & 0.079 & $64-68$ \\
$28-32$ & 0.025 & 0.017 & 0.110 & 0.083 & $68-72$ \\
$32-36$ & 0.029 & 0.021 & 0.121 & 0.085 & $72-76$ \\
$36-40$ & 0.035 & 0.026 & 0.136 & 0.093 & $\geq 76$ \\
\hline
\end{tabular}

In tabel 27b zijn voor praktisch gebruik de kapkansen per zwaarteklasse berekend. In Tabel 27a een volledig over voor alle diameterklassen

Tabel 27b. Kapkansen per soortgroep en zwaarteklasse

Table 27b. Cutting probabilities per species group and timber class

\begin{tabular}{|l|c|cc|c|}
\hline \multirow{2}{*}{ timber class } & diameter & \multicolumn{3}{c|}{ cutting probabilities per 4 year } \\
\cline { 3 - 5 } in $\mathbf{~ c m ~}$ & \multicolumn{1}{c|}{ bu } & ov & total \\
\hline Light & $\leq 30$ & 0.006 & 0.002 & 0.005 \\
Medium & $30-50$ & 0.044 & 0.046 & 0.044 \\
Heavy & $>50$ & 0.098 & 0.078 & 0.094 \\
\hline \multicolumn{2}{|c|}{ total } & 0.011 & 0.006 & 0.010 \\
\hline
\end{tabular}

Omdat er vanaf een diameter van $12 \mathrm{~cm}$ gekapt wordt, zijn tot die diameter de sterftekansen van Tabel 26 aangehouden, voor de klasse $12-16 \mathrm{~cm}$ is $20 \%$ en daarboven $10 \%$ van de sterfte zonder kap aangehouden. Dat resulteert in de sterftekansen van Tabel 28

Tabel 28. Sterftekansen per soortgroep en diameterklasse in het model met kap.

Table 28. Mortality rates per species group and diameter class in the model with harvest.

\begin{tabular}{|c|c|c|c|c|c|}
\hline \multirow{2}{*}{$\begin{array}{c}\text { diameter } \\
\text { in } \mathbf{c m}\end{array}$} & \multicolumn{4}{|c|}{ Mortality rates per jaar per species group and diameter class } & \multirow{2}{*}{$\begin{array}{c}\text { diameter } \\
\text { in } \mathrm{cm}\end{array}$} \\
\hline & beech & other & beech & other & \\
\hline $0-4$ & 0.049 & 0.105 & 0.001 & 0.003 & $40-44$ \\
\hline $4-8$ & 0.022 & 0.053 & 0.001 & 0.003 & $44-48$ \\
\hline $8-12$ & 0.017 & 0.043 & 0.001 & 0.003 & $48-52$ \\
\hline $12-16$ & 0.003 & 0.004 & 0.001 & 0.003 & $52-56$ \\
\hline $16-20$ & 0.001 & 0.004 & 0.001 & 0.003 & $56-60$ \\
\hline $20-24$ & 0.001 & 0.003 & 0.001 & 0.003 & $60-64$ \\
\hline $24-28$ & 0.001 & 0.003 & 0.001 & 0.003 & $64-68$ \\
\hline $28-32$ & 0.001 & 0.003 & 0.001 & 0.003 & $68-72$ \\
\hline $32-36$ & 0.001 & 0.003 & 0.001 & 0.003 & $72-76$ \\
\hline $36-40$ & 0.001 & 0.003 & 0.001 & 0.003 & $\geq 76$ \\
\hline
\end{tabular}


In Tabel 29 is de kapstrategie vergeleken met de toestand tussen 1985 en 2002.

Tabel 29. Vergelijking van de strategie met en zonder kap met de gemiddelde toestand tussen 1985 en 2002.

Table 29. Comparison of the strategy with and without harvest with the average state between 1985 and 2002.

\begin{tabular}{|l|l|c|c|c|}
\hline characteristic & unit & $\begin{array}{c}\text { Boombos } \\
\mathbf{1 9 8 5 - 2 0 0 2}\end{array}$ & $\begin{array}{c}\text { stable state } \\
\text { with harvest }\end{array}$ & $\begin{array}{c}\text { stable state } \\
\text { without harvest }\end{array}$ \\
\hline number of trees $N$ & $\mathrm{ha}^{-1}$ & 192 & 1117 & 2075 \\
basal area $G$ & $\mathrm{~m}^{2} \mathrm{ha}^{-1}$ & 27.5 & 27.5 & 27.5 \\
volume $V$ & $\mathrm{~m}^{3} \mathrm{ha}^{-1}$ & 282 & 270 & 265 \\
light timber $V_{I}$ & $\%$ & $7 \%$ & $14 \%$ & $22 \%$ \\
medium timber $V_{m}$ & $\%$ & $54 \%$ & $37 \%$ & $31 \%$ \\
heavy timber $V_{z}$ & $\%$ & $39 \%$ & $49 \%$ & $48 \%$ \\
"mean" diameter $d_{g}$ & $\mathrm{~cm}$ & 42.7 & 17.7 & 13.0 \\
current volume increment $/ \mathrm{cV}$ & $\mathrm{m}^{3} \mathrm{ha}^{-1} \mathrm{yr}^{-1}$ & 4.2 & 4.6 & 114.1 \\
Ingrowth $N_{R}$ & $\mathrm{ha}^{-1} \mathrm{yr}^{-1}$ & 0.1 & 42.1 & 113.7 \\
mortality $N_{M}$ & $\mathrm{ha}^{-1} \mathrm{yr}^{-1}$ & 7.6 & 39.2 & 0.0 \\
harvest $N_{H}$ & $\mathrm{ha}^{-1} \mathrm{yr}^{-1}$ & 0.0 & 2.7 & 0.0 \\
harvested volume $V_{H}$ & $\mathrm{~m}^{3} \mathrm{ha}^{-1} \mathrm{yr}^{-1}$ & 0.0 & 3.5 & 4.1 \\
volume of mortality $V_{M}$ & $\mathrm{~m}^{3} \mathrm{ha}^{-1} \mathrm{yr}^{-1}$ & 10.5 & 0.8 & 1.55 \\
mean Lioucourt ratio q & & 1.31 & 1.40 & 5.2 \\
\hline
\end{tabular}

${ }^{*}$ for $d b h>12 \mathrm{~cm}$

Met Formule (1) van Heyer (1834) wordt de verantwoorde kap als volgt berekend:

$A C=4.2+\frac{282-270}{30}=4.7 \mathrm{~m}^{3} \mathrm{ha}^{-1} \mathrm{yr}^{-1}$, De Klein et al. (1997) geven een toegestane marge van 80 tot $120 \%$. Een uitkap 15 tot $22 \mathrm{~m}^{3}$ per ha per rotatie van 4 jaar is daarmee mogelijk in dit boombos.

In Figuur 24 en Figuur 25 zijn het oogstvolume en de volumebijgroei per diameterklasse en soortgroep weergegeven.

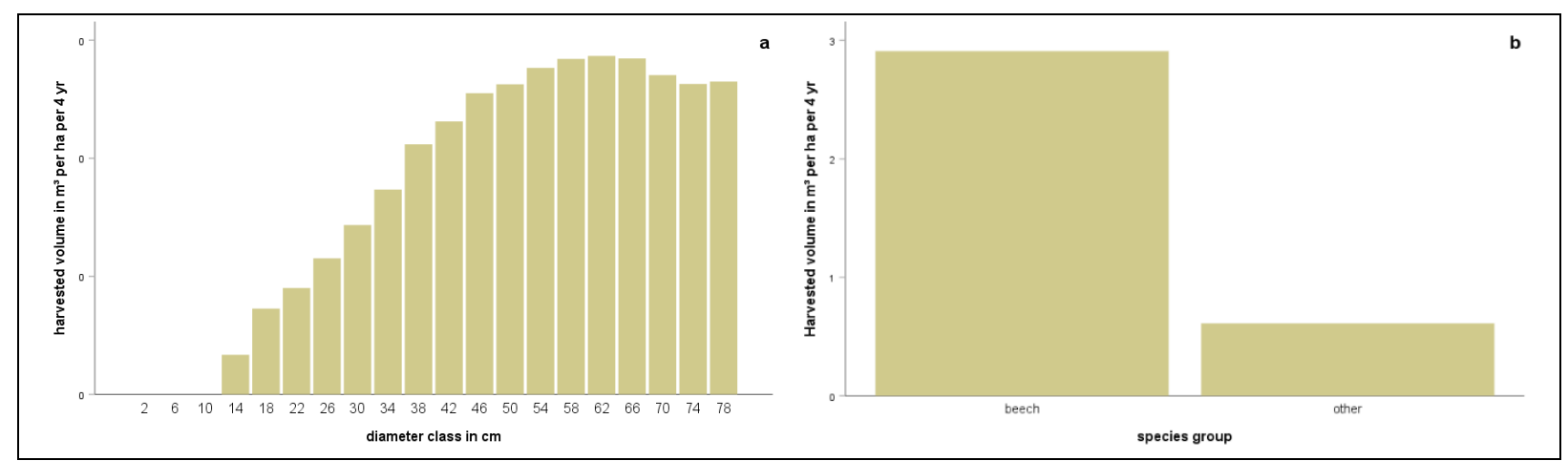

Figuur 24. Boombos evenwichtstoestand met kap, gekapt volume in $m^{3}$ per ha per 4 jaar per diameterklasse (a) en soort (b).

Figure 24. Boombos Stable state with harvest, harvested volume in $m^{3}$ per ha per 4 years per diameter class (a) and species (b). 


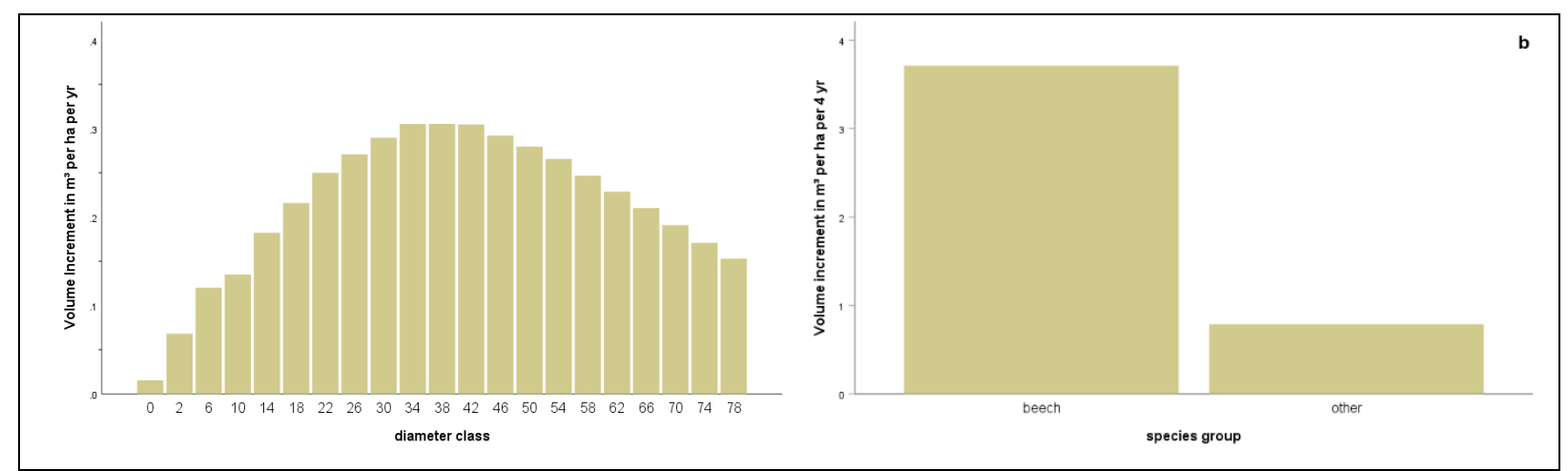

Figuur 25. Boombos evenwichtstoestand met kap, volumebijgroei in $m^{3}$ per ha per 4 jaar per diameterklasse (a) en soortgroep (b)

Figure 25. Boombos Stable state with harvest, volume increment in $m^{3}$ per ha per 4 years per diameter class (a) and species (b).

In Bijlage 4B zijn nog wat aanvullende kenmerken van de evenwichtstoestand vermeld.

\subsection{Natuurlijke verjonging}

Dat boombos zich goed kan verjongen was al eerder gebleken uit onderzoek van Oosterbaan \& van Tol (1984), door wat stormschade in 1991 in een deel van de proefperken bleek dit ook in ons onderzoek te kwantificeren.

In 1995 is een ruwe schatting gemaakt van de verjonging in SP12 en SP13, en in 2002 is de verjonging steekproefsgewijs is opgenomen in SP11, SP12, SP13 en SP14.

Omgerekend naar aantal per ha voor alle 6 proefperken staan in Tabel 30 de gevonden waarden in 1995 en in Tabel 31 die van 2002.

Tabel 30. Stamtal per ha per boomsoort en afmeting in 1995.

Table 30. Number of trees per ha per species and size in 1995.

\begin{tabular}{|c|c|c|c|c|c|c|c|}
\hline \multirow[b]{2}{*}{ size class } & \multicolumn{6}{|c|}{ species } & \multirow[b]{2}{*}{ Total } \\
\hline & beech & oak & birch & Scots pne & holly & other & \\
\hline $\mathrm{h}=0-20 \mathrm{~cm}$ & 871.7 & 8.3 & & 8.3 & & 9.3 & 897.7 \\
\hline $\mathrm{h}=20-50 \mathrm{~cm}$ & 278.3 & 16.7 & & 1.7 & & 18.2 & 314.8 \\
\hline $\mathrm{h}=50-130 \mathrm{~cm}$ & 116.7 & 0.8 & & & 0.2 & 8.7 & 126.3 \\
\hline $\mathrm{dbh}=0-4 \mathrm{~cm}$ & 233.3 & & & & 0.2 & & 233.5 \\
\hline $\mathrm{dbh}=4-8 \mathrm{~cm}$ & & & & & & & 0.0 \\
\hline Total & 1500.0 & 25.8 & 0.0 & 10.0 & & 36.2 & 1572.3 \\
\hline
\end{tabular}

Tabel 31. Stamtal per ha per boomsoort en afmeting in $\mathbf{2 0 0 2}$

Table 31. Number of trees per ha per species and size in 2002.

\begin{tabular}{|c|c|c|c|c|c|c|c|}
\hline \multirow[b]{2}{*}{ size class } & \multicolumn{6}{|c|}{ species } & \multirow[b]{2}{*}{ Total } \\
\hline & beech & oak & birch & Scots pne & holly & other & \\
\hline $\mathrm{h}=0-20 \mathrm{~cm}$ & 3056.0 & 53.3 & & & 469.3 & 64.0 & 3642.7 \\
\hline $\mathrm{h}=20-50 \mathrm{~cm}$ & 720.0 & 10.7 & & & 202.7 & 53.3 & 986.7 \\
\hline$h=50-130 \mathrm{~cm}$ & 1584.0 & 10.7 & & 5.3 & 128.0 & 21.3 & 1749.3 \\
\hline $\mathrm{dbh}=0-4 \mathrm{~cm}$ & 1568.0 & 10.7 & 5.3 & 16.0 & 53.3 & 53.3 & 1706.7 \\
\hline $\mathrm{dbh}=4-8 \mathrm{~cm}$ & 21.3 & & & 10.7 & & & 32.0 \\
\hline Totaal & 6949.3 & 85.3 & 5.3 & 32.0 & 853.3 & 192.0 & 8117.3 \\
\hline
\end{tabular}

In 1995 troffen we wat betreft de eik alleen wintereik aan in SP12, deze was ingeplant en de verjongingsvlakte was ingerasterd. Alle exemplaren van de andere soorten en betroffen natuurlijke verjonging. In 2002 werden er geen wintereiken waargenomen, maar wel zomereik. 
Bij de overige soorten werden douglas, tsuga, lijsterbes, Amerikaanse vogelkers en wegedoorn waargenomen. De gap in SP12 bedraagt ongeveer 6 are en die in SP13 ongeveer 3 are, in de overige proefperken gaat het om gaten van een boom. Bij deze omvang blijken beuk en hulst goed te verjongen, de lichthoutsoorten eik, berk en grove den blijken bij deze omvang van de gaps moeilijk te verjongen. In Tabel 32 zijn de opnamegegevens van de bomen uit Tabel 31 gecombineerd met de data van Figuur 22b (zie voor de data zelf Tabel B4B-1 in Bijlage 4B) voor de boomsoortgroepen bu en ov. In de laatste kolom is de evenwichtstoestand met kap uitgebreid voor de drie laagste afmetingsklassen (cursief) door een $q$-waarde te gebruiken van 2.15 ( $q$-waarde tussen $d b h$-klasse 2 en $6 \mathrm{~cm}$ ). Dat geeft dan een ruwe schatting voor een evenwichtstoestand bij een boomsgewijze kap om de 4 jaar en een groepenkap per 15 tot 20 jaar van ongeveer 10 are.

Tabel 32. Stamtallen per ha per afmetingsklasse en soortgroep

Table 32. Number of trees per ha per size class and species group

\begin{tabular}{|c|c|c|c|c|c|}
\hline \multicolumn{2}{|c|}{ size class } & \multicolumn{2}{|c|}{ species group } & \multirow[b]{2}{*}{ Total } & \multirow[b]{2}{*}{ Stable state } \\
\hline$h$ in $\mathrm{cm}$ & $d b h$ in $\mathrm{cm}$ & beech & other & & \\
\hline $0-$ & & 3056 & 587 & 3643 & 4276 \\
\hline $20-$ & & 720 & 267 & 987 & 1986 \\
\hline $50-$ & & 1584 & 165 & 1749 & 923 \\
\hline & $0-4$ & 1568 & 139 & 1707 & 429 \\
\hline & $4-8$ & 23 & 10 & 33 & 199 \\
\hline & $8-12$ & 5 & & 5 & 111 \\
\hline & $12-16$ & 1 & 1 & 1 & 89 \\
\hline & $16-20$ & 1 & 1 & 2 & 68 \\
\hline & $20-24$ & 2 & 1 & 3 & 53 \\
\hline & $24-28$ & 9 & 3 & 12 & 40 \\
\hline & $28-32$ & 6 & 1 & 7 & 31 \\
\hline & $32-36$ & 12 & 5 & 17 & 24 \\
\hline & $36-40$ & 18 & 3 & 21 & 18 \\
\hline & $40-44$ & 17 & 6 & 23 & 14 \\
\hline & $44-48$ & 14 & 3 & 17 & 11 \\
\hline & $48-52$ & 17 & 1 & 18 & 8 \\
\hline & $52-56$ & 19 & 3 & 22 & 6 \\
\hline & $56-60$ & 12 & 1 & 13 & 5 \\
\hline & $60-64$ & 4 & 1 & 5 & 4 \\
\hline & $64-68$ & 8 & 1 & 9 & 3 \\
\hline & $68-72$ & 4 & & 4 & 2 \\
\hline & $72-76$ & 1 & & 1 & 2 \\
\hline & $\geq 76$ & 2 & & 2 & 1 \\
\hline Total & & 7100 & 1199 & 8299 & 8302 \\
\hline
\end{tabular}

\subsection{Bosstructuur.}

Op de 25 steekproefvlakten van $100 \mathrm{~m}^{2}$ per proefperk uit 2002 zijn de structuurparameters van Paragraaf 3.6 berekend per proefperk en opname. Er bleek voor de Cox-index $Q$ verschil tussen de gebieden zie Tabel 33. Het stamvoetenpatroon in de Drieërsingels duidt op een regelmatig patroon behorend bij aangeplant bos en in de Woeste Wouden ligt het veel dichter bij een Poissonbos. Dit strookt dan met de voetnoot 4 uit paragraaf 6.1 dat de helft van de Drieërsingels niet uit boombos, maar uit geplante beuk uit 1780 zou bestaan 
Tabel 33 Cox-index per gebied

Table 33 Cox-index per subarea

\begin{tabular}{|l|rrr|}
\hline subarea & Q_mean & Q_min & Q_max \\
\hline Drieërsingels & 0.42 & 0.21 & 0.61 \\
Woeste Wouden & 0.82 & 0.61 & 1.04 \\
\hline
\end{tabular}

Hiertoe is een groepsindeling gemaakt met de zwaarteklasse, boomsoort, en dood. Met in totaal 10 groepen zijn de Shannon en Simpson indices berekend. In Tabel 34 zijn de resultaten vermeld. De huidige variatie in groepsstructuur is dus op ruim $80 \%$ die van het ideale boombos met kap.

Tabel 34. Structuurparameters.

Table 34. Structure parameters.

\begin{tabular}{|l|c|c|}
\hline weighted mean recording & Shannon-index & Simpson-index \\
\hline $\mathrm{n}$ & 148 & 148 \\
mean & 1.43 & 0.69 \\
$\mathrm{sdv}$ & 0.38 & 0.10 \\
minimum & 0.89 & 0.89 \\
maximum & 0.89 & 0.89 \\
\hline theoretisal minimum & 0.00 & 0.00 \\
theoretical maximum & 2.20 & 0.89 \\
stable state & 1.75 & 0.79 \\
\hline relative score & 0.82 & 0.87 \\
\hline
\end{tabular}

\subsection{Overige aandachtspunten}

Het gevolgde systeem bij het vaststellen van de grootte van de eigenvector leidt ertoe dat de gemiddelde verhouding in grondvlakaandelen van de twee soortgroepen gefixeerd zijn bij de bepaling van de evenwichtstoestand. Het echte bos is natuurlijk veel flexibeler en verschuivingen ten gunste van schaduwverdragende boomsoorten zal zeker plaatsvinden. Door ingrepen in de vorm van enige groepenkap en kunstmatige verjonging is hier een beetje in te sturen. Maar zonder het ontstaan van grotere gaten in het boombos zullen de aandelen wintereik, zomereik, berk en grove den sterk reduceren of geheel verdwijnen. In het verleden hebben die soorten zich kunnen vestigen door storm- en brandschade. Uit de toponiemen op de beheerkaart blijkt dat vooral branden een rol hebben gespeeld, maar destijds is gekozen om de brandvlakten te herbebossen met aanplant van andere soorten, zoals bijvoorbeeld in het Van Welsumsbrandje, het Pijpenbrandje en de Varkensbrand. Wachten op dit soort calamiteiten blijft een noodzaak voor een volledig creëren van een ongelijkjarig wintereiken-beuken-bos. Mondiaal gezien zijn volgens Peters (1992) orkanen de sturende factor achter de grootschalige verjonging van natuurlijke beukenbossen, dat lijkt voor het boombos niet op te gaan. Uitkap met een rotatie van een jaar is modelmatig aangehouden, maar een langere periode zal naar verwachting geen problemen opleveren, door bijvoorbeeld verhoogde sterfte of het uitblijven van verjonging. 


\section{CONCLUSIES EN DISCUSSIE}

Er bleek wat verschil in de wijze waarop Usher (1966) en Buongiorno \& Michie (1980) een transitionmatrix definieerden. Omdat wij een meetdrempel hanteerden voor de diametermeting was het gebruik Ushers transitionmatrix niet mogelijk omdat hij de verjonging rechtstreeks kon verklaren uit de kap. Ook de wijze waarop Buongiorno \& Michie (1980) een transitionmatrix definieerden bleek in combinatie met de wijze waarop ze de kap aan het model toevoegde niet bruikbaar omdat ze daarmee een onzuivere schatter van de evenwichtstoestand creëerden. De veranderingen in het uitkapbos zijn daarom opnieuw gedefinieerd door naast de natuurlijke veranderingen groei, ingroei en sterfte ook de kap in het transitionmodel op te nemen. Voor de kansen op springen en blijven zijn twee methoden onderzocht, te weten:

- De ratioschatter;

- IPM van Easterling et al. (2000);

De ratioschatter is zuiver, IPM is het de nauwkeurigst, maar gaf een $10 \%$ overschatting van de springkansen, dat komt omdat deze geen rekening houdt, met het verloop binnen en diameterklasse. De oorspronkelijk IPM-schatter is daarom aangepast voor het verloop binnen en diameterklasse hier is een exponentiële kansdichtheid verondersteld. Hiervoor moest de $q$-waarde van De Liocourt worden geschat, de nauwkeurigheid daarvan bleek gering, omdat de diameterstamtal verdeling van het huidige bos nog te veel afweek van een uitkapbosstructuur. Er is enigszins arbitrair een vaste $q$-waarde verondersteld. Met Formule (59) zijn daarna de aangepaste IPM-schatting de springkansen berekend.

Een van de onderzoeksvragen betrof het aspect van de tijdseries. In alle onderzochte publicaties gaat het om twee waarnemingen in de tijd, wij hebben series van 4 tot 5 opnamen. Bij de ratioschatter voor springkansen en vergelijkbare schatters voor bijvoorbeeld sterfte is gekozen om niet met een stamtal van 1 stuks per boom maar met een gewicht $1 / \Delta$ t per boom te werken. Afhankelijk van de situatie moet voor de keuze van $\Delta \mathrm{t}$ (de tijd tussen twee opnamen) vooruit- of teruggekeken worden. $\mathrm{Bij}$ het werken met de regressiemodellen voor diameterbijgroei is dit opgelost met een periode-index $P I$ voor de groei tussen twee opnemen als volgt $i d=f\left(d b h\right.$, species, $\left.G_{g r, i p}\right) \cdot P I$, waarbij uiteraard geldt $\sum P I=1$. Voor de case Kolkbos bleek $R^{2}$ adj voor alleen een tweedegraadspolynoom $i d=f(d b h)$ slechts 0.015 , met toevoeging van de boomsoort, de grondvlakcomponenten voor licht, middelzwaar en zwaar hout en de periode-index steeg $R^{2}$ adj naar 0.241 . Voor de beide andere cases werd met hetzelfde model een veel betere verklaring gevonden $\left(R^{2} \mathrm{adj}>0.5\right)$.

De sterftekansen bleken bij de cases Kolkbos en Oude Trekerbos zeer gering, in het boombos waren deze wat groter. Na voorbereiding met de ratio met de gewichten en een voortschrijdend gemiddelde bleken de sterftekansen te verklaren per soort en diameter met een hyperbool, dus hoe lager de diameter hoe groter de kans op sterven ( $R^{2}$ adj varieerde van 0.460 tot 0.792 ).

De ingroei bleek niet te verklaren uit de huidige toestand van het bos, daarom is een praktische oplossing gekozen met behulp van Formule (76) die er voor zorgt dat eigenwaarde en de eigenvector van de transitionmatrix met een eigenwaarde van 1 werden geschat.

De kapkansen die behoren bij het gevoerde beheer in het Kolkbos leiden weliswaar tot een duurzame verantwoorde houtkap, maar niet tot een evenwichtstoestand met de door De Liocourt (1898) gedefinieerde vaste $q$-waarde. De gewenste kapkansen zijn daarom berekend met Formule (89). Dit is ook gebeurd bij beide andere cases. De eigenwaarde is slechts een wiskundig berekende eigenschap van een transitionmatrix en geeft de richting van deze vector aan, maar nog niet de lengte. Als schaalfactor is daartoe voor het Kolkbos en het Oude Trekerbos een waarde van $125 \%$ van het werkelijk grondvlak aangehouden. Voor het Boombos is deze op 100\% gesteld.

Het inproduct van de eerste rij van de transitionmatrix met de eigenvector levert nu het eerste element van de eigenvector op, deze zou moeten bestaan uit een component "blijvers" en "ingroeiers". 
Als het model echt in evenwicht is zou het stamtal van de ingroei $N_{R}$ gelijk moeten zijn aan de som van de verdwenen bomen door kap $N_{H}$ en sterfte $N_{M}$, dat bleek niet het geval. De verschillen zijn zeer gering (minder dan $1 \%$ verschil). Door in Formule (89) een aangepaste $q$-waarde te schatten, bleek het mogelijk om die gelijkheid wel te creëren. Maar dan is de q-waarde niet langer gelijk aan de qwaarde gebruikt in Formule (89). Aangezien deze informatie niet van belang voor de verdere verwerking en omdat de verschillen zeer gering waren, is hier geen nadere invulling aan gegeven.

De evenwichtstoestand heeft betrekking op het stamtal per ha. Er is ook berekend wat dit betekent voor het volume per ha. Daartoe is gebruikt gemaakt van de volumetarieffuncties uit de databases, hiermee zijn zowel $V_{\text {weg }}=V_{H}+V_{M}$ berekend als de lopende volumebijgroei $I c V$. Aangezien de bijgroei veelal in andere diameterklassen culmineert, waar veel volume gekapt wordt, is zo'n verschil logisch. Overigens was ook het verschil gering (ongeveer $10 \%$ ).

Om te beoordelen of het gevoerde uitkapbeheer voldoet aan de eisen van verantwoorde kap is gebruik gemaakt van Formule (1) van Heyer (1834), daarbij is een vereffeningsperiode van 30 jaar aangehouden. Dat bleek voor het Kolkbos het geval, maar in het Oude Trekerbos werd veel minder gekapt dan zou mogen volgens deze benadering. Maar aangezien in de evenwichtstoestand geldt $I C V \neq V_{H}$ is het gebruik van de formule van Heyer voor de verantwoorde kap toch geen geschikte keuze. In Hoofdstuk 1 is echter al aangegeven dat er geen bruikbare alternatieven zijn.

De gebruikte methode is ook toegepast op het Boombos, hierbij is aangenomen dat in de voormalige malenschappen dit bos deels boomsgewijs, deels via groepenkap is beheerd. Er zijn geen referenties gevonden die deze aanname onderbouwen, maar uit de huidige verschijningsvorm en de leeftijden van afzonderlijke bomen (zie Bijlage 5.2) is dit aannemelijk. Met de data van den Ouden et al. (2016) bleek ook duurzaam uitkapbeheer voor het Boombos te modelleren. Gegeven de huidige officieuze status van natuurreservaat is niet te verwachten dat dit zal worden toegepast. Maar het blijft een optie, elders in Nederland is een andere archaïsche vorm van bosbeheer, het Middenbos in ere hersteld.

Een niet te onderschatte probleem voor het beheer van de bossen in alle casestudies is de instandhouding van een zekere aandeel lichtboomsoort, zonder calamiteiten als grootschalige brand- of stormschade zullen deze sterk reduceren of geheel verdwijnen.

Met de structuurparameters Cox-index, Shannon-index en Simpson-index is onderzocht hoe gevarieerd de bossen van onze casestudie zijn en of het stamvoetenpatroon al opschuift in de richting van een poissonbos. Eigenlijk voldeed alleen het Boombos deels aan onze verwachtingen In de ander studiecase is de oorsprong (zeer kleinschalige gelijkjarige mengingen en monoculturen) nog te veel dominant.

Met het onderzoek is dus vastgesteld dat het gebruik van transitionmatrices en evenwichtstoestand van nut bij uitkapbeheer van bossen in overgang naar uitkapbos. Maar dat moet gezien worden als een wetenschappelijk antwoord.

Het praktisch nut voor het Nederlandse bosbeheer is overigens van marginale betekenis, niet alleen vanwege de gecompliceerde berekeningen, maar ook omdat uitkapbeheer voor zover ons bekend behalve op de twee besproken locaties nergens wordt toegepast. In de $4^{\mathrm{e}}$ bosstatistiek (CBS, 1985) was uitkapbos een apart terreintype, het werd in 37 opstanden gekozen, maar 5 daarvan vallen af omdat er sprake was van een kiemjaar en ook 8 opstanden vallen af omdat ze niet gemengd zijn. Resteren 24 opstanden in 1980-1984, met een gezamenlijke oppervlakte van 57 ha, waar sprake was van een ongelijkjarig gemend bos. Daarvan bestaat $70 \%$ uit gemengd naald/loofhout, $5 \%$ uit gemengd naaldhout en $25 \%$ uit gemengd loofhout. Dit gaat om individuele opstanden met oppervlakte variërend van 0.4 tot 9.1 ha. Geen daarvan lag in het Kolkbos of Oude Trekerbos en ook niet in twee andere bekende bosgebieden met een kleinschalige gemengde en deels ongelijkjarige bosstructuur de Emmerdennen en het Zeisterbos. Deze twee laatste twee locaties stonden destijds op de nominatie om er proefperken in aan te leggen, maar daar zijn we nooit aan toegekomen.

Boombos komt met 608 ha (CBS, 1985) overigens wel vaker voor. 


\section{SAMENVATTING}

Tussen 1984 en 2012 zijn er 3 studies verricht met permanente (steek)proefperken in ongelijkjarig gemengd bos. Alle data zijn beschikbaar in databases, dat betreffen 3 locaties te weten het Kolkbos, zie voor de database De Klein et al. (2016), het Oude Trekerbos, zie Jansen et al. (2016) en het Boombos van Speuld, zie Den Ouden et al. (2016). In dit rapport zijn die data geanalyseerd met stochastische transitionmatrices (Usher, 1966), waarbij een verwachte evenwichtssituatie met behulp van de eigenwaarde-methode is bepaald, die voldoet aan curve van De Liocourt (1798). De transitionmatrices bevatten anders dan bij Usher (1966) en Buongiorno \& Michie (1980) naast natuurlijke veranderingen (groei, ingroei en sterfte) ook kunstmatige veranderingen (uitkap). De kansen op springen (diametergroei waarbij de diameter één klasse opschuift) zijn berekend met twee verschillende methoden (ratioschatter en IPM). Gekozen is voor IPM van Easterling et al. (2000), vanwege de nauwkeurigheid. De IPM-schatter is gebaseerd op de schatter van de diameterbijgroei, deze bleek te schatten met een tweedegraadspolynoom in $d b h$ aan gevuld met een grondvlakcomponent, vermenigvuldigd met een periode-index $P I$ :

$$
\begin{aligned}
\hat{i d_{i}}= & f(d, s g, G, g r) \cdot P I_{j}\left(\Delta t_{j}\right)+\sigma_{\underline{\boldsymbol{e}}_{i d}} \\
& \text { met } \sum_{j=1}^{j_{\text {mat }}} P I_{j}=1 \text { en } f(d, s g, G, g r) i d_{i j}=c_{0}\left(s g_{i}\right)+c_{1}\left(s g_{i}\right) \cdot d_{i j}+c_{2}\left(s g_{i}\right) \cdot d_{i j}^{2}+\sum_{g r=1}^{3} b_{g r} \cdot G_{g r, j, i p} \\
& \text { met verschillende waarden voor } c_{0}, c_{1} \text { en } c_{2} \text { per soortgroep } s g \\
& G_{G r, j, i p}=\text { grondvlak per ha per groep op } t_{j} \text { of het } i p^{\text {de }} \text { plot met de groepen: } \\
& \mathrm{L} \text { (= licht hout) }(d b h \leq 30 \mathrm{~cm}), \mathrm{M}(=\text { middelzwaar hout) }(30<d b h \leq 50 \mathrm{~cm}) \text { en Z (= zwaar hout) }(d b h>50 \mathrm{~cm})
\end{aligned}
$$

Voor het boombos is deze functie enigszins gemodificeerd. De nauwkeurigheid bleek gering, voor het Kolkbos $R^{2}$ adj $=0.246$, voor het oude Trekerbos 0.549 en voor het boombos 0.517 .

IPM is vervolgens gemodificeerd in verband met een negatief exponentiële kansdichtheid binnen een diameterklasse, door niet steeds 1 boom maar $p_{d}$ bomen te laten groeien bij iedere $j^{\mathrm{e}}$ stap in de numerieke integratie in het IPM-model. Bij een numerieke integratie met stappen van $0.01 \mathrm{~cm}$, klassebreedte van $4 \mathrm{~cm}$ en een ondergrens $d_{0}$ binnen de klasse volgt $p_{d_{j}}=\frac{e^{-\lambda \cdot\left(d_{j}-0.005\right)}-e^{-\lambda \cdot\left(d_{j}+0.005\right)}}{e^{-\lambda \cdot\left(d_{0}\right)}-e^{-\lambda \cdot\left(d_{0}+4\right)}}$. Door deze aanpassing vallen de berekende springkansen ongeveer $10 \%$ lager uit dan berekend zonder deze $p_{d}$ correctie.

Sterftekansen zijn berekend met een ratioschatter, ze bleken gering en niet onderscheidend genoeg per soortgroep en diameterklasse, daarom is met een voortschrijdend gemiddelde gewerkt De aldus berekende kansen zijn gefit met de hyperbool $\underline{p}_{M}=b_{0}+b_{1} / d b h$ met verschillende parameters voor de boomsoortgroepen, met $R^{2}$ adj variërend van 0.460 tot 0.792 .

Voor het berekenen van het grondvlak per ha per diameterklasse wordt normalter de correctie van Sheppard gebuikt, maar deze is gebaseerd op een uniforme kansdichtheid, daarom is ook hier de $p_{d}$ correctie gebruikt. De volumetarieffunctie $v_{i}=c_{0} \cdot d b h^{c_{1}}$ van Berkhout (1922) is gebruikt en per klasse is ook hier de $p_{d}$ correctie toegepast.

De modellen bleken bruikbaar en uitkap is mogelijk op de experimentele locaties Kolkbos en Oude Trekerbos. Er zijn daarbij nieuwe kappercentage bepaald waarmee het proces te versnellen is. Zonder af en toe grootschalige ingrepen (kap, brand of storm) zullen de lichtboomsoorten verdwijnen. Het geoogst volume in het Kolkbos bleek te voldoen aan de verantwoorde kap van Heyer (1841). Er zijn aanwijzingen gevonden dat het Boombos middels uitkap en groepenkap beheerd werd. Anders dan jarenlang verondersteld werd, verjongt boombos zich probleemloos. 


\section{SUMMARY}

Between 1984 and 2012, 3 studies were carried out in permanent experimental and permanent sample plots in uneven-aged mixed forests. In two studies selection cutting was practised and in one study stand development without harvest was monitored. All data are made available in databases, concerning three locations namely Kolkbos (De Klein et al. 2016), Oude Trekerbos (Jansen et al. 2016) and Boombos (Den Ouden et al. 2016). Here, these data are analyzed using stochastic transition matrices (Usher, 1966), with the expected stable sate determined using the eigenvector method, according to De Lioucourt (1798). Unlike Usher (1966) and Buongiorno \& Michie (1980), transition matrices contain natural changes (growth, ingrowth and mortality) as well as artificial changes (harvest). The probabilities for moving up (diameter increment in which the tree diameter moves up one class) were calculated using 2 different method (ratio estimator and IPM). IPM as described by Easterling et al. (2000) was chosen, because of the accuracy of the estimator, based on a description of diameter growth, using a second-degree polynomial in $d b h$, and further a basal area component, multiplied by a period index Pl:

$$
\begin{aligned}
\hat{i d}_{i}= & f(d, s g, G, g r) \cdot P I_{j}\left(\Delta t_{j}\right)+\sigma_{\underline{e}_{i d_{i}}} \\
& \text { where } \sum_{j=1}^{j_{\text {max }}} P I_{j}=1 \text { and } f(d, s g, G, g r) i d_{i j}=c_{0}\left(s g_{i}\right)+c_{1}\left(s g_{i}\right) \cdot d_{i j}+c_{2}\left(s g_{i}\right) \cdot d_{i j}^{2}+\sum_{g r=1}^{3} b_{g r} \cdot G_{g r, j, i p} \\
& \text { with different value for } c_{0}, c_{1} \text { and } c_{2} \text { per species group } s g \\
& G_{G r, j, i p}=\text { basal area per ha per group at } t_{j} \text { of the } i p^{\text {th }} \text { plot with the groups } \\
& \mathrm{L}(=\text { light timber) }(d b h \leq 30 \mathrm{~cm}), \mathrm{M}(=\text { medium timber) }(30<d b h \leq 50 \mathrm{~cm}) \text { and } \mathrm{Z} \text { (= heavy timber })(d b h>50 \mathrm{~cm})
\end{aligned}
$$

For the Boombos site, this function was slightly modified. The accuracy turned out to be low, with $R^{2}$ adj equal to 0.246 for Kolkbos, 0.549 for Oude Trekerbos and 0.517 for Boombos.

Next, the IPM model was modified using a negative exponential probability density within a diameter class, by not growing 1 tree but $p_{d}$ trees at every step in the numerical integration in the IPM model. With a numerical integration with steps of $0.01 \mathrm{~cm}$, a $4 \mathrm{~cm}$ class width and a lower boundary $d_{0}$ within the class follows $p_{d_{j}}=\frac{e^{-\lambda \cdot\left(d_{j}-0.005\right)}-e^{-\lambda \cdot\left(d_{j}+0.005\right)}}{e^{-\lambda \cdot\left(d_{0}\right)}-e^{-\lambda \cdot\left(d_{0}+4\right)}}$.

Due to this adjustment, the calculated moving-up probabilities were $10 \%$ lower than calculated without this $p_{d}$ correction.

Mortality rates were calculated with a ratio estimator, they were found to be low and not significantly different enough per species group and diameter class, therefore a running average was used and the probability was estimated using a hyperbola: $\underline{p}_{M}=b_{0}+b_{1} / d b h$ with different parameters for species groups. The $R^{2}$ adj varies from van 0.460 to 0.792 .

For the calculation of the basal area per ha per diameter class, Sheppard's correction is normally used. As this is based on a uniform probability density, a $p_{d}$ correction was used here, corresponding to the adjusted probability distribution for moving up as described above. The same correction was used for the application of Berkhout 's (1922) volume tariff function $v_{i}=c_{0} \cdot d b h^{c_{1}}$ in the calculation of the volume per diameter class, species group, and per ha.

The models proved useful and selection cut was possible at the experimental locations Kolkbos and Oude Trekerbos. A new harvest percentage was been determined to accelerate the process. Using selection cutting, the light demanding tree species will disappear without occasional largescale interventions (group cutting, fire or storm).

The harvested volume in Kolkbos was found to meet the allowable cut of Heyer (1834). For Boombos, there are indications that the forest was managed partly by means of selection cut and partly by group cut. In contrast to previous assumptions, the Boombos plot has no regeneration problems. 


\section{LITERATUUR}

Berkhout, A.H., 1922. Het berekenen van den aanwas bij grove dennen in Nederland. Mededeelingen van de Landbouwhoogeschool en van de daaraan verbonden instituten 23. Veenman, Wageningen.

Bonnor, G.M. and S.Magnussen, 1987, Predicting stem diameter distributions from growth probability equations,

Buongiorno, J. and B.R. Mitchie, 1980. A matrix model of uneven-aged forest mangement. Forest Sci 26: 609-635.

Biolley, H., 1920. L' Amenagement des forets par la methode experimentale et specialement la methode du contrôle. Paris Attinger freres, 108 p., Paris-Neuchatel

Brandis, D. 1897. Indian Forestry. Woking : Oriental University Institute.

Buis, J., 1985 Historia forestis : Nederlandse bosgeschiedenis. Dissertation, Landbouwhogeschool Wageningen.

C.B.S. (Centraal Bureau voor de Statistiek), 1985. De Nederlandse Bosstatistiek, deel 1: de oppervlakte bos,1980 1983. Staatsuitgeverij, s'Gravenhage

Cox, D. R. and P. A. W. Lewis, 1966. The Statistical Analysis of Series of Events. London: Methuen

Daamen, W. en H. Schoonderwoerd, 1990. Bijgroeischatters voor individuele bomen in bosverband. Projekt "Houtoogststatistiek en Prognose Oogstbaar Hout". Verwerking gegevens heropname steekproefpunten, onderdeel bijgroei. Rapportserie nr. 10 Bureau Daamen \& Schoonderwoerd.

Dawkins, H.C., 1956. Crown classification of natural forest trees. Uganda Forest Department Technical Note 17/56 2pp.

De Klein, J.P.G en J.J. Jansen, 1992. Planning en controle in ongelijkjarig bos, Nederlands Bosbouwtijdschrift 64: 313-322.

De Klein, J.P.G. , J.J. Jansen, G.M.J. Mohren \& J. den Ouden, 2016. FEM growth and yield data Selection forest - Kolkbos. DANS: https://doi.org/10.17026/dans-zt3-7qfc.

De Klein, J.P.G, A.M. Filius en J.J.Jansen, 1997. Inleiding Bosbeheer en Bosteelt. Bosbeheer Collegediktaat 06038305 bij het vak F500-205. Landbowuniversiteit Wageningen.

De Liocourt, F., 1898. De l'amenagement des sapinires. Bull. Soc. Forest. Franche-Comte et Belfort. 6: 369- 405. In: Picard, N. \& D. Gasparotto., 2016. Liocourt's law for tree diameter distribution in forest stands. Annals of Forest Science 73: 751-755.

Den Ouden, J., J.J. Jansen, L.G. Goudzwaard, J.F. Oldenburger,\& G.M.J. Mohren. 2016. FEM growth and yield data - Uneven-aged - Beech-Oak. Dans: http://dx.doi.org/10.17026/dans-zdq-b8vz.

De Vries, P.G., 1986. Sampling theory for forest inventory, a teach-yourself course. Springer Verlag Berlin Heidelberg New York. 399 p.

Easterling, M.R., Ellner, S.P. \& Dixon, P.M., 2000. Size-specific sensitivity: applying a new structured population model. Ecology 81: 694-708.

Essed, F.E., 1957. Estimation of standing timber. Dissertation Wageningen. H. Veenman \& Zonen, Wageningen.

Harrison, T.P. and B.R. Mitchie, 1985. A generalized Approach to the Use of Matrix Growth Models, Forest Sci. 31: 850-856.

Heyer, C. 1841. Die Waldertrags-Regelung, Gießen, Ferber

Haight, R.G., J.D. Brodie and D,M. Adams, 1985. Optimizing the sequence of diameter distributions and selection harvests for uneven-aged stand management. ForestSci. 31: 451- 462.

Jansen, J.J., J.P.G. de Klein, G.M.J. Mohren \& J. den Ouden, 2016. FEM growth and yield data Selection forest - Het Oude Trekerbos. DANS: http://dx.doi.org/10.17026/dans-29d-qffx

Kalman, R.E., 1960. A New Approach to Linear Filtering and Prediction Problems. Journal of Basic Engineering 82: 35-45.

Kraft G., 1884. Beiträge zur Lehre von den Durchforstungen, Schlagstellungen und Lichtungshieben. Hannover. 
Leak, W.B., 1965. The J-shaped probability distribution. Forest Sci. 11: 405-409.

Lefkovitch, L.P., 1965. The population growth of organisms grouped by stages. Biometrics 21: 118.

Leibundgut, H., 1978. Die waldpflege (unter Mitverwendung von "Auslesedurchforstung als Erziehungsbetrieb höchster Wertleistung" von Walter Schädelin 1966. P.Haupt, Bern.

Leslie, P.H., 1945. The use of matrices in certain population mathematics. Biometrika, 33: 183212

Mendoza, G.A. \& Setyarso, A. 1986. A transition matrix forest growth model for evaluating alternative harvesting schemes in Indonesia. Forest Ecology and Management 15: 219228.

Metcalf, C.J.E., S.M. McMahon, R.Salguero-Gomez and E. Jongejans, 2013. IPMpack: an R package for integral projectionmodels. Methods in Ecology and Evolution 4: 195-200. https://doi.org/10.1111/2041-210x.12001

Meyer, H.A., 1933. Eine mathematisch-statistische Untersuchung tiber den Aufbau des Plenterwaldes. Schweiz. Zeitschr. Z. Forstwesen 84: 33-40, 88-103, 124-131.

Mitchie, B.R. and J. Buongiorno, 1984. Estimation of a matrix model of forest growth from remeasured permanent plots. Forest Ecology and Management 8:127-135.

Morisito, M. 1954. Estimation of population density by spacing method. Kyushu Univ. Mem. Fac. Sci. Vol. 1(E), pp 187-197.

Oosterbaan, A. en G. van Tol, 1984. Natuurlijke verjonging van beuk op holtpodzolgronden. Nederlans Bosbouw Tijdschrift 56: $145-153$

Picard, N. \& D. Gasparotto., 2016. Liocourt's law for tree diameter distribution in forest stands. Annals of Forest Science 73:751-755. DOI 10.1007/s13595-016-0563-4

Peters, R., 1992. Ecology of beech forests in the northern hemisphere. Dissertatie Landbouwuniversiteit Wageningen

Prodan. M., 1949. Die theoretische Bestimmung des Gleichgewichtszustandes im Plenterwalde. Schweiz. Zeitschr. f. Forstwesen 100: 81-99.

Pukkala T. and T. Kolström, 1988. Simulation of the development of Norway Spruce stands using a Transition matrix. Forest Ecology and Management 25: 255-267.

Schmidt(-Haas), P., 1969. Stichproben am Waldrand. Mitteilungen Schweizerische Anstalt fiir das forstliche Versuchwesen 45: 234-318.

Schoonderwoerd, H. 1993. Schatters voor de grondvlakbijgroei van individuele bomen. Rapport / Maatschap Daamen Schoonderwoerd Miedema \& de Klein 38, 35 p.

Shannon, C E., 1948. "A Mathematical Theory of Communication". Bell System Technical Journal. 27: 379-423.

Shifley, R.E., A.R. Ek and T.E. Burk, 1993. A Generalized Methodology for Estimating Forest Ingrowth at Multiple Threshold Diameters. Forest Sci. 39: 776-798.

Simpson, E.H., 1949. Measurement of diversity. Nature 163: 688.

Usher, M.B., 1966. A matrix approach to the management of renewable resources with special reference to selection forests. Journal of Applied Ecology 6: 355-367.

Vanclay, J.K., 1991, Aggregating tree species to develop diameter increment equations for tropical rainforests, Forest Ecology and Management 42: 143-168.

Vanclay, J.K., 1995. Growth models for tropical forests: a synthesis of models and methods, Forest Sci. 41: 7-42.

Zuidema, P.A., Jongejans, E., Chien, P.D., During, H.J. \& Schieving, F., 2010. Integral Projection Models for trees: a new parameterization method and a validation of model output. Journal of Ecology, 98, 345-355. https://doi.org/10.1111/j.1365-2745.2009.01626.x 


\section{BIJLAGE 1. LIJST MET SYMBOLEN/LIST WITH SYMBOLS}

a parameter in regressiemodel/ parameter in regression model

AC verantwoorde kap/ allowable cut

$b_{g r} \quad$ parameter in regressiemodel voor een groep/ parameter in regression model for a group

c parameter in regressiemodel/ parameter in regression model

array met regressiecoëfficiënten/ array with regression coefficients

$d$ boomdiameter op borsthoogte /diameter breast height

dbh als $d /$ see $d$

$D_{0} \quad$ meetdrempel diametermeting bij inventarisatie/ threshold for diameter measurement during recording

$\Delta k \quad$ aantal diameterklassen dat boom door groei opschuift/number of moving up classes

$\Delta t \quad$ tijd tussen opname op $t_{j}$ en $t_{j+1} /$ time between the recordings at $t_{j}$ and $t_{j+1}$

e grondgetal natuurlijke logaritme/ base of natural logarithm

$\vec{e} \quad$ eigenvector/ eigenvector

e gestandaardiseerde errorterm/ standardized error term

$\varepsilon \quad$ symbool voor verwachting van stochastische variabele/ symbol for the expectation of a stochastically variable

$f(. .$.$) \quad functie in regressievergelijkingen/ function in regression equation$

$f_{z}$

fpc

G continue kansdichtheid (van z)/ continuous probability density (of z)

Ggr

$G_{L}$ grondvlak in $\mathrm{m}^{2} \mathrm{ha} \mathrm{a}^{-1}$ / basal area in $\mathrm{m}^{2} \mathrm{ha} \mathrm{a}^{-1}$ grondvlak voor een groep bomen/ basal area for a group of trees grondvlak van licht hout $(d b h \leq 30 \mathrm{~cm}) /$ basal area of light timber $(d b h \leq 30 \mathrm{~cm})$ grondvlak van middelzwaar hout $(30<d b h \leq 50 \mathrm{~cm}) /$ basal area of intermediate timber $(30<d b h \leq 50 \mathrm{~cm})$

grondvlak van zwaar hout $(d b h>50 \mathrm{~cm}) /$ basal area of heavy timber $(d b h>50 \mathrm{~cm})$ boomhoogte/ tree height index voor oogst/ index for harvest functie $h$ van variabele $z$ (bij waarschijlijkheidstransformaties)/ function $h$ for variable $z$ (for probability transformation) index (betekenis verschilt per formule)/ index (meaning differs per formula) lopende (volume)bijgroei/ current volume increment diameterbijgroei per jaar/ diameter increment per year index voor plotnummer/index foe plot number index voor het opnamenummer/ index for recording number diameterklasse/ diameter class index voor tijdelijk gebruik/ index for temporarily use eigenwaarde/eigenvalue parameter van exponentiele kansdichtheid/ parameter in exponential density hulpvariabele, betekenis verschil per formule/ auxiliary variable, meaning differs per formula hulpvariabele, betekenis verschil per formule/ auxiliary variable, meaning differs per formula index voor maximale waarde van variabele/index for maximal value of a variable index voor meetfout/ index for measuring error index voor sterfte/ index for mortality totaal aantal bomen/total number of trees aantal boomsoortgroepen/number of species groups nulvector/ zero vector alle mogelijke gebeurtenissen/all possible events 


\begin{tabular}{|c|c|}
\hline $\mathbf{P}$ & verwachting van transitionmatrix $\underline{\mathbf{T}}$ /expectation of transition matrix $\underline{\mathbf{T}}$ \\
\hline$p_{G, 1 k}$ & $\begin{array}{l}\text { springkansen (element uit matrix } \mathbf{P} \text { ) voor een jaar/ moving up probabilities (element of } \\
\text { matrix } \mathbf{P} \text { ) for one year }\end{array}$ \\
\hline PI & periode-index/ period index \\
\hline$p_{H}$ & kapkans/ harvest probability \\
\hline$p_{M}$ & sterftekans/ mortality rate \\
\hline$P_{R}$ & ingroeikans/ingrowth probability \\
\hline$q$ & constante van de Liocourt/constant of de Liocourt \\
\hline$\vec{r}$ & $\begin{array}{l}\text { hulparray om lineaire combinatie van regressiecoëfficiënten te maken/ auxiliary array to } \\
\text { create a linear combination of regression coefficients }\end{array}$ \\
\hline $\mathrm{R}$ & index voor ingroei en verjonging/ index for ingrowth and regeneration \\
\hline$s g$ & boomsoortgroep/tree species group \\
\hline$\sigma$ & standaard afwijking/ standard deviation \\
\hline$t$ & tijd/time \\
\hline$\underline{t}_{i j}$ & element in $i^{\mathrm{e}}$ rij en $j^{\mathrm{e}}$ kolom in $\underline{\mathbf{T}}$ / element op $i^{\mathrm{e}}$ rij en $j^{\mathrm{e}}$ column $\ln \underline{\mathbf{T}}$ \\
\hline$t_{a d j}$ & vereffeningsperiode/ adjusting time \\
\hline$\underline{\mathbf{T}}$ & $\begin{array}{l}\text { stochastische transitionmatrix voor groei, sterfte, ingroei of verjonging en kap/ stochas- } \\
\text { tic transition matrix for growth, mortality, ingrowth or regeneration and harvest }\end{array}$ \\
\hline$\underline{t}_{G, \Delta k, k}$ & $\begin{array}{l}\text { groei van } \Delta k \text { klassen, indien bestaande boomklasse } k \text { is ( element uit matrix } \underline{\mathbf{T}} \text { )/ growth } \\
\text { of } \Delta k \text { classes, for a tree in tree class } k \text { element of matrix } \underline{\mathbf{T}} \text { ) }\end{array}$ \\
\hline$\underline{t}_{H, k}$ & kap in boomklasse $k$ (element uit matrix $\underline{\mathbf{T}}$ )/ harvest in tree class $k$ (element of matrix $\underline{\mathbf{I}}$ ) \\
\hline$\underline{t}_{M, k}$ & $\begin{array}{l}\text { sterfte voor boomklasse (element uit matrix } \underline{\mathbf{T}} \text { )/ mortality in tree class } k \text { element of ma- } \\
\text { trix } \mathbf{I} \text { ) }\end{array}$ \\
\hline$\mu$ & hulpvariabele/ auxiliary variable \\
\hline$v$ & hulpvariabele/ auxiliary variable \\
\hline v & boomvolume/ tree volume \\
\hline$V$ or $V_{w}$ & werkelijke opstandsvolume/ actual stand volume \\
\hline$V_{n}$ & normale volume/ normal volume \\
\hline var & variantie/ variance \\
\hline$w$ & breedte van de diameterklassen/width of diameter class \\
\hline$w g t$ & gewicht bij tijdseries tussen opnamen bij ratioschatters/ ratio weight in time series \\
\hline$\vec{y}$ & vector met boomklasse-frequenties /vector with tree class frequencies \\
\hline$y_{j, k}$ & $\begin{array}{l}k^{\mathrm{e}} \text { element van de boomklasse- vector bij } j^{\mathrm{e}} \text { opname } / k^{\text {th }} \text { element of the tree class vector } \\
\text { in } j^{\text {th }} \text { recording }\end{array}$ \\
\hline$y_{H, k}$ & $\begin{array}{l}k^{\mathrm{e}} \text { element van de boomklassevector met alleen gekapte bomen/ } k^{\text {th }} \text { element of the tree } \\
\text { class vector with only harvested trees }\end{array}$ \\
\hline$y_{M, k}$ & $\begin{array}{l}k^{\mathrm{e}} \text { element van de boomklassevector met alleen dode bomen } / k^{\text {th }} \text { element of the tree } \\
\text { class vector with only dead trees }\end{array}$ \\
\hline$z$ & $\begin{array}{l}\text { hulpvariabele, betekenis verschilt per formule/ auxiliary variable, meaning differs per } \\
\text { formula }\end{array}$ \\
\hline$Z$ & $\begin{array}{l}\text { hulpvariabele (matrix) met verklarende variabelen in regressiemodel/ auxiliary variable } \\
\text { (matrix) with dependent variables in regression model }\end{array}$ \\
\hline
\end{tabular}

\footnotetext{
$\boldsymbol{P}^{(m)} \quad \boldsymbol{P} \cdot \boldsymbol{P} \cdot \boldsymbol{P} \ldots \boldsymbol{P}$ (product van $m$ matrices $\left.\boldsymbol{P}\right) /$ product of $m$ matrices

$\overrightarrow{v a r} \quad$ pijl boven variabele wil zeggen variabele is vector/ arrow above variable defines an array $\overline{v a r} \quad$ streep boven variabele wil zeggen gemiddelde waarde van de variabele/ line above a variable indicates an average value

var onderstreepte variabele betreft een stochastische variabele/ underscore variable refers a stochastically variable
} 
Var dakje boven variabele betreft een schatter van variabele/ circumflex above a variable refers to an estimated value

$a \mid b \quad a$ geldt onder de voorwaarde $b / a$ applies under the condition $b$ 


\section{BIJLAGE 2. EVENWICHTSTOESTAND KOLKBOS}

In Tabel 10 Staan de kapkansen vermeld bij oogst met het doel een q-waarde van 1.25 te realiseren.

Gevonden werd een stamtal-, grondvlak- en volumeverdeling zoals weergegeven in de tabellen B2-1, B2-2 en B2-3 en de Figuren B2-1, B2-2 en B2-3.

Tabel B2-1. Stamtal per ha per soortgroep en diameterklasse in evenwichtstoestand in Kolkbos.

Table B2-1. Number of trees per ha per species group and diameter class in stable state in Kolkbos.

\begin{tabular}{|c|c|c|c|c|c|c|c|c|}
\hline \multirow{2}{*}{$\begin{array}{l}\text { diameter } \\
\text { in } \mathrm{cm}\end{array}$} & \multicolumn{8}{|c|}{ species group } \\
\hline & DF & GF & SP & con & CB & CO & n.c. & total \\
\hline $12-16$ & 49.5 & 6.9 & 5.0 & 6.8 & 11.3 & 7.5 & 8.9 & 96.0 \\
\hline $16-20$ & 39.6 & 5.5 & 2.8 & 5.2 & 9.0 & 4.3 & 7.1 & 73.6 \\
\hline $20-24$ & 33.0 & 4.9 & 2.2 & 4.5 & 7.4 & 3.4 & 6.3 & 61.7 \\
\hline $24-28$ & 26.4 & 3.9 & 1.7 & 3.6 & 5.9 & 2.6 & 5.0 & 49.1 \\
\hline $28-32$ & 21.1 & 3.1 & 1.3 & 2.9 & 4.7 & 2.1 & 4.0 & 39.3 \\
\hline $32-36$ & 16.9 & 2.5 & 1.1 & 2.3 & 3.8 & 1.8 & 3.2 & 31.6 \\
\hline $36-40$ & 13.5 & 2.0 & 0.9 & 1.8 & 3.0 & 1.4 & 2.6 & 25.3 \\
\hline $40-44$ & 10.8 & 1.6 & 0.7 & 1.5 & 2.4 & 1.1 & 2.1 & 20.2 \\
\hline $44-48$ & 8.6 & 1.3 & 0.6 & 1.2 & 1.9 & 0.9 & 1.6 & 16.2 \\
\hline $48-52$ & 6.9 & 1.0 & 0.5 & 0.9 & 1.6 & 0.7 & 1.3 & 12.9 \\
\hline $52-56$ & 5.5 & 0.8 & 0.4 & 0.7 & 1.2 & 0.6 & 1.1 & 10.4 \\
\hline $56-60$ & 4.4 & 0.7 & 0.3 & 0.6 & 1.0 & 0.5 & 0.8 & 8.3 \\
\hline $60-64$ & 3.5 & 0.5 & 0.2 & 0.5 & 0.8 & 0.4 & 0.7 & 6.6 \\
\hline $64-68$ & 2.8 & 0.4 & 0.2 & 0.4 & 0.6 & 0.3 & 0.5 & 5.3 \\
\hline$\geq 68$ & 2.3 & 0.3 & 0.2 & 0.3 & 0.5 & 0.2 & 0.4 & 4.2 \\
\hline Total & 245.0 & 35.4 & 18.1 & 33.2 & 55.4 & 27.9 & 45.8 & 460.7 \\
\hline
\end{tabular}

Tabel B2-2. Grondvlak in $\mathrm{m}^{2}$ per ha per soortgroep en diameterklasse in evenwichtstoestand in Kolkbos

Table B2-2. Basal area in $\mathrm{m}^{2}$ per ha per species group and diameter class in stable state in Kolkbos.

\begin{tabular}{|c|c|c|c|c|c|c|c|c|}
\hline \multirow{2}{*}{$\begin{array}{l}\text { diameter } \\
\text { in } \mathrm{cm}\end{array}$} & \multicolumn{8}{|c|}{ species group } \\
\hline & DF & GF & SP & con & CB & CO & n.c. & total \\
\hline $12-16$ & 0.8 & 0.1 & 0.1 & 0.1 & 0.2 & 0.1 & 0.1 & 1.5 \\
\hline $16-20$ & 1.0 & 0.1 & 0.1 & 0.1 & 0.2 & 0.1 & 0.2 & 1.9 \\
\hline $20-24$ & 1.3 & 0.2 & 0.1 & 0.2 & 0.3 & 0.1 & 0.2 & 2.4 \\
\hline $24-28$ & 1.4 & 0.2 & 0.1 & 0.2 & 0.3 & 0.1 & 0.3 & 2.6 \\
\hline $28-32$ & 1.5 & 0.2 & 0.1 & 0.2 & 0.3 & 0.1 & 0.3 & 2.8 \\
\hline $32-36$ & 1.5 & 0.2 & 0.1 & 0.2 & 0.3 & 0.2 & 0.3 & 2.9 \\
\hline $36-40$ & 1.5 & 0.2 & 0.1 & 0.2 & 0.3 & 0.2 & 0.3 & 2.9 \\
\hline $40-44$ & 1.5 & 0.2 & 0.1 & 0.2 & 0.3 & 0.2 & 0.3 & 2.8 \\
\hline $44-48$ & 1.4 & 0.2 & 0.1 & 0.2 & 0.3 & 0.2 & 0.3 & 2.7 \\
\hline $48-52$ & 1.4 & 0.2 & 0.1 & 0.2 & 0.3 & 0.1 & 0.3 & 2.6 \\
\hline $52-56$ & 1.3 & 0.2 & 0.1 & 0.2 & 0.3 & 0.1 & 0.2 & 2.4 \\
\hline $56-60$ & 1.2 & 0.2 & 0.1 & 0.2 & 0.3 & 0.1 & 0.2 & 2.2 \\
\hline $60-64$ & 1.1 & 0.2 & 0.1 & 0.1 & 0.2 & 0.1 & 0.2 & 2.0 \\
\hline $64-68$ & 1.0 & 0.1 & 0.1 & 0.1 & 0.2 & 0.1 & 0.2 & 1.8 \\
\hline$\geq 68$ & 0.9 & 0.1 & 0.1 & 0.1 & 0.2 & 0.1 & 0.2 & 1.6 \\
\hline Total & 18.7 & 2.7 & 1.3 & 2.5 & 4.2 & 2.0 & 3.6 & 35.0 \\
\hline
\end{tabular}


Tabel B2-3 Volume in $\mathrm{m}^{3}$ per ha per soortgroep en diameterklasse in evenwichtstoestand in Kolkbos

Table B2-3. Volume in $\mathrm{m}^{3}$ per ha per species group and diameter class in stable state in Kolkbos.

\begin{tabular}{|c|c|c|c|c|c|c|c|c|}
\hline \multirow{2}{*}{$\begin{array}{c}\text { diameter } \\
\text { in } \mathbf{c m}\end{array}$} & \multicolumn{8}{|c|}{ species group } \\
\hline & DF & GF & SP & con & CB & CO & n.c. & total \\
\hline $12-16$ & 4.9 & 0.9 & 0.7 & 0.9 & 1.5 & 1.0 & 1.1 & 11.1 \\
\hline $16-20$ & 7.3 & 1.3 & 0.7 & 1.2 & 2.1 & 1.0 & 1.5 & 15.1 \\
\hline $20-24$ & 9.8 & 1.8 & 0.8 & 1.6 & 2.7 & 1.3 & 2.1 & 20.2 \\
\hline $24-28$ & 11.8 & 2.1 & 0.9 & 1.9 & 3.2 & 1.4 & 2.4 & 23.7 \\
\hline $28-32$ & 13.4 & 2.3 & 1.0 & 2.1 & 3.5 & 1.5 & 2.7 & 26.5 \\
\hline $32-36$ & 14.6 & 2.4 & 1.1 & 2.2 & 3.7 & 1.7 & 2.8 & 28.6 \\
\hline $36-40$ & 15.4 & 2.5 & 1.1 & 2.3 & 3.8 & 1.8 & 2.9 & 29.7 \\
\hline $40-44$ & 15.7 & 2.5 & 1.1 & 2.3 & 3.8 & 1.8 & 2.9 & 30.1 \\
\hline $44-48$ & 15.7 & 2.4 & 1.1 & 2.2 & 3.7 & 1.8 & 2.8 & 29.8 \\
\hline $48-52$ & 15.4 & 2.3 & 1.1 & 2.2 & 3.6 & 1.7 & 2.7 & 29.0 \\
\hline $52-56$ & 14.9 & 2.2 & 1.0 & 2.1 & 3.4 & 1.6 & 2.6 & 27.8 \\
\hline $56-60$ & 14.2 & 2.1 & 1.0 & 1.9 & 3.2 & 1.5 & 2.4 & 26.3 \\
\hline $60-64$ & 13.4 & 1.9 & 0.9 & 1.8 & 3.0 & 1.4 & 2.3 & 24.6 \\
\hline $64-68$ & 12.5 & 1.8 & 0.8 & 1.6 & 2.7 & 1.3 & 2.1 & 22.8 \\
\hline$\geq 68$ & 11.5 & 1.6 & 0.7 & 1.5 & 2.5 & 1.2 & 1.9 & 21.0 \\
\hline Total & 190.5 & 30.3 & 14.0 & 27.9 & 46.5 & 21.9 & 35.2 & 366.4 \\
\hline
\end{tabular}

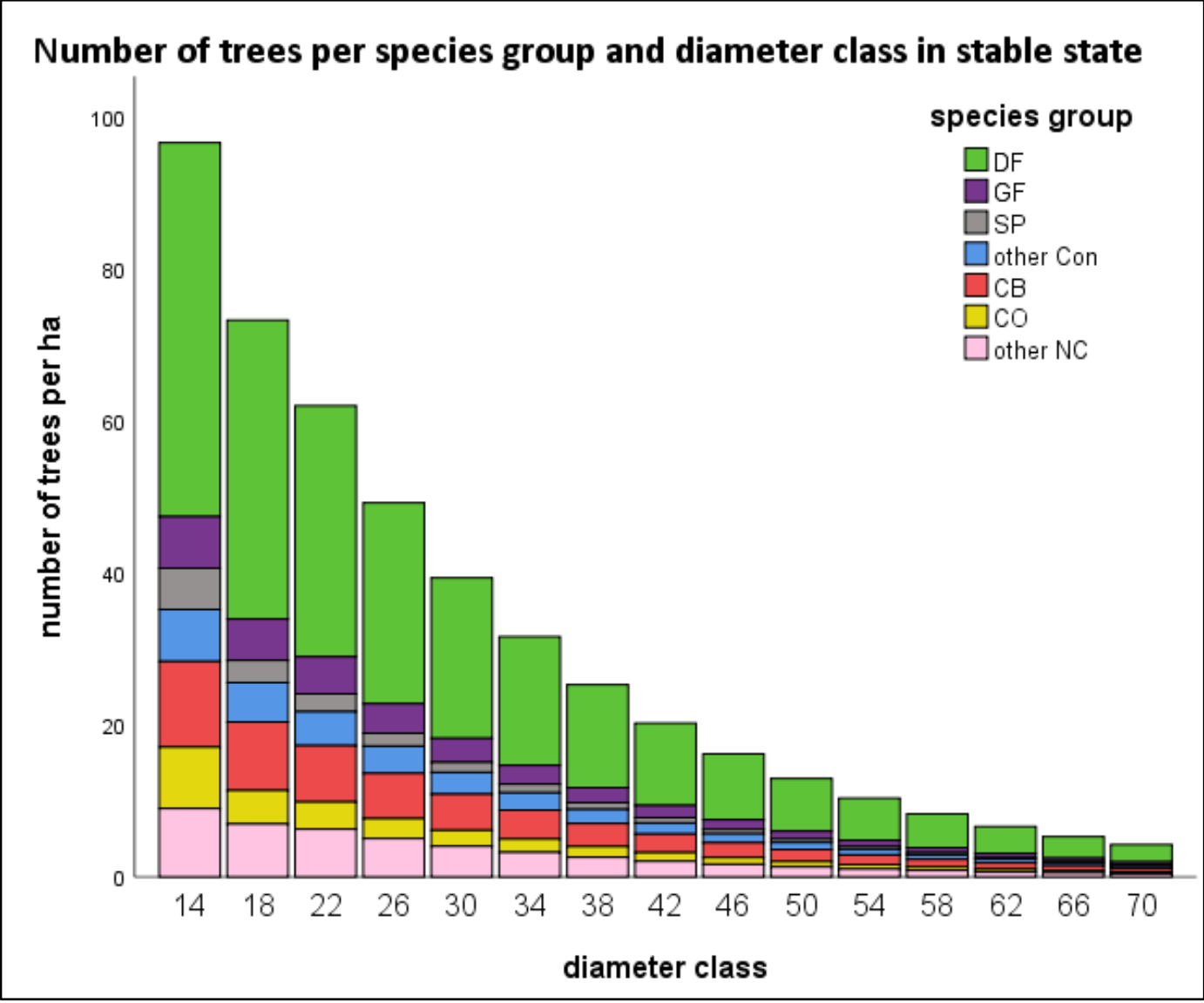

Figuur B2-1. Stamtal per ha per diameterklasse en soort in evenwichtstoestand Kolkbos.

Figure B2-1. Number of trees per ha per diameter class and species group in stable state Kolkbos. 


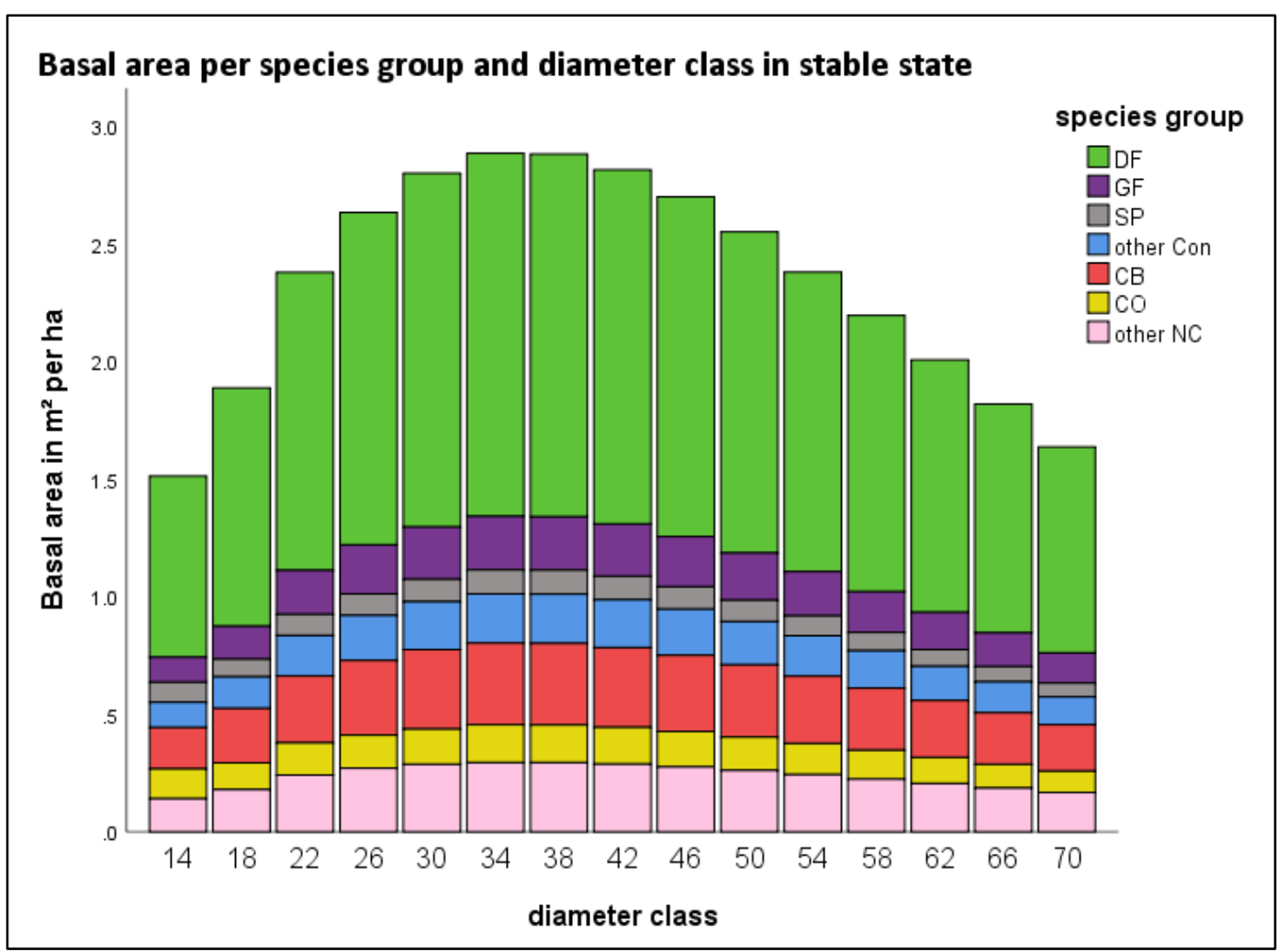

Figuur B2-2. Grondvlak in $\mathrm{m}^{2}$ per ha per diameterklasse en soort in evenwichtstoestand Kolkbos. Figure B2-2. Basal area in $\mathrm{m}^{2}$ per ha per diameter class and species in stable sate Kolkbos.

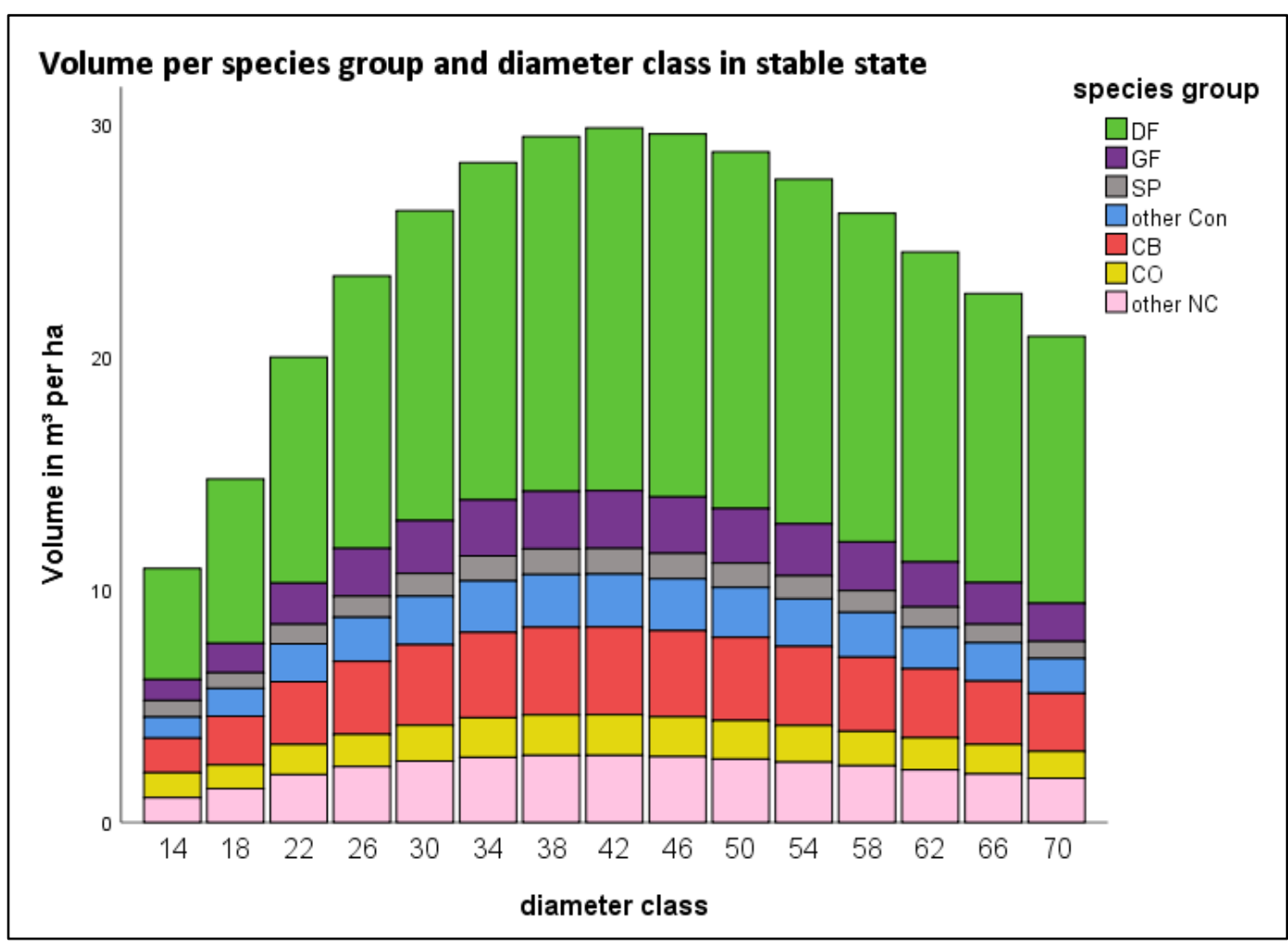

Figuur B2-3. Volume in $\mathrm{m}^{3}$ per ha per diameterklasse en soort in evenwichtstoestand Kolkbos. Figure B2-3. Volume in $m^{3}$ per ha per diameter class and species in stable state Kolkbos.

In de tabellen B2-4a tot en met B2-4g zijn de transitionmatrices $\mathrm{T}$ voor achtereenvolgens de verschillende soortgroepen $\mathrm{dg}$, ag, gd, no, bu, ei en lo weergegeven. 
Tabel B2-4a. Transitionmatrix T Kolkbos voor douglas.

Table B2-4a. Transitionmatrix T Kolkbos for Douglas fir.

\begin{tabular}{|c|c|c|c|c|c|c|c|c|c|c|c|c|c|c|c|}
\hline DF & 1 & 2 & 3 & 4 & 5 & 6 & 7 & 8 & 9 & 10 & 11 & 12 & 13 & 14 & 15 \\
\hline 1 & 0.891 & 0.136 & 0 & 0 & 0 & 0 & 0 & 0 & 0 & 0 & 0 & 0 & 0 & 0 & 0 \\
\hline 2 & 0.098 & 0.877 & 0 & 0 & 0 & 0 & 0 & 0 & 0 & 0 & 0 & 0 & 0 & 0 & 0 \\
\hline 3 & 0 & 0.110 & 0.869 & 0 & 0 & 0 & 0 & 0 & 0 & 0 & 0 & 0 & 0 & 0 & 0 \\
\hline 4 & 0 & 0 & 0.120 & 0.849 & 0 & 0 & 0 & 0 & 0 & 0 & 0 & 0 & 0 & 0 & 0 \\
\hline 5 & 0 & 0 & 0 & 0.130 & 0.838 & 0 & 0 & 0 & 0 & 0 & 0 & 0 & 0 & 0 & 0 \\
\hline 6 & 0 & 0 & 0 & 0 & 0.137 & 0.828 & 0 & 0 & 0 & 0 & 0 & 0 & 0 & 0 & 0 \\
\hline 7 & 0 & 0 & 0 & 0 & 0 & 0.144 & 0.821 & 0 & 0 & 0 & 0 & 0 & 0 & 0 & 0 \\
\hline 8 & 0 & 0 & 0 & 0 & 0 & 0 & 0.148 & 0.814 & 0 & 0 & 0 & 0 & 0 & 0 & 0 \\
\hline 9 & 0 & 0 & 0 & 0 & 0 & 0 & 0 & 0.152 & 0.810 & 0 & 0 & 0 & 0 & 0 & 0 \\
\hline 10 & 0 & 0 & 0 & 0 & 0 & 0 & 0 & 0 & 0.154 & 0.807 & 0 & 0 & 0 & 0 & 0 \\
\hline 11 & 0 & 0 & 0 & 0 & 0 & 0 & 0 & 0 & 0 & 0.155 & 0.806 & 0 & 0 & 0 & 0 \\
\hline 12 & 0 & 0 & 0 & 0 & 0 & 0 & 0 & 0 & 0 & 0.00 & 0.154 & 0.807 & 0 & 0 & 0 \\
\hline 13 & 0 & 0 & 0 & 0 & 0 & 0 & 0 & 0 & 0 & 0 & 0 & 0.152 & 0.810 & 0 & 0 \\
\hline 14 & 0 & 0 & 0 & 0 & 0 & 0 & 0 & 0 & 0 & 0 & 0 & 0 & 0.149 & 0.814 & 0 \\
\hline 15 & 0 & 0 & 0 & 0 & 0 & 0 & 0 & 0 & 0 & 0 & 0 & 0 & 0 & 0.144 & 0.820 \\
\hline
\end{tabular}

Tabel B2-4b. Transitionmatrix T Kolkbos voor reuzenzilverspar.

Table B2-4b. Transitionmatrix T Kolkbos for grand fir.

\begin{tabular}{|c|c|c|c|c|c|c|c|c|c|c|c|c|c|c|c|}
\hline GF & 1 & 2 & 3 & 4 & 5 & 6 & 7 & 8 & 9 & 10 & 11 & 12 & 13 & 14 & 15 \\
\hline 1 & 0.867 & 0.167 & 0 & 0 & 0 & 0 & 0 & 0 & 0 & 0 & 0 & 0 & 0 & 0 & 0 \\
\hline 2 & 0.109 & 0.863 & 0 & 0 & 0 & 0 & 0 & 0 & 0 & 0 & 0 & 0 & 0 & 0 & 0 \\
\hline 3 & 0 & 0.114 & 0.873 & 0 & 0 & 0 & 0 & 0 & 0 & 0 & 0 & 0 & 0 & 0 & 0 \\
\hline 4 & 0 & 0 & 0.118 & 0.852 & 0 & 0 & 0 & 0 & 0 & 0 & 0 & 0 & 0 & 0 & 0 \\
\hline 5 & 0 & 0 & 0 & 0.124 & 0.845 & 0 & 0 & 0 & 0 & 0 & 0 & 0 & 0 & 0 & 0 \\
\hline 6 & 0 & 0 & 0 & 0 & 0.130 & 0.838 & 0 & 0 & 0 & 0 & 0 & 0 & 0 & 0 & 0 \\
\hline 7 & 0 & 0 & 0 & 0 & 0 & 0.137 & 0.829 & 0 & 0 & 0 & 0 & 0 & 0 & 0 & 0 \\
\hline 8 & 0 & 0 & 0 & 0 & 0 & 0 & 0.144 & 0.820 & 0 & 0 & 0 & 0 & 0 & 0 & 0 \\
\hline 9 & 0 & 0 & 0 & 0 & 0 & 0 & 0 & 0.152 & 0.810 & 0 & 0 & 0 & 0 & 0 & 0 \\
\hline 10 & 0 & 0 & 0 & 0 & 0 & 0 & 0 & 0 & 0.160 & 0.800 & 0 & 0 & 0 & 0 & 0 \\
\hline 11 & 0 & 0 & 0 & 0 & 0 & 0 & 0 & 0 & 0 & 0.169 & 0.789 & 0 & 0 & 0 & 0 \\
\hline 12 & 0 & 0 & 0 & 0 & 0 & 0 & 0 & 0 & 0 & 0.00 & 0.179 & 0.777 & 0 & 0 & 0 \\
\hline 13 & 0 & 0 & 0 & 0 & 0 & 0 & 0 & 0 & 0 & 0 & 0 & 0.188 & 0.764 & 0 & 0 \\
\hline 14 & 0 & 0 & 0 & 0 & 0 & 0 & 0 & 0 & 0 & 0 & 0 & 0 & 0.199 & 0.751 & 0 \\
\hline 15 & 0 & 0 & 0 & 0 & 0 & 0 & 0 & 0 & 0 & 0 & 0 & 0 & 0 & 0.211 & 0.737 \\
\hline
\end{tabular}

Tabel B2-4c. Transitionmatrix T Kolkbos voor grove den.

Table B2-4c. Transitionmatrix T Kolkbos for Scots pine.

\begin{tabular}{|c|c|c|c|c|c|c|c|c|c|c|c|c|c|c|c|}
\hline SP & 1 & 2 & 3 & 4 & 5 & 6 & 7 & 8 & 9 & 10 & 11 & 12 & 13 & 14 & 15 \\
\hline 1 & 0.952 & 0.090 & 0 & 0 & 0 & 0 & 0 & 0 & 0 & 0 & 0 & 0 & 0 & 0 & 0 \\
\hline 2 & 0.030 & 0.945 & 0 & 0 & 0 & 0 & 0 & 0 & 0 & 0 & 0 & 0 & 0 & 0 & 0 \\
\hline 3 & 0 & 0.041 & 0.949 & 0 & 0 & 0 & 0 & 0 & 0 & 0 & 0 & 0 & 0 & 0 & 0 \\
\hline 4 & 0 & 0 & 0.051 & 0.930 & 0 & 0 & 0 & 0 & 0 & 0 & 0 & 0 & 0 & 0 & 0 \\
\hline 5 & 0 & 0 & 0 & 0.060 & 0.924 & 0 & 0 & 0 & 0 & 0 & 0 & 0 & 0 & 0 & 0 \\
\hline 6 & 0 & 0 & 0 & 0 & 0.067 & 0.919 & 0 & 0 & 0 & 0 & 0 & 0 & 0 & 0 & 0 \\
\hline 7 & 0 & 0 & 0 & 0 & 0 & 0.073 & 0.908 & 0 & 0 & 0 & 0 & 0 & 0 & 0 & 0 \\
\hline 8 & 0 & 0 & 0 & 0 & 0 & 0 & 0.078 & 0.902 & 0 & 0 & 0 & 0 & 0 & 0 & 0 \\
\hline 9 & 0 & 0 & 0 & 0 & 0 & 0 & 0 & 0.081 & 0.898 & 0 & 0 & 0 & 0 & 0 & 0 \\
\hline 10 & 0 & 0 & 0 & 0 & 0 & 0 & 0 & 0 & 0.083 & 0.896 & 0 & 0 & 0 & 0 & 0 \\
\hline 11 & 0 & 0 & 0 & 0 & 0 & 0 & 0 & 0 & 0 & 0.084 & 0.895 & 0 & 0 & 0 & 0 \\
\hline 12 & 0 & 0 & 0 & 0 & 0 & 0 & 0 & 0 & 0 & 0.00 & 0.083 & 0.896 & 0 & 0 & 0 \\
\hline 13 & 0 & 0 & 0 & 0 & 0 & 0 & 0 & 0 & 0 & 0 & 0 & 0.081 & 0.898 & 0 & 0 \\
\hline 14 & 0 & 0 & 0 & 0 & 0 & 0 & 0 & 0 & 0 & 0 & 0 & 0 & 0.078 & 0.903 & 0 \\
\hline 15 & 0 & 0 & 0 & 0 & 0 & 0 & 0 & 0 & 0 & 0 & 0 & 0 & 0 & 0.073 & 0.909 \\
\hline
\end{tabular}


Tabel B2-4d. Transitionmatrix T Kolkbos voor overig naaldhout.

Table B2-4d. Transitionmatrix T Kolkbos for other conifers.

\begin{tabular}{|c|c|c|c|c|c|c|c|c|c|c|c|c|c|c|c|}
\hline con & 1 & 2 & 3 & 4 & 5 & 6 & 7 & 8 & 9 & 10 & 11 & 12 & 13 & 14 & 15 \\
\hline 1 & 0.929 & 0.093 & 0 & 0 & 0 & 0 & 0 & 0 & 0 & 0 & 0 & 0 & 0 & 0 & 0 \\
\hline 2 & 0.060 & 0.920 & 0 & 0 & 0 & 0 & 0 & 0 & 0 & 0 & 0 & 0 & 0 & 0 & 0 \\
\hline 3 & 0 & 0.072 & 0.917 & 0 & 0 & 0 & 0 & 0 & 0 & 0 & 0 & 0 & 0 & 0 & 0 \\
\hline 4 & 0 & 0 & 0.082 & 0.898 & 0 & 0 & 0 & 0 & 0 & 0 & 0 & 0 & 0 & 0 & 0 \\
\hline 5 & 0 & 0 & 0 & 0.091 & 0.886 & 0 & 0 & 0 & 0 & 0 & 0 & 0 & 0 & 0 & 0 \\
\hline 6 & 0 & 0 & 0 & 0 & 0.099 & 0.877 & 0 & 0 & 0 & 0 & 0 & 0 & 0 & 0 & 0 \\
\hline 7 & 0 & 0 & 0 & 0 & 0 & 0.105 & 0.869 & 0 & 0 & 0 & 0 & 0 & 0 & 0 & 0 \\
\hline 8 & 0 & 0 & 0 & 0 & 0 & 0 & 0.110 & 0.863 & 0 & 0 & 0 & 0 & 0 & 0 & 0 \\
\hline 9 & 0 & 0 & 0 & 0 & 0 & 0 & 0 & 0.113 & 0.859 & 0 & 0 & 0 & 0 & 0 & 0 \\
\hline 10 & 0 & 0 & 0 & 0 & 0 & 0 & 0 & 0 & 0.115 & 0.856 & 0 & 0 & 0 & 0 & 0 \\
\hline 11 & 0 & 0 & 0 & 0 & 0 & 0 & 0 & 0 & 0 & 0.116 & 0.855 & 0 & 0 & 0 & 0 \\
\hline 12 & 0 & 0 & 0 & 0 & 0 & 0 & 0 & 0 & 0 & 0.00 & 0.115 & 0.856 & 0 & 0 & 0 \\
\hline 13 & 0 & 0 & 0 & 0 & 0 & 0 & 0 & 0 & 0 & 0 & 0 & 0.113 & 0.859 & 0 & 0 \\
\hline 14 & 0 & 0 & 0 & 0 & 0 & 0 & 0 & 0 & 0 & 0 & 0 & 0 & 0.109 & 0.864 & 0 \\
\hline 15 & 0 & 0 & 0 & 0 & 0 & 0 & 0 & 0 & 0 & 0 & 0 & 0 & 0 & 0.104 & 0.870 \\
\hline
\end{tabular}

Tabel B2-4e. Transitionmatrix T Kolkbos voor beuk.

Table B2-4e. Transitionmatrix T Kolkbos for common beech.

\begin{tabular}{|c|c|c|c|c|c|c|c|c|c|c|c|c|c|c|c|}
\hline CB & 1 & 2 & 3 & 4 & 5 & 6 & 7 & 8 & 9 & 10 & 11 & 12 & 13 & 14 & 15 \\
\hline 1 & 0.894 & 0.133 & 0 & 0 & 0 & 0 & 0 & 0 & 0 & 0 & 0 & 0 & 0 & 0 & 0 \\
\hline 2 & 0.086 & 0.893 & 0 & 0 & 0 & 0 & 0 & 0 & 0 & 0 & 0 & 0 & 0 & 0 & 0 \\
\hline 3 & 0 & 0.087 & 0.894 & 0 & 0 & 0 & 0 & 0 & 0 & 0 & 0 & 0 & 0 & 0 & 0 \\
\hline 4 & 0 & 0 & 0.089 & 0.889 & 0 & 0 & 0 & 0 & 0 & 0 & 0 & 0 & 0 & 0 & 0 \\
\hline 5 & 0 & 0 & 0 & 0.092 & 0.885 & 0 & 0 & 0 & 0 & 0 & 0 & 0 & 0 & 0 & 0 \\
\hline 6 & 0 & 0 & 0 & 0 & 0.095 & 0.881 & 0 & 0 & 0 & 0 & 0 & 0 & 0 & 0 & 0 \\
\hline 7 & 0 & 0 & 0 & 0 & 0 & 0.099 & 0.876 & 0 & 0 & 0 & 0 & 0 & 0 & 0 & 0 \\
\hline 8 & 0 & 0 & 0 & 0 & 0 & 0 & 0.104 & 0.870 & 0 & 0 & 0 & 0 & 0 & 0 & 0 \\
\hline 9 & 0 & 0 & 0 & 0 & 0 & 0 & 0 & 0.109 & 0.863 & 0 & 0 & 0 & 0 & 0 & 0 \\
\hline 10 & 0 & 0 & 0 & 0 & 0 & 0 & 0 & 0 & 0.116 & 0.855 & 0 & 0 & 0 & 0 & 0 \\
\hline 11 & 0 & 0 & 0 & 0 & 0 & 0 & 0 & 0 & 0 & 0.123 & 0.847 & 0 & 0 & 0 & 0 \\
\hline 12 & 0 & 0 & 0 & 0 & 0 & 0 & 0 & 0 & 0 & 0.00 & 0.130 & 0.837 & 0 & 0 & 0 \\
\hline 13 & 0 & 0 & 0 & 0 & 0 & 0 & 0 & 0 & 0 & 0 & 0 & 0.139 & 0.827 & 0 & 0 \\
\hline 14 & 0 & 0 & 0 & 0 & 0 & 0 & 0 & 0 & 0 & 0 & 0 & 0 & 0.148 & 0.815 & 0 \\
\hline 15 & 0 & 0 & 0 & 0 & 0 & 0 & 0 & 0 & 0 & 0 & 0 & 0 & 0 & 0.157 & 0.803 \\
\hline
\end{tabular}

Tabel B2-4f. Transitionmatrix T Kolkbos voor eik.

Table B2-4f. Transitionmatrix T Kolkbos for common oak.

\begin{tabular}{|c|c|c|c|c|c|c|c|c|c|c|c|c|c|c|c|}
\hline $\mathrm{CO}$ & 1 & 2 & 3 & 4 & 5 & 6 & 7 & 8 & 9 & 10 & 11 & 12 & 13 & 14 & 15 \\
\hline 1 & 0.954 & 0.084 & 0 & 0 & 0 & 0 & 0 & 0 & 0 & 0 & 0 & 0 & 0 & 0 & 0 \\
\hline 2 & 0.030 & 0.946 & 0 & 0 & 0 & 0 & 0 & 0 & 0 & 0 & 0 & 0 & 0 & 0 & 0 \\
\hline 3 & 0 & 0.041 & 0.949 & 0 & 0 & 0 & 0 & 0 & 0 & 0 & 0 & 0 & 0 & 0 & 0 \\
\hline 4 & 0 & 0 & 0.051 & 0.931 & 0 & 0 & 0 & 0 & 0 & 0 & 0 & 0 & 0 & 0 & 0 \\
\hline 5 & 0 & 0 & 0 & 0.060 & 0.925 & 0 & 0 & 0 & 0 & 0 & 0 & 0 & 0 & 0 & 0 \\
\hline 6 & 0 & 0 & 0 & 0 & 0.067 & 0.920 & 0 & 0 & 0 & 0 & 0 & 0 & 0 & 0 & 0 \\
\hline 7 & 0 & 0 & 0 & 0 & 0 & 0.073 & 0.908 & 0 & 0 & 0 & 0 & 0 & 0 & 0 & 0 \\
\hline 8 & 0 & 0 & 0 & 0 & 0 & 0 & 0.078 & 0.902 & 0 & 0 & 0 & 0 & 0 & 0 & 0 \\
\hline 9 & 0 & 0 & 0 & 0 & 0 & 0 & 0 & 0.081 & 0.898 & 0 & 0 & 0 & 0 & 0 & 0 \\
\hline 10 & 0 & 0 & 0 & 0 & 0 & 0 & 0 & 0 & 0.083 & 0.896 & 0 & 0 & 0 & 0 & 0 \\
\hline 11 & 0 & 0 & 0 & 0 & 0 & 0 & 0 & 0 & 0 & 0.084 & 0.895 & 0 & 0 & 0 & 0 \\
\hline 12 & 0 & 0 & 0 & 0 & 0 & 0 & 0 & 0 & 0 & 0.00 & 0.083 & 0.896 & 0 & 0 & 0 \\
\hline 13 & 0 & 0 & 0 & 0 & 0 & 0 & 0 & 0 & 0 & 0 & 0 & 0.081 & 0.899 & 0 & 0 \\
\hline 14 & 0 & 0 & 0 & 0 & 0 & 0 & 0 & 0 & 0 & 0 & 0 & 0 & 0.078 & 0.903 & 0 \\
\hline 15 & 0 & 0 & 0 & 0 & 0 & 0 & 0 & 0 & 0 & 0 & 0 & 0 & 0 & 0.073 & 0.909 \\
\hline
\end{tabular}


Tabel B2-4g. Transitionmatrix T Kolkbos voor overig loofhout.

Table B2-4g. Transitionmatrix T Kolkbos for other non-conifers.

\begin{tabular}{|c|c|c|c|c|c|c|c|c|c|c|c|c|c|c|c|}
\hline NC & 1 & 2 & 3 & 4 & 5 & 6 & 7 & 8 & 9 & 10 & 11 & 12 & 13 & 14 & 15 \\
\hline 1 & 0.908 & 0.119 & 0 & 0 & 0 & 0 & 0 & 0 & 0 & 0 & 0 & 0 & 0 & 0 & 0 \\
\hline 2 & 0.074 & 0.905 & 0 & 0 & 0 & 0 & 0 & 0 & 0 & 0 & 0 & 0 & 0 & 0 & 0 \\
\hline 3 & 0 & 0.081 & 0.911 & 0 & 0 & 0 & 0 & 0 & 0 & 0 & 0 & 0 & 0 & 0 & 0 \\
\hline 4 & 0 & 0 & 0.087 & 0.891 & 0 & 0 & 0 & 0 & 0 & 0 & 0 & 0 & 0 & 0 & 0 \\
\hline 5 & 0 & 0 & 0 & 0.093 & 0.884 & 0 & 0 & 0 & 0 & 0 & 0 & 0 & 0 & 0 & 0 \\
\hline 6 & 0 & 0 & 0 & 0 & 0.099 & 0.877 & 0 & 0 & 0 & 0 & 0 & 0 & 0 & 0 & 0 \\
\hline 7 & 0 & 0 & 0 & 0 & 0 & 0.103 & 0.871 & 0 & 0 & 0 & 0 & 0 & 0 & 0 & 0 \\
\hline 8 & 0 & 0 & 0 & 0 & 0 & 0 & 0.107 & 0.866 & 0 & 0 & 0 & 0 & 0 & 0 & 0 \\
\hline 9 & 0 & 0 & 0 & 0 & 0 & 0 & 0 & 0.111 & 0.861 & 0 & 0 & 0 & 0 & 0 & 0 \\
\hline 10 & 0 & 0 & 0 & 0 & 0 & 0 & 0 & 0 & 0.114 & 0.858 & 0 & 0 & 0 & 0 & 0 \\
\hline 11 & 0 & 0 & 0 & 0 & 0 & 0 & 0 & 0 & 0 & 0.116 & 0.855 & 0 & 0 & 0 & 0 \\
\hline 12 & 0 & 0 & 0 & 0 & 0 & 0 & 0 & 0 & 0 & 0.00 & 0.118 & 0.853 & 0 & 0 & 0 \\
\hline 13 & 0 & 0 & 0 & 0 & 0 & 0 & 0 & 0 & 0 & 0 & 0 & 0.119 & 0.852 & 0 & 0 \\
\hline 14 & 0 & 0 & 0 & 0 & 0 & 0 & 0 & 0 & 0 & 0 & 0 & 0 & 0.119 & 0.851 & 0 \\
\hline 15 & 0 & 0 & 0 & 0 & 0 & 0 & 0 & 0 & 0 & 0 & 0 & 0 & 0 & 0.119 & 0.851 \\
\hline
\end{tabular}




\section{BIJLAGE 3. EVENWICHTSTOESTAND OUDE TREKERBOS}

In Tabel 18 Staan de kapkansen vermeld bij oogst met het doel een q-waarde van 1.30 te realiseren.

Gevonden werd een stamtal, grondvlak en volumeverdeling zoals weergegeven in de tabellen B3-1, B3-2 en B3-3 en de Figuren B3-1, B3-2 en B3-3.

Tabel B3-1. Stamtal per ha per soortgroep en diameterklasse in evenwichtstoestand in Oude Trekerbos

Table B3-1. Number of trees per ha per species group and diameter class in stable state in Oude Trekerbos

\begin{tabular}{|c|rrrrrr|r|}
\hline diameter & \multicolumn{7}{|c|}{ species group } \\
\cline { 2 - 8 } in & DF & NS & SP & JL & CB & CO & Total \\
\hline $12-16$ & 18.3 & 13.0 & 14.0 & 4.7 & 24.4 & 8.0 & 82.5 \\
$16-20$ & 14.1 & 10.0 & 10.8 & 3.7 & 18.8 & 6.1 & 63.5 \\
$20-24$ & 11.0 & 7.9 & 8.6 & 2.8 & 14.6 & 4.9 & 49.8 \\
$24-28$ & 8.4 & 6.1 & 6.6 & 2.2 & 11.2 & 3.7 & 38.2 \\
$28-32$ & 6.5 & 4.7 & 5.0 & 1.7 & 8.6 & 2.8 & 29.2 \\
$32-36$ & 5.0 & 3.6 & 3.7 & 1.3 & 6.6 & 2.1 & 22.3 \\
$36-40$ & 3.8 & 2.8 & 2.9 & 1.0 & 5.1 & 1.6 & 17.2 \\
$40-44$ & 3.0 & 2.1 & 2.2 & 0.8 & 3.9 & 1.2 & 13.2 \\
$44-48$ & 2.3 & 1.6 & 1.7 & 0.6 & 3.0 & 0.9 & 10.2 \\
$48-52$ & 1.7 & 1.3 & 1.3 & 0.5 & 2.3 & 0.7 & 7.8 \\
$52-56$ & 1.3 & 1.0 & 1.0 & 0.3 & 1.8 & 0.6 & 6.0 \\
$56-60$ & 1.0 & 0.7 & 0.8 & 0.3 & 1.4 & 0.4 & 4.6 \\
$60-64$ & 0.8 & 0.6 & 0.6 & 0.2 & 1.1 & 0.3 & 3.6 \\
$64-68$ & 0.6 & 0.4 & 0.5 & 0.2 & 0.8 & 0.3 & 2.7 \\
$68-72$ & 0.5 & 0.3 & 0.4 & 0.1 & 0.6 & 0.2 & 2.1 \\
$72-76$ & 0.4 & 0.3 & 0.3 & 0.1 & 0.5 & 0.2 & 1.6 \\
$76-80$ & 0.3 & 0.2 & 0.2 & 0.1 & 0.4 & 0.1 & 1.2 \\
$\geq 82$ & 0.2 & 0.2 & 0.1 & 0.1 & 0.3 & 0.1 & 0.9 \\
\hline Total & 79.2 & 56.8 & 60.6 & 20.5 & 105.4 & 34.2 & 356.6 \\
\hline
\end{tabular}


Tabel B3-2. Grondvlak in $\mathrm{m}^{2}$ per ha i per soortgroep en diameterklasse $\mathrm{n}$ evenwichtstoestand in Oude Trekerbos

Table B3-2. Basal area in $\mathrm{m}^{2}$ per ha per species group and diameter class in stable state in Oude Trekerbos.

\begin{tabular}{|c|rrrrrr|r|}
\hline diameter & \multicolumn{7}{|c|}{ species group } \\
\cline { 2 - 7 } in cm & DF & NS & SP & JL & CB & CO & Total \\
\hline $12-16$ & 0.3 & 0.2 & 0.2 & 0.1 & 0.4 & 0.1 & 1.3 \\
$16-20$ & 0.4 & 0.3 & 0.3 & 0.1 & 0.5 & 0.2 & 1.6 \\
$20-24$ & 0.4 & 0.3 & 0.3 & 0.1 & 0.6 & 0.2 & 1.9 \\
$24-28$ & 0.4 & 0.3 & 0.3 & 0.1 & 0.6 & 0.2 & 2.0 \\
$28-32$ & 0.5 & 0.3 & 0.4 & 0.1 & 0.6 & 0.2 & 2.1 \\
$32-36$ & 0.5 & 0.3 & 0.3 & 0.1 & 0.6 & 0.2 & 2.0 \\
$36-40$ & 0.4 & 0.3 & 0.3 & 0.1 & 0.6 & 0.2 & 1.9 \\
$40-44$ & 0.4 & 0.3 & 0.3 & 0.1 & 0.5 & 0.2 & 1.8 \\
$44-48$ & 0.4 & 0.3 & 0.3 & 0.1 & 0.5 & 0.2 & 1.7 \\
$48-52$ & 0.3 & 0.2 & 0.3 & 0.1 & 0.5 & 0.1 & 1.5 \\
$52-56$ & 0.3 & 0.2 & 0.2 & 0.1 & 0.4 & 0.1 & 1.4 \\
$56-60$ & 0.3 & 0.2 & 0.2 & 0.1 & 0.4 & 0.1 & 1.2 \\
$60-64$ & 0.2 & 0.2 & 0.2 & 0.1 & 0.3 & 0.1 & 1.1 \\
$64-68$ & 0.2 & 0.2 & 0.2 & 0.1 & 0.3 & 0.1 & 0.9 \\
$68-72$ & 0.2 & 0.1 & 0.1 & 0.0 & 0.2 & 0.1 & 0.8 \\
$72-76$ & 0.2 & 0.1 & 0.1 & 0.0 & 0.2 & 0.1 & 0.7 \\
$76-80$ & 0.1 & 0.1 & 0.1 & 0.0 & 0.2 & 0.1 & 0.6 \\
$\geq 82$ & 0.1 & 0.1 & 0.1 & 0.0 & 0.1 & 0.0 & 0.5 \\
\hline Total & 5.6 & 4.0 & 4.2 & 1.4 & 7.4 & 2.4 & 25.0 \\
\hline
\end{tabular}

Tabel B3-3. Volume in $\mathrm{m}^{3}$ per ha per soortgroep en diameterklasse in evenwichtstoestand in Oude Trekerbos

Table B2-3. Volume in $\mathrm{m}^{3}$ per ha per species group and diameter class in stable state in Oude Trekerbos.

\begin{tabular}{|c|rrrrrr|r|}
\hline diameter & \multicolumn{7}{|c|}{ species group } \\
\cline { 2 - 8 } in $\mathbf{c m}$ & DF & NS & SP & JL & CB & CO & Total \\
\hline $12-16$ & 2.1 & 1.5 & 1.6 & 0.5 & 2.4 & 0.7 & 8.9 \\
$16-20$ & 2.9 & 2.1 & 2.1 & 0.8 & 3.4 & 1.0 & 12.4 \\
$20-24$ & 3.7 & 2.7 & 2.7 & 1.0 & 4.3 & 1.4 & 15.7 \\
$24-28$ & 4.3 & 3.0 & 3.0 & 1.1 & 5.0 & 1.6 & 18.0 \\
$28-32$ & 4.6 & 3.2 & 3.2 & 1.3 & 5.4 & 1.7 & 19.4 \\
$32-36$ & 4.8 & 3.3 & 3.1 & 1.3 & 5.6 & 1.8 & 20.0 \\
$36-40$ & 4.9 & 3.3 & 3.1 & 1.4 & 5.6 & 1.8 & 20.0 \\
$40-44$ & 4.8 & 3.2 & 3.0 & 1.3 & 5.5 & 1.8 & 19.6 \\
$44-48$ & 4.6 & 3.0 & 2.8 & 1.3 & 5.3 & 1.8 & 18.7 \\
$48-52$ & 4.3 & 2.8 & 2.6 & 1.2 & 4.9 & 1.7 & 17.6 \\
$52-56$ & 4.0 & 2.6 & 2.4 & 1.2 & 4.6 & 1.6 & 16.3 \\
$56-60$ & 3.6 & 2.3 & 2.2 & 1.1 & 4.2 & 1.5 & 14.9 \\
$60-64$ & 3.3 & 2.1 & 2.0 & 1.0 & 3.8 & 1.3 & 13.4 \\
$64-68$ & 2.9 & 1.9 & 1.7 & 0.9 & 3.4 & 1.2 & 12.0 \\
$68-72$ & 2.6 & 1.7 & 1.5 & 0.8 & 3.0 & 1.1 & 10.6 \\
$72-76$ & 2.3 & 1.4 & 1.2 & 0.7 & 2.6 & 1.0 & 9.2 \\
$76-80$ & 2.0 & 1.2 & 1.1 & 0.6 & 2.3 & 0.8 & 8.0 \\
$\geq 82$ & 1.7 & 1.1 & 0.9 & 0.5 & 2.0 & 0.7 & 7.0 \\
\hline Total & 63.4 & 42.4 & 40.4 & 17.8 & 73.1 & 24.5 & 261.6 \\
\hline
\end{tabular}




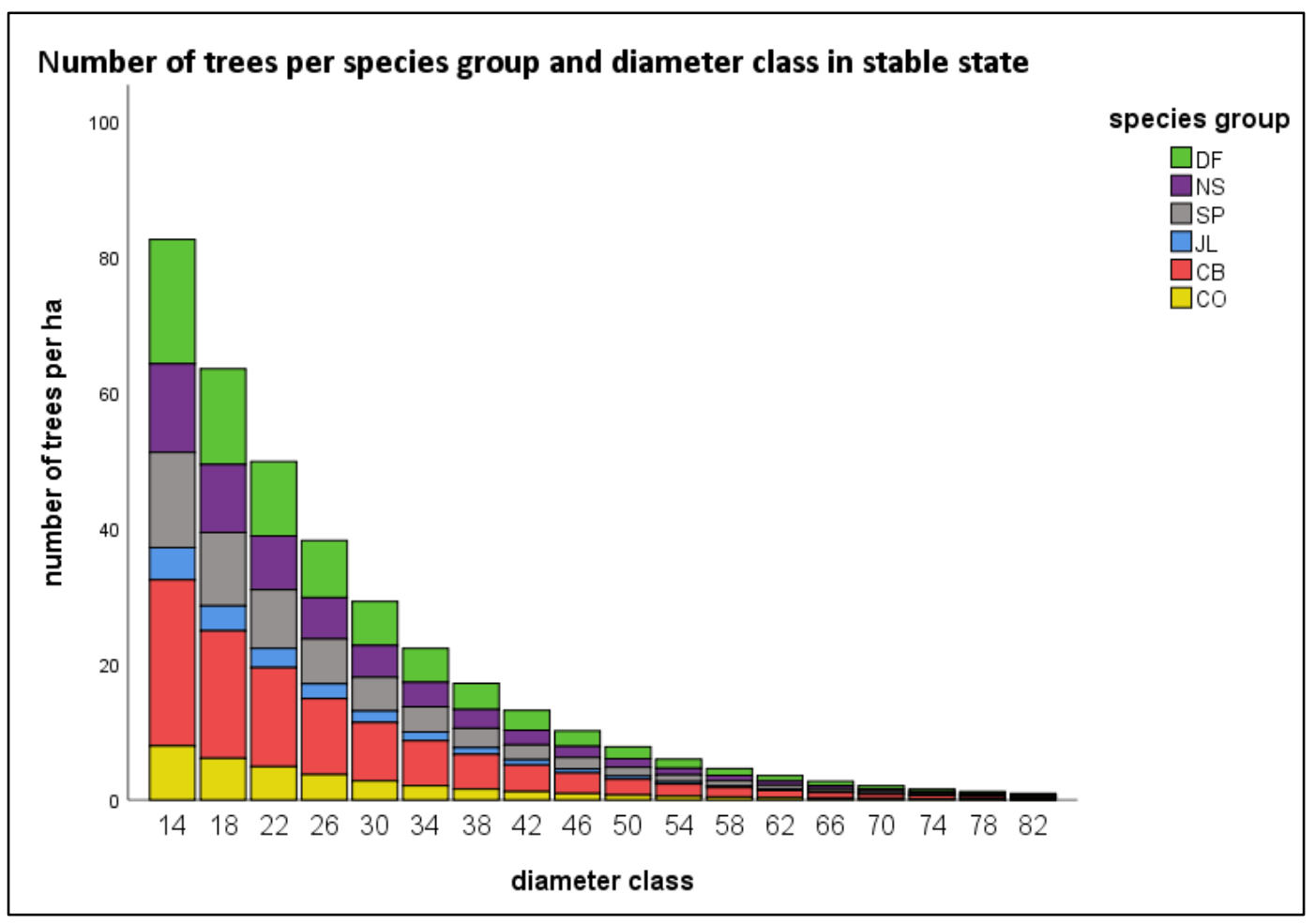

Figuur B3-1. Stamtal per ha per diameterklasse en soort in evenwichtstoestand Oude Trekerbos. Figure B3-1. Number of trees per ha per diameter class and species in stable state Oude Trekerbos.

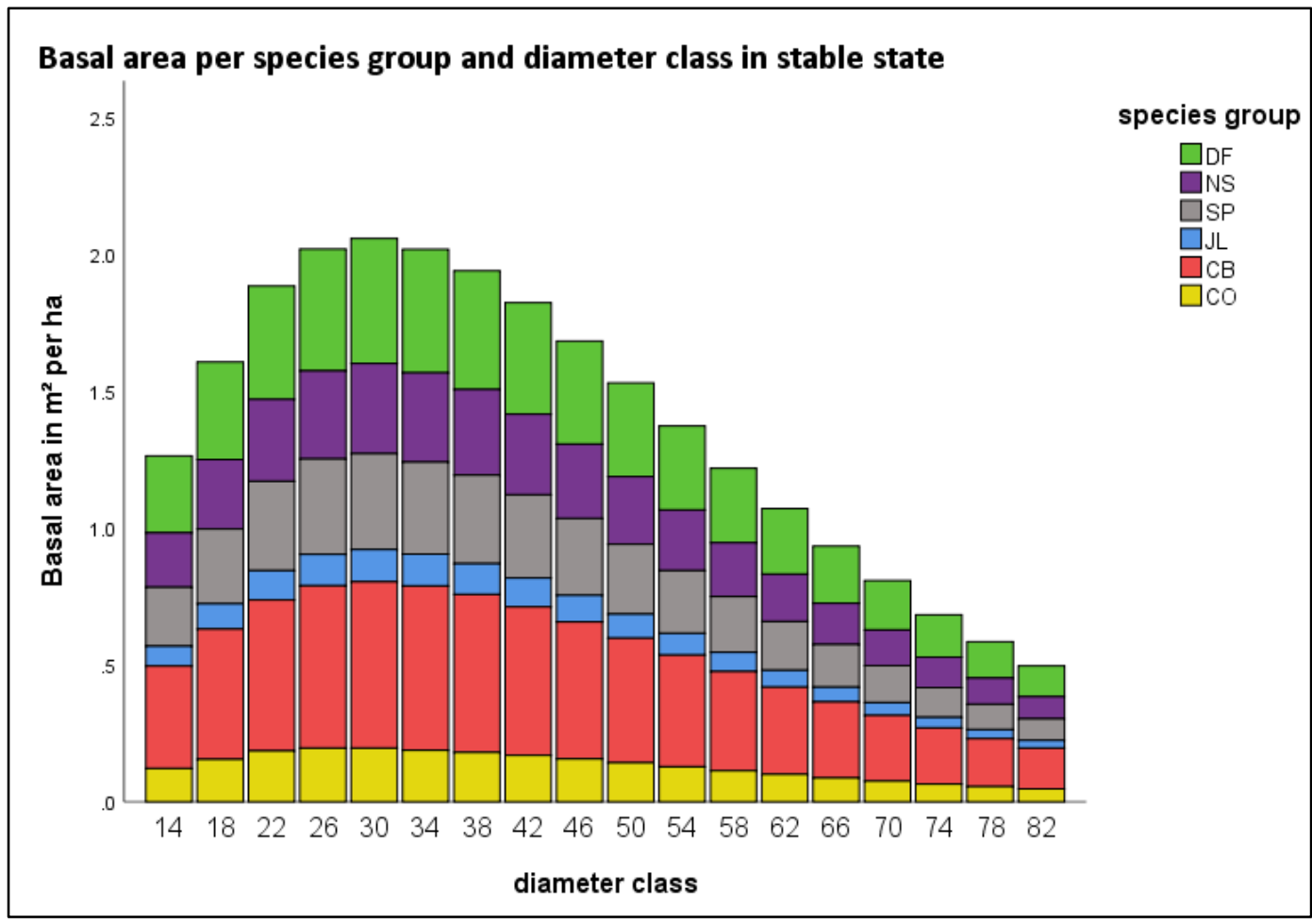

Figuur B3-2. Grondvlak in $\mathrm{m}^{2}$ per ha per diameterklasse en soort in evenwichtstoestand Oude Trekerbos.

Figure B3-2. Basal area in $\mathrm{m}^{2}$ per ha per diameter class and species in stable sate Oude Trekerbos. 


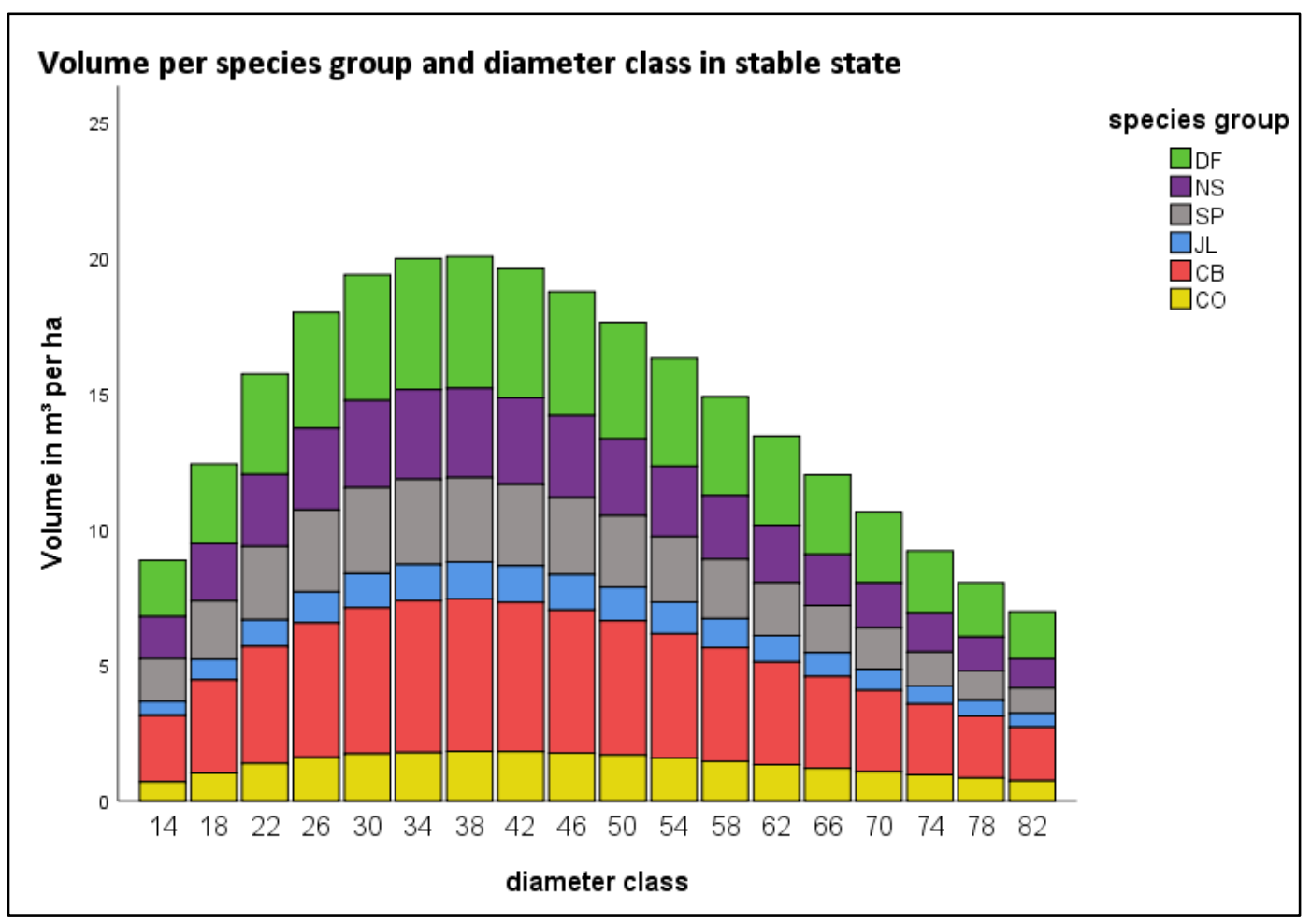

Figuur B3-3. Volume in $\mathrm{m}^{3}$ per ha per diameterklasse en soort in evenwichtstoestand Oude Trekerbos.

Figure B3-3. Volume in $m^{3}$ per ha per diameter class and species in stable state Oude Trekerbos.

In de tabellen B3-4a tot en met B3-4g zijn de matrices $\mathbf{T}$ voor achtereenvolgens de verschillende soortgroepen $\mathrm{dg}$, ag, gd, no, bu, ei en lo weergegeven.

Tabel B3-4a. Transitionmatrix T Oude Trekerbos voor douglas.

Table B3-4a. Transitionmatrix T Oude Trekerbos for Douglas fir.

\begin{tabular}{|c|c|c|c|c|c|c|c|c|c|c|c|c|c|c|c|c|c|c|}
\hline DF & 1 & 2 & 3 & 4 & 5 & 6 & 7 & 8 & 9 & 10 & 11 & 12 & 13 & 14 & 15 & 16 & 17 & 18 \\
\hline 1 & 0.813 & 0.243 & 0 & 0 & 0 & 0 & 0 & 0 & 0 & 0 & 0 & 0 & 0 & 0 & 0 & 0 & 0 & 0 \\
\hline 2 & 0.159 & 0.793 & 0 & 0 & 0 & 0 & 0 & 0 & 0 & 0 & 0 & 0 & 0 & 0 & 0 & 0 & 0 & 0 \\
\hline 3 & 0 & 0.173 & 0.778 & 0 & 0 & 0 & 0 & 0 & 0 & 0 & 0 & 0 & 0 & 0 & 0 & 0 & 0 & 0 \\
\hline 4 & 0 & 0 & 0.185 & 0.759 & 0 & 0 & 0 & 0 & 0 & 0 & 0 & 0 & 0 & 0 & 0 & 0 & 0 & 0 \\
\hline 5 & 0 & 0 & 0 & 0.196 & 0.745 & 0 & 0 & 0 & 0 & 0 & 0 & 0 & 0 & 0 & 0 & 0 & 0 & 0 \\
\hline 6 & 0 & 0 & 0 & 0 & 0.205 & 0.733 & 0 & 0 & 0 & 0 & 0 & 0 & 0 & 0 & 0 & 0 & 0 & 0 \\
\hline 7 & 0 & 0 & 0 & 0 & 0 & 0.213 & 0.723 & 0 & 0 & 0 & 0 & 0 & 0 & 0 & 0 & 0 & 0 & 0 \\
\hline 8 & 0 & 0 & 0 & 0 & 0 & 0 & 0.219 & 0.715 & 0 & 0 & 0 & 0 & 0 & 0 & 0 & 0 & 0 & 0 \\
\hline 9 & 0 & 0 & 0 & 0 & 0 & 0 & 0 & 0.224 & 0.709 & 0 & 0 & 0 & 0 & 0 & 0 & 0 & 0 & 0 \\
\hline 10 & 0 & 0 & 0 & 0 & 0 & 0 & 0 & 0 & 0.227 & 0.705 & 0 & 0 & 0 & 0 & 0 & 0 & 0 & 0 \\
\hline 11 & 0 & 0 & 0 & 0 & 0 & 0 & 0 & 0 & 0 & 0.228 & 0.703 & 0 & 0 & 0 & 0 & 0 & 0 & 0 \\
\hline 12 & 0 & 0 & 0 & 0 & 0 & 0 & 0 & 0 & 0 & 0.00 & 0.228 & 0.703 & 0 & 0 & 0 & 0 & 0 & 0 \\
\hline 13 & 0 & 0 & 0 & 0 & 0 & 0 & 0 & 0 & 0 & 0 & 0 & 0.227 & 0.706 & 0 & 0 & 0 & 0 & 0 \\
\hline 14 & 0 & 0 & 0 & 0 & 0 & 0 & 0 & 0 & 0 & 0 & 0 & 0 & 0.223 & 0.710 & 0 & 0 & 0 & 0 \\
\hline 15 & 0 & 0 & 0 & 0 & 0 & 0 & 0 & 0 & 0 & 0 & 0 & 0 & 0 & 0.218 & 0.716 & 0 & 0 & 0 \\
\hline 16 & 0 & 0 & 0 & 0 & 0 & 0 & 0 & 0 & 0 & 0 & 0 & 0 & 0 & 0 & 0.212 & 0.724 & 0 & 0 \\
\hline 17 & 0 & 0 & 0 & 0 & 0 & 0 & 0 & 0 & 0 & 0 & 0 & 0 & 0 & 0 & 0 & 0.204 & 0.735 & 0 \\
\hline 18 & 0 & 0 & 0 & 0 & 0 & 0 & 0 & 0 & 0 & 0 & 0 & 0 & 0 & 0 & 0 & 0 & 0.194 & 0.748 \\
\hline
\end{tabular}


Tabel B3-4b. Transitionmatrix T Oude Trekerbos voor fijnspar.

Table B3-4b. Transitionmatrix T Oude Trekerbos for Norway spruce.

\begin{tabular}{|c|c|c|c|c|c|c|c|c|c|c|c|c|c|c|c|c|c|c|}
\hline NS & 1 & 2 & 3 & 4 & 5 & 6 & 7 & 8 & 9 & 10 & 11 & 12 & 13 & 14 & 15 & 16 & 17 & 18 \\
\hline 1 & 0.885 & 0.150 & 0 & 0 & 0 & 0 & 0 & 0 & 0 & 0 & 0 & 0 & 0 & 0 & 0 & 0 & 0 & 0 \\
\hline 2 & 0.093 & 0.879 & 0 & 0 & 0 & 0 & 0 & 0 & 0 & 0 & 0 & 0 & 0 & 0 & 0 & 0 & 0 & 0 \\
\hline 3 & 0 & 0.098 & 0.876 & 0 & 0 & 0 & 0 & 0 & 0 & 0 & 0 & 0 & 0 & 0 & 0 & 0 & 0 & 0 \\
\hline 4 & 0 & 0 & 0.101 & 0.869 & 0 & 0 & 0 & 0 & 0 & 0 & 0 & 0 & 0 & 0 & 0 & 0 & 0 & 0 \\
\hline 5 & 0 & 0 & 0 & 0.104 & 0.865 & 0 & 0 & 0 & 0 & 0 & 0 & 0 & 0 & 0 & 0 & 0 & 0 & 0 \\
\hline 6 & 0 & 0 & 0 & 0 & 0.106 & 0.862 & 0 & 0 & 0 & 0 & 0 & 0 & 0 & 0 & 0 & 0 & 0 & 0 \\
\hline 7 & 0 & 0 & 0 & 0 & 0 & 0.107 & 0.861 & 0 & 0 & 0 & 0 & 0 & 0 & 0 & 0 & 0 & 0 & 0 \\
\hline 8 & 0 & 0 & 0 & 0 & 0 & 0 & 0.108 & 0.860 & 0 & 0 & 0 & 0 & 0 & 0 & 0 & 0 & 0 & 0 \\
\hline 9 & 0 & 0 & 0 & 0 & 0 & 0 & 0 & 0.108 & 0.860 & 0 & 0 & 0 & 0 & 0 & 0 & 0 & 0 & 0 \\
\hline 10 & 0 & 0 & 0 & 0 & 0 & 0 & 0 & 0 & 0.107 & 0.861 & 0 & 0 & 0 & 0 & 0 & 0 & 0 & 0 \\
\hline 11 & 0 & 0 & 0 & 0 & 0 & 0 & 0 & 0 & 0 & 0.106 & 0.863 & 0 & 0 & 0 & 0 & 0 & 0 & 0 \\
\hline 12 & 0 & 0 & 0 & 0 & 0 & 0 & 0 & 0 & 0 & 0.00 & 0.104 & 0.865 & 0 & 0 & 0 & 0 & 0 & 0 \\
\hline 13 & 0 & 0 & 0 & 0 & 0 & 0 & 0 & 0 & 0 & 0 & 0 & 0.101 & 0.869 & 0 & 0 & 0 & 0 & 0 \\
\hline 14 & 0 & 0 & 0 & 0 & 0 & 0 & 0 & 0 & 0 & 0 & 0 & 0 & 0.097 & 0.874 & 0 & 0 & 0 & 0 \\
\hline 15 & 0 & 0 & 0 & 0 & 0 & 0 & 0 & 0 & 0 & 0 & 0 & 0 & 0 & 0.093 & 0.879 & 0 & 0 & 0 \\
\hline 16 & 0 & 0 & 0 & 0 & 0 & 0 & 0 & 0 & 0 & 0 & 0 & 0 & 0 & 0 & 0.088 & 0.885 & 0 & 0 \\
\hline 17 & 0 & 0 & 0 & 0 & 0 & 0 & 0 & 0 & 0 & 0 & 0 & 0 & 0 & 0 & 0 & 0.082 & 0.893 & 0 \\
\hline 18 & 0 & 0 & 0 & 0 & 0 & 0 & 0 & 0 & 0 & 0 & 0 & 0 & 0 & 0 & 0 & 0 & 0.076 & 0.901 \\
\hline
\end{tabular}

Tabel B3-4c. Transitionmatrix T Oude Trekerbos voor grove den.

Table B3-4c. Transitionmatrix T Oude Trekerbos for Scots pine.

\begin{tabular}{|c|c|c|c|c|c|c|c|c|c|c|c|c|c|c|c|c|c|c|}
\hline SP & 1 & 2 & 3 & 4 & 5 & 6 & 7 & 8 & 9 & 10 & 11 & 12 & 13 & 14 & 15 & 16 & 17 & 18 \\
\hline 1 & 0.890 & 0.144 & 0 & 0 & 0 & 0 & 0 & 0 & 0 & 0 & 0 & 0 & 0 & 0 & 0 & 0 & 0 & 0 \\
\hline 2 & 0.082 & 0.894 & 0 & 0 & 0 & 0 & 0 & 0 & 0 & 0 & 0 & 0 & 0 & 0 & 0 & 0 & 0 & 0 \\
\hline 3 & 0 & 0.079 & 0.902 & 0 & 0 & 0 & 0 & 0 & 0 & 0 & 0 & 0 & 0 & 0 & 0 & 0 & 0 & 0 \\
\hline 4 & 0 & 0 & 0.075 & 0.901 & 0 & 0 & 0 & 0 & 0 & 0 & 0 & 0 & 0 & 0 & 0 & 0 & 0 & 0 \\
\hline 5 & 0 & 0 & 0 & 0.072 & 0.905 & 0 & 0 & 0 & 0 & 0 & 0 & 0 & 0 & 0 & 0 & 0 & 0 & 0 \\
\hline 6 & 0 & 0 & 0 & 0 & 0.068 & 0.909 & 0 & 0 & 0 & 0 & 0 & 0 & 0 & 0 & 0 & 0 & 0 & 0 \\
\hline 7 & 0 & 0 & 0 & 0 & 0 & 0.064 & 0.917 & 0 & 0 & 0 & 0 & 0 & 0 & 0 & 0 & 0 & 0 & 0 \\
\hline 8 & 0 & 0 & 0 & 0 & 0 & 0 & 0.060 & 0.922 & 0 & 0 & 0 & 0 & 0 & 0 & 0 & 0 & 0 & 0 \\
\hline 9 & 0 & 0 & 0 & 0 & 0 & 0 & 0 & 0.055 & 0.928 & 0 & 0 & 0 & 0 & 0 & 0 & 0 & 0 & 0 \\
\hline 10 & 0 & 0 & 0 & 0 & 0 & 0 & 0 & 0 & 0.051 & 0.934 & 0 & 0 & 0 & 0 & 0 & 0 & 0 & 0 \\
\hline 11 & 0 & 0 & 0 & 0 & 0 & 0 & 0 & 0 & 0 & 0.046 & 0.940 & 0 & 0 & 0 & 0 & 0 & 0 & 0 \\
\hline 12 & 0 & 0 & 0 & 0 & 0 & 0 & 0 & 0 & 0 & 0.00 & 0.041 & 0.947 & 0 & 0 & 0 & 0 & 0 & 0 \\
\hline 13 & 0 & 0 & 0 & 0 & 0 & 0 & 0 & 0 & 0 & 0 & 0 & 0.036 & 0.953 & 0 & 0 & 0 & 0 & 0 \\
\hline 14 & 0 & 0 & 0 & 0 & 0 & 0 & 0 & 0 & 0 & 0 & 0 & 0 & 0.030 & 0.960 & 0 & 0 & 0 & 0 \\
\hline 15 & 0 & 0 & 0 & 0 & 0 & 0 & 0 & 0 & 0 & 0 & 0 & 0 & 0 & 0.025 & 0.968 & 0 & 0 & 0 \\
\hline 16 & 0 & 0 & 0 & 0 & 0 & 0 & 0 & 0 & 0 & 0 & 0 & 0 & 0 & 0 & 0.019 & 0.973 & 0 & 0 \\
\hline 17 & 0 & 0 & 0 & 0 & 0 & 0 & 0 & 0 & 0 & 0 & 0 & 0 & 0 & 0 & 0 & 0.013 & 0.983 & 0 \\
\hline 18 & 0 & 0 & 0 & 0 & 0 & 0 & 0 & 0 & 0 & 0 & 0 & 0 & 0 & 0 & 0 & 0 & 0.008 & 0.989 \\
\hline
\end{tabular}

Tabel B3-4d. Transitionmatrix T Oude Trekerbos voor Japanse lariks.

Table B3-4d. Transitionmatrix T Oude Trekerbos for Japanese Larch.

\begin{tabular}{|c|c|c|c|c|c|c|c|c|c|c|c|c|c|c|c|c|c|c|}
\hline $\mathrm{JL}$ & 1 & 2 & 3 & 4 & 5 & 6 & 7 & 8 & 9 & 10 & 11 & 12 & 13 & 14 & 15 & 16 & 17 & 18 \\
\hline 1 & 0.825 & 0.228 & 0 & 0 & 0 & 0 & 0 & 0 & 0 & 0 & 0 & 0 & 0 & 0 & 0 & 0 & 0 & 0 \\
\hline 2 & 0.141 & 0.817 & 0 & 0 & 0 & 0 & 0 & 0 & 0 & 0 & 0 & 0 & 0 & 0 & 0 & 0 & 0 & 0 \\
\hline 3 & 0 & 0.145 & 0.812 & 0 & 0 & 0 & 0 & 0 & 0 & 0 & 0 & 0 & 0 & 0 & 0 & 0 & 0 & 0 \\
\hline 4 & 0 & 0 & 0.148 & 0.807 & 0 & 0 & 0 & 0 & 0 & 0 & 0 & 0 & 0 & 0 & 0 & 0 & 0 & 0 \\
\hline 5 & 0 & 0 & 0 & 0.150 & 0.805 & 0 & 0 & 0 & 0 & 0 & 0 & 0 & 0 & 0 & 0 & 0 & 0 & 0 \\
\hline 6 & 0 & 0 & 0 & 0 & 0.150 & 0.806 & 0 & 0 & 0 & 0 & 0 & 0 & 0 & 0 & 0 & 0 & 0 & 0 \\
\hline 7 & 0 & 0 & 0 & 0 & 0 & 0.148 & 0.808 & 0 & 0 & 0 & 0 & 0 & 0 & 0 & 0 & 0 & 0 & 0 \\
\hline 8 & 0 & 0 & 0 & 0 & 0 & 0 & 0.145 & 0.812 & 0 & 0 & 0 & 0 & 0 & 0 & 0 & 0 & 0 & 0 \\
\hline 9 & 0 & 0 & 0 & 0 & 0 & 0 & 0 & 0.140 & 0.818 & 0 & 0 & 0 & 0 & 0 & 0 & 0 & 0 & 0 \\
\hline 10 & 0 & 0 & 0 & 0 & 0 & 0 & 0 & 0 & 0.133 & 0.827 & 0 & 0 & 0 & 0 & 0 & 0 & 0 & 0 \\
\hline 11 & 0 & 0 & 0 & 0 & 0 & 0 & 0 & 0 & 0 & 0.125 & 0.837 & 0 & 0 & 0 & 0 & 0 & 0 & 0 \\
\hline 12 & 0 & 0 & 0 & 0 & 0 & 0 & 0 & 0 & 0 & 0.00 & 0.116 & 0.850 & 0 & 0 & 0 & 0 & 0 & 0 \\
\hline 13 & 0 & 0 & 0 & 0 & 0 & 0 & 0 & 0 & 0 & 0 & 0 & 0.105 & 0.864 & 0 & 0 & 0 & 0 & 0 \\
\hline 14 & 0 & 0 & 0 & 0 & 0 & 0 & 0 & 0 & 0 & 0 & 0 & 0 & 0.092 & 0.881 & 0 & 0 & 0 & 0 \\
\hline 15 & 0 & 0 & 0 & 0 & 0 & 0 & 0 & 0 & 0 & 0 & 0 & 0 & 0 & 0.078 & 0.899 & 0 & 0 & 0 \\
\hline 16 & 0 & 0 & 0 & 0 & 0 & 0 & 0 & 0 & 0 & 0 & 0 & 0 & 0 & 0 & 0.062 & 0.916 & 0 & 0 \\
\hline 17 & 0 & 0 & 0 & 0 & 0 & 0 & 0 & 0 & 0 & 0 & 0 & 0 & 0 & 0 & 0 & 0.045 & 0.942 & 0 \\
\hline 18 & 0 & 0 & 0 & 0 & 0 & 0 & 0 & 0 & 0 & 0 & 0 & 0 & 0 & 0 & 0 & 0 & 0.027 & 0.964 \\
\hline
\end{tabular}


Tabel B3-4e. Transitionmatrix T Oude Trekerbos voor beuk.

Table B3-4e. Transitionmatrix T Oude Trekerbos for Common beech.

\begin{tabular}{|c|c|c|c|c|c|c|c|c|c|c|c|c|c|c|c|c|c|c|}
\hline CB & 1 & 2 & 3 & 4 & 5 & 6 & 7 & 8 & 9 & 10 & 11 & 12 & 13 & 14 & 15 & 16 & 17 & 18 \\
\hline 1 & 0.851 & 0.193 & 0 & 0 & 0 & 0 & 0 & 0 & 0 & 0 & 0 & 0 & 0 & 0 & 0 & 0 & 0 & 0 \\
\hline 2 & 0.113 & 0.853 & 0 & 0 & 0 & 0 & 0 & 0 & 0 & 0 & 0 & 0 & 0 & 0 & 0 & 0 & 0 & 0 \\
\hline 3 & 0 & 0.111 & 0.856 & 0 & 0 & 0 & 0 & 0 & 0 & 0 & 0 & 0 & 0 & 0 & 0 & 0 & 0 & 0 \\
\hline 4 & 0 & 0 & 0.110 & 0.857 & 0 & 0 & 0 & 0 & 0 & 0 & 0 & 0 & 0 & 0 & 0 & 0 & 0 & 0 \\
\hline 5 & 0 & 0 & 0 & 0.108 & 0.860 & 0 & 0 & 0 & 0 & 0 & 0 & 0 & 0 & 0 & 0 & 0 & 0 & 0 \\
\hline 6 & 0 & 0 & 0 & 0 & 0.106 & 0.862 & 0 & 0 & 0 & 0 & 0 & 0 & 0 & 0 & 0 & 0 & 0 & 0 \\
\hline 7 & 0 & 0 & 0 & 0 & 0 & 0.104 & 0.865 & 0 & 0 & 0 & 0 & 0 & 0 & 0 & 0 & 0 & 0 & 0 \\
\hline 8 & 0 & 0 & 0 & 0 & 0 & 0 & 0.102 & 0.868 & 0 & 0 & 0 & 0 & 0 & 0 & 0 & 0 & 0 & 0 \\
\hline 9 & 0 & 0 & 0 & 0 & 0 & 0 & 0 & 0.099 & 0.871 & 0 & 0 & 0 & 0 & 0 & 0 & 0 & 0 & 0 \\
\hline 10 & 0 & 0 & 0 & 0 & 0 & 0 & 0 & 0 & 0.097 & 0.874 & 0 & 0 & 0 & 0 & 0 & 0 & 0 & 0 \\
\hline 11 & 0 & 0 & 0 & 0 & 0 & 0 & 0 & 0 & 0 & 0.094 & 0.878 & 0 & 0 & 0 & 0 & 0 & 0 & 0 \\
\hline 12 & 0 & 0 & 0 & 0 & 0 & 0 & 0 & 0 & 0 & 0.00 & 0.091 & 0.881 & 0 & 0 & 0 & 0 & 0 & 0 \\
\hline 13 & 0 & 0 & 0 & 0 & 0 & 0 & 0 & 0 & 0 & 0 & 0 & 0.088 & 0.885 & 0 & 0 & 0 & 0 & 0 \\
\hline 14 & 0 & 0 & 0 & 0 & 0 & 0 & 0 & 0 & 0 & 0 & 0 & 0 & 0.085 & 0.889 & 0 & 0 & 0 & 0 \\
\hline 15 & 0 & 0 & 0 & 0 & 0 & 0 & 0 & 0 & 0 & 0 & 0 & 0 & 0 & 0.082 & 0.893 & 0 & 0 & 0 \\
\hline 16 & 0 & 0 & 0 & 0 & 0 & 0 & 0 & 0 & 0 & 0 & 0 & 0 & 0 & 0 & 0.079 & 0.897 & 0 & 0 \\
\hline 17 & 0 & 0 & 0 & 0 & 0 & 0 & 0 & 0 & 0 & 0 & 0 & 0 & 0 & 0 & 0 & 0.075 & 0.902 & 0 \\
\hline 18 & 0 & 0 & 0 & 0 & 0 & 0 & 0 & 0 & 0 & 0 & 0 & 0 & 0 & 0 & 0 & 0 & 0.072 & 0.907 \\
\hline
\end{tabular}

Tabel B3-4f. Transitionmatrix T Oude Trekerbos voor eik.

Table B3-4f. Transitionmatrix T Oude Trekerbos for Common oak.

\begin{tabular}{|r|rrrrrrrrrrrrrrrr|r|r|r|r}
\hline CO & 1 & 2 & 3 & 4 & 5 & 6 & 7 & 8 & 9 & 10 & 11 & 12 & 13 & 14 & 15 & 16 & 17 & 18 \\
\hline 1 & 0.891 & 0.142 & 0 & 0 & 0 & 0 & 0 & 0 & 0 & 0 & 0 & 0 & 0 & 0 & 0 & 0 & 0 & 0 \\
2 & 0.082 & 0.894 & 0 & 0 & 0 & 0 & 0 & 0 & 0 & 0 & 0 & 0 & 0 & 0 & 0 & 0 & 0 & 0 \\
3 & 0 & 0.080 & 0.901 & 0 & 0 & 0 & 0 & 0 & 0 & 0 & 0 & 0 & 0 & 0 & 0 & 0 & 0 & 0 \\
4 & 0 & 0 & 0.078 & 0.897 & 0 & 0 & 0 & 0 & 0 & 0 & 0 & 0 & 0 & 0 & 0 & 0 & 0 & 0 \\
5 & 0 & 0 & 0 & 0.077 & 0.898 & 0 & 0 & 0 & 0 & 0 & 0 & 0 & 0 & 0 & 0 & 0 & 0 & 0 \\
6 & 0 & 0 & 0 & 0 & 0.076 & 0.898 & 0 & 0 & 0 & 0 & 0 & 0 & 0 & 0 & 0 & 0 & 0 & 0 \\
7 & 0 & 0 & 0 & 0 & 0 & 0.075 & 0.902 & 0 & 0 & 0 & 0 & 0 & 0 & 0 & 0 & 0 & 0 & 0 \\
8 & 0 & 0 & 0 & 0 & 0 & 0 & 0.075 & 0.903 & 0 & 0 & 0 & 0 & 0 & 0 & 0 & 0 & 0 & 0 \\
9 & 0 & 0 & 0 & 0 & 0 & 0 & 0 & 0.075 & 0.902 & 0 & 0 & 0 & 0 & 0 & 0 & 0 & 0 & 0 \\
10 & 0 & 0 & 0 & 0 & 0 & 0 & 0 & 0 & 0.075 & 0.902 & 0 & 0 & 0 & 0 & 0 & 0 & 0 & 0 \\
11 & 0 & 0 & 0 & 0 & 0 & 0 & 0 & 0 & 0 & 0.076 & 0.901 & 0 & 0 & 0 & 0 & 0 & 0 & 0 \\
12 & 0 & 0 & 0 & 0 & 0 & 0 & 0 & 0 & 0 & 0.00 & 0.077 & 0.900 & 0 & 0 & 0 & 0 & 0 & 0 \\
13 & 0 & 0 & 0 & 0 & 0 & 0 & 0 & 0 & 0 & 0 & 0 & 0.079 & 0.898 & 0 & 0 & 0 & 0 & 0 \\
14 & 0 & 0 & 0 & 0 & 0 & 0 & 0 & 0 & 0 & 0 & 0 & 0 & 0.080 & 0.895 & 0 & 0 & 0 & 0 \\
15 & 0 & 0 & 0 & 0 & 0 & 0 & 0 & 0 & 0 & 0 & 0 & 0 & 0 & 0.083 & 0.893 & 0 & 0 & 0 \\
16 & 0 & 0 & 0 & 0 & 0 & 0 & 0 & 0 & 0 & 0 & 0 & 0 & 0 & 0 & 0.085 & 0.890 & 0 & 0 \\
17 & 0 & 0 & 0 & 0 & 0 & 0 & 0 & 0 & 0 & 0 & 0 & 0 & 0 & 0 & 0 & 0.088 & 0.886 \\
18 & 0 & 0 & 0 & 0 & 0 & 0 & 0 & 0 & 0 & 0 & 0 & 0 & 0 & 0 & 0 & 0 & 0 \\
\end{tabular}




\section{BIJLAGE 4A. EVENWICHTSTOESTAND BOOMBOS ZONDER KAP}

In Tabel 26 staan de sterftekansen en In Tabel 24 de springkansen voor beheer voor zowel zonder als met kap.

Gevonden werd een stamtal, grondvlak en volumeverdeling zoals weergegeven in de tabellen B4A-1, B4A-2 en B4A-3 en de Figuren B4A-1, B4A-2 en B4A-3.

Tabel B4A-1. Stamtal per ha per soort en diameterklasse in evenwichtstoestand zonder kap in Boombos

Table B4A-1. Number of trees per ha per species and diameter class in stable state without harvest in Boombos

\begin{tabular}{|c|rr|r|}
\hline \multirow{2}{*}{$\begin{array}{c}\text { diameter } \\
\text { in } \mathbf{~ c m}\end{array}$} & \multicolumn{3}{|c|}{ Number of trees per ha } \\
\cline { 2 - 4 } $0-4$ & 409.7 & other & total \\
$4-8$ & 220.7 & 218.4 & 1028.1 \\
$8-12$ & 136.0 & 85.3 & 431.0 \\
$12-16$ & 89.9 & 38.2 & 221.3 \\
$16-20$ & 59.6 & 17.8 & 128.1 \\
$20-24$ & 41.7 & 9.0 & 77.4 \\
$24-28$ & 29.3 & 4.7 & 50.7 \\
$28-32$ & 21.5 & 2.6 & 34.0 \\
$32-36$ & 16.4 & 1.6 & 24.1 \\
$36-40$ & 12.5 & 1.0 & 17.9 \\
$40-44$ & 9.8 & 0.7 & 13.4 \\
$44-48$ & 7.7 & 0.5 & 10.5 \\
$48-52$ & 6.3 & 0.3 & 8.2 \\
$52-56$ & 5.2 & 0.2 & 6.6 \\
$56-60$ & 4.3 & 0.2 & 5.4 \\
$60-64$ & 3.6 & 0.1 & 4.4 \\
$64-68$ & 3.1 & 0.1 & 3.7 \\
$68-72$ & 2.7 & 0.1 & 3.2 \\
$72-76$ & 2.3 & 0.0 & 2.7 \\
$\geq 76$ & 2.0 & 0.0 & 2.3 \\
\hline Total & 1084.0 & 991.0 & 2.0 \\
\hline
\end{tabular}


Tabel B4A-2. Grondvlak in $\mathrm{m}^{2}$ per ha per soort en diameterklasse in evenwichtstoestand zonder kap in Boombos.

Table B4B-2. Basal area in $\mathrm{m}^{2}$ per ha per species and diameter class in stable state without harvest in Boombos.

\begin{tabular}{|c|rc|c|}
\hline \multirow{2}{*}{$\begin{array}{c}\text { diameter } \\
\text { in } \mathbf{~ c m ~}\end{array}$} & \multicolumn{3}{|c|}{ Basal area in $\mathbf{~ m}^{2}$ per ha } \\
\cline { 2 - 4 } & CB & other & total \\
\hline $0-4$ & 0.16 & 0.24 & 0.40 \\
$8-8$ & 0.63 & 0.60 & 1.23 \\
$12-16$ & 1.06 & 0.67 & 1.73 \\
$16-20$ & 1.38 & 0.58 & 1.96 \\
$20-24$ & 1.51 & 0.45 & 1.96 \\
$24-28$ & 1.58 & 0.34 & 1.92 \\
$28-32$ & 1.55 & 0.25 & 1.79 \\
$32-36$ & 1.51 & 0.19 & 1.70 \\
$36-40$ & 1.48 & 0.14 & 1.62 \\
$40-44$ & 1.41 & 0.11 & 1.52 \\
$44-48$ & 1.35 & 0.10 & 1.45 \\
$48-52$ & 1.28 & 0.08 & 1.36 \\
$52-56$ & 1.22 & 0.06 & 1.29 \\
$56-60$ & 1.18 & 0.05 & 1.23 \\
$60-64$ & 1.13 & 0.04 & 1.17 \\
$64-68$ & 1.09 & 0.03 & 1.12 \\
$68-72$ & 1.06 & 0.03 & 1.09 \\
$72-76$ & 1.02 & 0.02 & 1.04 \\
$\geq 76$ & 0.98 & 0.02 & 1.00 \\
\hline Total & 0.95 & 0.02 & 0.97 \\
\hline
\end{tabular}


Tabel B4A-3. Volume in $\mathrm{m}^{3}$ per ha per soort en diameterklasse in evenwichtstoestand zonder kap in Boombos.

Table B4A-3. Volume in $\mathrm{m}^{3}$ per ha per species and diameter class in stable state without harvest in Boombos.

\begin{tabular}{|c|rr|r|}
\hline \multirow{2}{*}{$\begin{array}{c}\text { diameter } \\
\text { in } \mathbf{~ c m}\end{array}$} & \multicolumn{3}{|c|}{ Volume in $\mathbf{~}^{\mathbf{3}}$ per ha } \\
\cline { 2 - 4 } o- -4 & 1.0 & 1.1 & total \\
$4-8$ & 4.5 & 4.2 & 2.1 \\
$8-12$ & 8.3 & 5.2 & 8.7 \\
$12-16$ & 11.4 & 4.9 & 13.5 \\
$16-20$ & 13.1 & 3.9 & 16.3 \\
$20-24$ & 14.2 & 3.1 & 17.0 \\
$24-28$ & 14.4 & 2.3 & 17.3 \\
$28-32$ & 14.4 & 1.8 & 16.7 \\
$32-36$ & 14.4 & 1.4 & 16.2 \\
$36-40$ & 14.0 & 1.1 & 15.8 \\
$40-44$ & 13.7 & 1.0 & 15.1 \\
$44-48$ & 13.2 & 0.8 & 14.7 \\
$48-52$ & 12.8 & 0.7 & 14.0 \\
$52-56$ & 12.6 & 0.5 & 13.5 \\
$56-60$ & 12.2 & 0.4 & 13.1 \\
$60-64$ & 11.9 & 0.4 & 12.6 \\
$64-68$ & 11.7 & 0.3 & 12.3 \\
$68-72$ & 11.4 & 0.3 & 12.0 \\
$72-76$ & 11.0 & 0.2 & 11.6 \\
$\geq 76$ & 10.9 & 0.2 & 11.2 \\
\hline Total & 231.1 & 33.8 & 11.1 \\
\hline & & & 265.0 \\
\hline
\end{tabular}




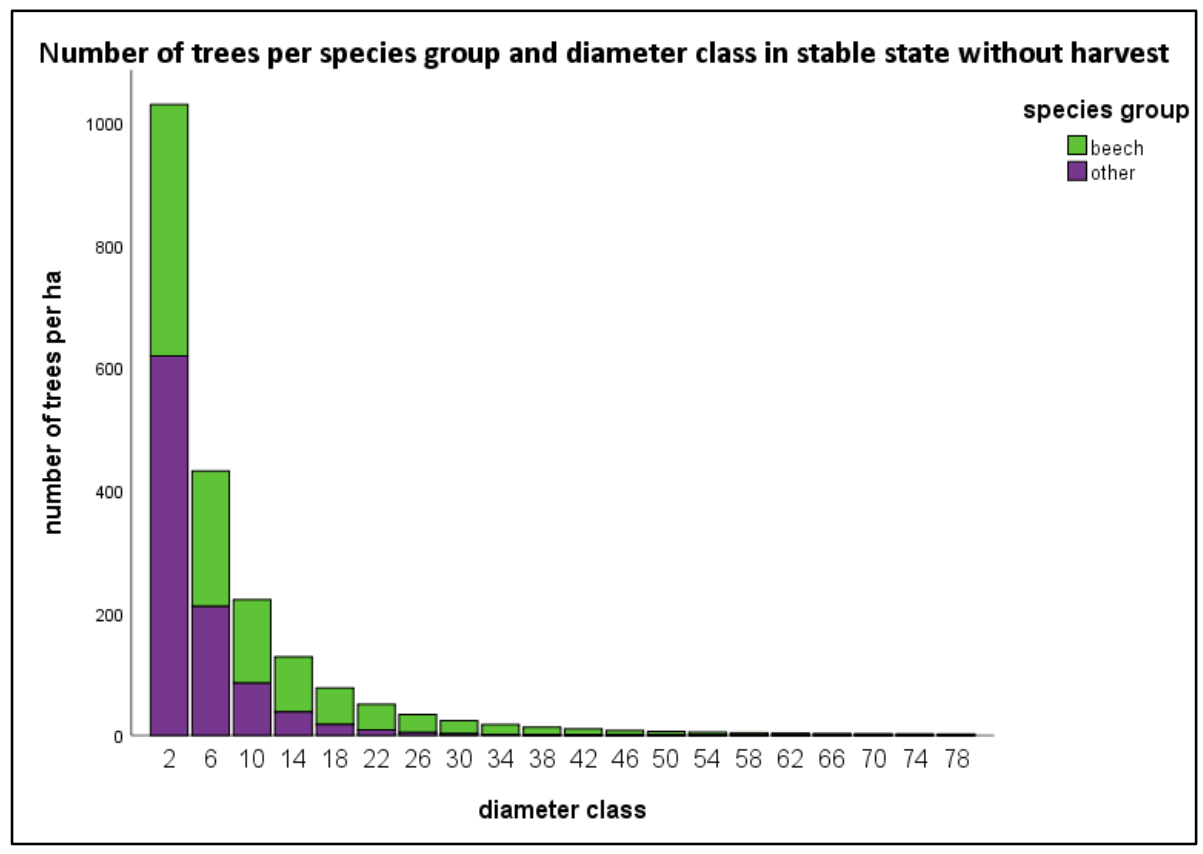

Figuur B4A-1. Stamtal per ha per soort en diameterklasse in evenwichtstoestand zonder kap in Boombos.

Figure B4A-1. Number of trees per ha per species and diameter class in stable state without harvest in Boombos.

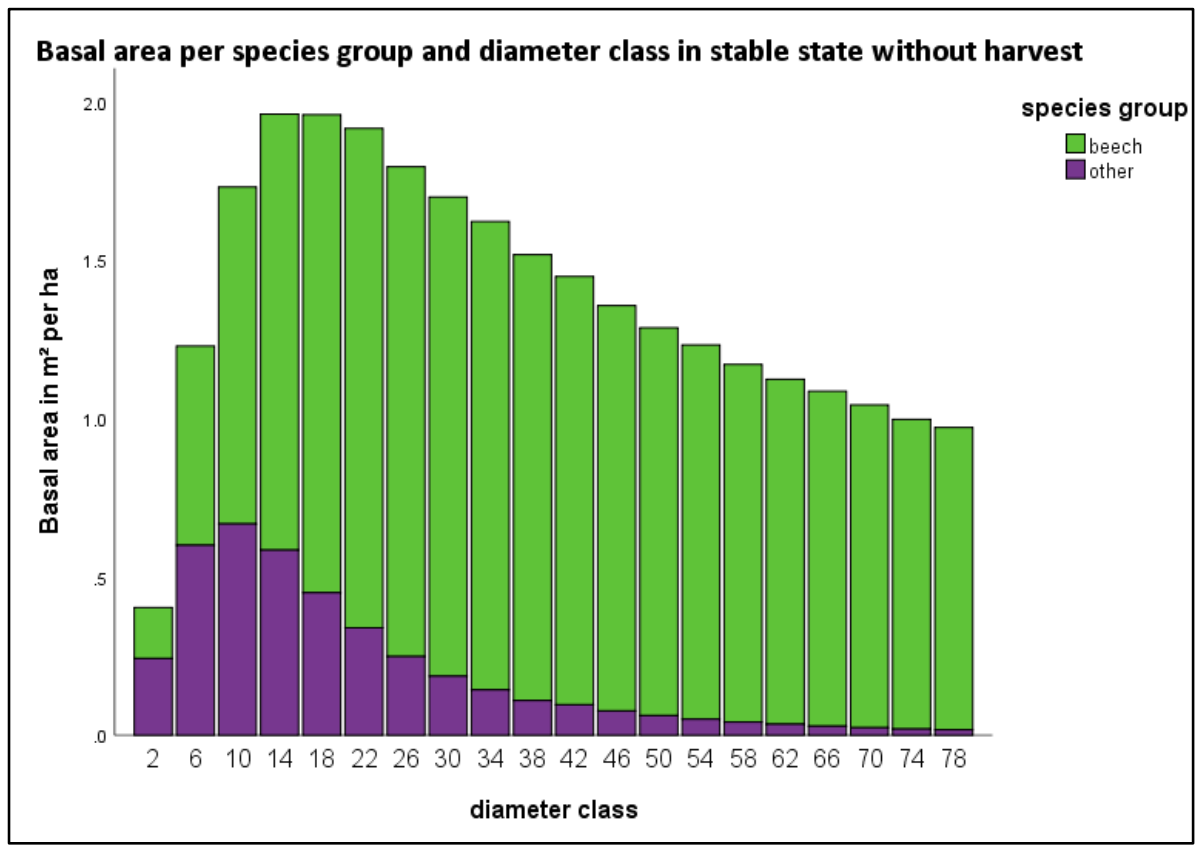

Figuur B4A-2. Grondvlak in $\mathrm{m}^{2}$ per ha per soort en diameterklasse in evenwichtstoestand zonder kap in Boombos.

Figure B4A-2. Basal area in $\mathrm{m}^{2}$ per ha per species and diameter class in stable state without harvest in Boombos. 


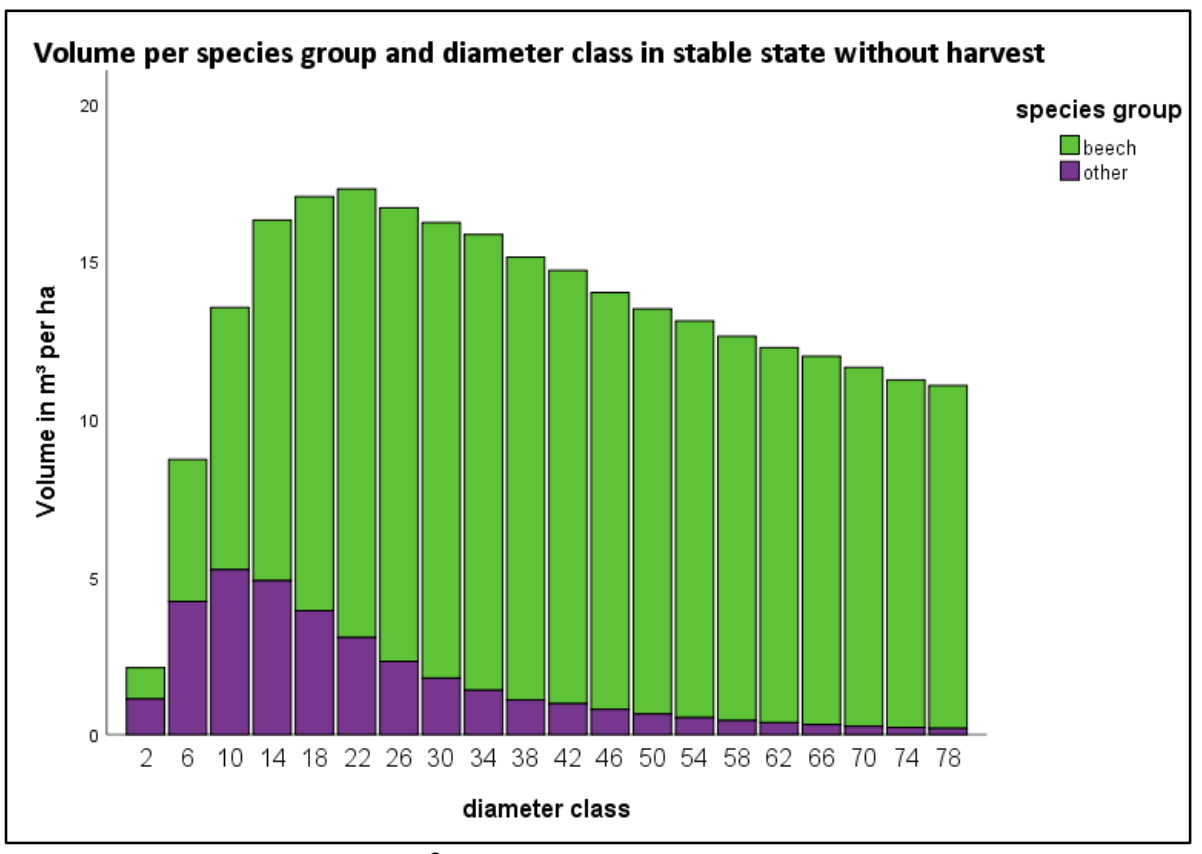

Figuur B4A-3. Volume in $m^{3}$ per ha per soort en diameterklasse in evenwichtstoestand zonder kap in Boombos

Figure B4A-3. Volume in $m^{3}$ per ha per species and diameter class in stable state with harvest in Boombos. 
In de tabellen B4A-4a en B4A-4b zijn de matrices $\mathbf{T}$ voor achtereenvolgens de soortgroepen bu, en ov weergegeven.

Tabel B4A-4a. Matrix T voor bepalen evenwichtstoestand zonder kap bij beuk.

Table B4A-4a. Matrix T for determining stable state without harvest for beech.

\begin{tabular}{|c|c|c|c|c|c|c|c|c|c|c|c|c|c|c|c|c|c|c|c|c|}
\hline CB & 1 & 2 & 3 & 4 & 5 & 6 & 7 & 8 & 9 & 10 & 11 & 12 & 13 & 14 & 15 & 16 & 17 & 18 & 19 & 20 \\
\hline 1 & 0.923 & 0.143 & 0 & 0 & 0 & 0 & 0 & 0 & 0 & 0 & 0 & 0 & 0 & 0 & 0 & 0 & 0 & 0 & 0 & 0 \\
\hline 2 & 0.029 & 0.947 & 0 & 0 & 0 & 0 & 0 & 0 & 0 & 0 & 0 & 0 & 0 & 0 & 0 & 0 & 0 & 0 & 0 & 0 \\
\hline 3 & 0 & 0.031 & 0.950 & 0 & 0 & 0 & 0 & 0 & 0 & 0 & 0 & 0 & 0 & 0 & 0 & 0 & 0 & 0 & 0 & 0 \\
\hline 4 & 0 & 0 & 0.033 & 0.950 & 0 & 0 & 0 & 0 & 0 & 0 & 0 & 0 & 0 & 0 & 0 & 0 & 0 & 0 & 0 & 0 \\
\hline 5 & 0 & 0 & 0 & 0.035 & 0.947 & 0 & 0 & 0 & 0 & 0 & 0 & 0 & 0 & 0 & 0 & 0 & 0 & 0 & 0 & 0 \\
\hline 6 & 0 & 0 & 0 & 0 & 0.040 & 0.943 & 0 & 0 & 0 & 0 & 0 & 0 & 0 & 0 & 0 & 0 & 0 & 0 & 0 & 0 \\
\hline 7 & 0 & 0 & 0 & 0 & 0 & 0.044 & 0.937 & 0 & 0 & 0 & 0 & 0 & 0 & 0 & 0 & 0 & 0 & 0 & 0 & 0 \\
\hline 8 & 0 & 0 & 0 & 0 & 0 & 0 & 0.051 & 0.931 & 0 & 0 & 0 & 0 & 0 & 0 & 0 & 0 & 0 & 0 & 0 & 0 \\
\hline 9 & 0 & 0 & 0 & 0 & 0 & 0 & 0 & 0.057 & 0.925 & 0 & 0 & 0 & 0 & 0 & 0 & 0 & 0 & 0 & 0 & 0 \\
\hline 10 & 0 & 0 & 0 & 0 & 0 & 0 & 0 & 0 & 0.064 & 0.916 & 0 & 0 & 0 & 0 & 0 & 0 & 0 & 0 & 0 & 0 \\
\hline 11 & 0 & 0 & 0 & 0 & 0 & 0 & 0 & 0 & 0 & 0.073 & 0.907 & 0 & 0 & 0 & 0 & 0 & 0 & 0 & 0 & 0 \\
\hline 12 & 0 & 0 & 0 & 0 & 0 & 0 & 0 & 0 & 0 & 0.00 & 0.082 & 0.896 & 0 & 0 & 0 & 0 & 0 & 0 & 0 & 0 \\
\hline 13 & 0 & 0 & 0 & 0 & 0 & 0 & 0 & 0 & 0 & 0 & 0 & 0.093 & 0.885 & 0 & 0 & 0 & 0 & 0 & 0 & 0 \\
\hline 14 & 0 & 0 & 0 & 0 & 0 & 0 & 0 & 0 & 0 & 0 & 0 & 0 & 0.104 & 0.874 & 0 & 0 & 0 & 0 & 0 & 0 \\
\hline 15 & 0 & 0 & 0 & 0 & 0 & 0 & 0 & 0 & 0 & 0 & 0 & 0 & 0 & 0.116 & 0.860 & 0 & 0 & 0 & 0 & 0 \\
\hline 16 & 0 & 0 & 0 & 0 & 0 & 0 & 0 & 0 & 0 & 0 & 0 & 0 & 0 & 0 & 0.129 & 0.847 & 0 & 0 & 0 & 0 \\
\hline 17 & 0 & 0 & 0 & 0 & 0 & 0 & 0 & 0 & 0 & 0 & 0 & 0 & 0 & 0 & 0 & 0.143 & 0.833 & 0 & 0 & 0 \\
\hline 18 & 0 & 0 & 0 & 0 & 0 & 0 & 0 & 0 & 0 & 0 & 0 & 0 & 0 & 0 & 0 & 0 & 0.157 & 0.817 & 0 & 0 \\
\hline 19 & 0 & 0 & 0 & 0 & 0 & 0 & 0 & 0 & 0 & 0 & 0 & 0 & 0 & 0 & 0 & 0 & 0 & 0.173 & 0.799 & 0 \\
\hline 20 & 0 & 0 & 0 & 0 & 0 & 0 & 0 & 0 & 0 & 0 & 0 & 0 & 0 & 0 & 0 & 0 & 0 & 0 & 0.191 & 0.783 \\
\hline
\end{tabular}

Tabel B4A-4b. Matrix T voor bepalen evenwichtstoestand zonder kap bij overige soorten

Table B4A-4b. Matrix T for determining stable state without harvest for other species.

\begin{tabular}{|c|c|c|c|c|c|c|c|c|c|c|c|c|c|c|c|c|c|c|c|c|}
\hline other & 1 & 2 & 3 & 4 & 5 & 6 & 7 & 8 & 9 & 10 & 11 & 12 & 13 & 14 & 15 & 16 & 17 & 18 & 19 & 20 \\
\hline 1 & 0.867 & 0.392 & 0 & 0 & 0 & 0 & 0 & 0 & 0 & 0 & 0 & 0 & 0 & 0 & 0 & 0 & 0 & 0 & 0 & 0 \\
\hline 2 & 0.029 & 0.916 & 0 & 0 & 0 & 0 & 0 & 0 & 0 & 0 & 0 & 0 & 0 & 0 & 0 & 0 & 0 & 0 & 0 & 0 \\
\hline 3 & 0 & 0.031 & 0.924 & 0 & 0 & 0 & 0 & 0 & 0 & 0 & 0 & 0 & 0 & 0 & 0 & 0 & 0 & 0 & 0 & 0 \\
\hline 4 & 0 & 0 & 0.033 & 0.926 & 0 & 0 & 0 & 0 & 0 & 0 & 0 & 0 & 0 & 0 & 0 & 0 & 0 & 0 & 0 & 0 \\
\hline 5 & 0 & 0 & 0 & 0.035 & 0.924 & 0 & 0 & 0 & 0 & 0 & 0 & 0 & 0 & 0 & 0 & 0 & 0 & 0 & 0 & 0 \\
\hline 6 & 0 & 0 & 0 & 0 & 0.040 & 0.922 & 0 & 0 & 0 & 0 & 0 & 0 & 0 & 0 & 0 & 0 & 0 & 0 & 0 & 0 \\
\hline 7 & 0 & 0 & 0 & 0 & 0 & 0.044 & 0.916 & 0 & 0 & 0 & 0 & 0 & 0 & 0 & 0 & 0 & 0 & 0 & 0 & 0 \\
\hline 8 & 0 & 0 & 0 & 0 & 0 & 0 & 0.051 & 0.910 & 0 & 0 & 0 & 0 & 0 & 0 & 0 & 0 & 0 & 0 & 0 & 0 \\
\hline 9 & 0 & 0 & 0 & 0 & 0 & 0 & 0 & 0.057 & 0.904 & 0 & 0 & 0 & 0 & 0 & 0 & 0 & 0 & 0 & 0 & 0 \\
\hline 10 & 0 & 0 & 0 & 0 & 0 & 0 & 0 & 0 & 0.064 & 0.896 & 0 & 0 & 0 & 0 & 0 & 0 & 0 & 0 & 0 & 0 \\
\hline 11 & 0 & 0 & 0 & 0 & 0 & 0 & 0 & 0 & 0 & 0.073 & 0.898 & 0 & 0 & 0 & 0 & 0 & 0 & 0 & 0 & 0 \\
\hline 12 & 0 & 0 & 0 & 0 & 0 & 0 & 0 & 0 & 0 & 0.00 & 0.071 & 0.894 & 0 & 0 & 0 & 0 & 0 & 0 & 0 & 0 \\
\hline 13 & 0 & 0 & 0 & 0 & 0 & 0 & 0 & 0 & 0 & 0 & 0 & 0.075 & 0.890 & 0 & 0 & 0 & 0 & 0 & 0 & 0 \\
\hline 14 & 0 & 0 & 0 & 0 & 0 & 0 & 0 & 0 & 0 & 0 & 0 & 0 & 0.080 & 0.886 & 0 & 0 & 0 & 0 & 0 & 0 \\
\hline 15 & 0 & 0 & 0 & 0 & 0 & 0 & 0 & 0 & 0 & 0 & 0 & 0 & 0 & 0.084 & 0.881 & 0 & 0 & 0 & 0 & 0 \\
\hline 16 & 0 & 0 & 0 & 0 & 0 & 0 & 0 & 0 & 0 & 0 & 0 & 0 & 0 & 0 & 0.089 & 0.879 & 0 & 0 & 0 & 0 \\
\hline 17 & 0 & 0 & 0 & 0 & 0 & 0 & 0 & 0 & 0 & 0 & 0 & 0 & 0 & 0 & 0 & 0.091 & 0.875 & 0 & 0 & 0 \\
\hline 18 & 0 & 0 & 0 & 0 & 0 & 0 & 0 & 0 & 0 & 0 & 0 & 0 & 0 & 0 & 0 & 0 & 0.095 & 0.871 & 0 & 0 \\
\hline 19 & 0 & 0 & 0 & 0 & 0 & 0 & 0 & 0 & 0 & 0 & 0 & 0 & 0 & 0 & 0 & 0 & 0 & 0.100 & 0.866 & 0 \\
\hline 20 & 0 & 0 & 0 & 0 & 0 & 0 & 0 & 0 & 0 & 0 & 0 & 0 & 0 & 0 & 0 & 0 & 0 & 0 & 0.104 & 0.864 \\
\hline
\end{tabular}




\section{BIJLAGE 4B. EVENWICHTSTOESTAND BOOMBOS MET KAP}

In Tabel 27 staan de kapkansen, In Tabel 28 de sterftekansen en In Tabel 24 de springkansen. Gevonden werd een stamtal, grondvlak en volumeverdeling zoals weergegeven in de tabellen B4B-1, B4B-2 en B4B-3 en de Figuren B4B-1, B4B-2 en B4B-3.

Tabel B4B-1. Stamtal per ha per soort en diameterklasse in evenwichtstoestand met kap in Boombos.

Table B4B-1. Number of trees per ha per species and diameter class in stable state with harvest in Boombos.

\begin{tabular}{|c|rr|r|}
\hline diameter & \multicolumn{3}{|c|}{ Number of trees per ha } \\
\cline { 2 - 4 } in cm & CB & other & total \\
\hline $0-4$ & 268.7 & 159.9 & 428.6 \\
$4-8$ & 144.7 & 54.4 & 199.1 \\
$8-12$ & 89.2 & 22.1 & 111.2 \\
$12-16$ & 71.2 & 17.7 & 88.9 \\
$16-20$ & 54.2 & 13.3 & 67.6 \\
$20-24$ & 42.3 & 10.4 & 52.7 \\
$24-28$ & 32.0 & 7.9 & 39.9 \\
$28-32$ & 24.6 & 6.1 & 30.7 \\
$32-36$ & 19.1 & 4.7 & 23.9 \\
$36-40$ & 14.6 & 3.4 & 18.0 \\
$40-44$ & 11.3 & 2.8 & 14.1 \\
$44-48$ & 8.6 & 2.1 & 10.7 \\
$48-52$ & 6.6 & 1.6 & 8.3 \\
$52-56$ & 5.1 & 1.3 & 6.4 \\
$56-60$ & 3.9 & 1.0 & 4.9 \\
$60-64$ & 3.0 & 0.7 & 3.8 \\
$64-68$ & 2.3 & 0.6 & 2.9 \\
$68-72$ & 1.8 & 0.4 & 2.2 \\
$72-76$ & 1.4 & 0.3 & 1.7 \\
$\geq 76$ & 1.0 & 0.3 & 1.3 \\
\hline Total & 805.9 & 311.0 & 116.9 \\
\hline
\end{tabular}


Tabel B4B-2. Grondvlak in $\mathrm{m}^{2}$ per ha per soort en diameterklasse in evenwichtstoestand met kap in Boombos.

Table B4B-2. Basal area in $\mathrm{m}^{2}$ per ha per species and diameter class in stable state with harvest in Boombos.

\begin{tabular}{|c|rc|c|}
\hline \multirow{2}{*}{$\begin{array}{c}\text { diameter } \\
\text { in } \mathbf{~ c m ~}\end{array}$} & \multicolumn{3}{|c|}{ Basal area in $\mathbf{~ m}^{2}$ per ha } \\
\cline { 2 - 4 } o -4 & 0.11 & 0.06 & total \\
$4-8$ & 0.41 & 0.16 & 0.17 \\
$8-12$ & 0.70 & 0.17 & 0.57 \\
$12-16$ & 1.09 & 0.27 & 0.87 \\
$16-20$ & 1.37 & 0.34 & 1.36 \\
$20-24$ & 1.60 & 0.39 & 1.71 \\
$24-28$ & 1.69 & 0.42 & 1.99 \\
$28-32$ & 1.73 & 0.43 & 2.11 \\
$32-36$ & 1.73 & 0.43 & 2.16 \\
$36-40$ & 1.65 & 0.39 & 2.16 \\
$40-44$ & 1.56 & 0.39 & 2.03 \\
$44-48$ & 1.43 & 0.35 & 1.95 \\
$48-52$ & 1.30 & 0.32 & 1.78 \\
$52-56$ & 1.17 & 0.29 & 1.62 \\
$56-60$ & 1.03 & 0.25 & 1.46 \\
$60-64$ & 0.91 & 0.23 & 1.28 \\
$64-68$ & 0.79 & 0.20 & 1.13 \\
$68-72$ & 0.69 & 0.17 & 0.99 \\
$72-76$ & 0.59 & 0.14 & 0.85 \\
$\geq 76$ & 0.50 & 0.12 & 0.73 \\
\hline Total & 22.03 & 5.51 & 0.62 \\
\hline
\end{tabular}


Tabel B4B-3. Volume in $\mathrm{m}^{3}$ per ha per soort en diameterklasse in evenwichtstoestand met kap in Boombos.

Table B4B-3. Volume in $\mathrm{m}^{3}$ per ha per species and diameter class in stable state with harvest in Boombos.

\begin{tabular}{|c|rr|r|}
\hline \multirow{2}{*}{$\begin{array}{c}\text { diameter } \\
\text { in } \mathbf{~ c m ~}\end{array}$} & \multicolumn{3}{|c|}{ Volume in $\mathbf{~ m}^{\mathbf{3}}$ per ha } \\
\cline { 2 - 4 } ( -4 & other & total \\
$4-8$ & 0.7 & 0.4 & 1.0 \\
$8-12$ & 3.0 & 1.1 & 4.1 \\
$12-16$ & 5.5 & 1.3 & 6.8 \\
$16-20$ & 9.0 & 2.2 & 11.3 \\
$20-24$ & 11.9 & 2.9 & 14.9 \\
$24-28$ & 14.4 & 3.5 & 18.0 \\
$28-32$ & 15.7 & 3.9 & 19.6 \\
$32-36$ & 16.6 & 4.1 & 20.6 \\
$36-40$ & 16.9 & 4.2 & 21.1 \\
$40-44$ & 16.4 & 3.9 & 20.3 \\
$44-48$ & 15.8 & 4.0 & 19.8 \\
$48-52$ & 14.7 & 3.6 & 18.4 \\
$52-56$ & 13.6 & 3.4 & 16.9 \\
$56-60$ & 12.4 & 3.1 & 15.5 \\
$60-64$ & 11.1 & 2.7 & 13.8 \\
$64-68$ & 9.9 & 2.5 & 12.4 \\
$68-72$ & 8.8 & 2.2 & 10.9 \\
$72-76$ & 7.7 & 1.9 & 9.5 \\
$\geq 76$ & 6.6 & 1.6 & 8.2 \\
\hline Total & 5.7 & 1.4 & 7.1 \\
\hline
\end{tabular}




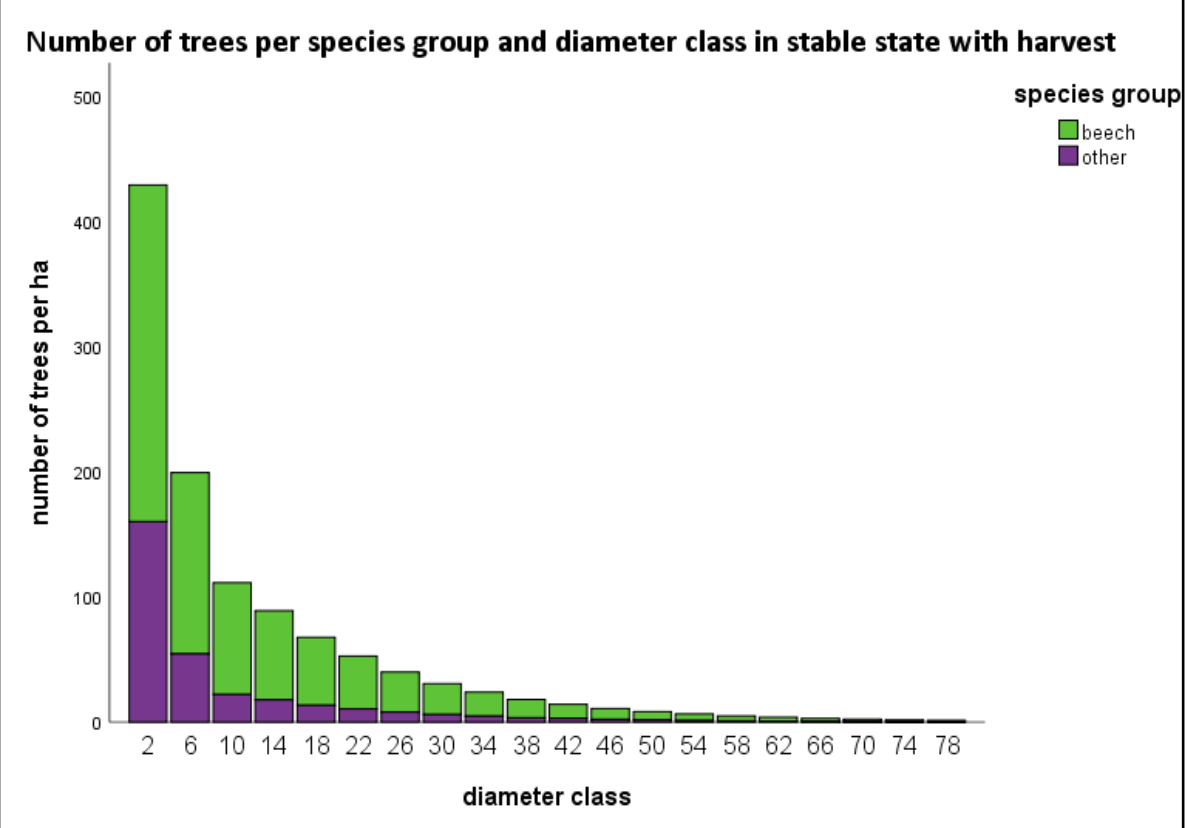

Figuur B4B-1. Stamtal per ha per soort en diameterklasse in evenwichtstoestand met kap in Boombos.

Figure B4B-1. Number of trees per ha per species and diameter class in stable state with harvest in Boombos. 


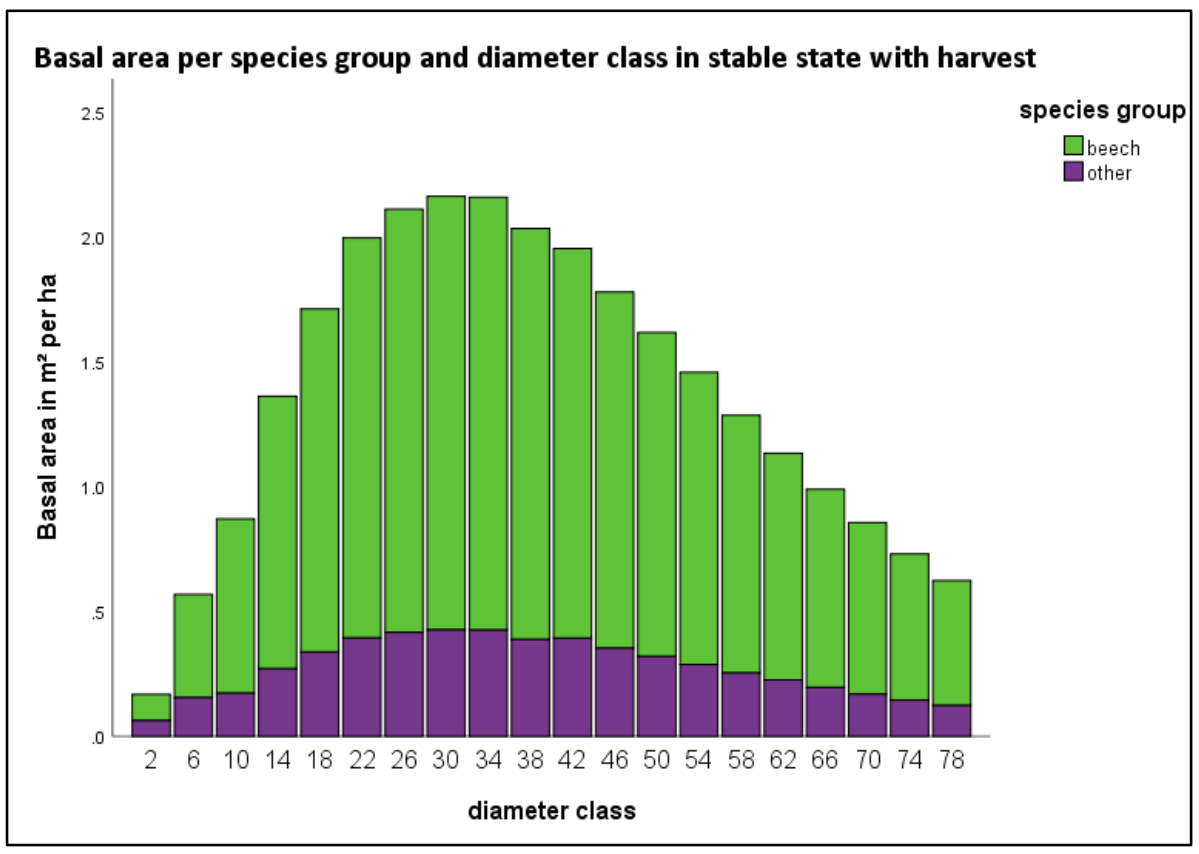

Figuur B4B-2. Grondvlak in $\mathrm{m}^{2}$ per ha per soort en diameterklasse in evenwichtstoestand met kap in Boombos

Figure B4B-2. Basal area in $\mathrm{m}^{2}$ per ha per species and diameter class in stable state with harvest in Boombos.

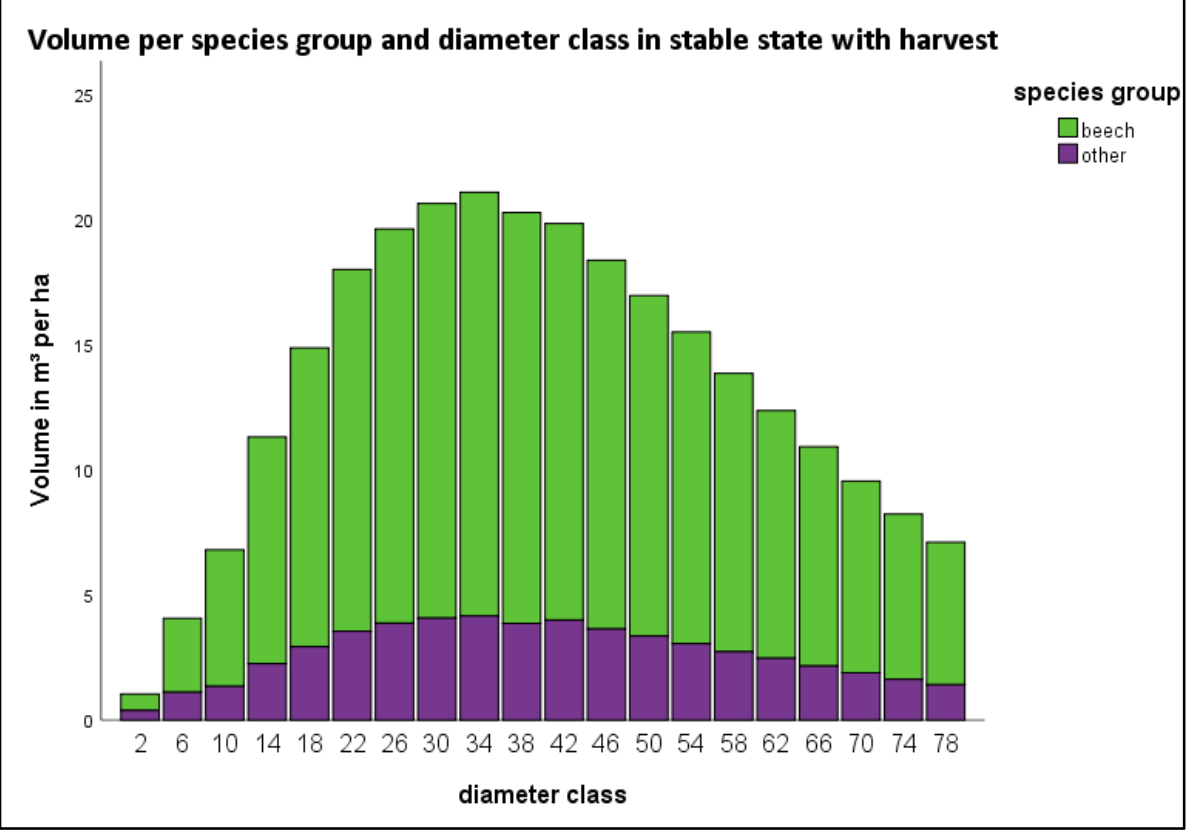

Figuur B4B-3. Volume in $\mathrm{m}^{3}$ per ha per soort en diameterklasse in evenwichtstoestand met kap in Boombos.

Figure B4B-3. Volume in $\mathrm{m}^{3}$ per ha per species and diameter class in stable state with harvest in Boombos.

In de tabellen B4B-4a en B4B-4b zijn de matrices T voor achtereenvolgens de soortgroepen bu, en ov weergegeven. 
Tabel B4B-4a. Matrix T voor bepalen evenwichtstoestand met kap bij beuk.

Table B4B-4a. Matrix T for determining stable state with harvest for beech.

\begin{tabular}{|c|c|c|c|c|c|c|c|c|c|c|c|c|c|c|c|c|c|c|c|c|}
\hline CB & 1 & 2 & 3 & 4 & 5 & 6 & 7 & 8 & 9 & 10 & 11 & 12 & 13 & 14 & 15 & 16 & 17 & 18 & 19 & 20 \\
\hline 1 & 0.923 & 0.143 & 0 & 0 & 0 & 0 & 0 & 0 & 0 & 0 & 0 & 0 & 0 & 0 & 0 & 0 & 0 & 0 & 0 & 0 \\
\hline 2 & 0.029 & 0.947 & 0 & 0 & 0 & 0 & 0 & 0 & 0 & 0 & 0 & 0 & 0 & 0 & 0 & 0 & 0 & 0 & 0 & 0 \\
\hline 3 & 0 & 0.031 & 0.950 & 0 & 0 & 0 & 0 & 0 & 0 & 0 & 0 & 0 & 0 & 0 & 0 & 0 & 0 & 0 & 0 & 0 \\
\hline 4 & 0 & 0 & 0.033 & 0.959 & 0 & 0 & 0 & 0 & 0 & 0 & 0 & 0 & 0 & 0 & 0 & 0 & 0 & 0 & 0 & 0 \\
\hline 5 & 0 & 0 & 0 & 0.035 & 0.954 & 0 & 0 & 0 & 0 & 0 & 0 & 0 & 0 & 0 & 0 & 0 & 0 & 0 & 0 & 0 \\
\hline 6 & 0 & 0 & 0 & 0 & 0.040 & 0.949 & 0 & 0 & 0 & 0 & 0 & 0 & 0 & 0 & 0 & 0 & 0 & 0 & 0 & 0 \\
\hline 7 & 0 & 0 & 0 & 0 & 0 & 0.044 & 0.942 & 0 & 0 & 0 & 0 & 0 & 0 & 0 & 0 & 0 & 0 & 0 & 0 & 0 \\
\hline 8 & 0 & 0 & 0 & 0 & 0 & 0 & 0.051 & 0.934 & 0 & 0 & 0 & 0 & 0 & 0 & 0 & 0 & 0 & 0 & 0 & 0 \\
\hline 9 & 0 & 0 & 0 & 0 & 0 & 0 & 0 & 0.057 & 0.926 & 0 & 0 & 0 & 0 & 0 & 0 & 0 & 0 & 0 & 0 & 0 \\
\hline 10 & 0 & 0 & 0 & 0 & 0 & 0 & 0 & 0 & 0.064 & 0.916 & 0 & 0 & 0 & 0 & 0 & 0 & 0 & 0 & 0 & 0 \\
\hline 11 & 0 & 0 & 0 & 0 & 0 & 0 & 0 & 0 & 0 & 0.073 & 0.906 & 0 & 0 & 0 & 0 & 0 & 0 & 0 & 0 & 0 \\
\hline 12 & 0 & 0 & 0 & 0 & 0 & 0 & 0 & 0 & 0 & 0.00 & 0.082 & 0.893 & 0 & 0 & 0 & 0 & 0 & 0 & 0 & 0 \\
\hline 13 & 0 & 0 & 0 & 0 & 0 & 0 & 0 & 0 & 0 & 0 & 0 & 0.093 & 0.879 & 0 & 0 & 0 & 0 & 0 & 0 & 0 \\
\hline 14 & 0 & 0 & 0 & 0 & 0 & 0 & 0 & 0 & 0 & 0 & 0 & 0 & 0.104 & 0.865 & 0 & 0 & 0 & 0 & 0 & 0 \\
\hline 15 & 0 & 0 & 0 & 0 & 0 & 0 & 0 & 0 & 0 & 0 & 0 & 0 & 0 & 0.116 & 0.849 & 0 & 0 & 0 & 0 & 0 \\
\hline 16 & 0 & 0 & 0 & 0 & 0 & 0 & 0 & 0 & 0 & 0 & 0 & 0 & 0 & 0 & 0.129 & 0.832 & 0 & 0 & 0 & 0 \\
\hline 17 & 0 & 0 & 0 & 0 & 0 & 0 & 0 & 0 & 0 & 0 & 0 & 0 & 0 & 0 & 0 & 0.143 & 0.815 & 0 & 0 & 0 \\
\hline 18 & 0 & 0 & 0 & 0 & 0 & 0 & 0 & 0 & 0 & 0 & 0 & 0 & 0 & 0 & 0 & 0 & 0.157 & 0.796 & 0 & 0 \\
\hline 19 & 0 & 0 & 0 & 0 & 0 & 0 & 0 & 0 & 0 & 0 & 0 & 0 & 0 & 0 & 0 & 0 & 0 & 0.173 & 0.774 & 0 \\
\hline 20 & 0 & 0 & 0 & 0 & 0 & 0 & 0 & 0 & 0 & 0 & 0 & 0 & 0 & 0 & 0 & 0 & 0 & 0 & 0.191 & 0.752 \\
\hline
\end{tabular}

Tabel B4B-4b. Matrix T voor bepalen evenwichtstoestand met kap bij overige soorten

Table B4B-4b. Matrix T for determining stable state with harvest for other species.

\begin{tabular}{|c|c|c|c|c|c|c|c|c|c|c|c|c|c|c|c|c|c|c|c|c|}
\hline other & 1 & 2 & 3 & 4 & 5 & 6 & 7 & 8 & 9 & 10 & 11 & 12 & 13 & 14 & 15 & 16 & 17 & 18 & 19 & 20 \\
\hline 1 & 0.867 & 0.392 & 0 & 0 & 0 & 0 & 0 & 0 & 0 & 0 & 0 & 0 & 0 & 0 & 0 & 0 & 0 & 0 & 0 & $\overline{0}$ \\
\hline 2 & 0.029 & 0.916 & 0 & 0 & 0 & 0 & 0 & 0 & 0 & 0 & 0 & 0 & 0 & 0 & 0 & 0 & 0 & 0 & 0 & 0 \\
\hline 3 & 0 & 0.031 & 0.924 & 0 & 0 & 0 & 0 & 0 & 0 & 0 & 0 & 0 & 0 & 0 & 0 & 0 & 0 & 0 & 0 & 0 \\
\hline 4 & 0 & 0 & 0.033 & 0.959 & 0 & 0 & 0 & 0 & 0 & 0 & 0 & 0 & 0 & 0 & 0 & 0 & 0 & 0 & 0 & 0 \\
\hline 5 & 0 & 0 & 0 & 0.035 & 0.953 & 0 & 0 & 0 & 0 & 0 & 0 & 0 & 0 & 0 & 0 & 0 & 0 & 0 & 0 & 0 \\
\hline 6 & 0 & 0 & 0 & 0 & 0.040 & 0.949 & 0 & 0 & 0 & 0 & 0 & 0 & 0 & 0 & 0 & 0 & 0 & 0 & 0 & 0 \\
\hline 7 & 0 & 0 & 0 & 0 & 0 & 0.044 & 0.942 & 0 & 0 & 0 & 0 & 0 & 0 & 0 & 0 & 0 & 0 & 0 & 0 & 0 \\
\hline 8 & 0 & 0 & 0 & 0 & 0 & 0 & 0.051 & 0.934 & 0 & 0 & 0 & 0 & 0 & 0 & 0 & 0 & 0 & 0 & 0 & 0 \\
\hline 9 & 0 & 0 & 0 & 0 & 0 & 0 & 0 & 0.057 & 0.926 & 0 & 0 & 0 & 0 & 0 & 0 & 0 & 0 & 0 & 0 & 0 \\
\hline 10 & 0 & 0 & 0 & 0 & 0 & 0 & 0 & 0 & 0.064 & 0.912 & 0 & 0 & 0 & 0 & 0 & 0 & 0 & 0 & 0 & 0 \\
\hline 11 & 0 & 0 & 0 & 0 & 0 & 0 & 0 & 0 & 0 & 0.073 & 0.912 & 0 & 0 & 0 & 0 & 0 & 0 & 0 & 0 & 0 \\
\hline 12 & 0 & 0 & 0 & 0 & 0 & 0 & 0 & 0 & 0 & 0.00 & 0.071 & 0.905 & 0 & 0 & 0 & 0 & 0 & 0 & 0 & 0 \\
\hline 13 & 0 & 0 & 0 & 0 & 0 & 0 & 0 & 0 & 0 & 0 & 0 & 0.075 & 0.902 & 0 & 0 & 0 & 0 & 0 & 0 & 0 \\
\hline 14 & 0 & 0 & 0 & 0 & 0 & 0 & 0 & 0 & 0 & 0 & 0 & 0 & 0.080 & 0.896 & 0 & 0 & 0 & 0 & 0 & 0 \\
\hline 15 & 0 & 0 & 0 & 0 & 0 & 0 & 0 & 0 & 0 & 0 & 0 & 0 & 0 & 0.084 & 0.890 & 0 & 0 & 0 & 0 & 0 \\
\hline 16 & 0 & 0 & 0 & 0 & 0 & 0 & 0 & 0 & 0 & 0 & 0 & 0 & 0 & 0 & 0.089 & 0.887 & 0 & 0 & 0 & 0 \\
\hline 17 & 0 & 0 & 0 & 0 & 0 & 0 & 0 & 0 & 0 & 0 & 0 & 0 & 0 & 0 & 0 & 0.091 & 0.881 & 0 & 0 & 0 \\
\hline 18 & 0 & 0 & 0 & 0 & 0 & 0 & 0 & 0 & 0 & 0 & 0 & 0 & 0 & 0 & 0 & 0 & 0.095 & 0.876 & 0 & 0 \\
\hline 19 & 0 & 0 & 0 & 0 & 0 & 0 & 0 & 0 & 0 & 0 & 0 & 0 & 0 & 0 & 0 & 0 & 0 & 0.100 & 0.869 & 0 \\
\hline 20 & 0 & 0 & 0 & 0 & 0 & 0 & 0 & 0 & 0 & 0 & 0 & 0 & 0 & 0 & 0 & 0 & 0 & 0 & 0.104 & 0.864 \\
\hline
\end{tabular}




\section{BIJLAGE 5. ANALYSE JAARRINGEN VAN STAMSCHIJVEN IN BOOMBOS}

\section{(uit rapport Leo Goudzwaard, 1994)}

Analyse jaarringen van stamschijven van gevelde bomen in boombos (Speulderbos Afd.117C) na dunning van voorjaar 1993 door L. Goudzwaard.

Van drie eiken en drie beuken, verzameld op korte afstand van elkaar $( \pm 100 \mathrm{~m})$, is de leeftijd bepaald door het tellen van de jaarringen, deels met de Positiometer van Johann, deels met het oog.

\begin{tabular}{|c|c|c|c|}
\hline $\mathrm{nr}$ & soort & leeftijd $^{1}$ & bijzonderheden \\
\hline 1 & beuk & $142 \mathrm{jr}$ & $\begin{array}{l}\text { oorspronkelijk tweestammig, afwisselend periodes van snelle en langzame } \\
\text { groei }\end{array}$ \\
\hline 2 & beuk & $174 \mathrm{jr}$ & afwisselend periodes van snelle en langzame groei \\
\hline 3 & beuk & $234 \mathrm{jr}$ & $\begin{array}{l}\text { oorspronkelijk tweestammig, afwisselend periodes van snelle en langzame } \\
\text { groei }\end{array}$ \\
\hline 4 & eik & $122 \mathrm{jr}$ & oorspronkelijk tweestammig \\
\hline 5 & eik & $151 \mathrm{jr}$ & \\
\hline 6 & eik & $234 \mathrm{jr}$ & oorspronkelijk tweestammig \\
\hline
\end{tabular}

${ }^{1}$ leeftijd in voorjaar 1993 voor alle bomen geldt een mogelijke afwijking: \pm 3 jaar

\section{Conclusies:}

1. De meerstammigheid van een aantal bomen kan duiden op voormalig hakhout of middenbos;

2. De afwisselende periodes van langzame en snellere groei duiden waarschijnlijk op periodes van open en dichte stand van de bosopstand;

3. Het grote leeftijdsverschil tussen bomen op een kleine oppervlakte duidt op een voormalig uitkapbeheer of op middenbos.

Leeftijdsbepaling van stamschijven van gevelde bomen in het boombos van de Drieërsingels na dunning van voorjaar 1993 door I.M. Bouwma en L. Goudzwaard m.b.v. de positiometer van Klaus Johann op 07-12-1994

Speulderbos afd 22b

\begin{tabular}{|c|c|c|c|}
\hline $\mathrm{nr}$ & soort & leeftijd ${ }^{1}$ & bijzonderheden \\
\hline $14 \mathrm{~A}$ & eik & 85 & $\begin{array}{l}\text { oorspronkelijk meerstammig; een deel van het spinthout is al } \\
\text { weggerot; mogelijke afwijking: } \pm 10 \text { jaar }\end{array}$ \\
\hline 14B & berk & 85 & jaarringen zijn onduidelijk; mogelijke afwijking: \pm 10 jaar \\
\hline $14 \mathrm{C}$ & beuk & 160 & mogelijke afwijking: \pm 5 jaar \\
\hline
\end{tabular}


Speulderbos afd 22e

\begin{tabular}{|c|c|c|c|}
\hline $\mathrm{nr}$ & soort & leeftijd $^{1}$ & bijzonderheden \\
\hline $13 \mathrm{~A}$ & eik & 183 & $\begin{array}{l}\text { stamschijf op } 6 \mathrm{~m} \text { hoogte van afgebroken boom, liggend op de grond; } \\
\text { mogelijke afwijking: } \pm 10 \text { jaar }\end{array}$ \\
\hline $13 B$ & beuk & 195 & oorspronkelijk tweestammig; hart rot; mogelijke afwijking: \pm 10 jaar \\
\hline $13 \mathrm{C}$ & beuk & 199 & hart rot; mogelijke afwijking: \pm 10 jaar \\
\hline 13D & beuk & 165 & oorspronkelijk meerstammig; mogelijke afwijking: \pm 5 jaar \\
\hline $13 \mathrm{E}$ & beuk & 190 & mogelijke afwijking: \pm 5 jaar \\
\hline $13 \mathrm{~F}$ & beuk & 194 & mogelijke afwijking: \pm 5 jaar \\
\hline
\end{tabular}

${ }^{1}$ leeftijd bepaald in voorjaar 1993

Speulderbos afd 22g

\begin{tabular}{|c|l|c|l|}
\hline nr & soort & leeftijd $^{\mathbf{1}}$ & bijzonderheden \\
\hline 12A & beuk & 191 & geveld door storm van 1990; mogelijke afwijking: \pm 10 jaar \\
12B & eik & 229 & mogelijke afwijking: \pm 3 jaar \\
12C & beuk & 229 & afgebroken stam 1 jaar dood; mogelijke afwijking: \pm 3 jaar \\
\hline
\end{tabular}

${ }^{1}$ leeftijd bepaald in voorjaar 1993

\section{Conclusies:}

1. Door schimmelaantasting van de stamschijven is de leeftijd niet meer exact te achterhalen

2. Van de onderzochte bomen zijn 4 leeftijdsklassen te onderscheiden, te weten:

$$
\begin{aligned}
& \pm 85 \text { jaar oud } \\
& \pm 165 \text { jaar oud } \\
& \pm 195 \text { jaar oud } \\
& \pm 229 \text { jaar oud }
\end{aligned}
$$

3. De meerstammigheid van een aantal bomen kan duiden op voormalig hakhoutbeheer of middenbos 